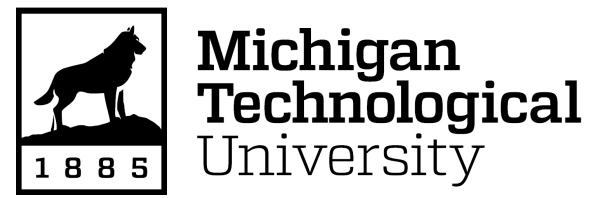

Michigan Technological University Digital Commons @ Michigan Tech

Dissertations, Master's Theses and Master's Reports

2017

\title{
IMPACT OF NATURAL GAS DIRECT INJECTION ON THERMAL EFFICINECY IN A SPARK IGNITION ENGINE
}

James Sevik

Michigan Technological University, jmsevik@mtu.edu

Copyright 2017 James Sevik

\section{Recommended Citation}

Sevik, James, "IMPACT OF NATURAL GAS DIRECT INJECTION ON THERMAL EFFICINECY IN A SPARK IGNITION ENGINE", Open Access Dissertation, Michigan Technological University, 2017.

https://doi.org/10.37099/mtu.dc.etdr/462

Follow this and additional works at: https://digitalcommons.mtu.edu/etdr

Part of the Energy Systems Commons, and the Heat Transfer, Combustion Commons 


\title{
IMPACT OF NATURAL GAS DIRECT INJECTION ON THERMAL EFFICIENCY IN A SPARK IGNITION ENGINE
}

\author{
By
}

James M. Sevik Jr.

\begin{abstract}
A DISSERTATION
Submitted in partial fulfillment of the requirements for the degree of DOCTOR OF PHILOSOPHY

In Mechanical Engineering-Engineering Mechanics

MICHIGAN TECHNOLOGICAL UNIVERSITY

2017
\end{abstract}

C 2017 James M. Sevik Jr 

This dissertation has been approved in partial fulfillment of the requirements for the Degree of DOCTOR OF PHILOSOPHY in Mechanical Engineering-Engineering Mechanics.

Department of Mechanical Engineering-Engineering Mechanics

Dissertation Advisor: $\quad$ Dr. Scott A. Miers

Committee Member: Dr. Thomas Wallner

Committee Member: $\quad$ Dr. Jeff D. Naber

Committee Member: $\quad$ Dr. David D. Wanless

Department Chair: Dr. William Predebon 



\section{Content}

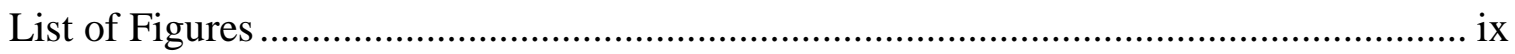

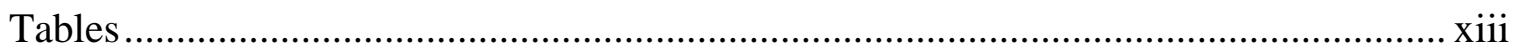

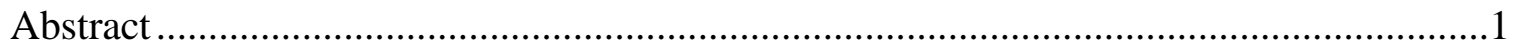

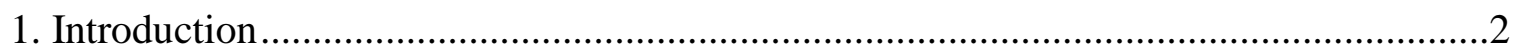

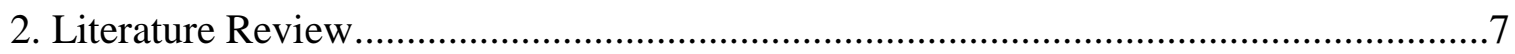

2.1 Influence of Port-Fuel Injection ................................................................... 10

2.1.1 Part-Load Dilution Tolerance …………………............................................ 10

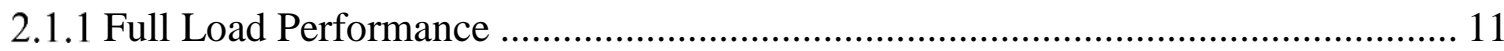

2.2 Influence of Direct Injection .......................................................................... 13

2.2.1 Added Charge Motion...................................................................................... 13

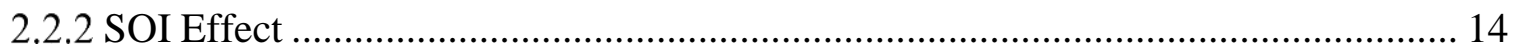

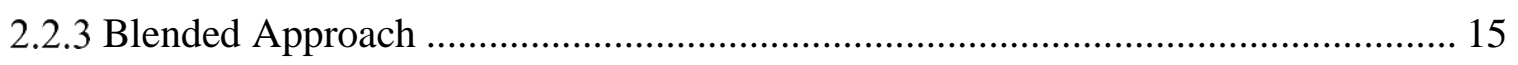

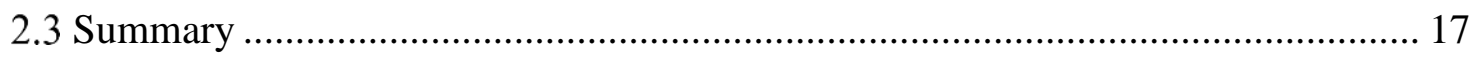

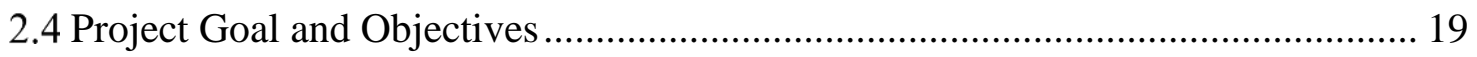

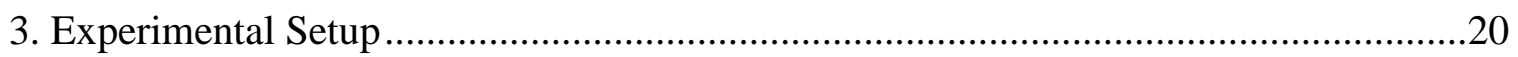

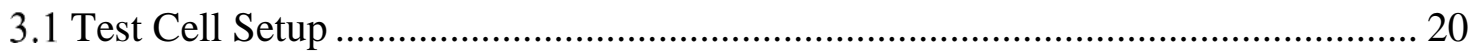

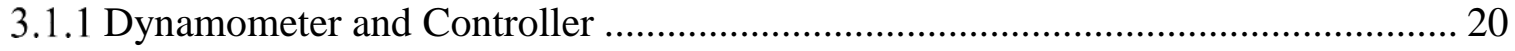

3.1.2 Combustion Air...................................................................................... 20

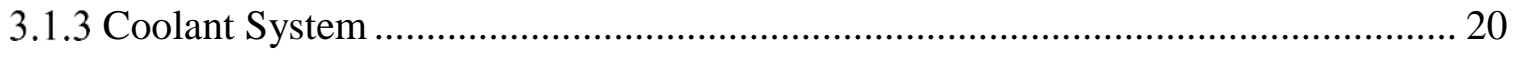

3.2 Engine

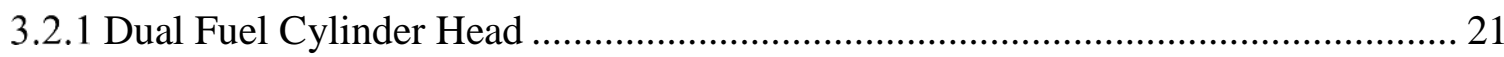

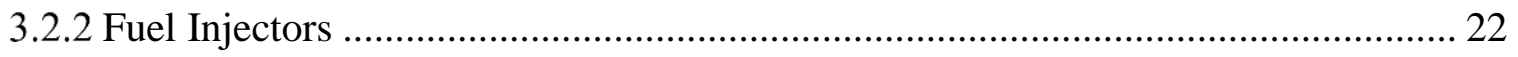

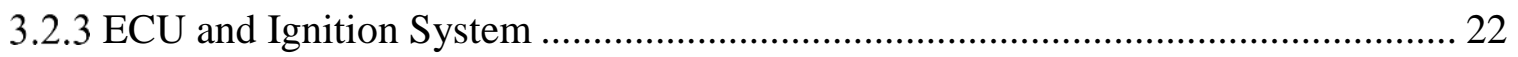




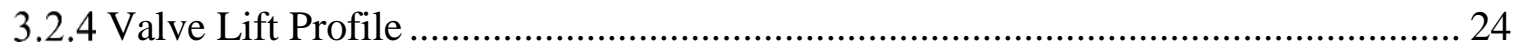

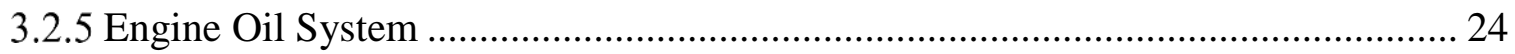

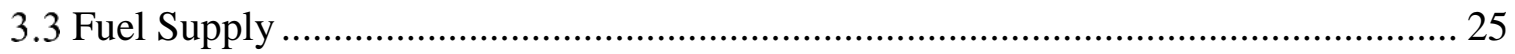

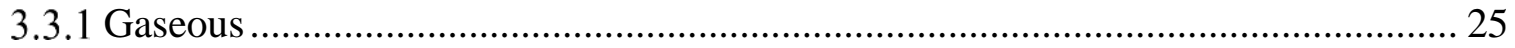

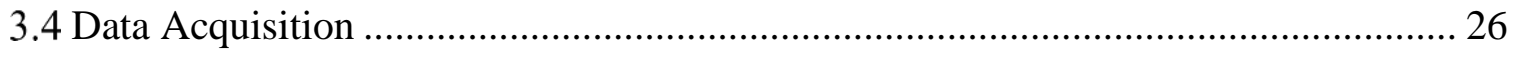

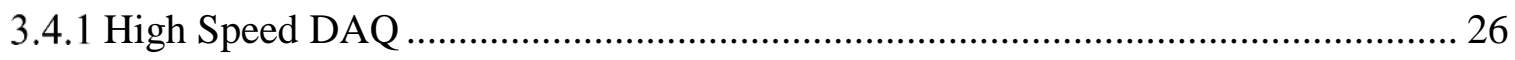

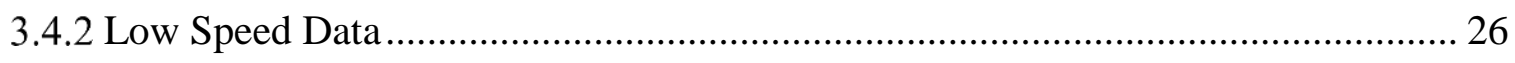

3.4.3 High Speed Pressure Transducers.................................................................... 26

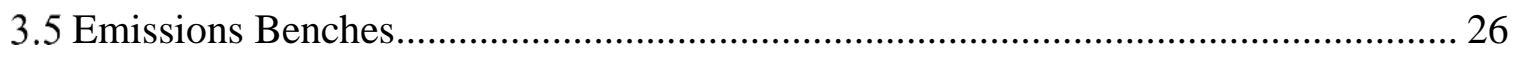

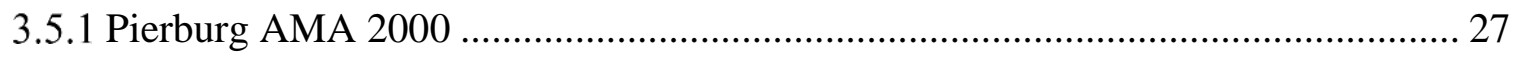

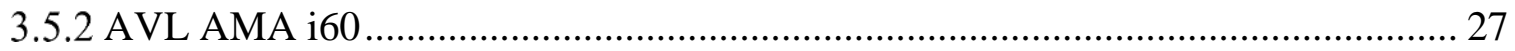

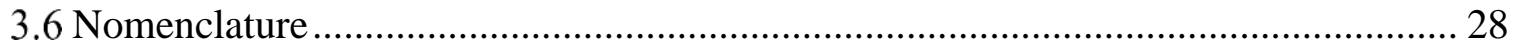

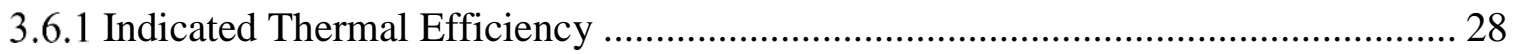

3.6.2 Coefficient of Variation of Indicated Mean Effective Pressure............................... 29

3.6.3 Flame Development Angle and Combustion Duration........................................... 29

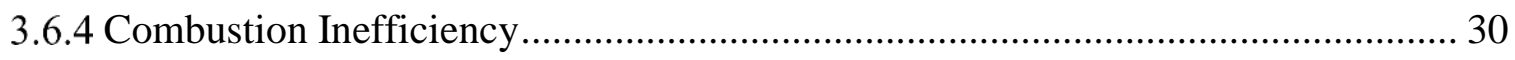

3.6.5 Indicated Specific Emissions …………………………................................. 30

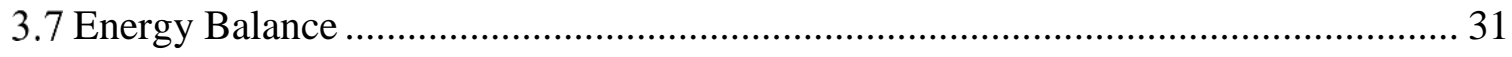

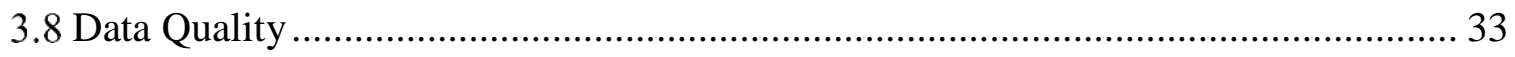

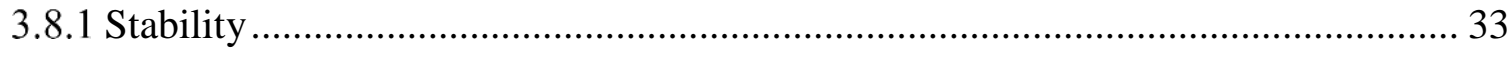

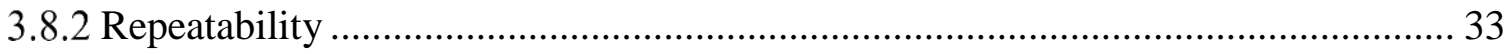

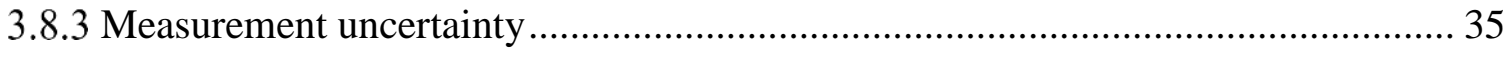

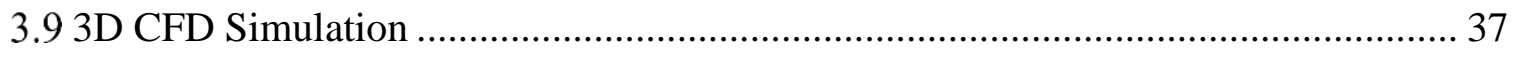

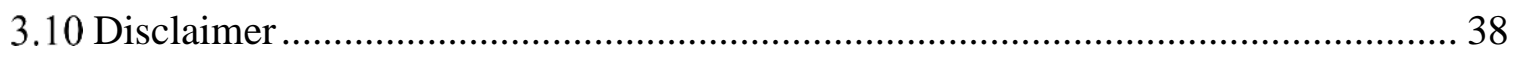

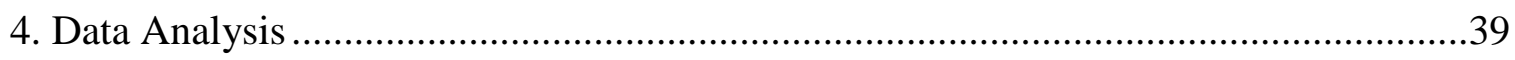


4.1 Injection Location and SOI Impact on ITE NET $_{\text {at }}$ 0\% EGR ............................... 40

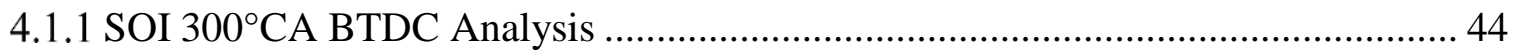

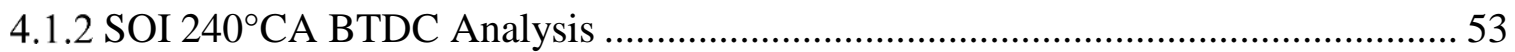

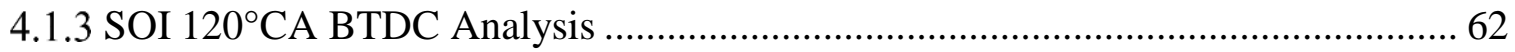

4.1.4 Summary of Injection Location and SOI Impact on ITE NET $_{\text {at }}$ 0\% EGR ............... 69

4.2 Injection Location and SOI Impact on ITE $_{\text {NET }}$ with EGR................................ 71

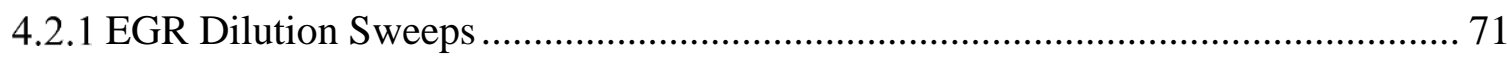

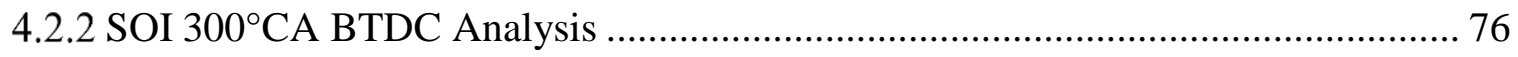

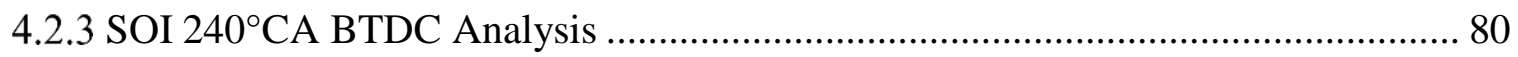

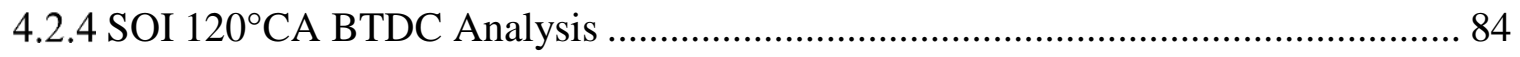

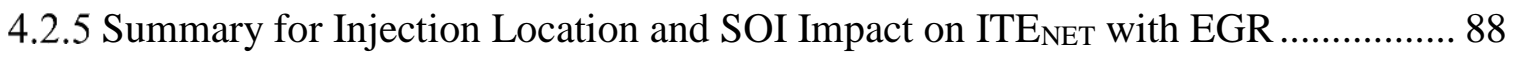

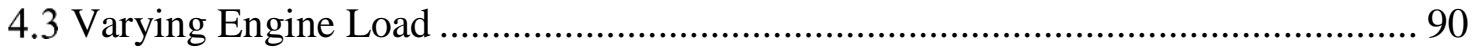

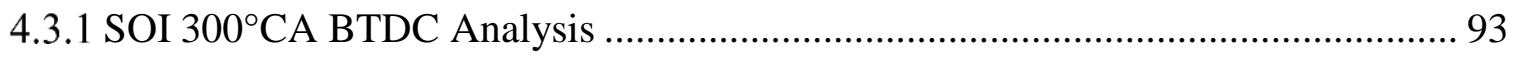

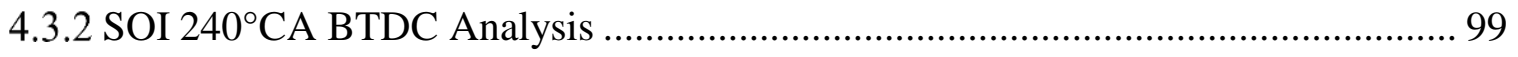

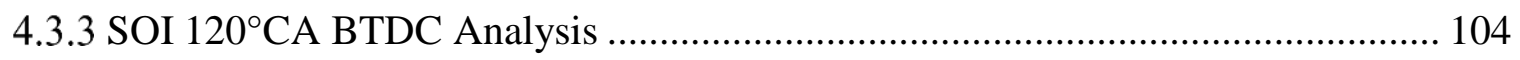

4.3.4 Summary for Varying Engine Load ........................................................... 111

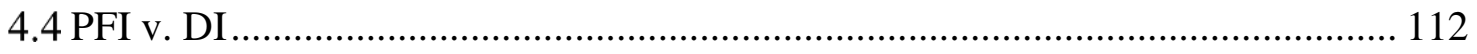

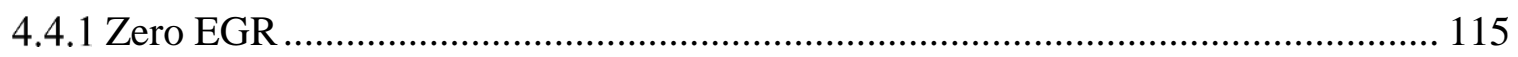

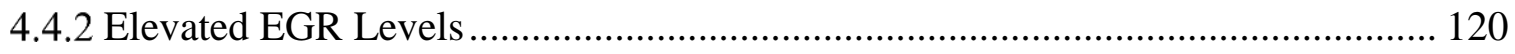

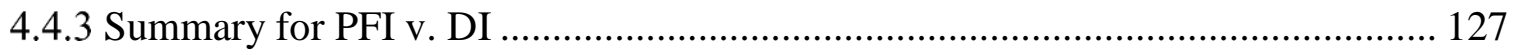

4.5 Extension of Experimental Data ........................................................... 128

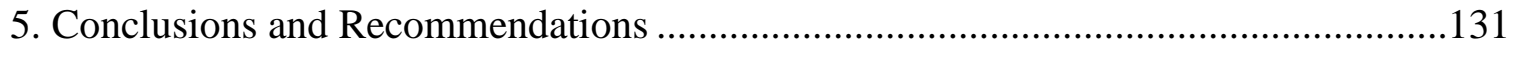

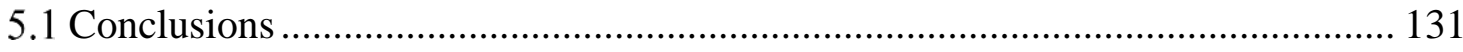

5.2 Recommendations for Future Work ........................................................... 132

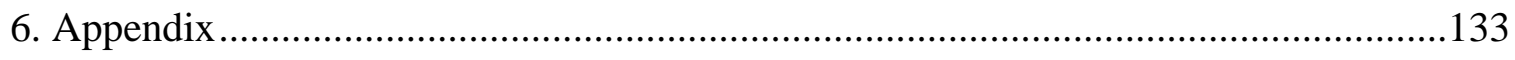




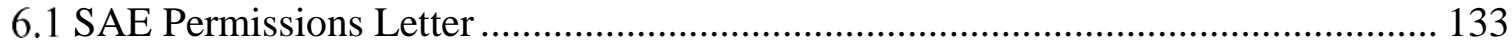

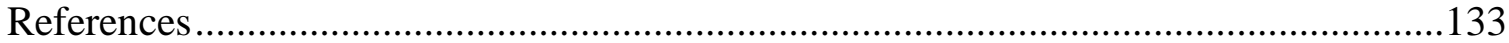




\section{List of Figures}

Figure 1.1: US Energy Production and Consumption [] ............................................ 2

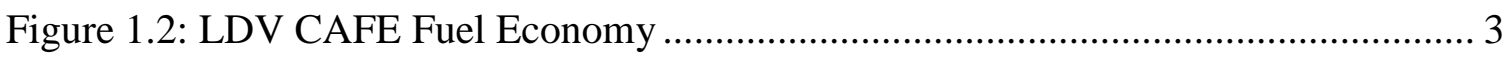

Figure 3.1: Combustion Chamber Schematic .......................................................... 21

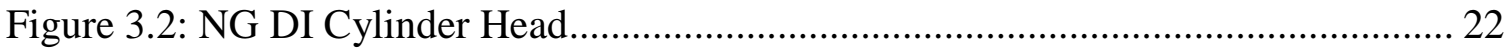

Figure 3.3: Valve Lift Profiles as a function of crank angle......................................... 24

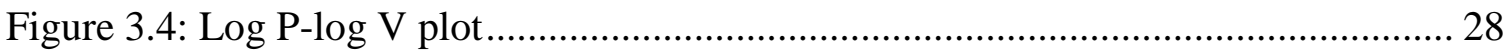

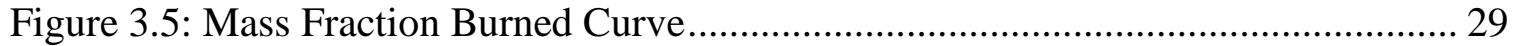

Figure 3.6: Control Volume for Conservation of Energy Analysis .............................. 31

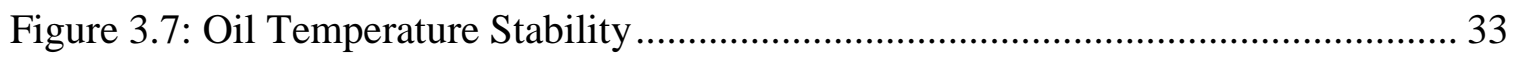

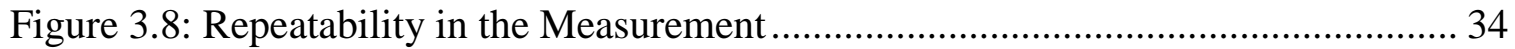

Figure 3.9: Repeatability in the Measurement - Checkpoints .................................... 35

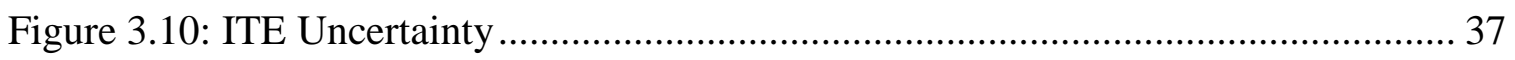

Figure 4.1: ITENET for 0\% EGR with Central and Side DI......................................... 40

Figure 4.2: ITEGross and PMEP for 0\% EGR with Central and Side DI ....................... 42

Figure 4.3: MAP as a function of SOI for Central and Side DI................................... 43

Figure 4.4: Energy Balance - Central and Side DI SOI 300 ${ }^{\circ} \mathrm{CA}$ BTDC ........................ 44

Figure 4.5: CD for Central and Side NG DI at SOI 300 ${ }^{\circ} \mathrm{CA}$ BTDC ............................. 45

Figure 4.6: In-Cylinder Tumble Motion for Central and Side NG DI at SOI $300^{\circ} \mathrm{CA}$

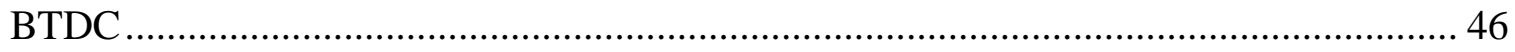

Figure 4.7: Global Turbulent Kinetic Energy for Central and Side DI at SOI $300^{\circ} \mathrm{CA}$

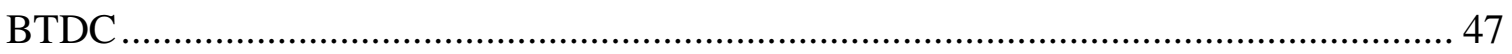

Figure 4.8: EGT for Central and Side DI at SOI $300^{\circ} \mathrm{CA}$ BTDC ................................ 48

Figure 4.9: iSHC for Central and Side DI at SOI 300 ${ }^{\circ} \mathrm{CA}$ BTDC ................................ 49

Figure 4.10: iSCO for Central and Side DI at SOI $300^{\circ} \mathrm{CA}$ BTDC ............................ 50

Figure 4.11: Global Standard Deviation of Phi for Central and Side DI at SOI $300^{\circ} \mathrm{CA}$

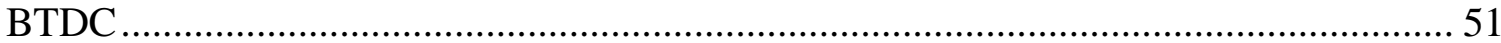

Figure 4.12: iSNOx for Central and Side DI at SOI 300 ${ }^{\circ} \mathrm{CA}$ BTDC ............................. 52

Figure 4.13: Energy Balance - Central and Side DI SOI 240 ${ }^{\circ} \mathrm{CA}$ BTDC ...................... 53

Figure 4.14: CD for Central and Side DI at SOI $240^{\circ} \mathrm{CA}$ BTDC.................................. 54 
Figure 4.15: In-Cylinder Tumble Motion for Central and Side NG DI at SOI $240^{\circ} \mathrm{CA}$

BTDC

Figure 4.16: Global Turbulent Kinetic Energy for Central and Side DI at SOI $240^{\circ} \mathrm{CA}$

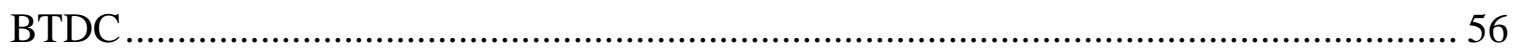

Figure 4.17: EGT for Central and Side DI at SOI $240^{\circ} \mathrm{CA}$ BTDC ............................... 57

Figure 4.18: iSHC for Central and Side DI at SOI $240^{\circ} \mathrm{CA}$ BTDC .............................. 58

Figure 4.19: iSCO for Central and Side DI at SOI $240^{\circ} \mathrm{CA}$ BTDC ............................... 59

Figure 4.20: Global Standard Deviation of Phi for Central and Side DI at SOI $240^{\circ} \mathrm{CA}$

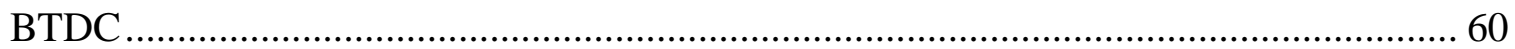

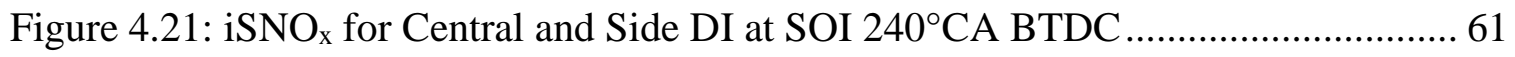

Figure 4.22: Energy Balance - Central and Side DI SOI $120^{\circ} \mathrm{CA}$ BTDC ...................... 62

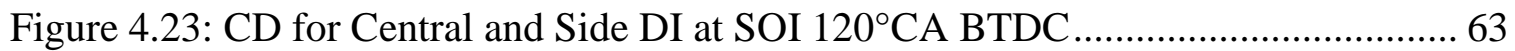

Figure 4.24: In-Cylinder Tumble Motion for Central and Side NG DI at SOI $120^{\circ} \mathrm{CA}$

BTDC.

Figure 4.25: Global Turbulent Kinetic Energy for Central and Side DI at SOI $120^{\circ} \mathrm{CA}$

BTDC

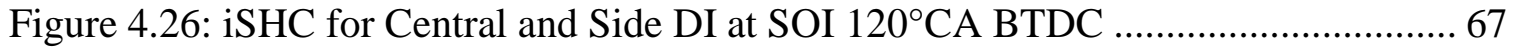

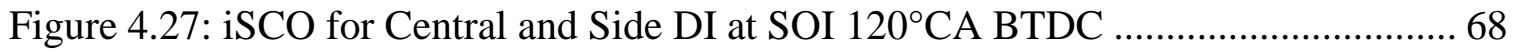

Figure 4.28: ITE $_{\mathrm{NET}}$ for Central and Side DI at the Three SOI Values........................... 69

Figure 4.29: ITENET as a function of EGR for Central and Side DI............................... 72

Figure 4.30: $\mathrm{COV}_{\text {IMEP }}$ as a function of EGR for Central and Side DI .......................... 74

Figure 4.31: Energy Balance - Central and Side DI SOI 300 ${ }^{\circ} \mathrm{CA}$ BTDC, with EGR ..... 76

Figure 4.32: CD for Central and Side DI at SOI 300 ${ }^{\circ} \mathrm{CA}$ BTDC ................................. 77

Figure 4.33: iSHC for Central and Side DI at SOI 300 CA BTDC …........................ 78

Figure 4.34: iSCO for Central and Side DI at SOI 300 ${ }^{\circ} \mathrm{CA}$ BTDC .............................. 79

Figure 4.35: Energy Balance - Central and Side DI SOI $240^{\circ} \mathrm{CA}$ BTDC, with EGR ..... 80

Figure 4.36: CD for Central and Side DI at SOI $240^{\circ} \mathrm{CA}$ BTDC ................................ 81

Figure 4.37: iSHC for Central and Side DI at SOI $240^{\circ} \mathrm{CA}$ BTDC ............................. 82

Figure 4.38: iSCO for Central and Side DI at SOI $240^{\circ} \mathrm{CA}$ BTDC ............................. 83

Figure 4.39: Energy Balance - Central and Side DI SOI $120^{\circ} \mathrm{CA}$ BTDC, with EGR ..... 84 


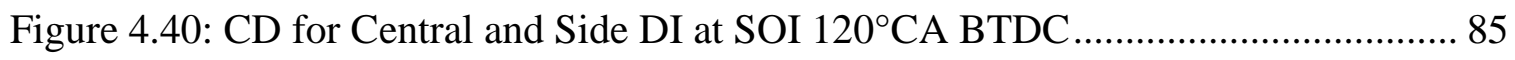

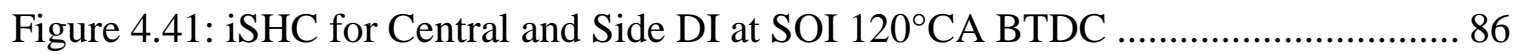

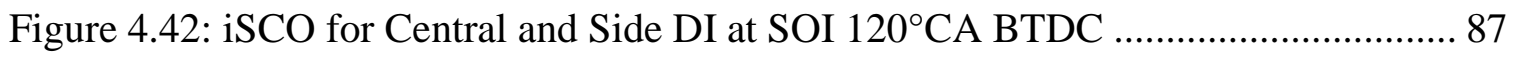

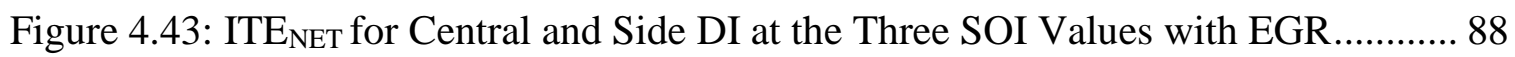

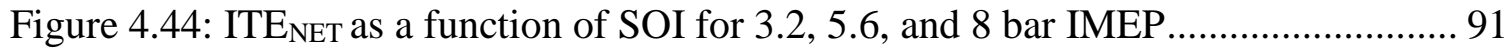

Figure 4.45: Energy Balance - Central and Side DI SOI 300 CA BTDC, 3.2, 5.6 and

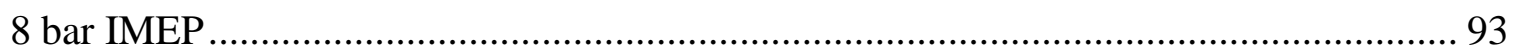

Figure 4.46: CD for Central and Side DI SOI 300 ${ }^{\circ} \mathrm{CA}$ BTDC, 3.2, 5.6 and 8 bar IMEP 94 Figure 4.47: EGT for Central and Side DI SOI $300^{\circ} \mathrm{CA}$ BTDC, 3.2, 5.6 and 8 bar IMEP

Figure 4.48: iSHC for Central and Side DI SOI 300 ${ }^{\circ} \mathrm{CA}$ BTDC, 3.2, 5.6 and 8 bar IMEP

Figure 4.49: iSCO for Central and Side DI SOI 300 ${ }^{\circ} \mathrm{CA}$ BTDC, 3.2, 5.6 and 8 bar IMEP

Figure 4.50: Energy Balance - Central and Side DI SOI 240 ${ }^{\circ}$ A BTDC, 3.2, 5.6 and 8 bar IMEP

Figure 4.51: CD for Central and Side DI SOI $240^{\circ} \mathrm{CA}$ BTDC, 3.2, 5.6 and 8 bar IMEP

Figure 4.52: EGT for Central and Side DI SOI $240^{\circ} \mathrm{CA}$ BTDC, 3.2, 5.6 and 8 bar IMEP 101

Figure 4.53: iSHC for Central and Side DI SOI $240^{\circ} \mathrm{CA}$ BTDC, 3.2, 5.6 and 8 bar IMEP 102

Figure 4.54: iSCO for Central and Side DI SOI $240^{\circ} \mathrm{CA}$ BTDC, 3.2, 5.6 and 8 bar IMEP 103

Figure 4.55: Energy Balance - Central and Side DI SOI $120^{\circ} \mathrm{CA}$ BTDC, 3.2, 5.6 and 8 bar IMEP. 104

Figure 4.56: CD for Central and Side DI SOI $120^{\circ} \mathrm{CA}$ BTDC, 3.2, 5.6 and 8 bar IMEP 105

Figure 4.57: Heat Release for Central and Side DI SOI 120CA BTDC, 8 bar IMEP .. 106 
Figure 4.58: EGT for Central and Side DI SOI $120^{\circ} \mathrm{CA}$ BTDC, 3.2, 5.6 and 8 bar IMEP 107

Figure 4.59: iSHC for Central and Side DI SOI 120 ${ }^{\circ} \mathrm{CA}$ BTDC, 3.2, 5.6 and 8 bar IMEP 108

Figure 4.60: iSCO for Central and Side DI SOI 120 CA BTDC, 3.2, 5.6 and 8 bar IMEP 109

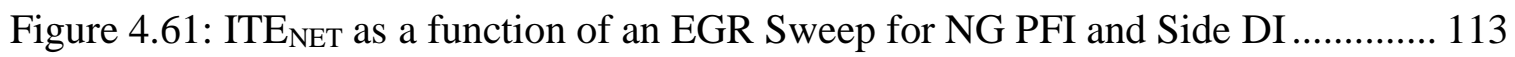

Figure 4.62: COVIMEP as a function of an EGR Sweep for NG PFI and Side DI ....... 114

Figure 4.63: Energy Balance for NG PFI and Side DI under Zero EGR Conditions ..... 115

Figure 4.64: CD for PFI and Side DI at 5.6 bar IMEP ........................................ 116

Figure 4.65: EGT for PFI and Side DI at 5.6 bar IMEP ........................................ 117

Figure 4.66: iSHC for PFI and Side DI at 5.6 bar IMEP ......................................... 118

Figure 4.67: iSCO for PFI and Side DI at 5.6 bar IMEP ...................................... 119

Figure 4.68: Energy Balance for NG PFI and Side DI at Elevated EGR Levels........... 120

Figure 4.69: CD for NG PFI and Side DI at 14\% EGR ........................................ 121

Figure 4.70: EGT for NG PFI and Side DI at 14\% EGR....................................... 122

Figure 4.71: iSHC for NG PFI and Side DI at 14\% EGR....................................... 123

Figure 4.72: iSCO for NG PFI and Side DI at 14\% EGR......................................... 124

Figure 4.73: Interpolate iSCO for NG PFI......................................................... 125 


\section{Tables}

Table 2.1: Properties of Methane and Isooctane at $1 \mathrm{~atm}$ and $300 \mathrm{~K}[9]$......................... 7

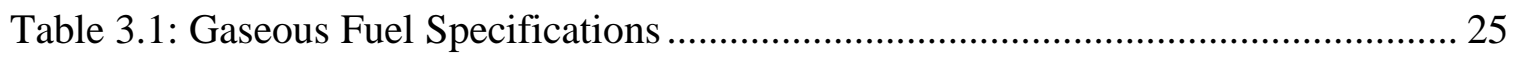

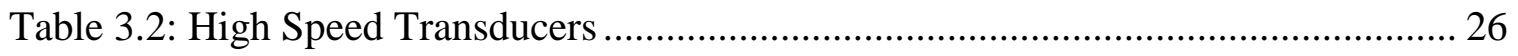

Table 3.3: Pierburg AMA 2000 Emissions Bench Specifications .................................. 27

Table 3.4: AVL i60 Emissions Bench Specifications................................................ 27

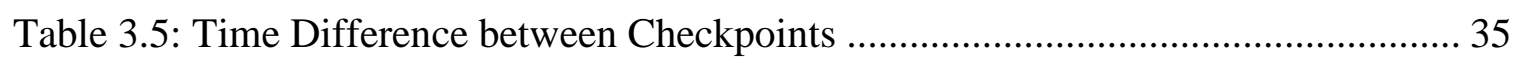

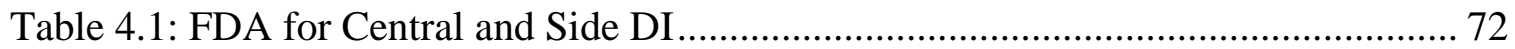

Table 4.2: ITE $\mathrm{NET}_{\mathrm{N}}$ with Zero EGR and Maximum Increase due to EGR ........................ 73

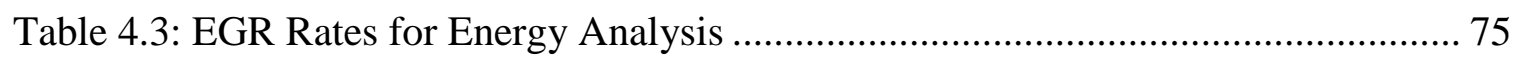





\section{Abstract}

Interest in natural gas as an internal combustion engine fuel has been renewed due to its increasing domestic availability and stable price relative to other petroleum fuel sources. Natural gas, comprised mainly of methane, allows for up to a $25 \%$ reduction in engine out $\mathrm{CO} 2$ emissions due to a more favorable hydrogen-to-carbon ratio, relative to traditional petroleum sources. Traditional methods of injecting natural gas can lead to poor part-load performance, as well as a power density loss at full load due to air displacement in the intake manifold. Natural gas direct injection, which allows the fuel to be injected directly into the cylinder, leads to an improvement in the in-cylinder charge motion due to the momentum of the gaseous injection event. While research performed with natural gas typically occurs at full load, the current research project focused on a part-load condition as this was most representative of real world driving conditions, becoming increasingly relevant for a downsized boosted application. The goal of this research was to further the understanding of natural gas direct injection and its resulting effect on the thermal efficiency of a GDI engine at a part-load condition. Key objectives were to measure and quantify the effects of injection location, injection timing, and exhaust gas recirculation on the thermal efficiency of the engine. A single-cylinder research engine was equipped for natural gas direct injection at Argonne National Laboratory, with detailed tests and analysis being performed.

Experimental results show that the injection location played a crucial role in the mixture formation process; injecting along the tumble motion led to a greater thermal efficiency than injecting directly towards the piston due to improved mixing. The start of injection had a strong impact on the thermal efficiency, which agreed well with literature. While injecting after intake valve closure led to increased mixture flame speeds, there was a decrease in thermal efficiency due to decreased mixing time leading to increased stratification. An advanced start of injection timing led to the highest thermal efficiency, as this provided the best tradeoff between mixing time and resulting heat losses. In addition, the injection location and timing directly influenced the dilution tolerance. Injecting along the tumble motion produced the highest dilution tolerance due to the gaseous injection event amplifying the tumble motion, improving in-cylinder mixing. 


\section{Introduction}

The U.S. Energy Information Administration (EIA) provides projections for the U.S. energy production and consumption out to 2040. Historical trends and current projections depicted in Figure 1.1 show that production and consumption of coal as an energy source will decrease over time, in part due to the retirement of power plants in response to Environmental Protection Agency's (EPA's) Mercury and Air Toxics Standards, as well as increasing competition of comparably cleaner burning natural gas power plants [1]. Crude oil and renewable energy production is also forecasted to continue to increase. However, production of natural gas is set to quickly out pace conventional energy sources. Natural gas, comprised mainly of methane, can be sourced domestically and has shown to have a more stable cost compared to petroleum derived fuel sources [2]. Energy consumption predictions show that petroleum sources are forecasted to stabilize, while consumption of natural gas and renewables is set to increase. Increasing the production and consumption of U.S. derived energy sources not only helps to promote job growth throughout the nation, it also reduces dependence on foreign oil, further preserving the welfare of the nation's homeland security [3].
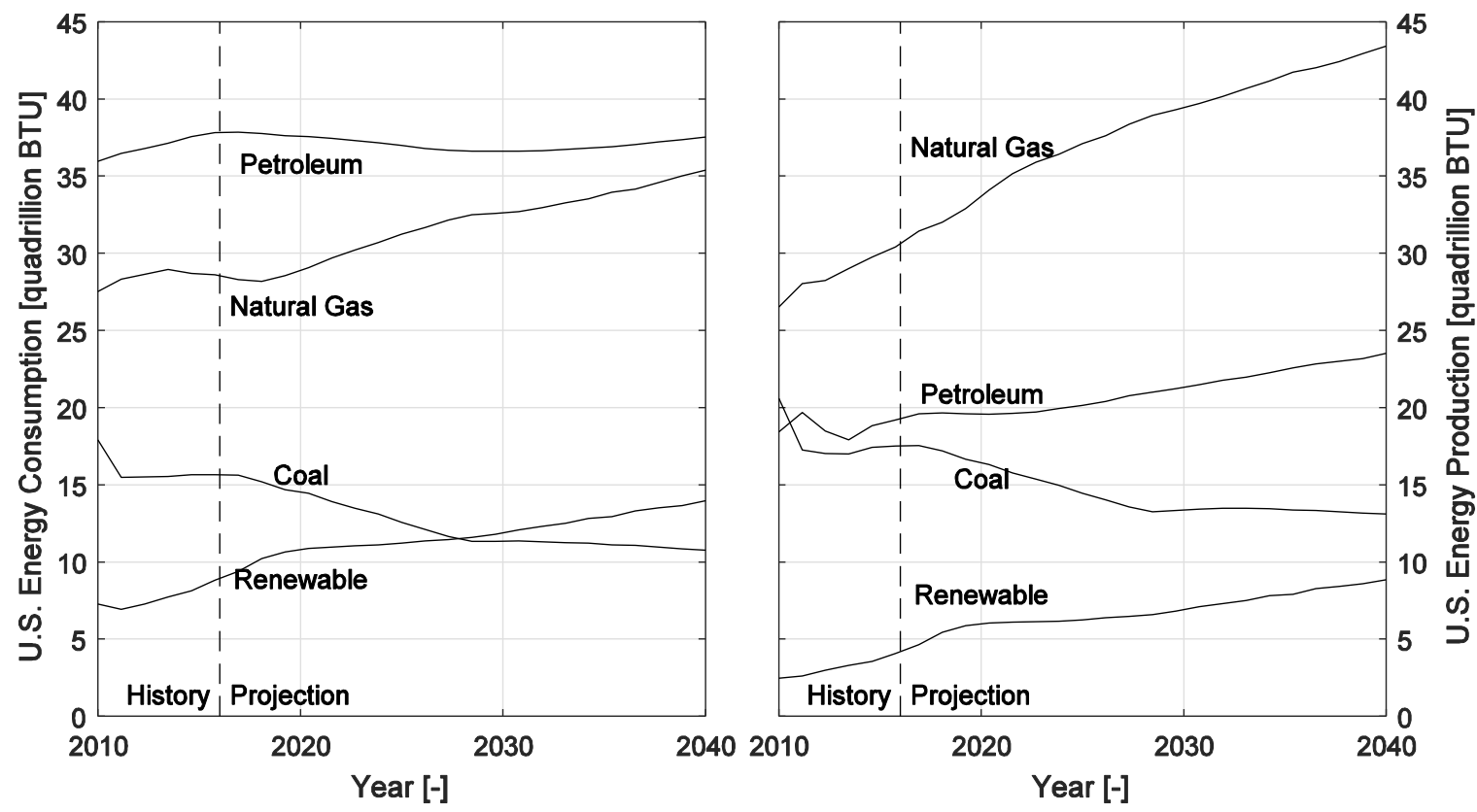

Figure 1.1: US Energy Production and Consumption [4]

In the United States, it is the role of the Environmental Protection Agency (EPA) to define all testing standards on how to measure, report and calculate emissions levels as 
well as fuel economy. However, the Department of Transportation (DOT) presides over the specific fuel economy levels for a given class of vehicle. Shown in Figure 1.2 are the corporate average fuel economy standards (CAFÉ) that an automotive manufacturer is required to meet. Due to recent legislation, a CAFÉ standard of 54.5 miles per gallon (MPG) has to be achieved for all light duty vehicles (LDV) by the year 2025 [5]. While there are many factors that affect the overall fuel economy of a vehicle, from the perspective of the engine, the pathway to improve the fuel economy is to increase the thermal efficiency. The thermal efficiency of an engine can be defined as the ratio of work output from the engine to the amount of fuel energy required to produce the work [6]. For a given work output, a reduction in the required fuel will result in an increase in the thermal efficiency.

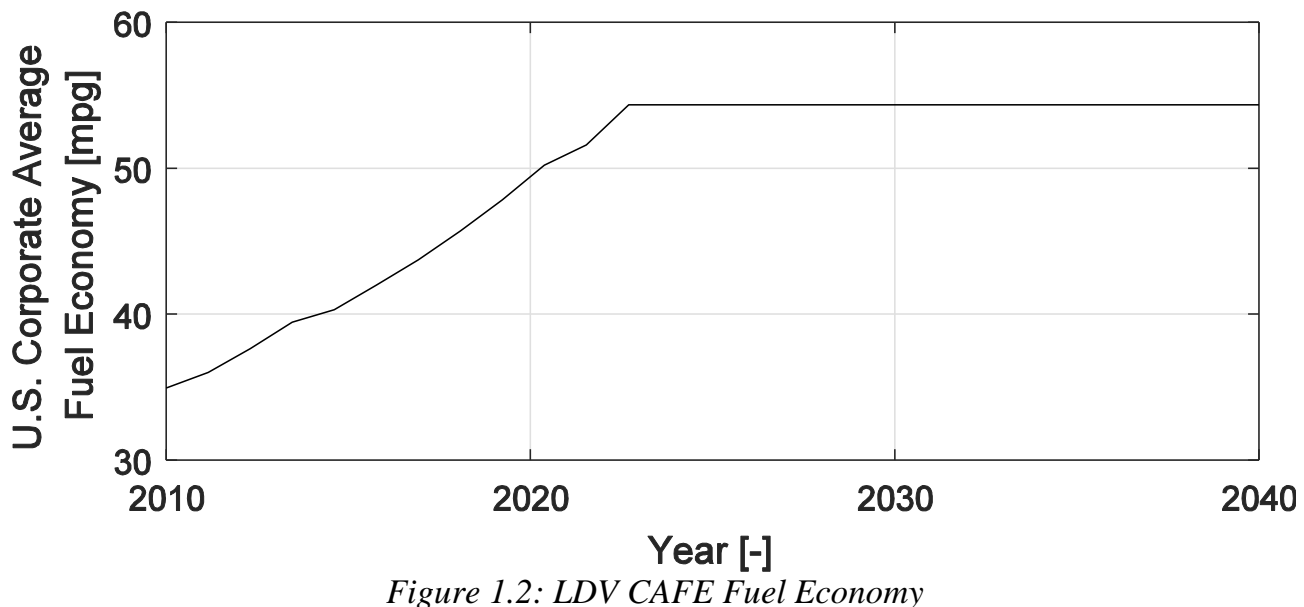

During an engine development project, an engineering team is required to meet specific emissions and fuel economy standards for that given class of vehicle. Throughout the development process, certain engine performance parameters may have to be compromised in order to achieve requirements of the given standards. For example, upon cold startup most gasoline passenger cars will increase idle speed and delay spark timing to decrease the three-way catalyst light off time. While this is done to ensure drive cycle emissions levels are met, this leads to a fuel economy penalty.

While consumers are generally concerned about vehicle emissions, the fuel economy has the greatest financial impact. There is a fundamental connection between the fuel 
economy of a given vehicle and the thermal efficiency of its engine. Therefore, one key parameter to improve vehicle fuel economy is the thermal efficiency of the engine.

In the following sections, experimental results from a single cylinder research engine at Argonne National Laboratory (ANL) are discussed. This engine was operated with prototype direct injection (DI) natural gas (NG) fuel injectors, which were used instead of traditional intake port mounted NG injectors. The main focus of subsequent discussions is the thermal efficiency of the test engine as certain control variables were varied, much like they would be optimized in an engine development program.

For this test program, there were three independent control parameters that were used to influence the thermal efficiency of the engine including: the injection location, start of injection (SOI) and exhaust gas recirculation (EGR) quantity. The two injection locations, central and side mounted, dictate how the injected fuel interacted with the incoming air charge, as well as if any impingement occurred in the combustion chamber. Changes in SOI affect the mixture formation process. An early SOI may lead to a more uniform air-fuel mixture, while delaying the SOI closer to top dead center (TDC) may decrease the level of mixture uniformity (stratification). While primarily used as an emissions control measure, EGR dilution can also increase ITE, due to reduced heat transfer losses and improved specific heat ratios. In addition, there are dependent parameters that are also varied for their resulting effect. For instance, spark timing is varied for each individual test condition in order to keep the center of combustion at the thermodynamic maximum. At the same time, intake air pressure may also vary in order to maintain the same engine load. Therefore, injection location, SOI, and EGR were the main independent control parameters.

When adjusting these three independent control parameters there were other factors that were affected, which ultimately influence the thermal efficiency. Because the injection location and SOI impact the mixture preparation process, the combination of the two influenced the rate at which the combustion event took place. A faster moving flame front is less susceptible to any stochastic changes in the in-cylinder flow field caused by residuals from a previous combustion cycle. A slower moving flame front may quench before reaching complete combustion due to these in-cylinder perturbations [7]. The rate 
of flame propagation becomes increasingly important with the application of EGR. EGR is primarily used to control nitric oxide (NOx) emissions, because the exhaust gas acts as a diluent in the cylinder lowering in-cylinder temperatures and decreasing the rate of NOx formation. However, increasing EGR rates leads to decreased mixture flame speeds, increasing the likelihood of a partial burn or complete misfire. Misfire events are to be avoided, because they lead to an increase in incomplete combustion products such as total hydrocarbons (THC) and carbon monoxide (CO), as well as a drop in thermal efficiency.

Data collected from the single-cylinder test engine was used to explain the trends observed in the thermal efficiency as the independent control parameters were manipulated. The data was separated into two subsets based on the rate of acquisition: low and high speed.

Low speed data corresponds to temperature, pressure, and emissions data that was collected at a $5 \mathrm{~Hz}$ sampling frequency. There are multiple locations where temperature and pressure were measured. These were used to quantify the state of a flow, as well as for energy calculations, such as heat rejected to the engine coolant loop. As control variables on the engine were changed, exhaust emissions also varied. Two separate emissions analyzers were used for different test phases. Standard five-gas emissions analyzers from AVL were used to measure exhaust emissions. These instruments measured on a volumetric basis: THC (C3), methane ( $\mathrm{CH} 4), \mathrm{CO}$, carbon dioxide $(\mathrm{CO} 2)$, as well as oxides of nitrogen (NOx). Measured constituents from exhaust emissions were used to quantify levels of regulated emissions. In addition, incomplete combustion products ( $\mathrm{THC}$ and $\mathrm{CO}$ ) and complete combustion products (CO2) were utilized to determine the combustion efficiency.

High speed in-cylinder pressure data, sampled at $800 \mathrm{MHz}$, was used to quantify phenomena occurring within the cylinder, on a crank angle basis. In-cylinder pressure was used to calculate the rate of flame propagation through the cylinder, the rate at which heat was released within the cylinder, as well as cycle-to-cycle variability. In addition, high speed pressure transducers were located in the intake and exhaust manifold, which were used as boundary conditions for 3D engine simulations. While the main focus of this research was experimental data collection and analysis, in-house 3D simulations 
were utilized as a literature source to further support results derived from the experimental data.

Specific performance parameters of the engine require the engine's power to be used in the calculations. For a single cylinder engine, losses due to friction are much higher than those of a multi cylinder engine. Because of higher frictional losses, if the power of a single cylinder engine were to be measured at the crankshaft, its value would not be representative of a multi cylinder engine with similar geometry and operating conditions. Therefore, any power values used for the single cylinder are calculated from high speed in-cylinder pressure data, subsequently referred to as indicated data. The indicated data only takes into account what happens in the cylinder and does not consider friction losses. Hereafter, the efficiency of the test engine is referred to as indicated thermal efficiency (ITE). This notation is also true of regulated emissions indexes, which utilize the mass flow rate of the given emissions constituent and normalize it by the indicated power. 


\section{Literature Review}

The use of NG as a transportation fuel is not new; its use can be traced back to the first and second World War, where it was used out of necessity due to petroleum shortages [8]. While prices of petroleum derived fuels have varied considerably over the last decade, the price of NG has remained relatively constant [2]. In addition, NG can be derived domestically, helping to reduce foreign oil dependence and promote job growth, which is vital for the US economy.

While there are desirable attributes of NG, there are also drawbacks that need to be understood relative to the fuels it is intended to replace. Table 2.1 shows specific fuel properties of methane and iso-octane, meant to represent NG and gasoline, respectively [9].

Table 2.1: Properties of Methane and Isooctane at 1 atm and $300 \mathrm{~K}$ [9]

\begin{tabular}{|l|l|l|}
\hline & Methane & Iso-octane \\
\hline Molecular Formula & $\mathrm{CH}_{4}$ & $\mathrm{C}_{8} \mathrm{H}_{18}$ \\
\hline Hydrogen-to-Carbon Ratio [-] & 4 & 2.25 \\
\hline Molecular Weight [g/mol] & 16.043 & 114.236 \\
\hline Lower Heating Value [MJ/kg] & 50 & 44.3 \\
\hline Higher Heating Value [MJ/kg] & 55.5 & 47.8 \\
\hline Density [kg/m3] & 0.65 & 692 \\
\hline Volumetric energy content (kJ/m3) & 3041 & 3704 \\
\hline Boiling Point [K] & $111^{[10]}$ & $372.4^{[11]}$ \\
\hline Stoichiometric air-to-fuel ratio (kg/kg) & 17.1 & 15.0 \\
\hline Flammability limits (l) & $2-0.6$ & $1.51-0.26$ \\
\hline Autoignition temperature (K) & 813 & 690 \\
\hline Adiabatic flame temperature (K) & 2226 & 2276 \\
\hline Mole Expansion (after/before combustion) & 1 & 2.6 \\
\hline Ratio of Specific Heats & 1.354 & 1.389 \\
\hline AKI ${ }^{[6]}$ & 120 & 100 \\
\hline
\end{tabular}

Methane contains a single bonded carbon atom while iso-octane contains multiple complex bonds. Considering a fundamental chemistry standpoint, the single bond of the methane molecule is extremely stable thus making it harder to break apart. However, the complex bonds of iso-octane lend themselves to break apart easier; these complex bonds also lead to branching reactions which can assist in initiating a combustion event. The higher hydrogen-to-carbon ratio allows for a direct reduction in engine out $\mathrm{CO} 2$ emissions relative to iso-octane $[12,13,14]$. When considering the energy content of the 
fuel, methane has a greater energy density than iso-octane from a mass perspective. However, the density of methane is three orders of magnitude lower than iso-octane. This means from a vehicle level standpoint, in order to maintain the same vehicle range, the tank size of methane needs to be considerably larger due to the lower volumetric energy content. Storing the gas in the liquid phase would alleviate the storage issues associated with methane; however, due to the extremely low boiling point of methane, this would require complex cryogenics that are not realistic for a LDV application.

The lower adiabatic flame temperature of methane can help to lower nitrogen oxide emissions [6]. However, this would then lower combustion temperatures, which can create issues with a traditional three-way catalyst; the combination of lower temperatures and the stable methane molecule pose problems for the catalysts ability to oxidize any unburned fuel [15].

The molar expansion ratio is defined as the ratio of products formed to reactants, when considering a stoichiometric combustion event. When considering an ideal cycle, the spark ignition engine follows the constant volume combustion process [6]. Under a constant volume combustion event, a higher molar expansion ratio will result in more work done to the piston, due to a higher volume expansion. The lower molar expansion ratio of methane leads to a decrease in efficiency of an engine when compared to operation with iso-octane, for similar conditions [16]. At the same time, when considering the theoretical efficiency of an engine, for a given compression ratio (CR) and operating condition, methane will result in a lower theoretical efficiency due to the lower specific heat ratio. However, when considering real engine operation, methane can attain a higher efficiency compared to iso-octane due to its high knock resistance.

As shown in the discussion for the data presented in Table 2.1, there are several benefits to methane relative iso-octane, but there are also limitations to the fuel. While the energy content per unit mass is greater for methane, the low density creates storage issues in a vehicle application. Moreover, the lower molar expansion ratio and specific heat ratio can lead to an efficiency loss for methane when the engine is not knock limited. While NG is very popular as a transportation fuel, it is important to understand the limitations associated with it. 
This chapter provides a review of literature relevant to NG research currently being performed; the chapter is split into two sections, PFI and DI. Discussion of PFI research includes full load conditions, dual fuel applications, as well as some part-load topics. The discussion of DI covers fundamental research performed in a rapid compression machine (RCM) as well as full load testing with NG DI. 


\subsection{Influence of Port-Fuel Injection}

In light duty spark ignition (SI) engines, the traditional method of introducing NG to the engine was through port injection into the intake manifold. Because of the low volumetric energy density, NG displaces air in the intake manifold. This leads to poor dilution tolerance at part-load as well as a loss in full load potential of the engine.

\subsubsection{Part-Load Dilution Tolerance}

The availability of production level NG vehicles has increased in recent years. Anderson et al. performed vehicle level tests on a chassis dynamometer over several drive cycles with two production level Honda Civics designed for NG and gasoline operation [17]. While the CR of the dedicated NG Civic was increased, the EGR loop was removed due to poor dilution tolerance for this vehicle. Despite having a higher CR, the NG vehicle yielded 3-9\% lower fuel economy than the gasoline comparator. Throughout the operating range of the engine, there was a power density loss for operation with NG, up to $21 \%$. It was concluded that manufacturing an engine specifically for NG operation, with features such as NG direct injection (DI) and increased charge motion, could meet or exceed efficiencies of current state-of-the-art gasoline engines.

Neame et al. used an automotive PFI V6 engine to investigate the effects of improving fuel economy using EGR and advanced ignition systems, while running gasoline, methanol and natural gas [18]. The fuels used in this study represented a broad spectrum of laminar burning velocity found in automotive fuels; natural gas having a low laminar burning velocity while methanol having a high laminar burning velocity. Utilizing a plasma jet ignition as a means of extending the dilution tolerance, EGR rates were increased until combustion quality exceeded an allowable threshold.

It was found that methanol provided the best improvement in fuel economy due to the highest EGR dilution tolerance. The high laminar burning velocity of methanol allowed for a higher EGR dilution tolerance. Consistent with the slowest laminar burning velocity, natural gas exhibited the lowest dilution tolerance, despite the advanced ignition system used. While fuel economy benefits were realized with natural gas due to the added EGR increasing the engines thermal efficiency, a point of diminishing returns 
quickly was reached. At moderately dilute mixtures, a high level of spark advanced was required in order to sustain combustion. However, such advanced spark timings were required to have optimal combustion phasing, which quickly exceeded flammability limits.

In order to extend part-load dilution tolerance, reformate technologies are often used, where carbon monoxide in the exhaust stream is converted into hydrogen through the water-gas shift reaction and introduced into the intake air stream. Alger et al. used a single cylinder engine at high EGR levels in order to investigate the influence of hydrogen enrichment on extending the dilution tolerance limit for gasoline and NG [19]. Enrichment with hydrogen has been shown to increase mixture flame speeds, allowing for an improvement in dilution tolerance and engine efficiency.

EGR dilution sweeps were performed at $1500 \mathrm{rpm} 5.5$ bar indicated mean effective pressure (IMEP), with a CR of 14:1. At the dilution tolerance limit for gasoline and NG, only a very small amount of hydrogen was required to bring combustion stability below allowable limits. $0.2 \%$ hydrogen by volume was required to bring the engine below its stability for gasoline, while $0.4 \%$ hydrogen by volume was required for NG. It is worth noting that there is a stark difference in dilution tolerance between gasoline and NG; at light loads gasoline could be extended to 40-50\% EGR whereas NG could only be extended to $20-28 \%$ EGR. The authors attribute the difference in dilution tolerance and required hydrogen enrichment to the properties of the two test fuels. For the same given engine architecture, NG with $0 \%$ hydrogen enrichment resulted in a lower dilution tolerance than gasoline. It is also worth noting that the engine in this study operated with a relatively low level of tumble, which further exacerbates the low flame speeds of NG.

\subsubsection{Full Load Performance}

Delpech et al. developed a concept called Concomitant Injection of Gas and Liquid fuels (CIGALTM) [20]. This concept, aimed at best utilizing fuel properties of two injected fuels, introduced the fuels into the intake manifold. Considering full engine load across all operating speeds, NG operation resulted in considerably higher brake torque, due to the ability to run ideal combustion phasing. In addition, brake specific fuel consumption 
(BSFC) was improved, due to enrichment no longer being required for knock mitigation, as compared to gasoline operation.

The authors also blended gasoline and NG at various engine operating conditions in order to study the effect of both fuels on knock resistance, as well as full load capability. For full load operation at a fixed $1750 \mathrm{rpm}, 70 \% \mathrm{NG}, 30 \%$ gasoline on a mass basis was required in order to mitigate knocking combustion. For this blended condition, increasing the mass percentage of gasoline increased torque due to an increase in volumetric efficiency from the charge cooling of the gasoline as well as reduced intake air displacement from the NG.

Sevik et al. investigated the effects of NG PFI relative to gasoline PFI under natural aspirated wide open throttle (WOT) conditions on a modern GDI engine [14]. At WOT, both injection systems resulted in similar full load performance. While operating with NG PFI typically reduces full load performance due to air displacement in the intake manifold, the engine in this study became knock limited on gasoline, requiring delayed combustion phasing. The delayed phasing resulted in reduced full load power and efficiency. Due to its high knock resistance, NG was able to operate with combustion phasing set to the thermodynamic optimum. Consistent with other literature sources, NG PFI resulted in up to a 5\% drop in volumetric efficiency relative to gasoline PFI due to air displacement in the intake manifold. 


\subsection{Influence of Direct Injection}

Direct injection of natural gas into the cylinder extends the EGR dilution tolerance and improves full load performance. Because the fuel is injected directly into the cylinder, the power loss associated with reduced volumetric efficiency from PFI NG does not occur.

\subsubsection{Added Charge Motion}

Shiga et al. studied the combustion behavior of NG DI in a rapid compression machine with CR of 10:1 by varying the SOI at 90 bar injection pressure [21]. For this study, there were two methods of introducing the fuel: a homogenous mixture prepared in a buffer tank and then NG DI. It was concluded that NG DI can have a positive impact on the combustion process over the homogenous injection operation. Under stoichiometric conditions, the initial burn (0-10\% pressure rise) and main burn duration (10-90\% pressure rise) of the combustion event were decreased, attributed to an increased level of turbulence from the gaseous injection. In addition, NG DI resulted in a higher combustion efficiency than homogenous operation due to less wall quenching from the increased turbulence.

While NG is touted for its high knock resistance, the stable structure of NG also increases the difficulty for traditional three-way catalysts to successfully oxidize any unburned fuel. This becomes increasingly important due to the high global warming potential of methane, which comprises nearly $90 \%$ of NG. Sebolt et al. recently investigated an approach using NG DI to reduce raw hydrocarbon emissions, using multiple injection events [15]. Results have shown that a single injection event can lead to a $23 \%$ reduction in $\mathrm{HC}$ emissions, while multiple injections only led to a $15 \%$ reduction. The multiple injections allowed for a strong reduction in the cyclic variability of the combustion event, due to an increase in the turbulent kinetic energy in the near spark plug region. However, the $\mathrm{HC}$ reduction of multiple injection events relative to single injection was lower due to stratification occurring from the late second injection event; further optimization of the second injection timing and quantity would assist in further reducing HC.

Iyer et al. published an extensive publication regarding the development of the 3.5 L V6 Ford EcoBoost Engine [22]. 3D CFD was used to optimize the in-cylinder flow for the 
EcoBoost, with experimental validation being performed for select hardware configurations. For a part-load condition, a series of different port blockers were used to increase the tumble ratio. It was determined for the part-load condition, improving the tumble motion makes the engine less susceptible to any stochastic changes in the flow field. An increase in tumble motion translates to higher turbulence intensity at TDC. This leads to increased mixture flame speeds and a reduction in cyclic variability, which results to an improvement in part-load EGR dilution tolerance.

It was computationally shown that for a given intake system, delaying the SOI allows for an increase in the tumble motion. Delaying the SOI allows the tumble motion to more fully develop and reach its maximum before the injection event occurs, increasing turbulence at TDC. However, delaying the SOI does come at a penalty; the decreased mixing time can lead to a decrease in mixture homogeneity, which results in an increase in incomplete combustion products.

\subsubsection{SOI Effect}

As a follow-up development to CIGALTM, Douailler et al. investigated the effects of NG DI on a high CR NG SI engine [23]. A 0.3651 single cylinder diesel engine was retrofitted for NG operation. Numerical simulations were performed to optimize the piston and combustion chamber shape; the main focus was to improve the in-cylinder tumble motion. After an optimized hardware configuration was chosen, engine testing was conducted for two injection pressures (1600 and 2900kPa), with intake and exhaust pressures set to mimic full load engine operation. By varying the SOI, it was concluded that a delayed SOI allowed the engine to aspirate more air before the fuel was injected, leading to an increase in volumetric efficiency. The biggest gain in volumetric efficiency occurred when the fuel was injected as the intake valves were closing. While delaying the SOI increased the volumetric efficiency, it also led to an increase in unburned fuel due to insufficient mixing time. In addition, the injection strategy and timing plays an important role on mixture homogeneity at the end of the compression stroke. While PFI NG generally leads to a $9 \%$ decrease in power output relative to PFI gasoline, an $8 \%$ improvement in full load potential for NG DI occurred over PFI NG due to improvements associated with the volumetric efficiency. 
Recent work by Tadesse et al. investigated the effects of boost pressure on the full-load performance of a four-stroke DI NG SI engine, optimized for NG with a CR of 14 [24]. For this study, the boost pressure (0-10 kPa) and engine speed (2000-5000 rpm) was swept for two different SOI values. The authors termed the SOI values as simulated port injection, corresponding to SOI $300^{\circ} \mathrm{CA}$ BTDC, and partial DI with injection timing at SOI $180^{\circ} \mathrm{CA} \mathrm{BTDC}$. The latter SOI is termed partial DI, because part of the injection event occurs when the intake valves are open, while the remainder occurs after the intake valves have closed. Experimental results have shown that increasing boost pressure results in better performance, while also helping to overcome volumetric efficiency loses associated with NG injection.

At engine speeds from 2000 to $4000 \mathrm{rpm}$, the partial DI injection resulted in an increase in torque due to reduced air displacement and thus increased volumetric efficiency. However, engine speeds above $4000 \mathrm{rpm}$ benefited from the earlier SOI timing, which reduced brake specific fuel consumption (BSFC), as well as engine out $\mathrm{HC}$ and $\mathrm{CO}$ emissions. These reductions occurred because there was more time for mixing at the higher engine speeds.

Zeng et al. investigated the effects of NG injection timing on combustion characteristics [25]. A 0.9L single cylinder engine was fitted with Hitachi Co. GDI injectors, modified for NG use. Under fixed spark timing and injection quantity, the SOI was swept from 210 to $150^{\circ} \mathrm{CA} \mathrm{BTDC}$, allowing for the fuel air mixture and engine load to vary. It was determined that there was an optimal timeframe for injecting natural gas. Injecting too late in the cycle does not provide sufficient mixing time, resulting in increased combustion duration and unburned fuel. Advancing the injection timing resulted in faster combustion and lower emissions. Injecting near bottom dead center of the intake stroke resulted in the overall shortest combustion duration, as well as the highest efficiency and engine load.

\subsubsection{Blended Approach}

Kalam et al. conducted a series of tests on a four cylinder, 1.51 engine, equipped for PFI gasoline as well as DI NG [26]. Tests were conducted with baseline fueling with PFI 
gasoline, DI NG, and simultaneous blending of gasoline and NG. Experimental results show NG DI produces only $4 \%$ more brake power at WOT conditions relative to gasoline PFI. In addition, NG DI reduced NOx emissions by $50 \%$, however it increased HC by $34 \%$ and $\mathrm{CO}$ by $48 \%$.

It should be noted that two important engine parameters were not reported for this study: the relative air-fuel ratio for each test condition and the start of injection for NG DI. Start of injection has a strong impact on mixture preparation and volumetric efficiency at WOT conditions. Injecting early in the cycle provides sufficient mixing time, while injecting late in the cycle leads to some stratification due to insufficient time between the end of injection and spark timing. At the same time, the injection timing at WOT has a direct influence on the volumetric efficiency and full power potential. Delaying the injection timing at WOT leads to an increase in the volumetric efficiency and consequently the engine power [27].

Recent research performed at ANL by Pamminger et al. investigated in-cylinder blending techniques using NG DI and E10 PFI on a modern single cylinder engine [16]. A series of tests were conducted where the start of injection (SOI) for NG DI was swept, while also sweeping the NG blending ratio on an energy basis, for a part-load condition of 1500 rpm, 5.6 bar IMEP. Despite the lower mixture flame speeds of natural gas, blending $25 \%$ NG with E10 extended the EGR dilution tolerance by $6 \%$ absolute relative to pure E10 operation. This is interesting, because comparatively, NG has a much slower laminar burning velocity than E10. It is believed that the induced charge motion from the DI event injection improved the dilution tolerance over the E10 fuel. As the blend fraction of NG increased above 25\%, the slower burning velocity of the NG dominated the combustion event, and the EGR dilution tolerance decreased. 


\subsection{Summary}

Due to its high knock resistance, a large quantity of research has focused on the high load capabilities of NG. As noted in previous studies, a power loss occurs with PFI NG due to air displacement in the intake manifold. While some of the power could be recuperated through turbocharging, a point of diminishing returns is reached due to hardware limitations of the turbocharger or the engine. With DI NG, the benefits at full load are clear; air displacement did not occur within the intake manifold and therefore any lost power due to traditional injection methods were recuperated. This also gives NG DI the unique opportunity to best realize any efficiency improvements due to an increase in CR when compared to NG PFI.

When using DI, the SOI had a crucial impact on combustion characteristics. The SOI dictated the amount of air displacement that occurred within the cylinder, ultimately affecting the volumetric efficiency at WOT. The later the SOI, the more air the engine could aspirate. At the same time, it was also shown that the SOI had an influence on mixing; early SOI values led to better mixing while delaying the SOI led to poor mixing due decreased mixing time.

Across the literature sources, there were two relevant issues not explored in detail and thus do not provide a comprehensive analysis of NG operation in an engine. The first issue is the engine architecture - a common practice was to take an existing diesel engine and retrofit it to NG SI operation. While this is an acceptable practice for research in stationary engines, the results obtained from such studies are not directly applicable to modern GDI style engines due to a fundamentally different combustion chamber design. For example, in-cylinder mixture control is achieved through swirl in a diesel engine, while tumble motion is used for SI engines.

Additionally, the absence of part-load testing with NG, and more importantly NG DI, is the second issue. At WOT, mixture ignitability is high due to higher in-cylinder velocities as well as elevated temperatures and pressures. However, when reducing to part-load operation, mixture ignitability decreases due to decreasing in-cylinder temperature and pressure. This decrease is further exacerbated when EGR dilution techniques are used, 
which is well known to reduce mixture ignitability. As Anderson, et al. [17] showed, the EGR loop was intentionally removed from a dedicated production NG vehicle, due to poor mixture ignitability associated with NG and PFI injection. In addition, Neame et al. showed that for the same given engine and ignition system, NG exhibited a comparatively poor dilution tolerance relative to gasoline and methanol [18]. While it is accepted that dilution tolerance is generally poor with NG PFI, DI offers unique opportunities. Shiga et al. [21] used a RCM to show that the gaseous injection event from NG DI can increase the turbulence and enhance mixing within the cylinder. An increase in turbulence can be beneficial, especially with NG, as it can improve ignitability [6]. Pamminger et al. showed that the NG DI impacted part-load performance considerably [16]. The SOI could be used to directly influence the length of the combustion process, while at the same time influencing the achieved dilution tolerance. However, the scope of the research performed was limited and mainly focused on proving the benefits of a dual fuel in-cylinder blended combustion concept. Also, Sebolt showed that NG DI can reduce $\mathrm{HC}$ emissions up to $23 \%$ relative to PFI operation, which is increasingly important for emissions compliance [15]. In conclusion, the advantages of DI NG are reduced air displacement, over PFI NG, improved EGR tolerance compared to PFI NG, and increased mixture flame speeds over PFI NG, due to increased in-cylinder turbulence. 


\subsection{Project Goal and Objectives}

The literature search has shown that the largest gap in knowledge is for part-load operation with natural gas, specifically for DI. Part-load conditions are becoming increasingly important as downsized engines push their main operating conditions to lower speeds [28]. This research consists of one main goal to be achieved through several key objectives. The goal of this research is to provide further understanding of NG DI on part-load SI engine operation and its resulting effect on the thermal efficiency of a modern GDI style engine. It is also hypothesized that NG DI can improve mixture flame speeds compared to PFI under part-load conditions due to the added charge motion of the gaseous injection event. Achievement of this goal will contribute to the understanding of NG DI in a LDV application, expanding upon traditional NG injection technologies.

Successful completion of this goal will be achieved through a series of objectives, listed below:

- Measure and quantify the effects of NG DI injection location on the combustion process, emissions, and resulting thermal efficiency

- Characterize the influence of injection timing on the combustion process, emissions, and resulting thermal efficiency

- Quantify the effects of NG DI on part-load EGR dilution tolerance

- Verify observed trends are consistent across other load conditions

While there are deficiencies in the literature, there are indications that NG DI can help to improve some of the problems associated with NG operation. 


\section{Experimental Setup}

The testing required to generate the experimental data for this analysis was performed at ANL, located in Test Cell \#1 of the Advanced Powertrain Research Facility (APRF). The main components of this test cell were the single cylinder engine, dynamometer, intake air system, and emissions analyzer. Test cell \#1 was originally configured in the early 2000's for hydrogen research. Since then, a number of research programs have been conducted in this test cell, including advanced ignition system research [29,30] as well as advanced fuel and dilute SI research [31]. Since the inception of this test cell, single cylinder hardware has been provided through the support of Ford Motor Company.

\subsection{Test Cell Setup}

\subsubsection{Dynamometer and Controller}

Test Cell \#1 is equipped with a General Electric direct current (DC) dynamometer, used for steady state testing. This dual ended dyno is capable of absorbing $140 \mathrm{HP}$ at 2500 rpm. A Digalog 2022B dyno controller controls the dynamometer.

\subsubsection{Combustion Air}

Combustion air was supplied to the engine from an Atlas Copco air compressor. Before reaching the engine, the air was cooled and dried. Therefore, air reaching the engine was at ambient conditions in the intake buffer tank, and relative humidity remained less than $20 \%$ for all operation. Because of the Atlas Copco compressor, the engine could be operated either throttled or boosted. Throttled conditions were achieved using a Parker pilot operated regulator in the intake stream. Downstream of the pilot operated regulator was a 0.190 " critical flow orifice manufactured by Flomaxx, used to calculate airflow to the engine. The critical orifice only requires upstream temperature and pressure to measure air flow.

\subsubsection{Coolant System}

The test cell was equipped with an engine coolant preheater, in order to maintain the engine coolant at $85^{\circ} \mathrm{C}$ and reduce warm-up time. A heat exchanger was installed between the engine and the preheater, to maintain coolant temperature. This heat exchanger was supplied with building cooling water, maintained at $22^{\circ} \mathrm{C}$. The flow of 
cooling water through the heat exchanged was controlled using a temperature regulated control valve.

\subsection{Engine}

All experiments were conducted on a single cylinder research engine, manufactured by Ford Motor Company. This engine configuration is representative of current gasoline direct injection engines, with geometry closely matching the Ford EcoBoost.

\subsubsection{Dual Fuel Cylinder Head}

The cylinder head for this research was specifically manufactured for use in a dual fuel combustion project sponsored by the Department of Energy. The cylinder head featured a $40^{\circ}$ pent roof combustion chamber, with a $48.3 \mathrm{cc}$ combustion chamber volume. Two valves each were used for intake and exhaust. A M10 spark plug was centrally mounted in the combustion chamber, adjacent to the central DI injector. All experiments were performed using a NGK CR10EIX spark plug, with a J-type electrode gap set to $0.7 \mathrm{~mm}$. Unique to this head was the availability to mount a direct injection NG injector either centrally or side mounted. The side injector, mounted at the base of the pent roof, was set to $60^{\circ}$ with respect to the vertical. A schematic of the cylinder head is shown in Figure 3.1 .

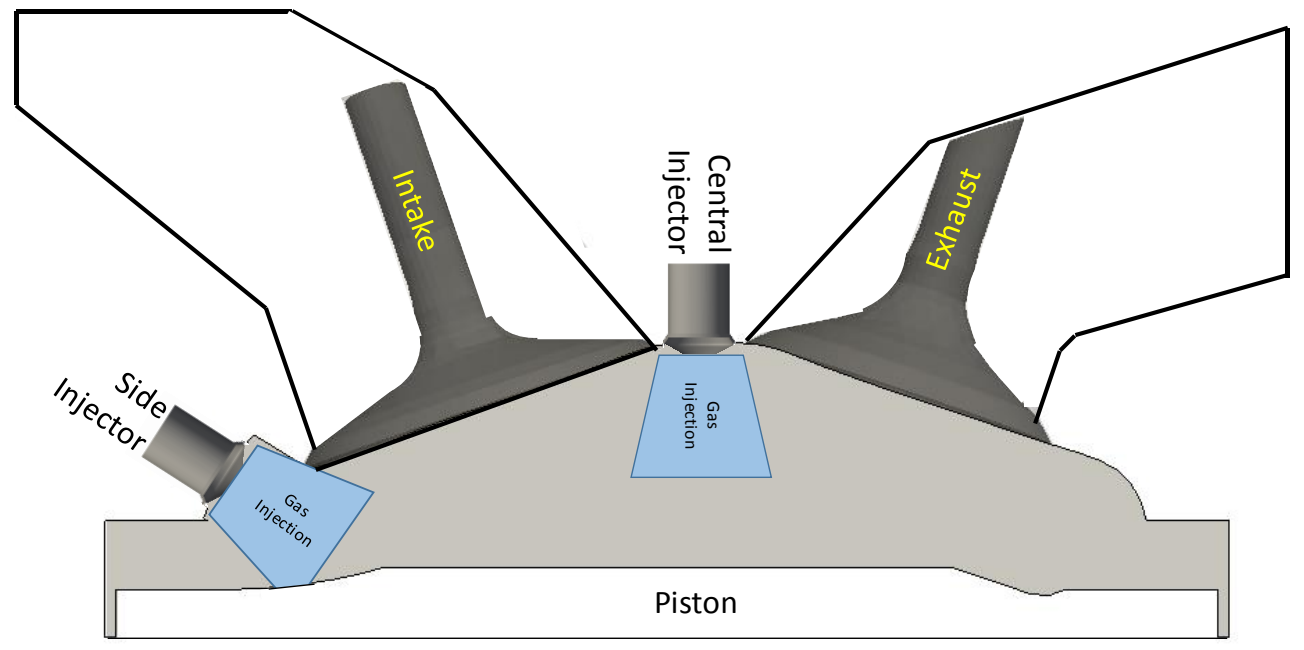

Figure 3.1: Combustion Chamber Schematic 
Figure 3.2 shows a picture of the cylinder head off the engine. An AVL GU21C cylinder pressure transducer was located near the squish region between an intake and exhaust valve. As can be seen, the central injection location was adjacent to the spark plug, while the side location was between the intake valves providing an injection event that occurred along the tumble axis.

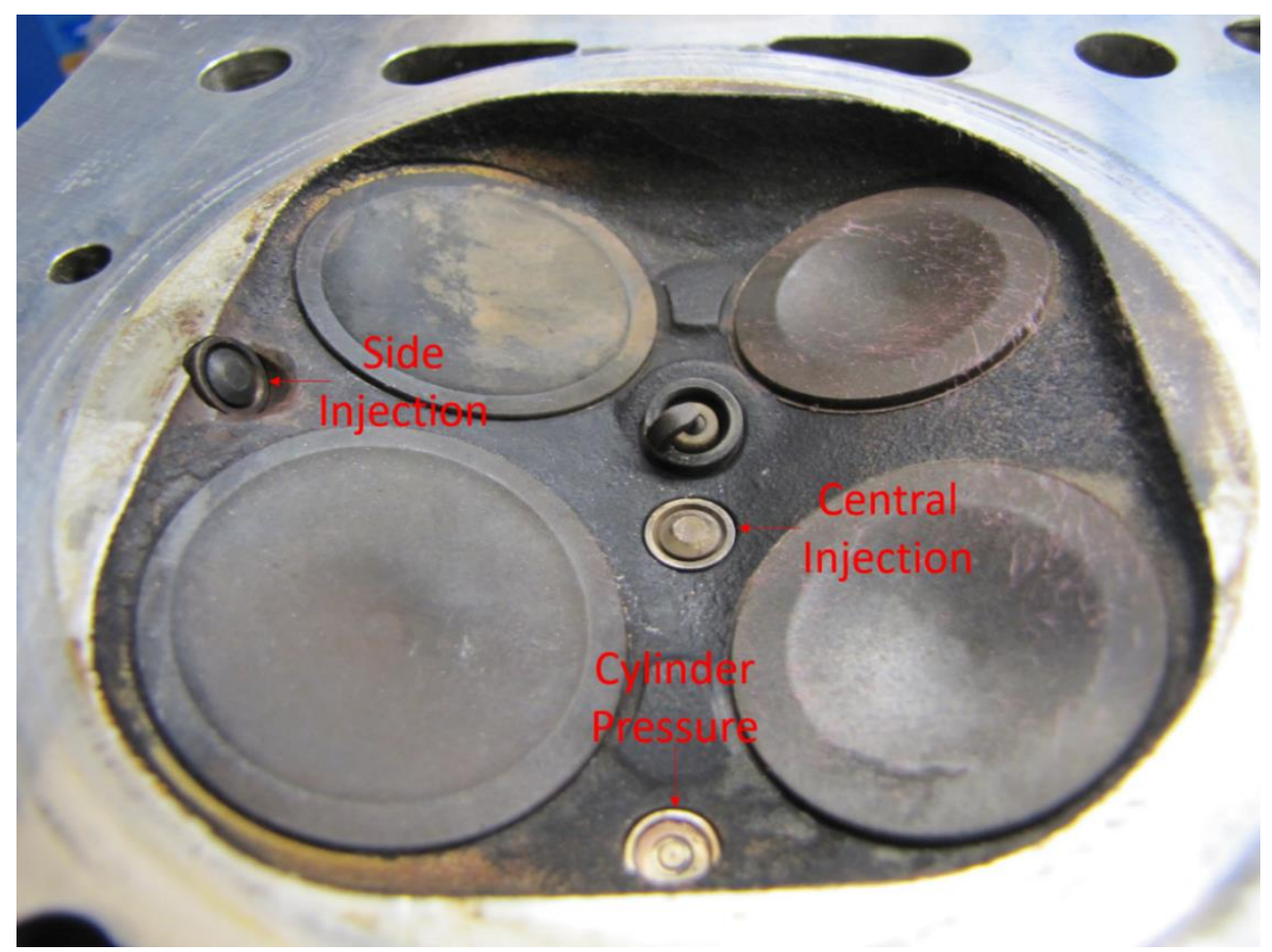

Figure 3.2: NG DI Cylinder Head

\subsubsection{Fuel Injectors}

Unique to this study was the utilization of a fourth generation NG DI injector, supplied by Delphi [32]. This injector featured an outward-opening valve, with maximum allowable injection pressure of up to 16 bar absolute. This injector allowed for injection events to occur after intake valve closure, which has shown to improve low speed, high load performance over gaseous port-fuel injection strategies [33].

\subsubsection{ECU and Ignition System}

A Motec M800 aftermarket ECU was configured to control the engine for steady state operation. The Motec was used to control spark timing, injection timing and duration, as well as lambda control. The ECU was configured to run in two-cylinder mode, to allow 
the engine to run on two fuel injectors simultaneously. Crank angle offsets were used within Motec to allow the two injectors to fire on the same combustion cycle. Closed loop control was used to maintain the lambda value at stoichiometry for all operating points.

An injector driver box was supplied by Delphi to drive the direct injection NG injectors, designed to act as a slave ECU. The driver box required a high to low transistor-transistor logic (TTL) signal. A zero-voltage level was required to fire the injector; 5 or $12 \mathrm{~V}$ was permissible for the high threshold. Because the master ECU sent a waveform designed to directly drive a fuel injector, signal conditioning was required before going to the Delphi driver box. A Schmitt trigger was placed in series with the Motec and Delphi driver box, in order to create the required high-low TTL signal.

A conventional transistorized coil ignition (TCI) system was used for all tests performed. The nominal energy level of this coil was 75 mJ. This coil was compatible with Ford's 2.0L EcoBoost engine, making it representative of coils currently implemented on GDI engines. 


\subsubsection{Valve Lift Profile}

The valve lift profiles of this engine are shown in Figure 3.3. As can be seen, any injection timing that occurs after $140^{\circ} \mathrm{CA}$ BTDC can be considered a closed valve injection event. At the same time, if the injection event occurs at $360^{\circ} \mathrm{CA} \mathrm{BTDC}$, some NG could short-circuit through the combustion chamber due to valve overlap occurring in this region.

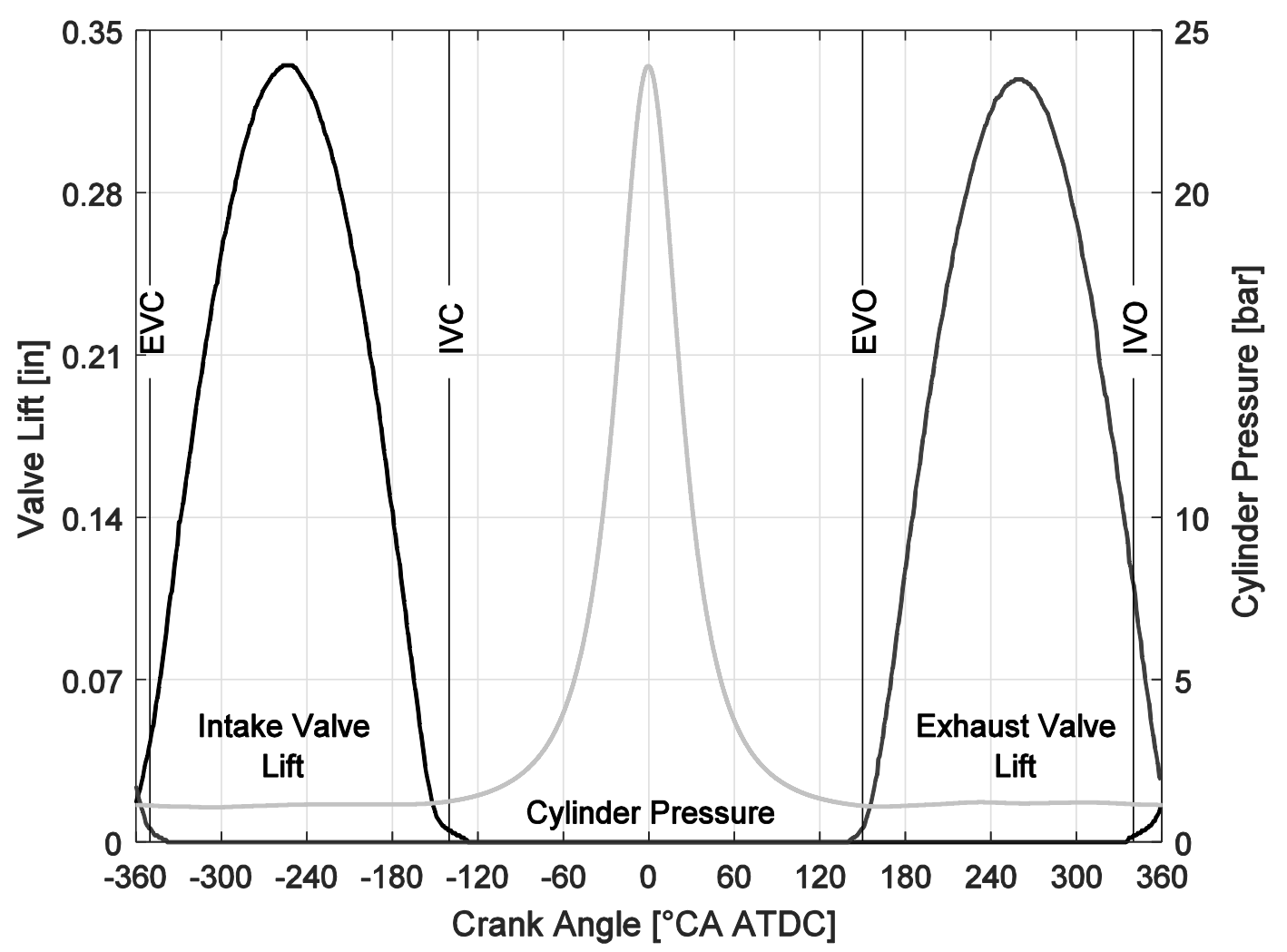

Figure 3.3: Valve Lift Profiles as a function of crank angle

\subsubsection{Engine Oil System}

A dry sump oiling system was configured for the engine, equipped with a 25qt external oil reservoir. Before the start of every test, a two-quart pressurized sump (Accusump) manufactured by Canton Racing Products was used. This pressurized external oil sump was discharged, supplying oil to all of the bearing surfaces. The internal pressure of the Accusump was held between 40-50psi. 


\subsection{Fuel Supply}

\subsubsection{Gaseous}

Compressed natural gas $(\mathrm{CNG})$ was supplied to the engine through the use of a high pressure distribution panel. This panel was originally installed and rated for use with high pressure hydrogen, as a part of a previous research program. The gaseous distribution panel was fed using one CNG cylinder, with a starting pressure of 2000 psig. Gaseous fuel flow measurements were performed within the panel using a Micro Motion CMF010M fuel flow meter. A total of three pressure regulators were installed into the system. The role of the final pressure regulator was to regulate the pressure to $15 \mathrm{barg}$ for the NG DI injector. In the event of an E-Stop event, the panel was designed to activate two safety valves that stop the flow of NG and vent the pressure of the entire panel to an exterior vent.

The composition of NG varies based off the regional location as well as the time of the year [34]. It was therefore decided to perform tests with custom blends of CNG from a regional distributor rather than pipeline $\mathrm{NG}$, in order to keep composition of the gas consistent. Table 3.1 shows the speciated composition of the $\mathrm{CNG}$, as well as other relevant parameters. Methane number ( $\mathrm{MN})$ was chosen to evaluate the knock resistance of $\mathrm{CNG}$, as opposed to using the motor octane number (MON). Test bounds setup to determine MON are designed for fuels with a maximum MON 120 and generally are not suited for fuels with very high knock resistance $[35,36]$. The methane number is a function of the hydrogen-to-carbon ratio, with pure methane having a reference number of 100 [37]. Heavier hydrocarbons such as ethane and propane lower the value of the methane number due to their lower knock resistance. At the same time, increasing the inert content of the fuel can raise the MN.

Table 3.1: Gaseous Fuel Specifications

\begin{tabular}{|l|l|}
\hline CH4, C2H6, CO2, N2 [mol\%] & $94,3,2,1$ \\
\hline MN [-] & 90.7 \\
\hline LHV [MJ/kg] & 46.93 \\
\hline AFRSTOICH [-] & 16.2 \\
\hline
\end{tabular}




\subsection{Data Acquisition}

\subsubsection{High Speed DAQ}

An AVL Indimodul 621 was used to collect all high-speed engine data. This 14 Bit data acquisition system was capable of collecting data at sampling rates of up to $800 \mathrm{kHz}$ for each of its 8 channels [38]. An AVL 365x optical crank angle encoder with a physical resolution of $0.5^{\circ} \mathrm{CA}$ was used to resolve all high-speed data on a crank angle basis. Software techniques native to indicating software were used to increase the resolution up to $0.1^{\circ} \mathrm{CA}$ [39]. High-speed data were collected and processed within AVL Indicom Software V1.6.

\subsubsection{Low Speed Data}

Low speed data were collected using a National Instruments SCXI-1001 chassis. Two BNC-2095 models were used for analog BNC inputs and one TC-2095 was used for thermocouple inputs. All data were collected on a 5-Hz basis. The LabView VI, originally generated by Dynamic Motion Control, Inc., was used as an interface to collect the data.

\subsubsection{High Speed Pressure Transducers}

Three high speed pressure transducers were located on the engine, measuring cylinder, intake, and exhaust pressure. Specifications for these transducers are listed in Table 3.2.

Table 3.2: High Speed Transducers

\begin{tabular}{|l|l|l|l|}
\hline Location & Manufacture & Model & Range \\
\hline In-Cylinder & AVL & GUI21C & 0-250barA \\
\hline Intake & Kulite & ETL-179B-190M & 0-2barA \\
\hline Exhaust & Kulite & EWCT-312M & 0-3.5barA \\
\hline
\end{tabular}

\subsection{Emissions Benches}

Exhaust emissions from the engine were sampled using a Pierburg AMA 2000 and AVL i60 emissions analyzer. Total hydrocarbon and methane emissions were sampled using separate heated flame ionization (FID) detectors; the latter of which included a methane cutter in order to measure only the $\mathrm{C} 1$ molecule. Non-dispersive detectors (NDIR) were used to measure carbon monoxide $(\mathrm{CO})$ and carbon dioxide $(\mathrm{CO} 2)$ emissions. Oxide of nitrogen emissions were measured using a chemiluminescence detector (CLD) and 
oxygen concentrations were measured using a paramagnetic detector (PMD). Before the start of each test, a zero and span check was performed on each emissions bench. In addition, each emissions bench was calibrated on a yearly basis by a qualified contractor.

\subsubsection{Pierburg AMA 2000}

Table 3.3 shows the specifications of each analyzer located in the Pierburg AMA 2000 emissions bench. Data presented in Section 4.1 and 4.2 utilized this emissions bench.

Table 3.3: Pierburg AMA 2000 Emissions Bench Specifications

\begin{tabular}{|l|l|l|l|l|l|l|}
\hline & $\begin{array}{l}\text { THC } \\
\text { (FID) }\end{array}$ & $\begin{array}{l}\text { CH4 } \\
\text { (FID) }\end{array}$ & $\begin{array}{l}\text { CO2 } \\
\text { (NDIR) }\end{array}$ & $\begin{array}{l}\text { O2 } \\
\text { (PMD) }\end{array}$ & $\begin{array}{l}\text { CO } \\
\text { (NDIR) }\end{array}$ & $\begin{array}{l}\text { NOx } \\
\text { (CLD) }\end{array}$ \\
\hline Zero Drift & $\leq 2 \% / 8 \mathrm{~h}$ & $\leq 1 \% / 1 \mathrm{~h}$ & $\leq 2 \% / \mathrm{wk}$ & $\leq 1 \% / \mathrm{wk}$ & $<2 \% / \mathrm{wk}$ & $\leq 1 \% / 8 \mathrm{~h}$ \\
\hline Sensitivity Drift & $\leq 2 \% / 8 \mathrm{~h}$ & $\leq 1 \% / 1 \mathrm{~h}$ & $\leq 0.5 \% / \mathrm{wk}$ & $\leq 2 \% / \mathrm{wk}$ & $<0.3 \% / \mathrm{wk}$ & $\leq 1 \% / 8 \mathrm{~h}$ \\
\hline Linearity Error & $\leq 2 \%$ & $\leq 1 \%$ & $\leq 1 \%$ & $\leq 1 \%$ & $<1 \%$ & $<1 \%$ \\
\hline Reproducibility & $\leq 1 \%$ & $\leq 0.5 \%$ & $\leq 1 \%$ & $\leq 1 \%$ & $<2 \%$ & $\leq 0.5 \%$ \\
\hline
\end{tabular}

3.5.2 AVL AMA i60

Table 3.4 shows the specifications of each analyzer located in the AVL AMA i60 emissions bench. Data presented in Section 4.3 and 4.4 utilized this emissions bench.

Table 3.4: AVL i60 Emissions Bench Specifications

\begin{tabular}{|l|l|l|l|l|l|l|}
\hline & $\begin{array}{l}\text { THC } \\
\text { (FID) }\end{array}$ & $\begin{array}{l}\text { CH4 } \\
(\text { FID) }\end{array}$ & $\begin{array}{l}\text { CO2 } \\
\text { (NDIR) }\end{array}$ & $\begin{array}{l}\text { O2 } \\
(\text { PMD) }\end{array}$ & $\begin{array}{l}\text { CO } \\
\text { (NDIR) }\end{array}$ & $\begin{array}{l}\text { NOx } \\
\text { (CLD) }\end{array}$ \\
\hline Sensitivity Drift & $\leq 1 \% / 24 h$ & $\leq 1 \% / 24 h$ & $\leq 1 \% / 24 h$ & $\leq 1 \% / 24 h$ & $\leq 1 \% / 24 h$ & $\leq 1 \% / 24 h$ \\
\hline Linearity Error & $\leq 1 \%$ & $\leq 1 \%$ & $\leq 1 \%$ & $\leq 1 \%$ & $\leq 1 \%$ & $\leq 1 \%$ \\
\hline Reproducibility & $\leq 0.5 \%$ & $\leq 0.5 \%$ & $\leq 0.5 \%$ & $\leq 0.5 \%$ & $\leq 0.5 \%$ & $\leq 0.5 \%$ \\
\hline
\end{tabular}




\subsection{Nomenclature}

\subsubsection{Indicated Thermal Efficiency}

The indicated thermal efficiency describes the engines ability to convert delivered fuel energy into a useful work output. Due to high frictional losses associated with a single cylinder research engine, all work outputs are indicated values, calculated from measured in-cylinder pressure data. The indicated mean effective pressure (IMEP) is obtained by integrating the cylinder pressure over the displaced volume, as shown in Equation 1. Here, the notation of Wcycle and IMEP are used interchangeably.

$$
W_{\text {cycle }}=\int P d V
$$

Shown in Figure 3.4 is an example of a $\log \mathrm{P}-\log \mathrm{V}$ plot from the test engine. The gross work loop is defined as the work delivered to the piston over the compression and expansion strokes only. The pumping loop is the work required by the piston for the exhaust and intake strokes. The net work is defined as the difference between the gross work and the pumping work. Within the indicating software (AVL Indicom), the distinction between the gross work area and pumping work area was defined as the intersection of the compression and exhaust lines.

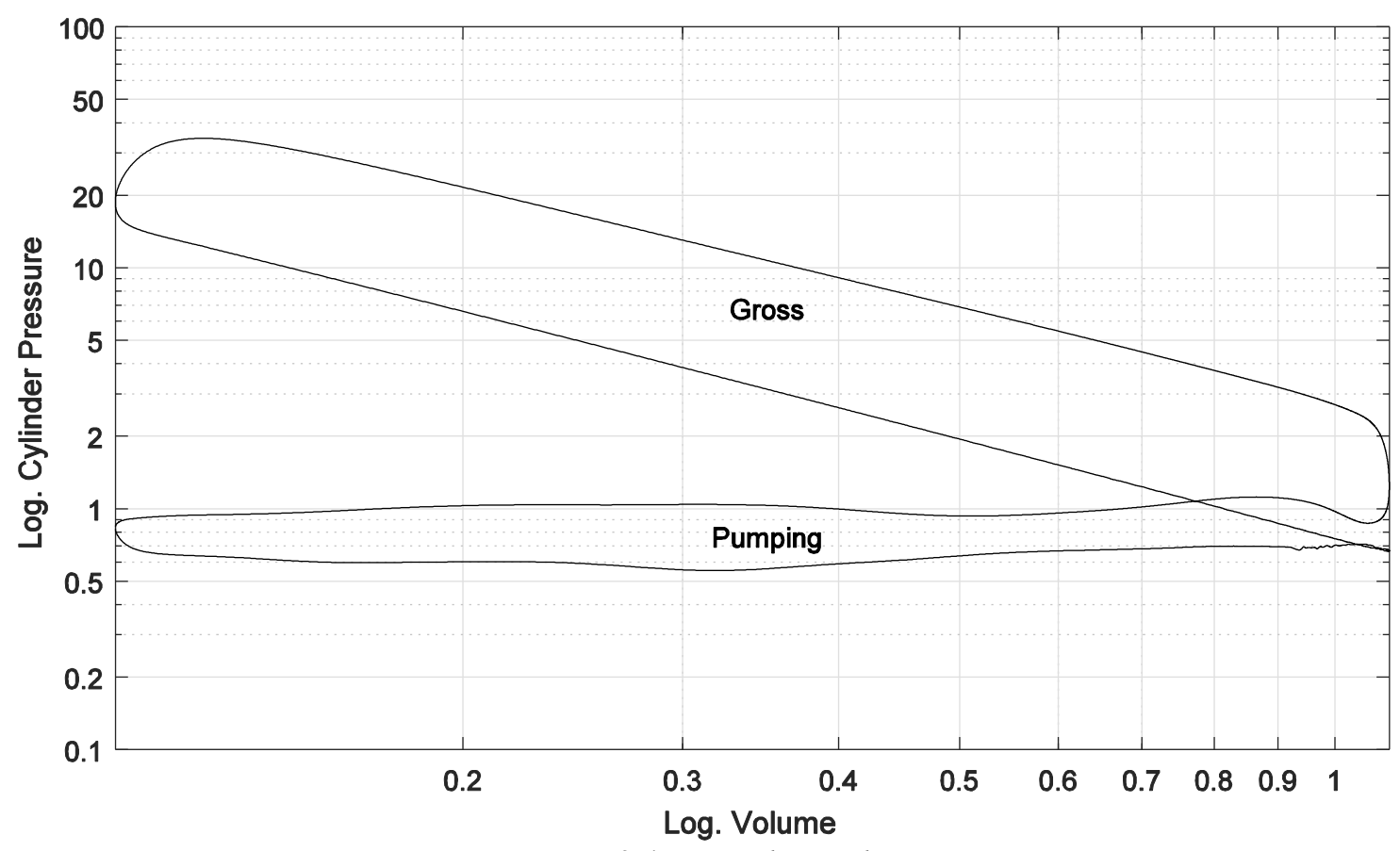

Figure 3.4: Log P-log V plot 
Therefore, the indicated thermal efficiency (ITE) is shown Equation 2 in the ratio of the work of the cycle to the delivered fuel energy.

$$
\text { ITE }=\frac{W_{\text {cycle }}}{\dot{m}_{f} Q_{L H V}}
$$

\subsubsection{Coefficient of Variation of Indicated Mean Effective Pressure}

Engine stability was evaluated using the coefficient of variation in the indicated mean effective pressure ( $\left.\mathrm{COV}_{\text {IMEP }}\right)$ defined as the standard deviation of IMEP divided by the mean of IMEP as shown in Equation 3. The current trend with automotive manufacturers is to maintain a $\mathrm{COV}_{\text {IMEP }}$ less than $3 \%$ to ensure stable engine operation. All high-speed data is analyzed over 375 cycles.

$$
C O V_{I M E P}=\frac{\sigma_{I M E P}}{\mu_{I M E P}}
$$

\subsubsection{Flame Development Angle and Combustion Duration}

Figure 3.5 shows a mass fraction burned (MFB) curve as a function of engine crank angle, used to describe the stages of the combustion event.

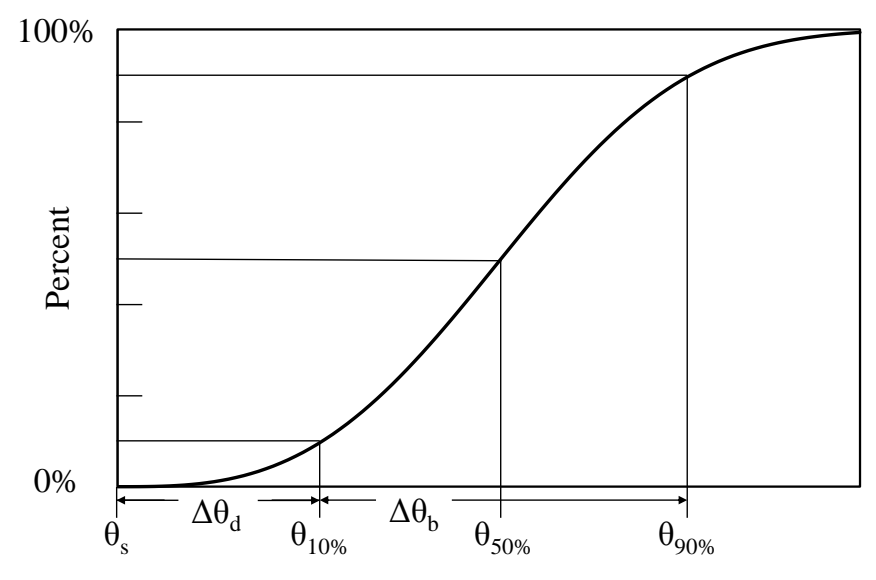

Figure 3.5: Mass Fraction Burned Curve

$\Delta \theta \mathrm{d}$, known as the flame development angle, is defined as the crank angle interval from the time of ignition until $10 \%$ of the cylinder mass has burned [6].

$\Delta \theta \mathrm{b}$, known as the combustion duration, is the crank angle interval from $10 \%$ to $90 \%$ MFB.

For all conditions presented, maximum brake torque (MBT) timing was held. The spark timing was adjusted for each condition to ensure the $50 \%$ MFB location, or $\theta_{50 \%}$ in Figure 
3.5, was at $8 \pm 1^{\circ} \mathrm{CA}$ ATDC. MBT timing corresponds to an optimal spark timing for engine operation; sparking too

\subsubsection{Combustion Inefficiency}

Combustion inefficiency was also analyzed, defined in Equation 4 as the rate at which the unburned exhaust components leave the engine to the rate at which fuel is supplied to the engine. For this analysis, only unburned combustible species in the exhaust were considered which include hydrogen, carbon monoxide, and total hydrocarbons.

$$
\eta_{c}=1-\frac{\Sigma_{i} x_{i} Q_{H V i}}{\left[\dot{m}_{f} /\left(\dot{m}_{a}+\dot{m}_{f}\right)\right] Q_{L H V f}}
$$

The relationship between combustion inefficiency and combustion efficiency is shown in Equation 5. Combustion inefficiency was used for the energy balance approach. It was utilized to show the percent of fuel energy that did not participate in the combustion event and is therefore a loss.

\section{Combustion Inefficiency $=1-$ Combustion Efficinecy 5 3.6.5 Indicated Specific Emissions}

Specific emissions were calculated using 40 CFR part 1065. Emissions computed using this standard were collected under steady-state conditions. The emissions are displayed as the mass flow rate of each consistent per unit of indicated work. It is worth mentioning that methane emissions in the exhaust were represented as data collected from the total hydrocarbon analyzer. Using the methane analyzer, it was determined that over $90 \%$ of the exhaust hydrocarbon was methane. 


\subsection{Energy Balance}

The conservation of energy states that energy cannot be created nor destroyed, it can only be transferred from one form to another. The first law of thermodynamics allows for the energy interactions of a system to be studied [40]. The conservation of energy can be applied to an engine operating condition, drawing a control volume around a specific boundary, accounting for energy that enters and exits the control volume. Figure 3.6 shows a control volume around the engine with energy inputs for fuel and intake air. Energy outputs include piston work, heat rejected to the coolant loop, exhaust enthalpy, unburned fuel, and miscellaneous heat losses, as adapted by R. Ogink presented in 2016 [41].

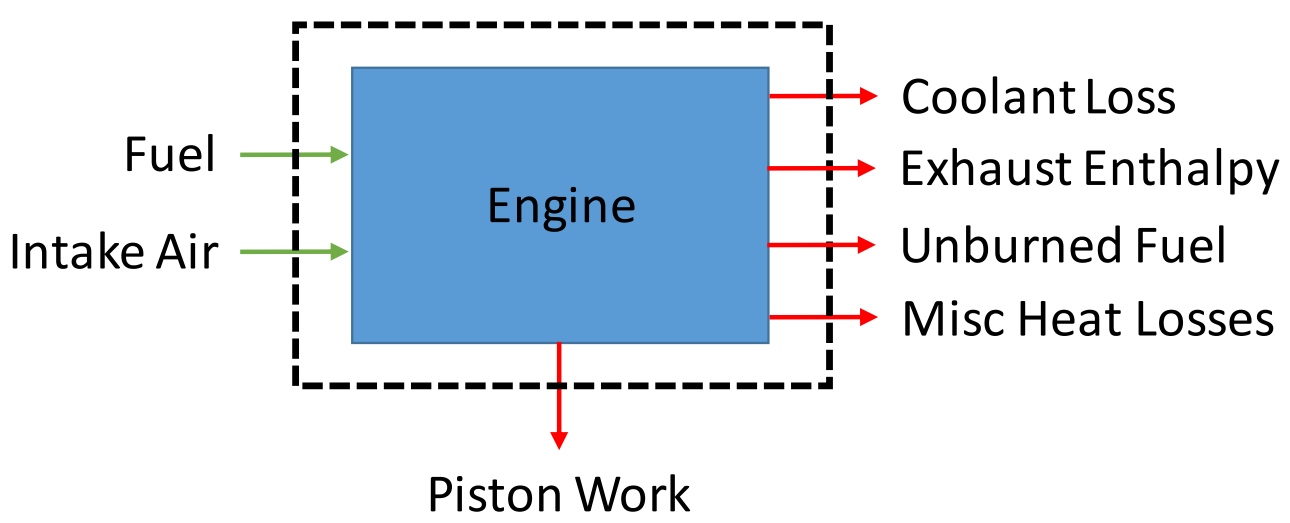

Figure 3.6: Control Volume for Conservation of Energy Analysis

Using the boundaries established in Figure 3.6, a relation of energy flowing into and out of the control volume can be established, shown in Equation 6 .

$$
\begin{aligned}
& \dot{m}_{\text {air }} h_{\text {air }}+\dot{m}_{f u e l} Q_{\text {fuel }} \\
&=\dot{W}_{\text {piston }} \\
&+\dot{Q}_{\text {coolant }}+\dot{m}_{\text {exh }} \dot{h}_{\text {exh }}+\dot{E}_{\text {unburned fuel }}+\dot{Q}_{\text {misc heat loss }}
\end{aligned}
$$

Steady state measurements of temperature, pressure and mass flows were used to determine the properties of variables shown in Equation 6. The delivered fuel energy was calculated using the lower heating value of NG and NG fuel mass flow rate; a Micro Motion Coriolis flow meter measured the gaseous fuel flow delivered to the engine. The mass flow rate of air delivered to the engine was calculated using the stoichiometric airfuel ratio of NG, NG delivered fuel flow rate, and actual air-fuel ratio of the engine calculated from exhaust emissions composition using the Brettschneider method [42]. 
The enthalpy of the dry intake air was calculated based off enthalpy values from the Engineering Equation Solver (EES®) and the inlet air temperature and pressure to fix the state.

Piston work produced was calculated from in-cylinder pressure data, as discussed in Equation 1 of Section 3.6.1.The heat transfer to the coolant was calculated from Equation 7 , using the mass flow rate of the coolant, specific heat of the coolant, and temperature change across the engine.

$$
\dot{Q}_{\text {Coolant }}=\dot{m}_{\text {Coolant }} c_{p}\left(T_{\text {Out }}-T_{\text {In }}\right) \quad 7
$$

In order to calculate the exhaust enthalpy, the exhaust composition was modeled as a three-component mixture considering carbon dioxide (CO2), water $(\mathrm{H} 2 \mathrm{O})$, and nitrogen (N2) and assuming complete combustion. The stoichiometric combustion equation was used in order to calculate the fraction of each constituent in the exhaust, shown in Equation 8. Enthalpy values for the three exhaust components were obtained from EES® and were specified at the exhaust gas temperature (EGT) for each condition.

$$
\begin{aligned}
& \mathrm{C}_{a} \mathrm{H}_{b}+\lambda\left(a+\frac{b}{4}\right)\left(\mathrm{O}_{2}+3.773 \mathrm{~N}_{2}\right)=a \mathrm{CO}_{2}+\frac{b}{2} \mathrm{H}_{2} \mathrm{O}+\quad 8 \\
& 3.773 \lambda\left(a+\frac{b}{4}\right) \mathrm{N}_{2}
\end{aligned}
$$

The molar flowrate of the exhaust was calculated using a carbon balance method, as shown in Equation 9 as moles per hour. This considered the rate at which the fuel was delivered to the engine and the concentration of all the carbon species in the exhaust.

$$
\begin{aligned}
\dot{N}_{E x h}=\dot{M}_{f u e l} & \cdot W_{C} \\
& \cdot \frac{1+X_{H 2 O}}{12.011 * X C_{\text {combdry }}}
\end{aligned}
$$

The unburned fuel energy term was calculated using carbon monoxide $(\mathrm{CO})$ and total hydrocarbons (THC) in the exhaust stream. The heating value of $\mathrm{CO}$ was referenced from literature [43] and the lower heating value of NG was used for THC. These two components were not included in the exhaust enthalpy computation because of their low overall concentration in the exhaust, compared to other constituents.

The miscellaneous heat loss term includes frictional and radiative losses from the block, as well as heat transfer to the oil reservoir. If the fuel energy delivered is to be considered $100 \%$, all of the other parameters in Equation 6 can be displayed as a percentage of the 
delivered fuel energy. The miscellaneous heat loss term was calculated as the summation of all the other terms subtracted from the total delivered fuel energy.

\subsection{Data Quality}

\subsubsection{Stability}

Data was not collected on the single cylinder engine until steady state conditions were reached. The requirement for this was for the engine oil temperature to be greater than $65^{\circ} \mathrm{C}$. Shown in Figure 3.7 is the oil temperature as a function of the sampling period, for central and side DI. For each injection system, it can be seen that the oil temperature was not varying over the sample duration. The oil temperature between the two shows some variation because these examples were taken at the beginning and end of the test.

However, the difference in the oil temperature is within acceptable limits.

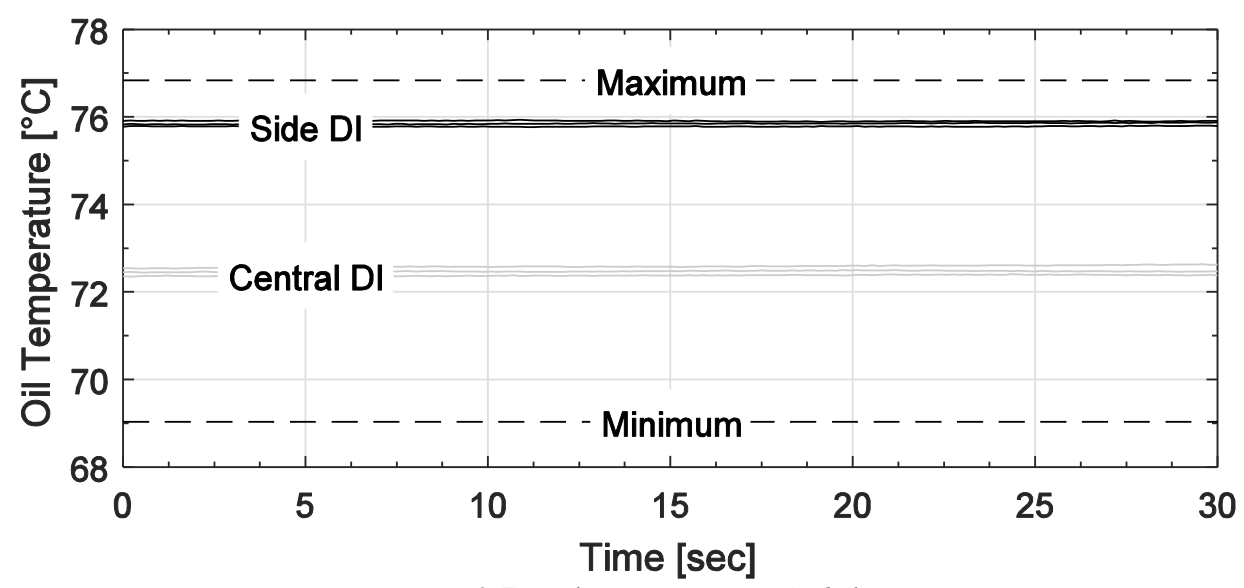

Figure 3.7: Oil Temperature Stability

\subsubsection{Repeatability}

In order to show repeatability within a given data set, three, 30 second data points were collected for each test condition. In Chapter 4, every data point represents an average of

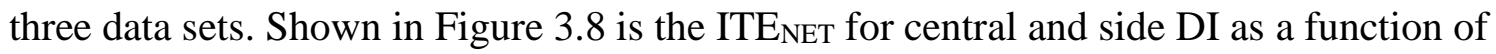
SOI. There are two metrics of repeatability shown in this plot. The error bars represent the measurement uncertainty in calculating the ITE $_{\mathrm{NET}}$, which is discussed in Section 3.8.3. In addition, the two black x's for each SOI value represent the minimum and maximum point that was collected over the three successive data points. For the instance of SOI $240^{\circ} \mathrm{CA}$ for both central and side DI, the minimum and maximum values are 
nearly indistinguishable from the average value. Delaying the SOI until $120^{\circ} \mathrm{CA}$ resulted in a greater spread between the minimum and maximum values. Because the minimum and maximum data points fall within the width of the error bars, they are deemed within measurement uncertainty. However, for SOI 360 and $150^{\circ} \mathrm{CA}$ and central DI, the minimum and maximum values fall outside of the error bars. Data for these conditions should either be not used for analysis, or retaken. For most of the conditions in Figure 3.8, the repeatability of the three collected points was high. Moving forward, any error bars placed onto graphs will represent the measurement uncertainty, as this represents a worst-case scenario.

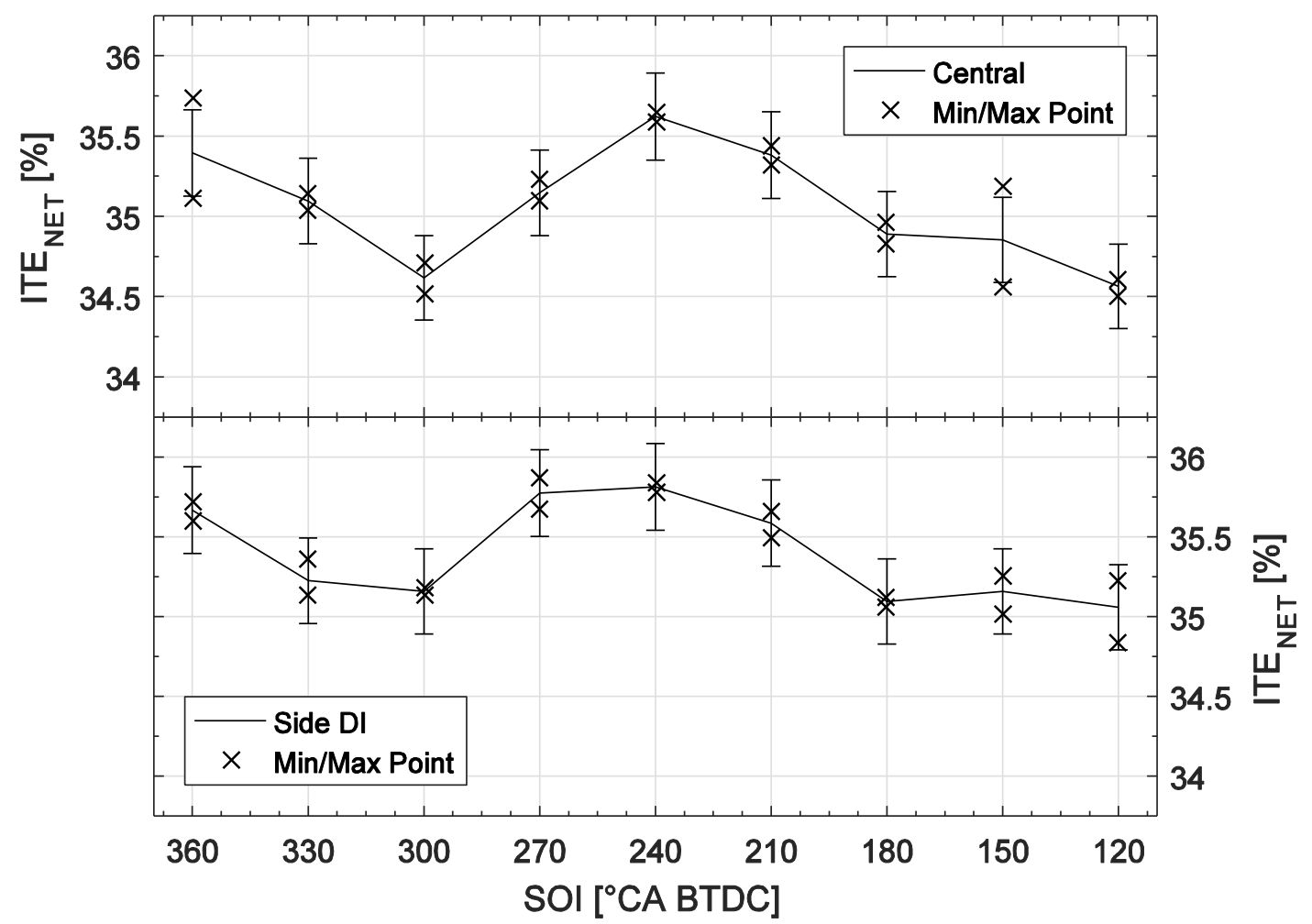

Figure 3.8: Repeatability in the Measurement

In addition, consistency checkpoints were performed throughout a given test. For the instance of data collected for Figure 3.8, SOI sweeps were performed first and then EGR sweeps were performed at three SOI values. Because a zero EGR condition was collected at the start of an EGR sweep for a given SOI, this data can then be compared to data collected during the SOI sweep. A comparison of similar data points was performed in Figure 3.9 with data from the SOI sweep on the left, EGR sweep on the right. The data 
shown was deliberately shifted about the $\mathrm{x}$-axis for sake of comparison. For each SOI condition, the error bars overlap indicating no statistical significance between collected data points.

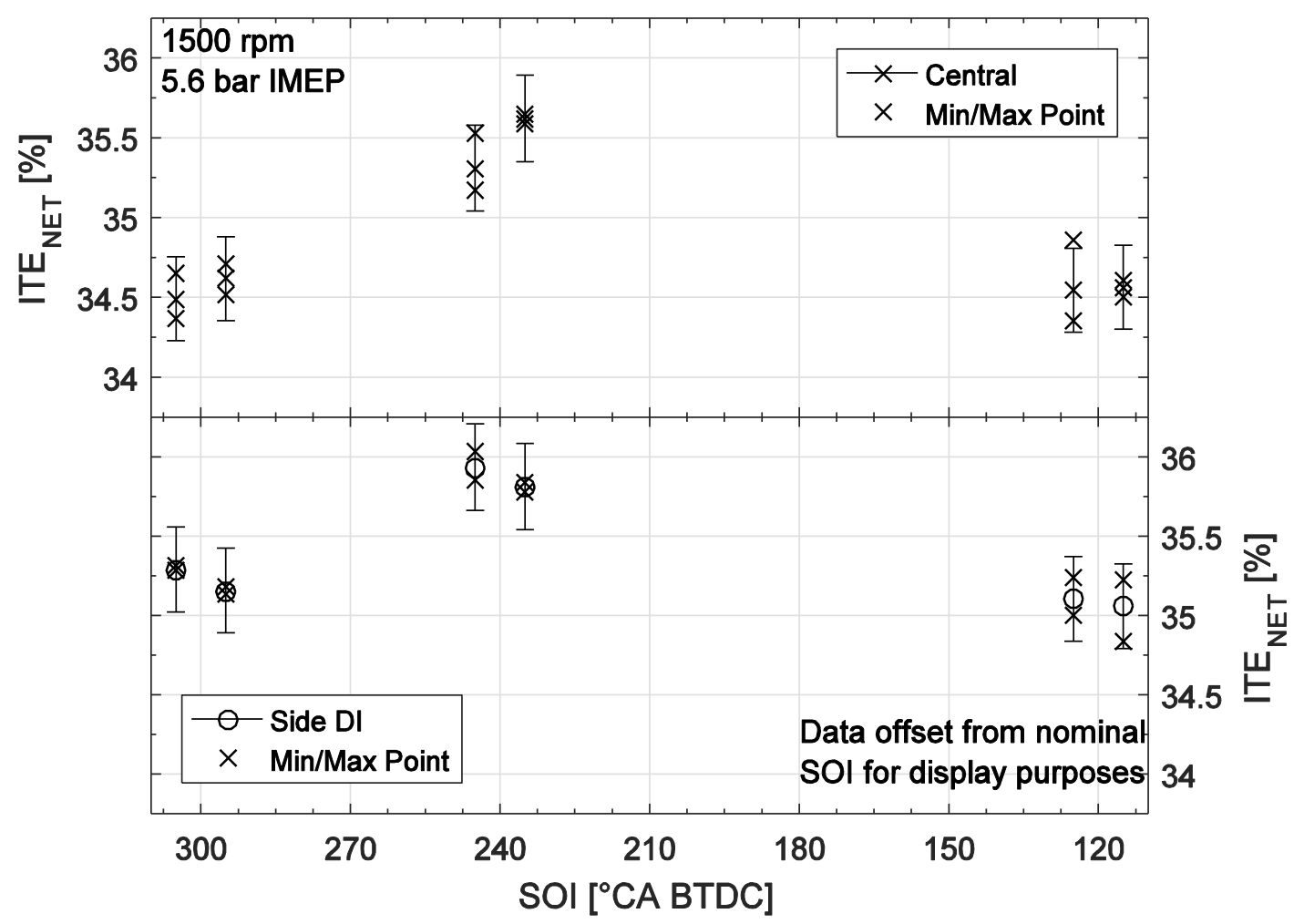

Figure 3.9: Repeatability in the Measurement - Checkpoints

The time difference between data points for both central and side DI is shown in Table 3.5.

Table 3.5: Time Difference between Checkpoints

\begin{tabular}{|l|l|l|l|}
\hline $\begin{array}{l}\text { Time Difference } \\
{[\mathrm{hh}: \mathrm{mm}]}\end{array}$ & $\begin{array}{l}\text { SOI } 300^{\circ} \mathrm{CA} \\
\text { BTDC }\end{array}$ & $\begin{array}{l}\text { SOI } 240^{\circ} \mathrm{CA} \\
\text { BTDC }\end{array}$ & $\begin{array}{l}\text { SOI } 120^{\circ} \mathrm{CA} \\
\text { BTDC }\end{array}$ \\
\hline Central & $2: 18$ & $1: 20$ & $0: 09$ \\
\hline Side & $2: 11$ & $1: 38$ & $0: 35$ \\
\hline
\end{tabular}

\subsubsection{Measurement uncertainty}

With any experimental measurement, there is some known error associated with the measurement devices. These uncertainties propagate through calculations, introducing deterministic variability in the data. The expected uncertainty of a measurement is shown 
in Equation 10, where $\omega \mathrm{R}$ is the uncertainty in the result and $\omega \mathrm{N}$ is the uncertainties in each variable $[44,45]$.

$$
\omega_{R}=\left[\left(\frac{\partial R}{\partial_{x_{1}}} \omega_{1}\right)^{2}+\left(\frac{\partial R}{\partial_{x_{2}}} \omega_{2}\right)^{2}+\cdots+\left(\frac{\partial R}{\partial_{x_{N}}} \omega_{N}\right)^{2}\right]^{\frac{1}{2}}
$$

For the experiments performed, gaseous fuel flow was measured using a Micro Motion CMF010M fuel flow meter. The error in the fuel flow measurement was dependent on the flow rate. Lower flow rates have a higher uncertainty while higher flow rates have a lower uncertainty [46]. There is uncertainty due to the cylinder pressure transducer and top dead center alignment. However, for these experiments, those were assumed constant because data for their uncertainty as a function gaseous fuel flow was not available. For the cylinder pressure transducer, an accuracy value from AVL was assumed. In order to determine the error for the top dead central alignment, the indicated work done to the piston was calculated using a volume and cylinder pressure trace. From there, the cylinder volume was shifted by $0.6^{\circ} \mathrm{CA}$, corresponding the loss angle. The difference between the shifted and non-shifted indicated work values was used for the top dead center alignment error.

The final derivation of the ITE uncertainty is shown in Equation 11, with error due to TDC offset, cylinder transducer error, and error associated with the fuel mass flow measurement. Considering the error from the fuel flow meter, a relation can be determined with the ITENET uncertainty as a function of fuel flow rate.

$$
\omega_{I T E}=\left[(T D C)^{2}+(\text { Cylinder Pressure })^{2}+4 \cdot\left(\dot{m}_{F U E L}\right)^{2}\right]^{\frac{1}{2}}
$$


Figure 3.10 shows the ITE $E_{\text {NET }}$ uncertainty as a function of fuel flow rate. The ITE NET curve has this given shape due to the nature of the fuel flow meter. At lower mass flow rates, the uncertainty of the Coriolis meter is high. However, beyond a certain mass flow rate the error becomes constant because the fuel flow meter is approaching the full-scale output and highest accuracy.

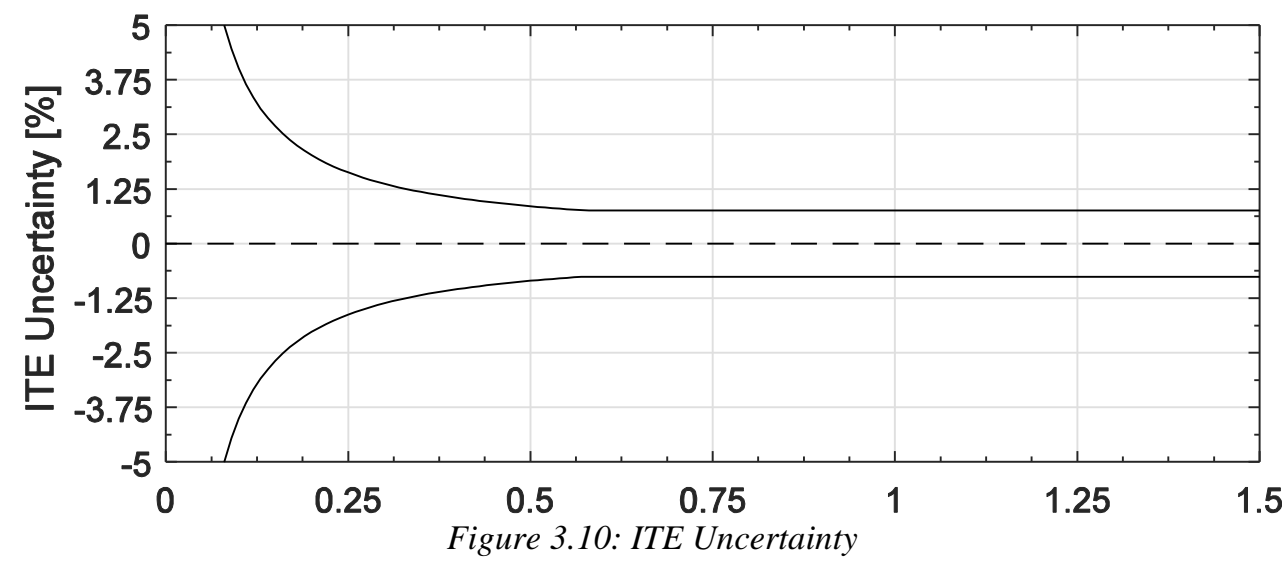

\subsection{D CFD Simulation}

To provide additional understanding of the trends observed in the experimental data, CFD simulations of the gas-exchange, fuel injection, and mixture formation processes were performed. This aided in understanding the impact of the gaseous injection event on the in-cylinder charge motion and mixture uniformity. These simulations were performed by researchers at ANL in order to further assist the experimental effort. Simulations were performed using the commercial CFD software CONVERGE. Researchers at ANL have previously focused on CFD simulations of the mixture formation of the same engine, however the focus was hydrogen DI and inward opening injectors $[47,48]$. More recently, CFD studies of mixture formation from the outward opening NG DI injector were performed and X-ray diagnostic techniques were used to validate simulation results [49]. The simulation data presented in this document is therefore not the work of the author, but rather available because of the collaborative efforts available at ANL. 


\subsection{Disclaimer}

The single cylinder engine used in these investigations was used for multiple research programs over the course of the data collection process for this dissertation. Each of the projects required the cylinder head to be changed, while the short block remained the same. There can be discrepancies in thermal efficiency values for similar hardware and operating conditions, if the hardware configuration has been changed in between tests. The following shows the time of year the data set for each respective section was collected:

- $\quad$ Section 4.1 and 4.2- December 18, 2015

- Section 4.3 - August 2, 2016

- $\quad$ Section 4.4 - December 22, 2016

In addition, two separate emissions benches were used for these investigations, due to the replacement of legacy equipment. Section 4.1 and 4.2 used a Pierburg AMA2000 fivegas emissions analyzer, while Section 4.3 and 4.4 used a new AVL i60 five-gas emissions analyzer.

Therefore, when comparing data sets between the multiple sections, the exact magnitudes may not be the same. However, the trends in the data remained consistent. 


\section{Data Analysis}

A series of steady state tests were performed in order to assess the impact of NG DI on the net indicated thermal efficiency (ITE $E_{N E T}$ ) at a part-load condition. The conditions selected represent part throttle road load conditions for a vehicle level application. An energy balance approach was used to analyze the data in subsequent sections.

It should be noted that all data presented in Section 4 is a part of a much larger Department of Energy program, aimed at demonstrating the benefits of NG DI and at the same time showing the benefits of in-cylinder blending techniques on engine performance and emissions [50]. Because the project was targeted for the US market, all data shown was collected under stoichiometric conditions in order to maintain compliance with traditional after treatment mechanisms. 


\subsection{Injection Location and SOI Impact on ITE IET $_{\text {at }}$ \% EGR $^{1}$}

In order to determine the effects of injection location and SOI on the indicated thermal efficiency, the start of injection (SOI) was swept for centrally and side mounted NG DI injectors under zero EGR conditions at 1500 rpm 5.6 bar IMEP NET. $_{\text {. }}$

Figure 4.1 shows the ITE $\mathrm{NET}_{\text {f }}$ for central and side DI at 0\% EGR, with error bars for each data point. The error bars shown represent the measurement uncertainty in the determination of ITE, which was discussed in Section 3.8.3. As shown in Figure 4.1, the ITE $_{\mathrm{NET}}$, which takes into account any gas exchange losses, varies considerably with changing the SOI and the injection location.

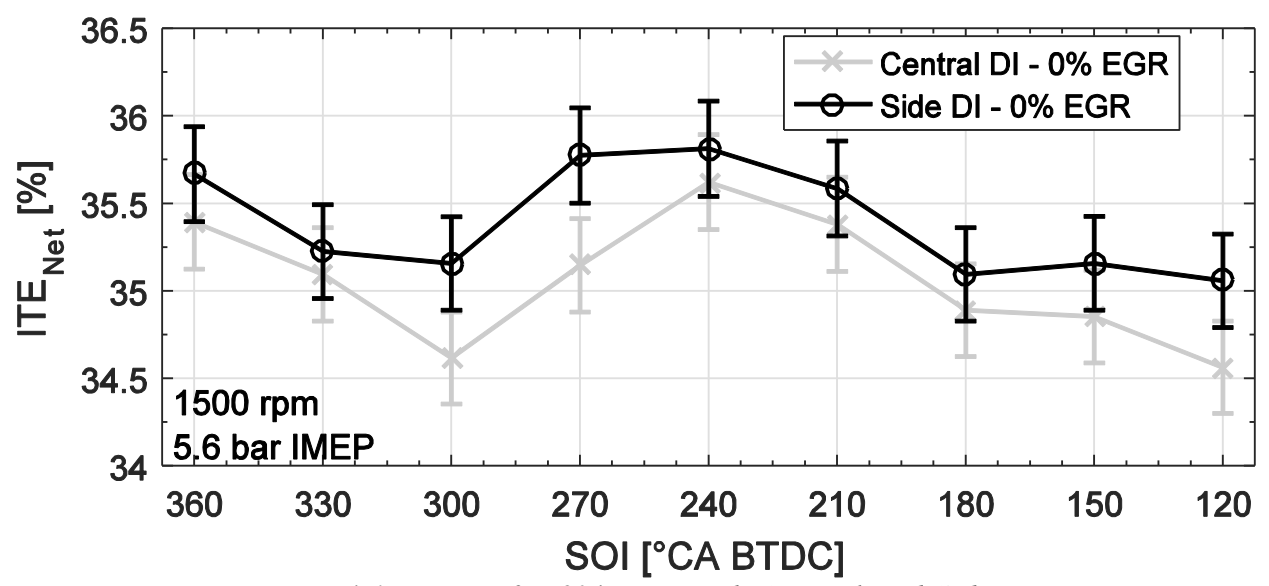

Figure 4.1: ITE $E_{\text {NET }}$ for 0\% EGR with Central and Side DI

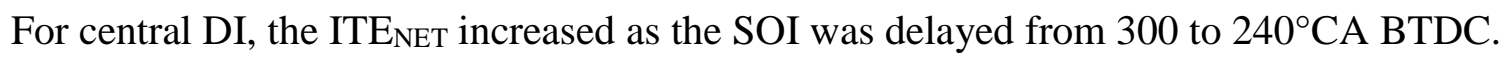
SOI $240^{\circ} \mathrm{CA}$ BTDC corresponded to a location where the maximum ITE $\mathrm{NET}_{\text {occurred. As }}$ the start of injection was delayed closer to TDC after maximum efficiency, ITE $E_{N E T}$ decreased. For both central and side DI, the general trend of ITENET followed for the duration of the SOI sweep. At SOI $300^{\circ} \mathrm{CA}$ BTDC, ITENET reached a local minimum of 34.6 and $35.2 \%$ for central and side DI, respectively. Because the error bars are not overlapping at this SOI, the difference in efficiency was statistically significant. It was anticipated that more advanced injection timing would lead to higher efficiency levels

1 Parts of the material contained in this chapter was previously published as a journal paper in the Society of Automotive Engineers. Reprinted with Permission from SAE International. 
due to improved mixing, it is possible that there is a poor interaction between the gaseous injection event and intake flow, leading to unfavorable conditions in the near spark region at the time of the spark event. This ultimately leads to higher cyclic variability, incomplete combustion products and lower efficiency.

Although SOI $120^{\circ} \mathrm{CA}$ BTDC showed similar efficiency levels as SOI $300^{\circ} \mathrm{CA}$ BTDC, there were added benefits to SOI $120^{\circ} \mathrm{CA}$ BTDC, as it was a fully closed intake valve injection event which is pertinent to a DI application. Injecting after intake valve closure (IVC) preserves the charge motion induced by the gaseous injection event, due to a decreased amount of time between the end of injection and the spark event. Central and side DI reached a maximum ITENET of $35.6 \%$ and $35.8 \%$, respectively, at $240^{\circ} \mathrm{CA}$ BTDC. When examining the error bars, there was no statistical significance at SOI 240 ${ }^{\circ} \mathrm{CA}$ BTDC for the two injection locations. However, at SOI $120^{\circ} \mathrm{CA}$ BTDC there was only $0.1 \%$ overlap, indicating a nearly significant difference. 
To further understand the trends identified in ITE $\mathrm{NET}_{\mathrm{N}}$, the ITE $\mathrm{IROSS}_{\mathrm{G}}$ and pumping mean effective pressure (PMEP) were analyzed, as shown in Figure 4.2. When analyzing

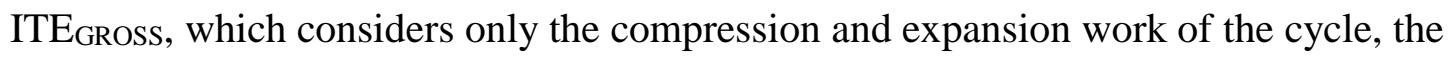

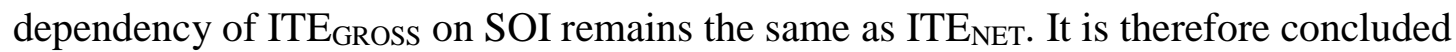

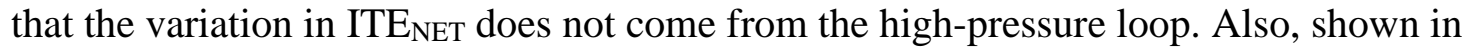
Figure 4.2 is the gas exchange work for the cycle, known as the PMEP. There was up to a $25 \%$ increase in gas exchange losses when delaying the SOI from 240 to $120^{\circ} \mathrm{CA}$ BTDC. Due to the low volumetric energy density of NG, a large volume of gas was injected, displacing a finite volume of air within the combustion chamber. As the SOI was delayed closer to TDC, more air was allowed to be trapped in the cylinder before IVC. Therefore, in order to maintain the same part-load condition, the engine had to be throttled more. This sharp increase in PMEP was one factor for a decrease in ITENET after SOI $240^{\circ} \mathrm{CA}$ BTDC.

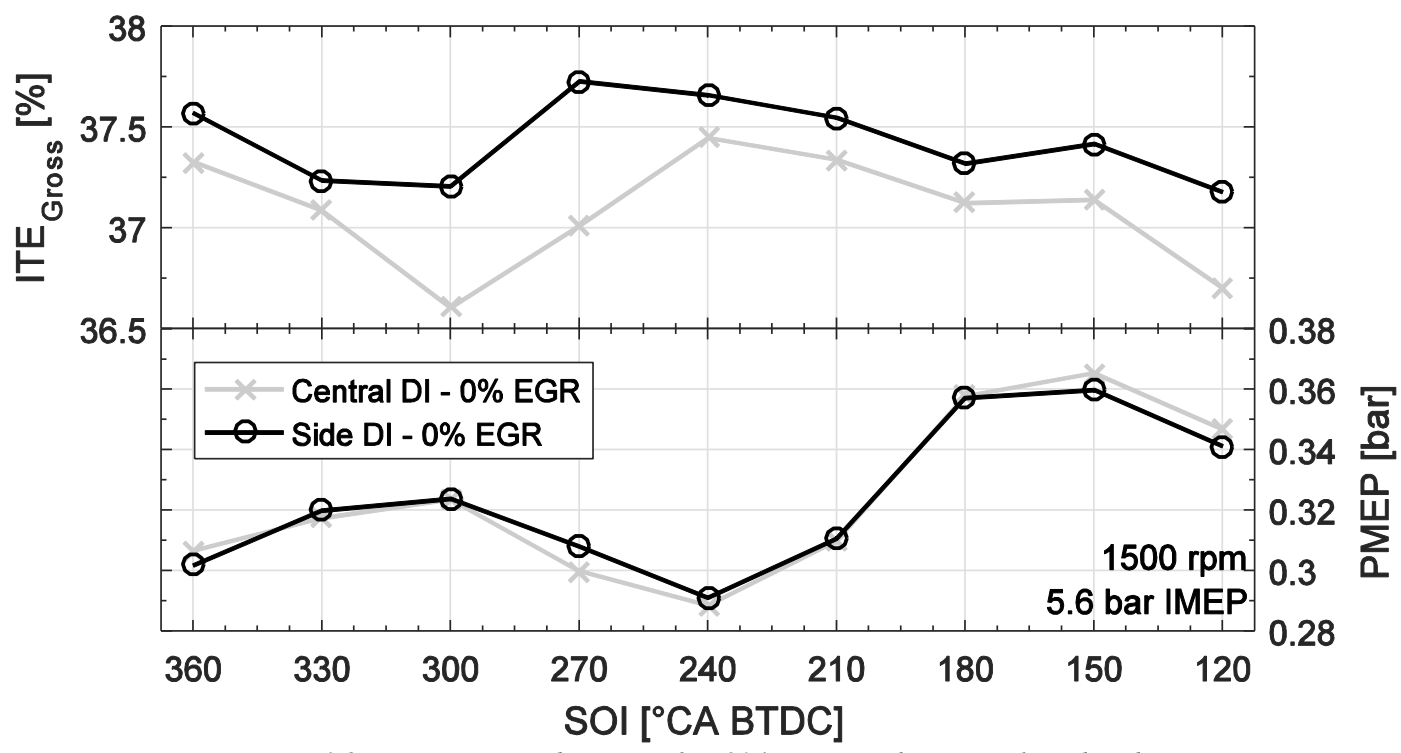

Figure 4.2: ITE $E_{\text {GROSS }}$ and PMEP for 0\% EGR with Central and Side DI 
As stated with regards to Figure 4.2, the PMEP increased as SOI was delayed from SOI $240^{\circ} \mathrm{CA}$ BTDC, due to increased throttling to maintain the same load. As shown in Figure 4.3, the manifold air pressure (MAP) decreased after SOI $240^{\circ} \mathrm{CA}$ BTDC. This decrease in MAP, in order to maintain the same load was the cause of the PMEP increase in Figure 4.2.

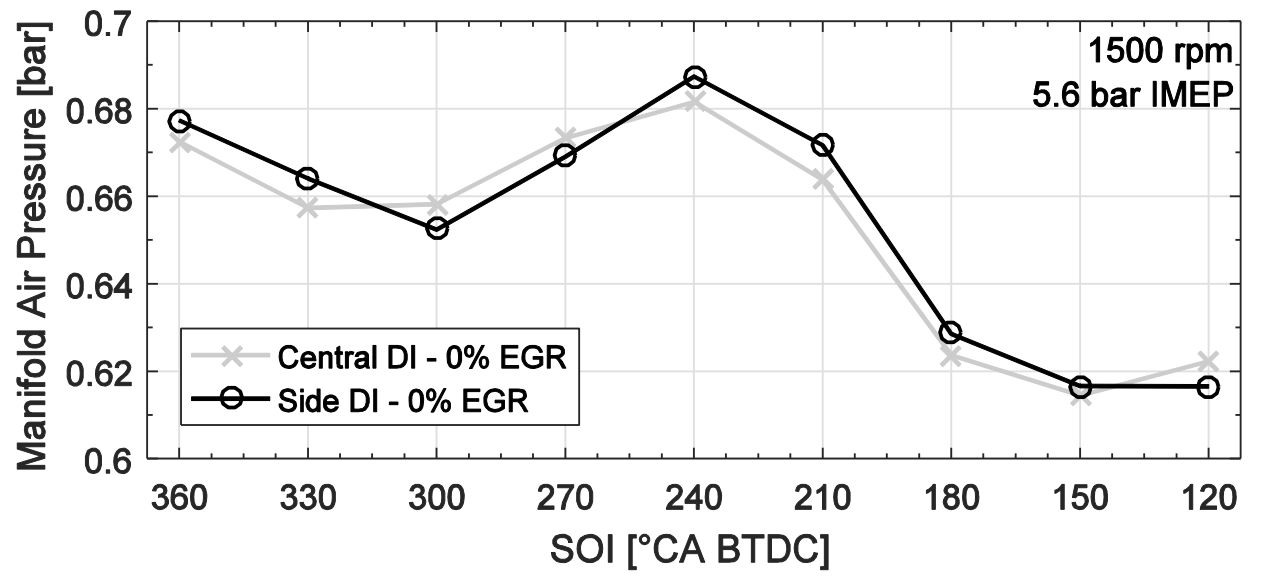

Figure 4.3: MAP as a function of SOI for Central and Side DI

Three unique SOI values were the focus of additional detailed analysis. An SOI of

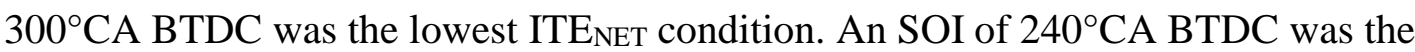

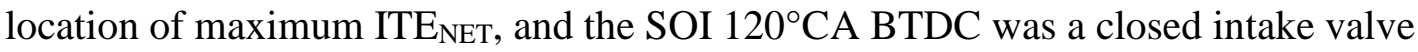
injection event.

In order to further understand the variation in $\mathrm{ITE}_{\mathrm{NET}}$ presented in Figure 4.1, an energy balance was performed for central and side DI at the three SOI values. 


\subsubsection{SOI $300^{\circ} \mathrm{CA}$ BTDC Analysis}

Figure 4.4 shows an energy balance for central and side DI locations, with the SOI set to $300^{\circ} \mathrm{CA}$ BTDC.

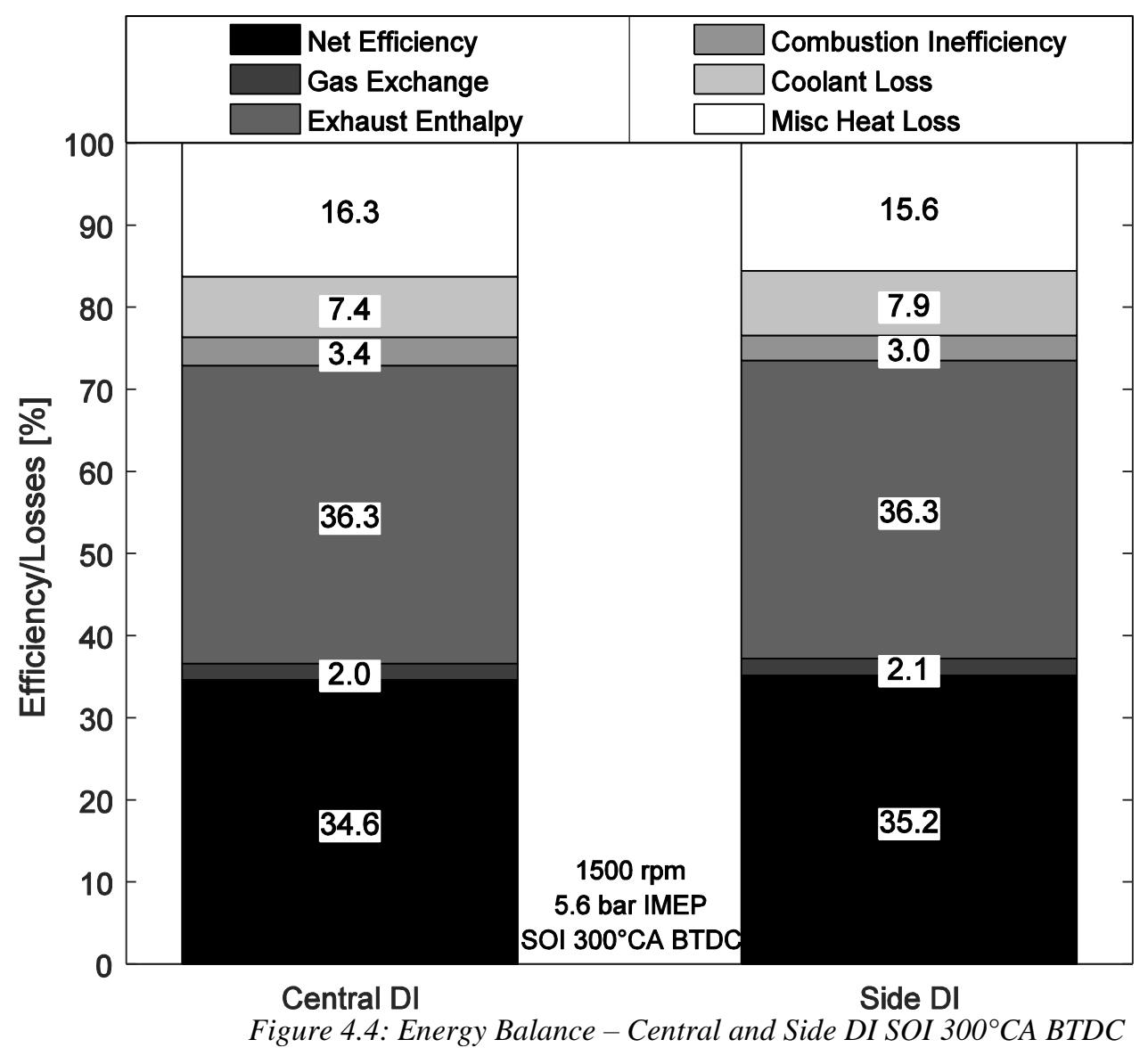

Side DI results in a greater net indicated thermal efficiency compared to central DI, by $0.6 \%$ absolute, which is also shown in Figure 4.1. While the energy balance shows how the delivered fuel energy was utilized during the combustion process, further data was required to explain the differences in net indicated thermal efficiency and subsequent losses shown in Figure 4.4. 
When considering an ideal thermodynamic cycle, the spark ignition engine follows the constant-volume combustion process [6]. This cycle assumes the combustion event occurs at constant volume. Therefore, the CD for central and side DI was investigated to determine any differences. Figure 4.5 shows the CD for central and side DI at SOI $300^{\circ} \mathrm{CA}$ BTDC. There was a $2.2^{\circ} \mathrm{CA}$ difference in the $\mathrm{CD}$ between central and side DI. Considering the injection path, central DI injects directly into the tumble motion while side DI injects along the tumble motion. Literature has shown that the NG DI injection event increases charge motion within the cylinder, increasing mixture flame speeds [21]. The added charge motion of the NG DI injection event along the tumble motion led to an increase in the rate of turbulent flame propagation, helping to improve ITE $_{\mathrm{NET}}$ for side DI.

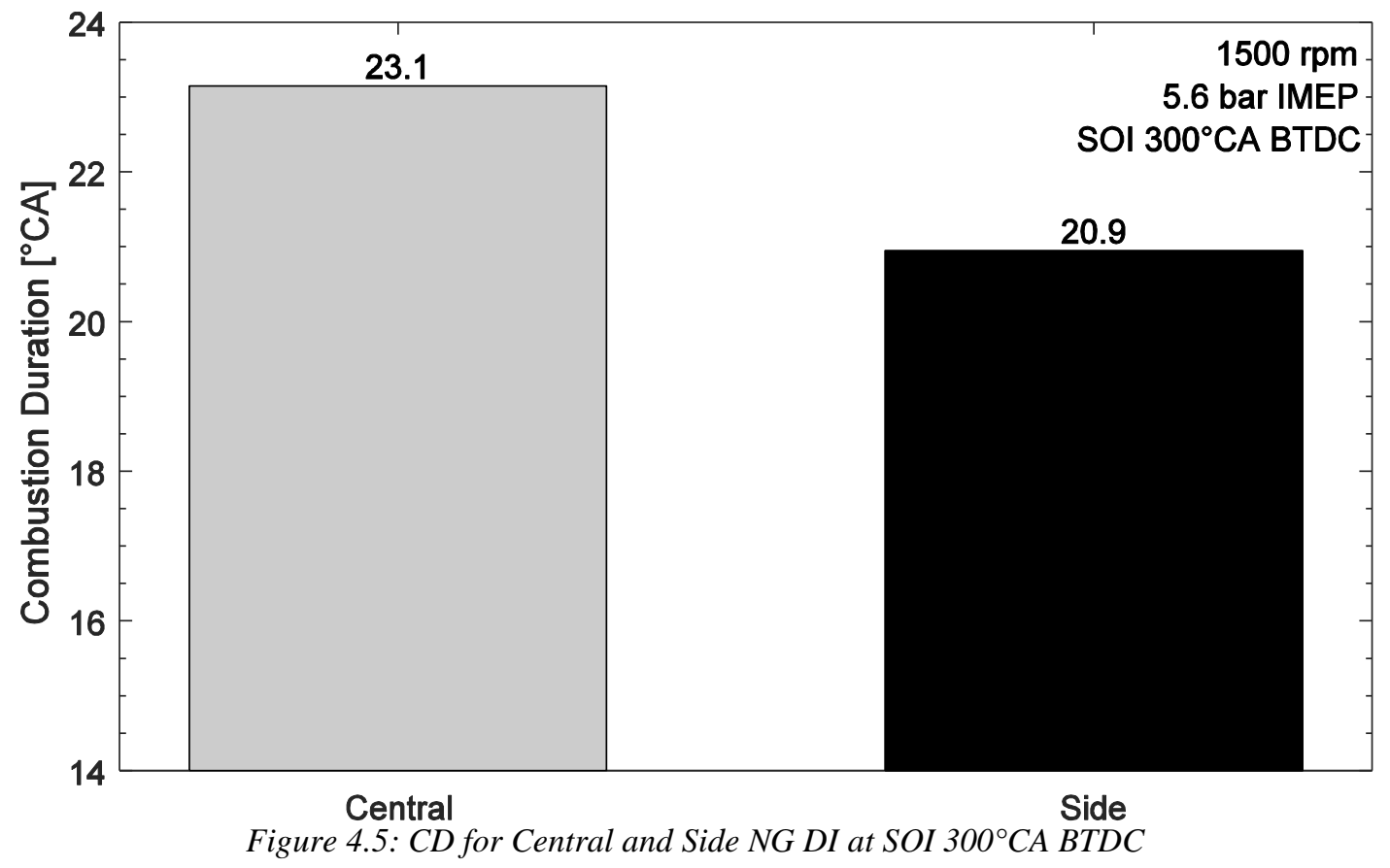


Shown in Figure 4.6 is the in-cylinder tumble ratio as calculated from 3D CFD for central and side DI at SOI $300^{\circ} \mathrm{CA} \mathrm{BTDC}$. Mixing for SI engines is accomplished through tumble motion, described as a rotational motion perpendicular to the cylinder axis. The CFD simulation predicted that both central and side DI reversed the tumble flow direction during the gaseous injection event. The reversed tumble flow, which led to a more non-uniform fuel-air mixture, characterizes SOI $300^{\circ} \mathrm{CA}$ BTDC as a poor mixing point. Central DI does not affect in-cylinder tumble like side DI, due to a more neutral path of the injected gas. At SOI $300^{\circ} \mathrm{CA}$ BTDC, the side DI location impinges on piston which causes the reversed tumble motion. The combination of shorter CD and improved tumble motion provide supporting data for the trend observed in ITE $\mathrm{NET}_{\text {. }}$

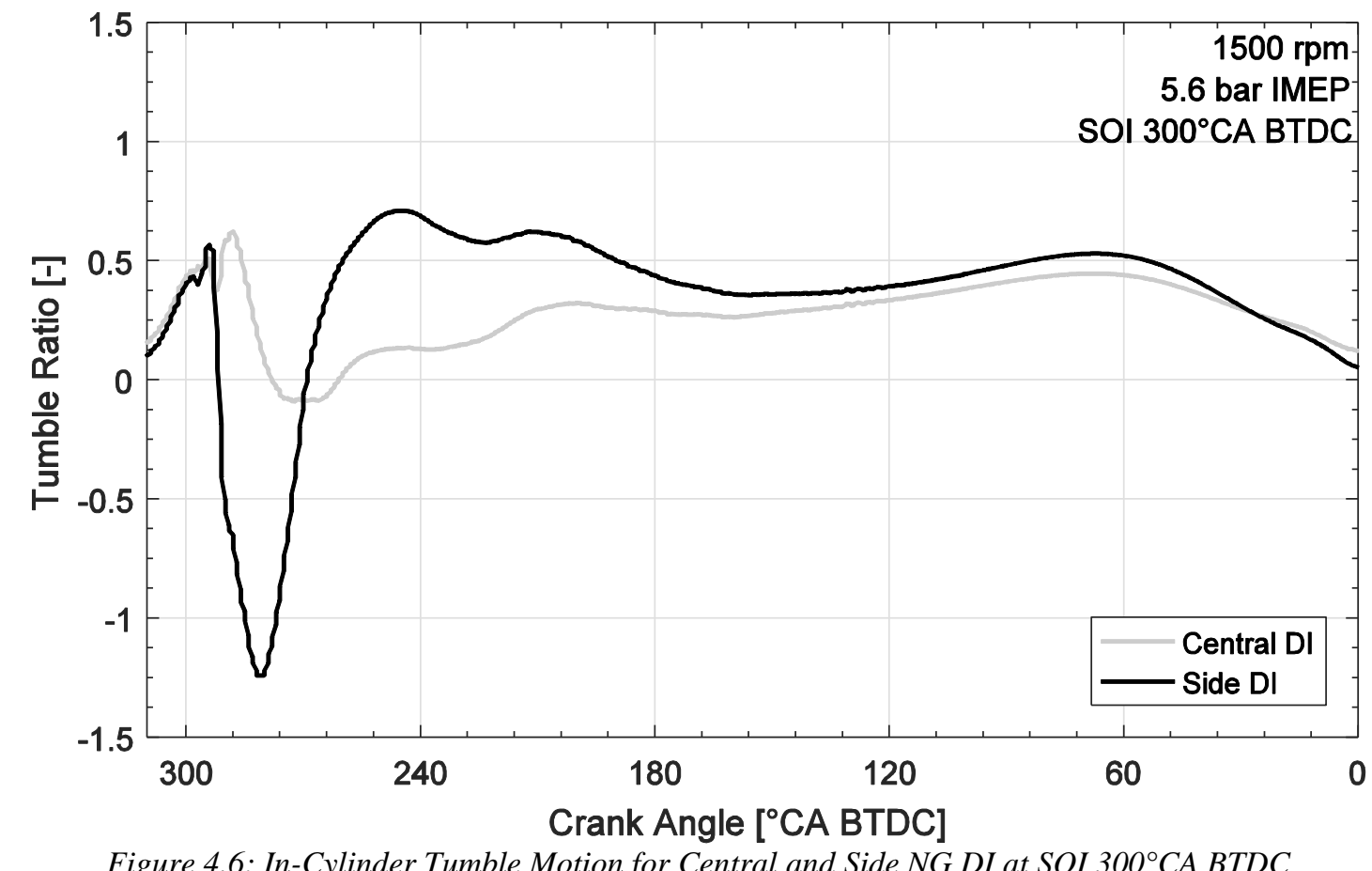

Figure 4.6: In-Cylinder Tumble Motion for Central and Side NG DI at SOI $300^{\circ} \mathrm{CA} B T D C$ 
Simulation also provided the average global turbulent kinetic energy (TKE) in the cylinder in Figure 4.7. The TKE at the time of spark, as indicated by the black square, was similar for both central and side DI at SOI $300^{\circ} \mathrm{CA}$, with a slightly higher TKE for side DI. This correlates with the $2.2^{\circ} \mathrm{CA}$ shorter $\mathrm{CD}$ for side DI shown earlier in Figure 4.5. Therefore, side DI injection was more effective than central DI injection in enhancing in-cylinder tumble and turbulence, and this had a positive impact on the CD and thus ITENET.

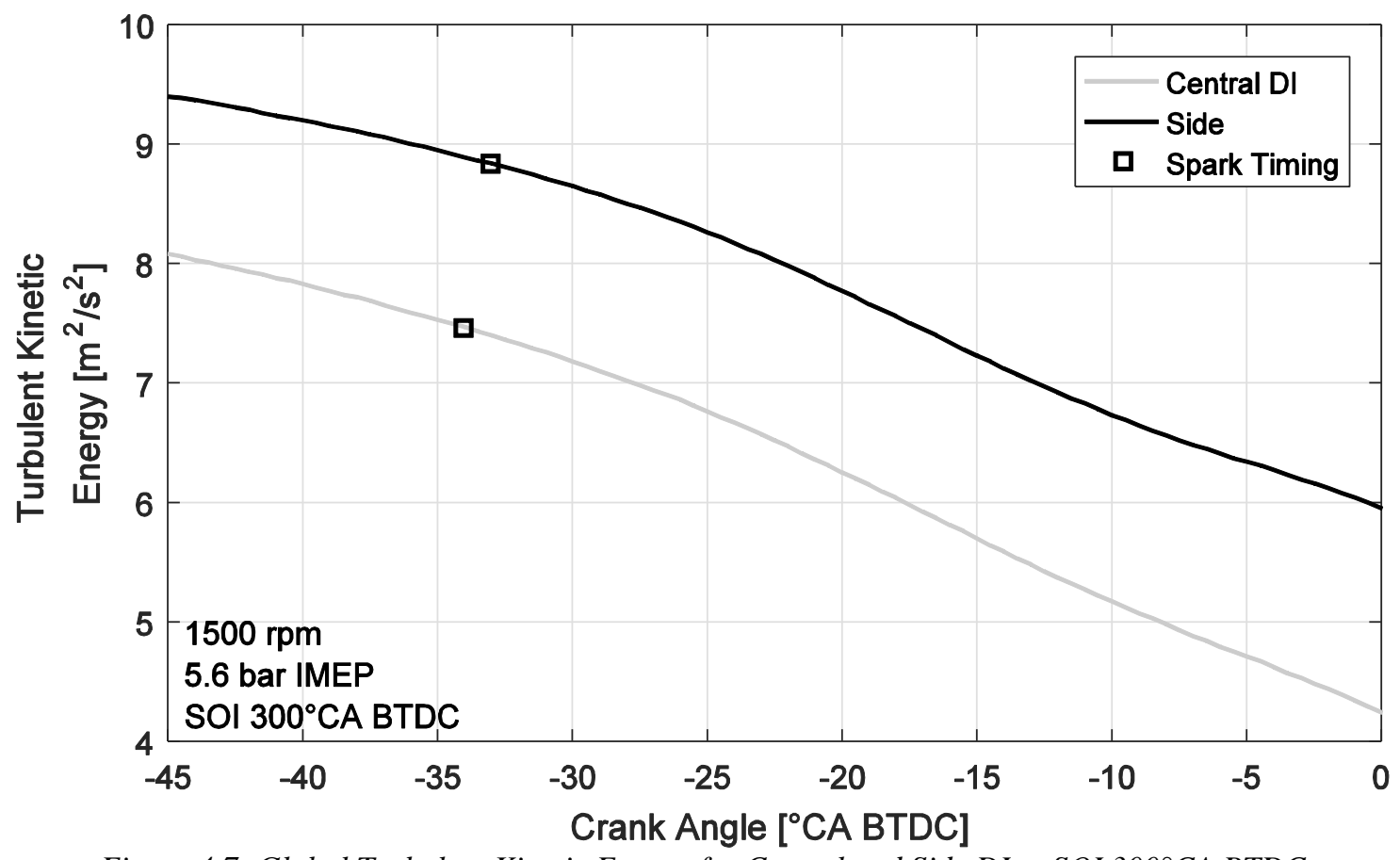

Figure 4.7: Global Turbulent Kinetic Energy for Central and Side DI at SOI $300^{\circ} \mathrm{CA} B T D C$ 
Figure 4.4 showed that the gas exchange losses were similar, because the same amount of throttling was required to maintain the load. The exhaust enthalpy was the same between central and side DI, indicating similar exhaust mass flow rates and EGT's. For reference, the EGT's for this condition were $613^{\circ} \mathrm{C}$ and $611^{\circ} \mathrm{C}$ for central and side DI as shown in Figure 4.8.

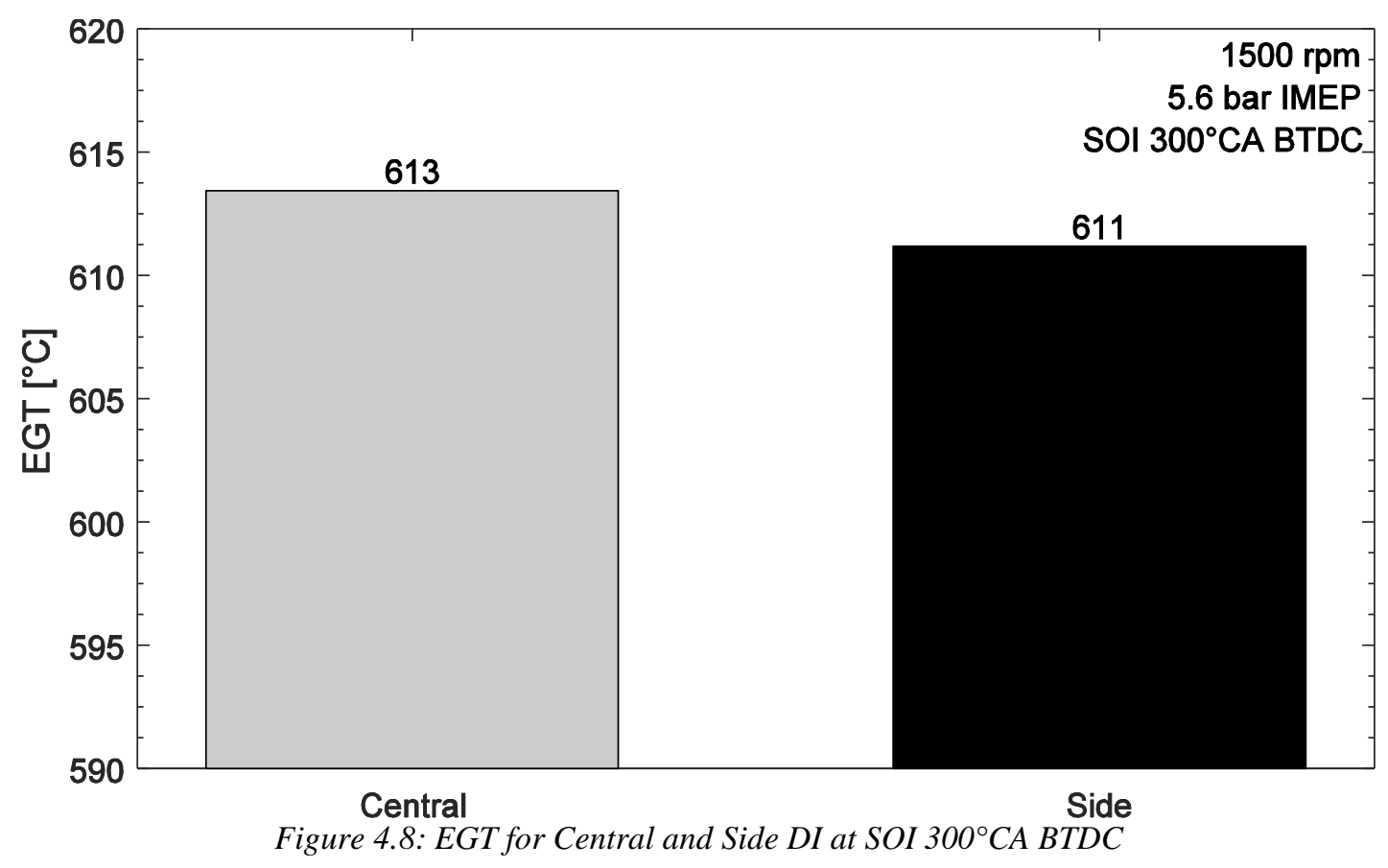


Also shown in Figure 4.4, side DI resulted in a $0.4 \%$ lower loss for incomplete combustion, compared to central DI. Figure 4.9 shows the iSHC emissions for central and side DI at SOI $300^{\circ} \mathrm{CA}$ BTDC. Despite having a higher net efficiency, side DI resulted in an $8 \%$ increase in iSHC emissions. While CFD predicted that side DI improved tumble motion at SOI $300^{\circ} \mathrm{CA} \mathrm{BTDC}$, it is plausible that the greater charge motion pushed more fuel into the crevice volume, leading to more unburned fuel in the exhaust.

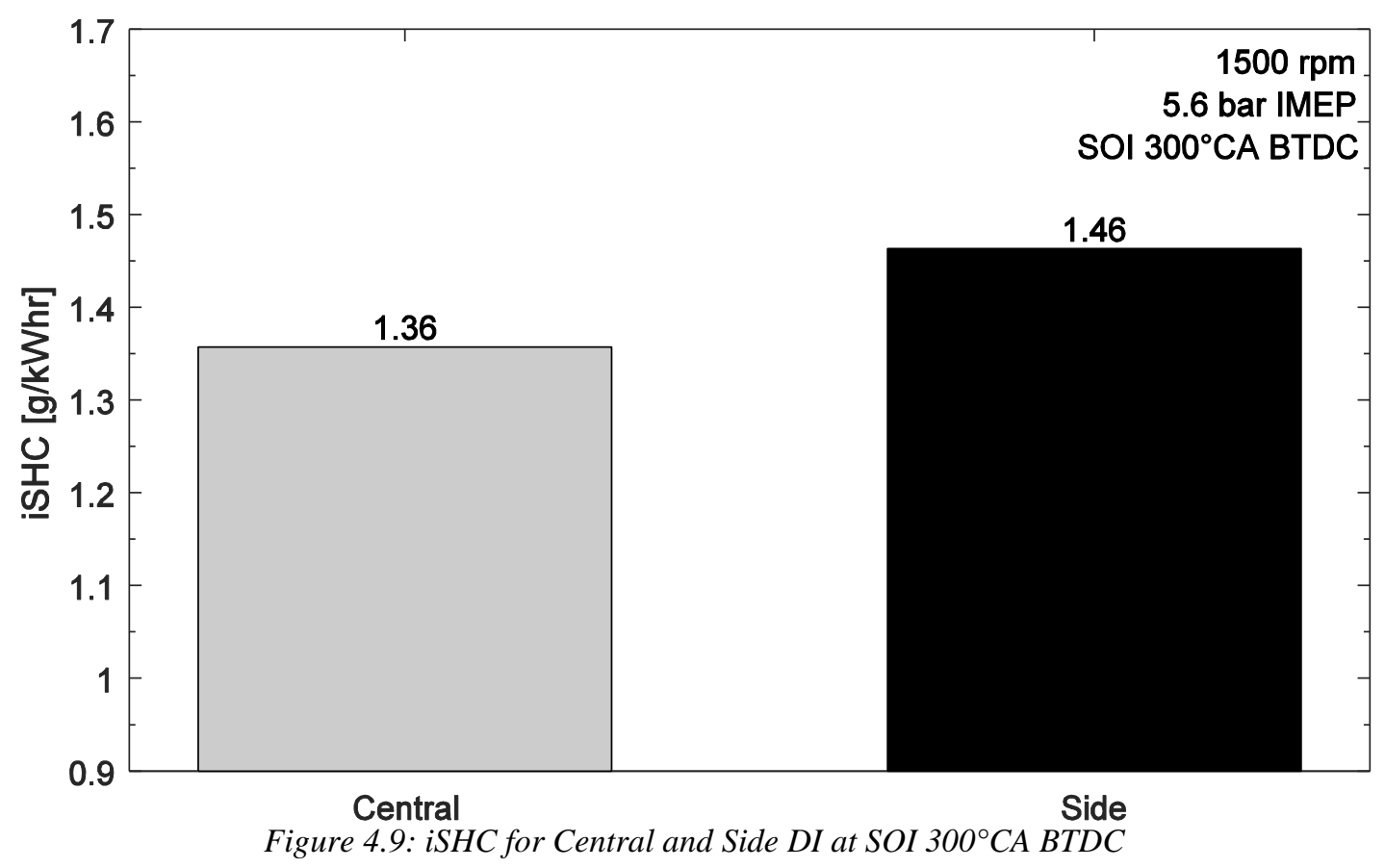


Figure 4.10 shows iSCO emissions for central and side DI at SOI $300^{\circ} \mathrm{CA}$ BTDC. Side DI results in a nearly $3.7 \mathrm{~g} / \mathrm{kWhr}$ lower iSCO emissions (22\% difference), compared to central DI. CO emissions directly correlate with the actual air-fuel ratio; operating rich and lean of stoichiometric leads to an increase and decrease in CO emissions, respectively [6]. Therefore, the Brettschneider method was utilized to calculate lambda from exhaust emissions [42]. The difference between lambda for central and side DI for this condition was less than $0.5 \%$, indicating the difference in iSCO emissions is due to inhomogeneity within the cylinder caused by central DI and not a shift in the global lambda value.

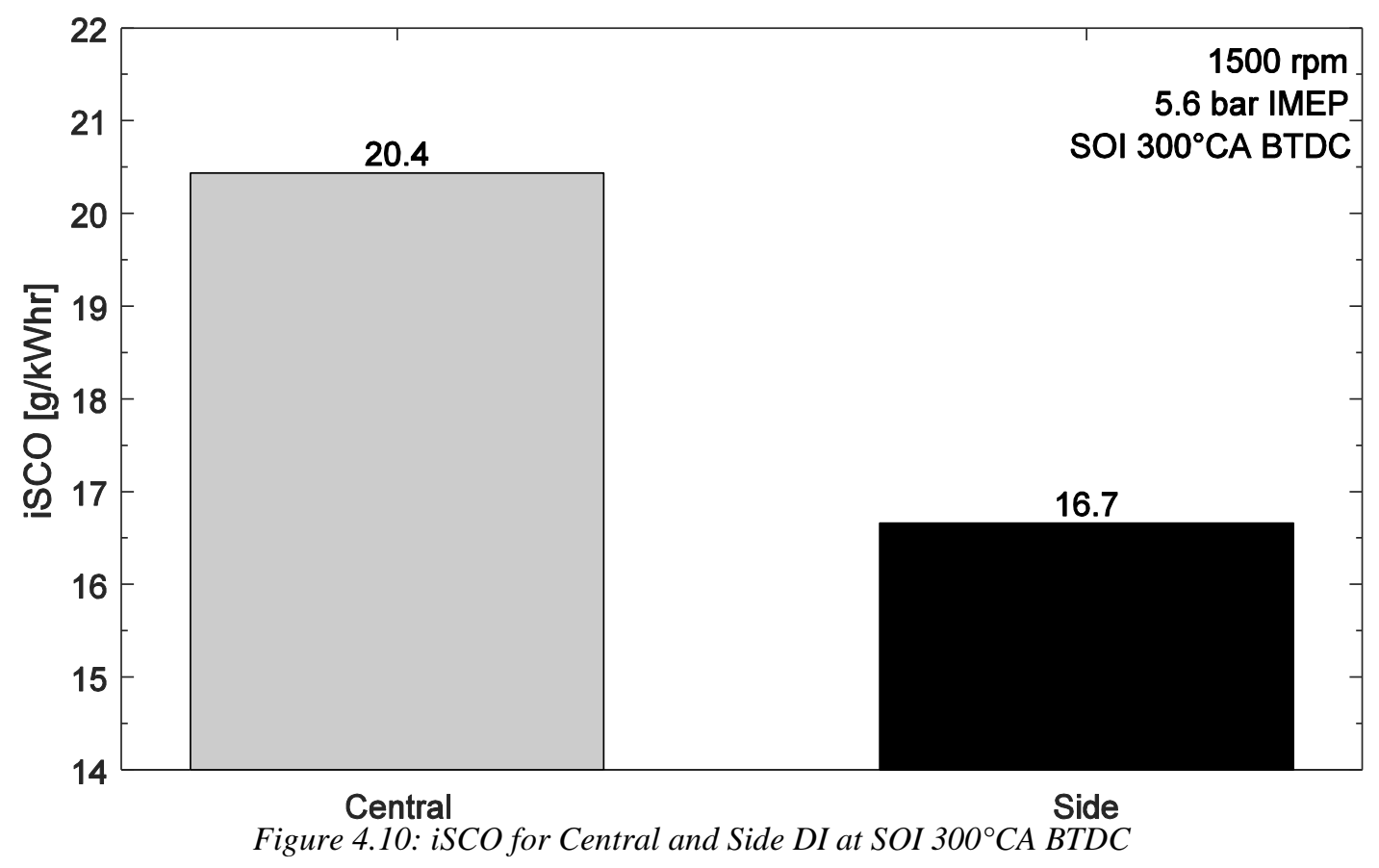


3D CFD analysis provided the global standard deviation of phi (relative fuel-air ratio) throughout the cylinder. While this metric does not provide an exact location of rich and lean pockets in the combustion chamber, it does provide a quantitative measure to the degree of homogeneity in the cylinder. Figure 4.11 shows the standard deviation of phi for central and side DI at SOI $300^{\circ} \mathrm{CA}$ BTDC, with the black squares indicating the time of spark. The standard deviation of phi for central DI was 1.5 times greater than side DI, indicating a larger degree of stratification for central DI. The improved mixing explains the reduction in iSCO emissions for side DI.

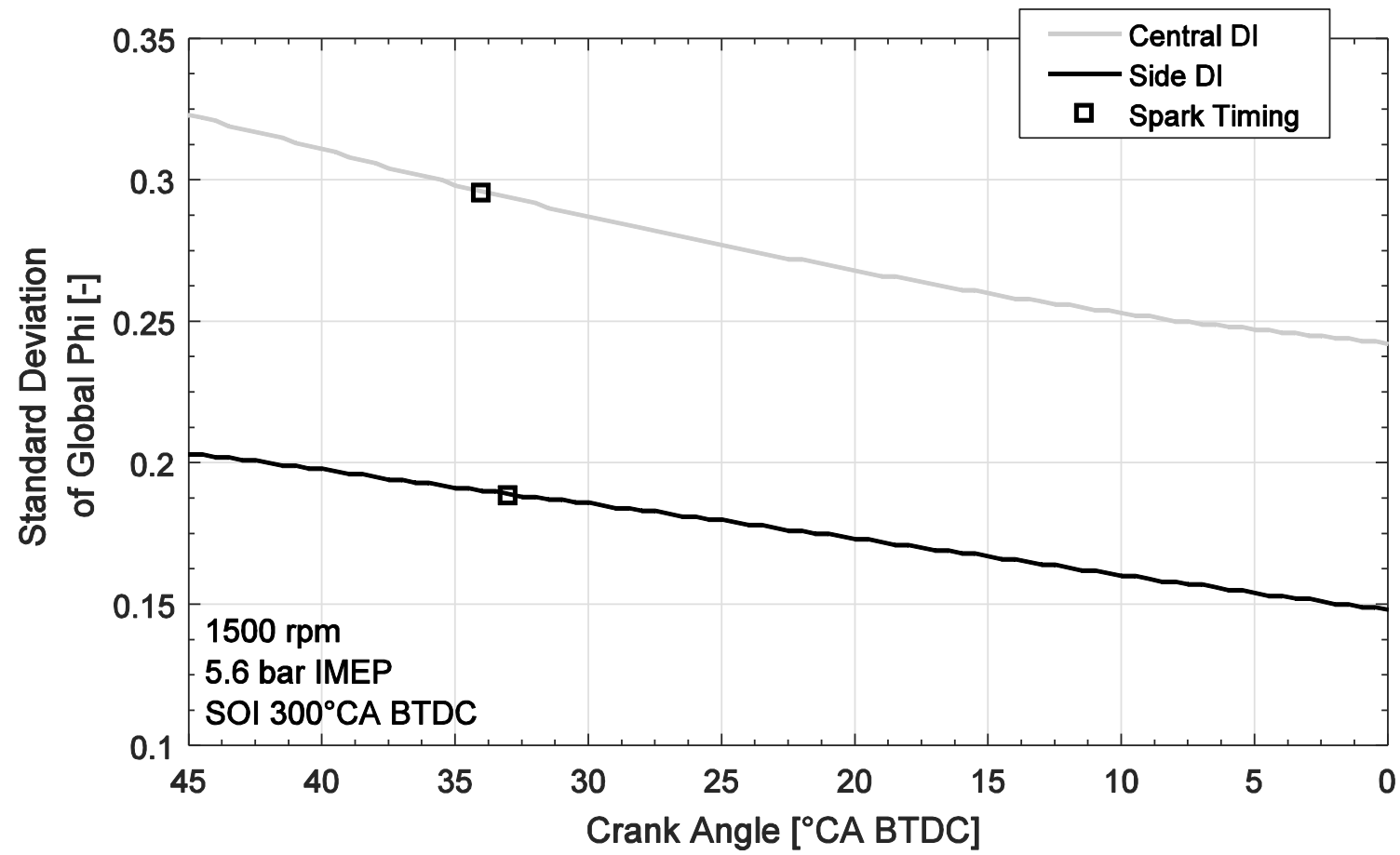

Figure 4.11: Global Standard Deviation of Phi for Central and Side DI at SOI $300^{\circ} \mathrm{CA} B T D C$ 
As shown in Figure 16, heat rejected to the coolant loop was $0.5 \%$ higher for side DI. The higher tumble motion of side DI would be expected to improve heat transfer to cylinder walls and thus to the coolant loop. At the same time, higher heat losses to the coolant loop may indicate a higher in-cylinder combustion temperature. Formation of $\mathrm{NO}_{\mathrm{x}}$ emissions is strongly dependent upon in-cylinder oxygen concentration and temperature [6]. Shown in Figure 4.12 is the $\mathrm{iSNO}_{\mathrm{X}}$ emissions for central and side DI at $\mathrm{SOI} 300^{\circ} \mathrm{CA}$ BTDC. There was a $0.3 \mathrm{~g} / \mathrm{kW}-\mathrm{hr}$ increase in iSNOx for side DI, supporting a higher incylinder combustion temperature argument. Additionally, the higher $\mathrm{iSNO}_{\mathrm{x}}$ emissions correlated with the shorter CD of side DI shown in Figure 4.5; the shorter CD would cause higher in-cylinder temperatures.

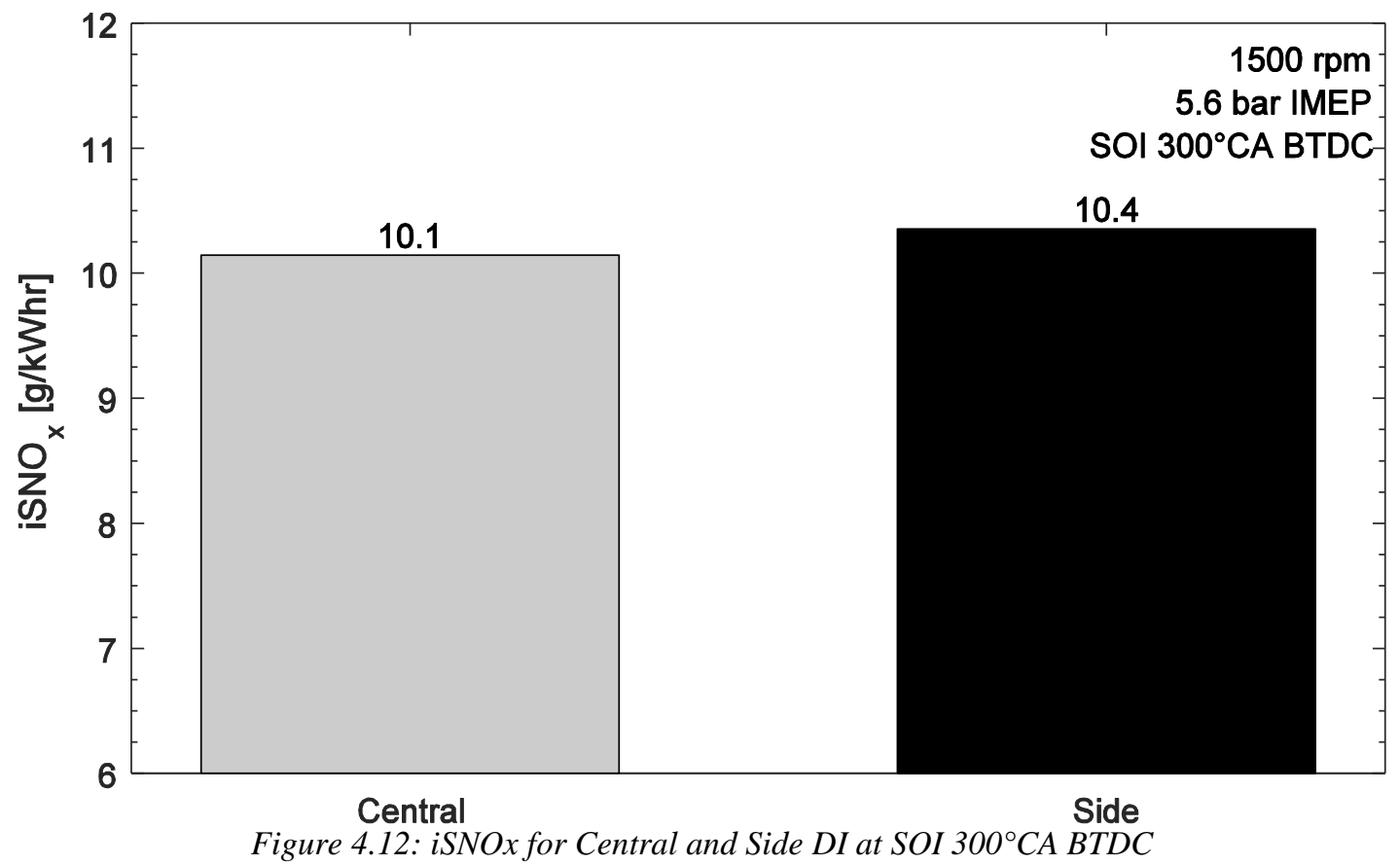

Finally, Figure 4.4 showed that central DI led to higher miscellaneous heat losses compared to side DI. At SOI $300^{\circ} \mathrm{CA}$ BTDC, the injection event occurred with the piston close to TDC and it is conceivable that the direct path to the piston led to a higher amount of heat transfer to the piston for central DI, transferring heat to the oil reservoir increasing overall heat losses [51]. 


\subsubsection{SOI $240^{\circ} \mathrm{CA}$ BTDC Analysis}

Figure 4.13 shows the results for an energy balance for SOI $240^{\circ} \mathrm{CA}$ BTDC. Consistent with SOI $300^{\circ} \mathrm{CA}$ BTDC, side DI results in a greater net indicated thermal efficiency, by $0.3 \%$ absolute.

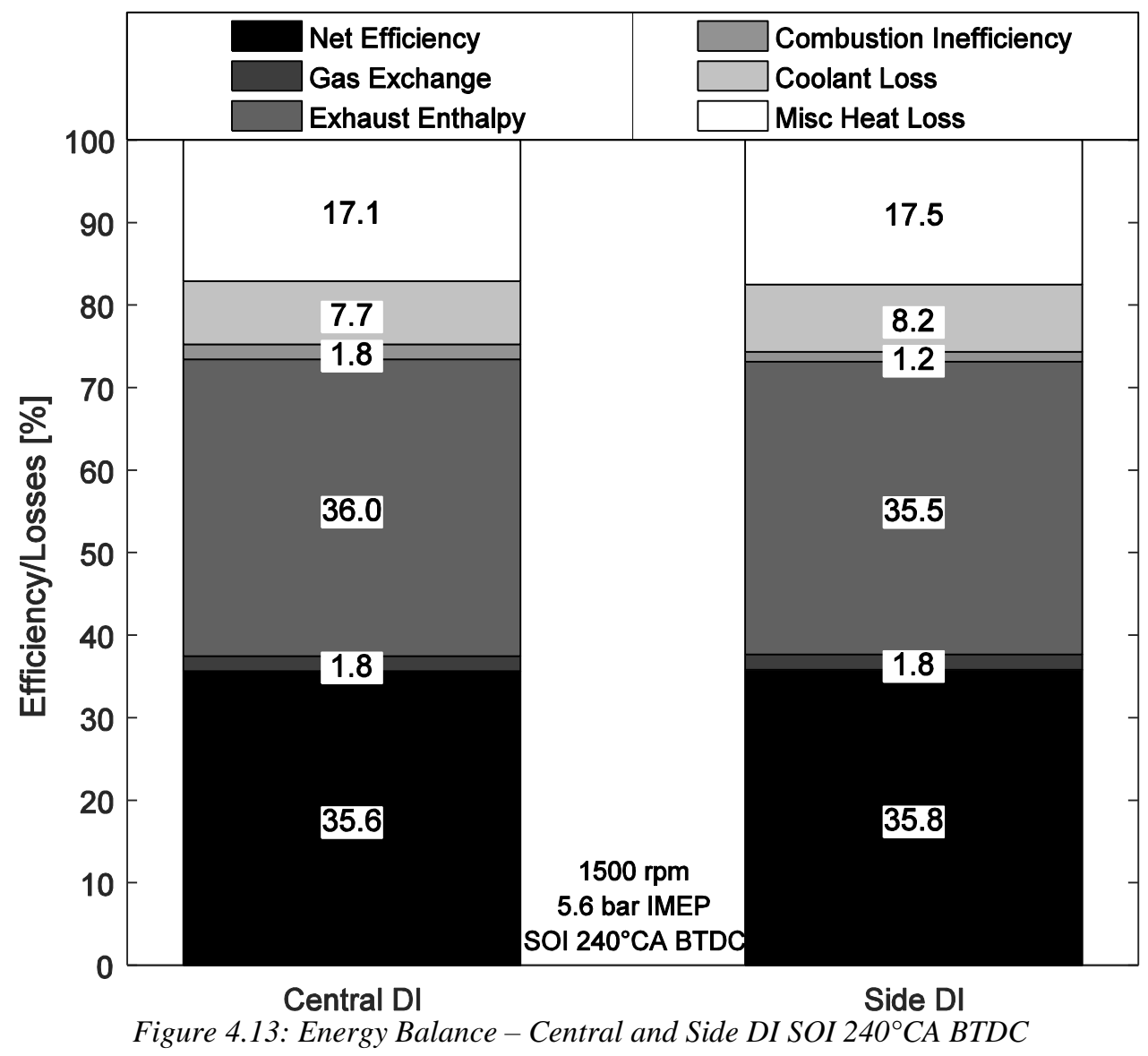


The CD is shown in Figure 4.14 for central and side DI at SOI $240^{\circ} \mathrm{CA}$ BTDC. At this condition, there is a $4.3^{\circ} \mathrm{CA}$ difference in the overall combustion duration between central and side DI. The shorter combustion duration for side DI supports the improvement in indicated thermal efficiency. There is a $5^{\circ} \mathrm{CA}$ reduction in $\mathrm{CD}$ for side DI from SOI 300 to SOI $240^{\circ} \mathrm{CA}$ BTDC.

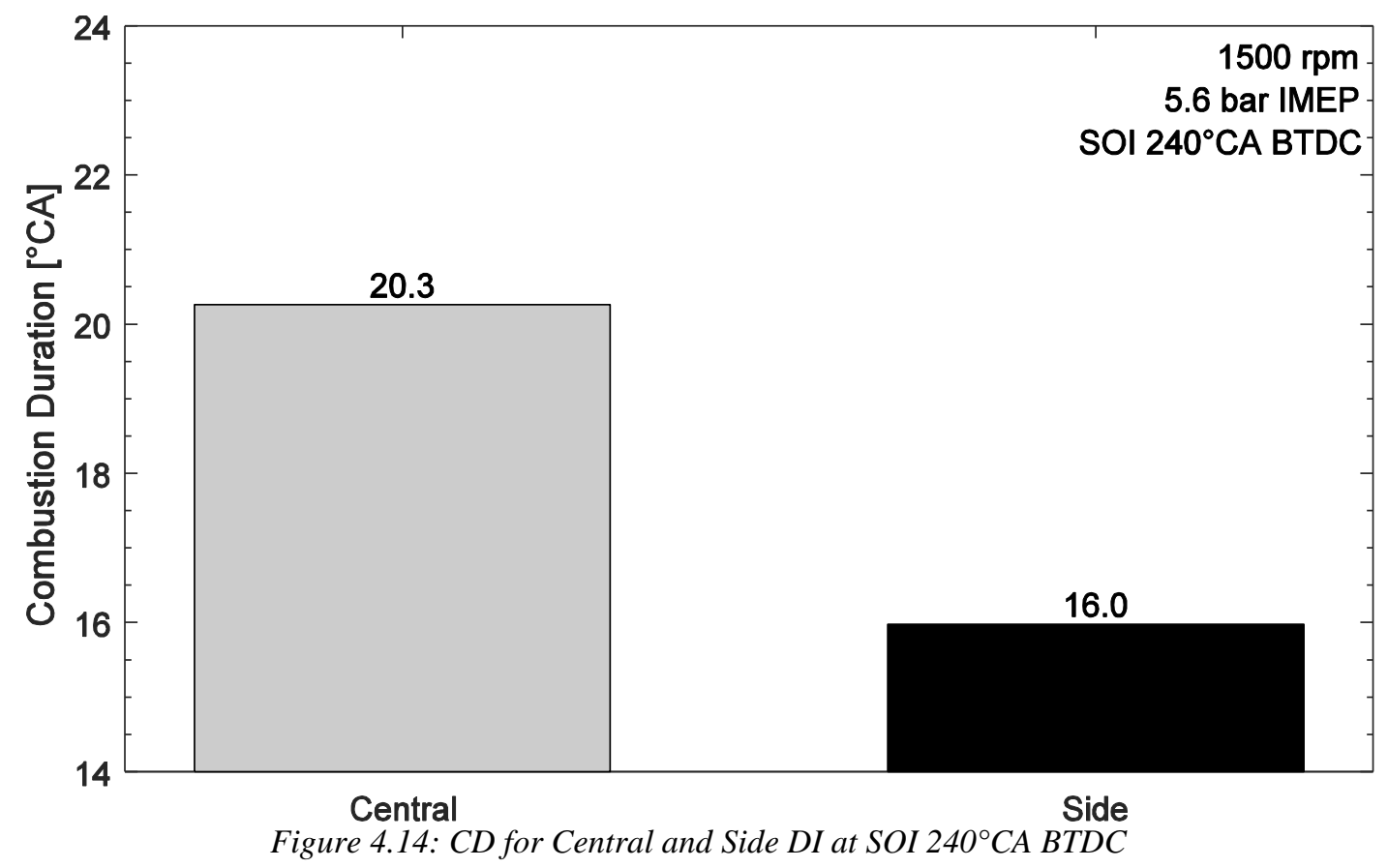


3D CFD was used to study the mixture formation process of central and side DI at this condition. Figure 4.15 shows the in-cylinder tumble motion for central and side DI at SOI $240^{\circ} \mathrm{CA}$ BTDC. It was previously noted that central DI does not enhance the tumble motion, side DI injects along the tumble motion, and can improve the in-cylinder tumble motion. At $180^{\circ} \mathrm{CA} \mathrm{BTDC}$, corresponding to bottom dead center of the intake stroke, the tumble motion generated by side DI is nearly eight times greater than central DI. An increase in tumble is desirable as it can improve mixture homogeneity as well as increase the rate of turbulent flame propagation and thus improve indicated thermal efficiency.

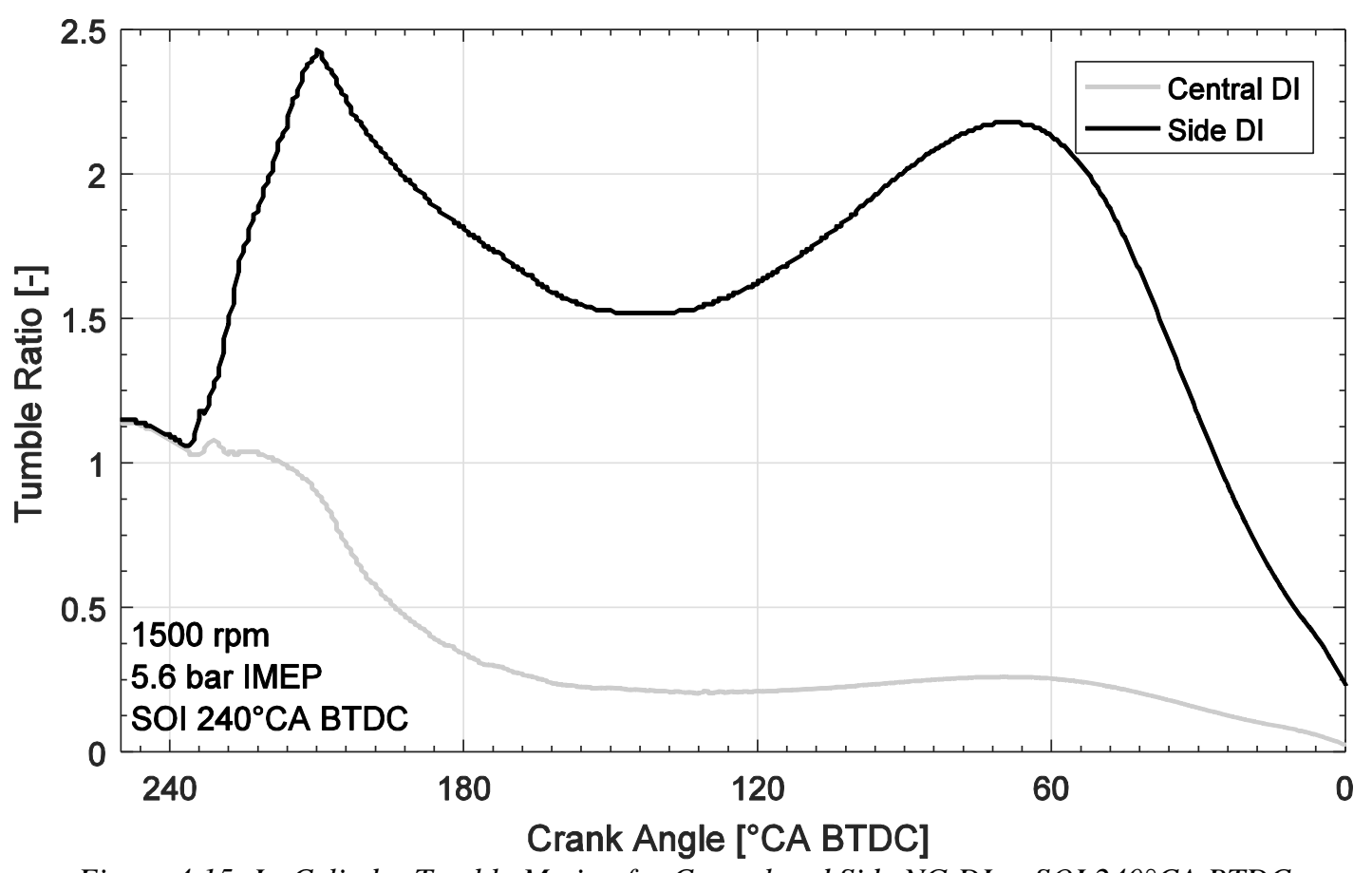

Figure 4.15: In-Cylinder Tumble Motion for Central and Side NG DI at SOI $240^{\circ} C A$ BTDC 
The global TKE for central and side DI at SOI $240^{\circ} \mathrm{CA}$ BTDC is plotted in Figure 4.16. At the time of spark, side DI results in a TKE level two times greater than central DI. A higher level of TKE is desirable because it helps to promote a faster developing flame kernel, leading to a shorter combustion duration improving indicated thermal efficiency.

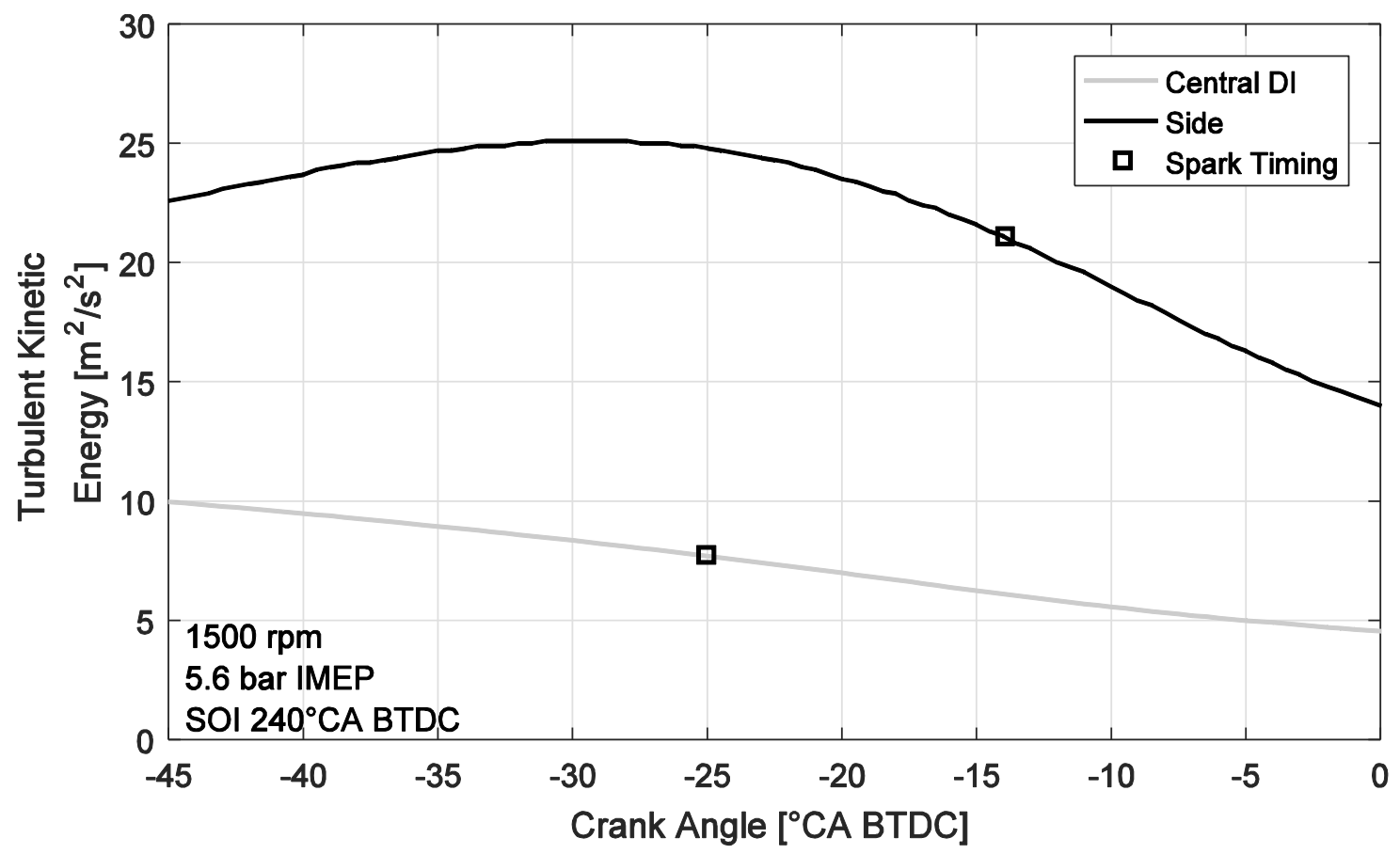

Figure 4.16: Global Turbulent Kinetic Energy for Central and Side DI at SOI $240^{\circ} \mathrm{CA}$ BTDC 
Gas exchange losses between central and side DI at this SOI are the same, because the same amount of throttling was required to maintain 5.6 bar IMEP. As shown in Figure 4.13, central DI results in higher exhaust enthalpy. The higher exhaust enthalpy was a result of higher EGTs for central DI, as shown in Figure 4.17.

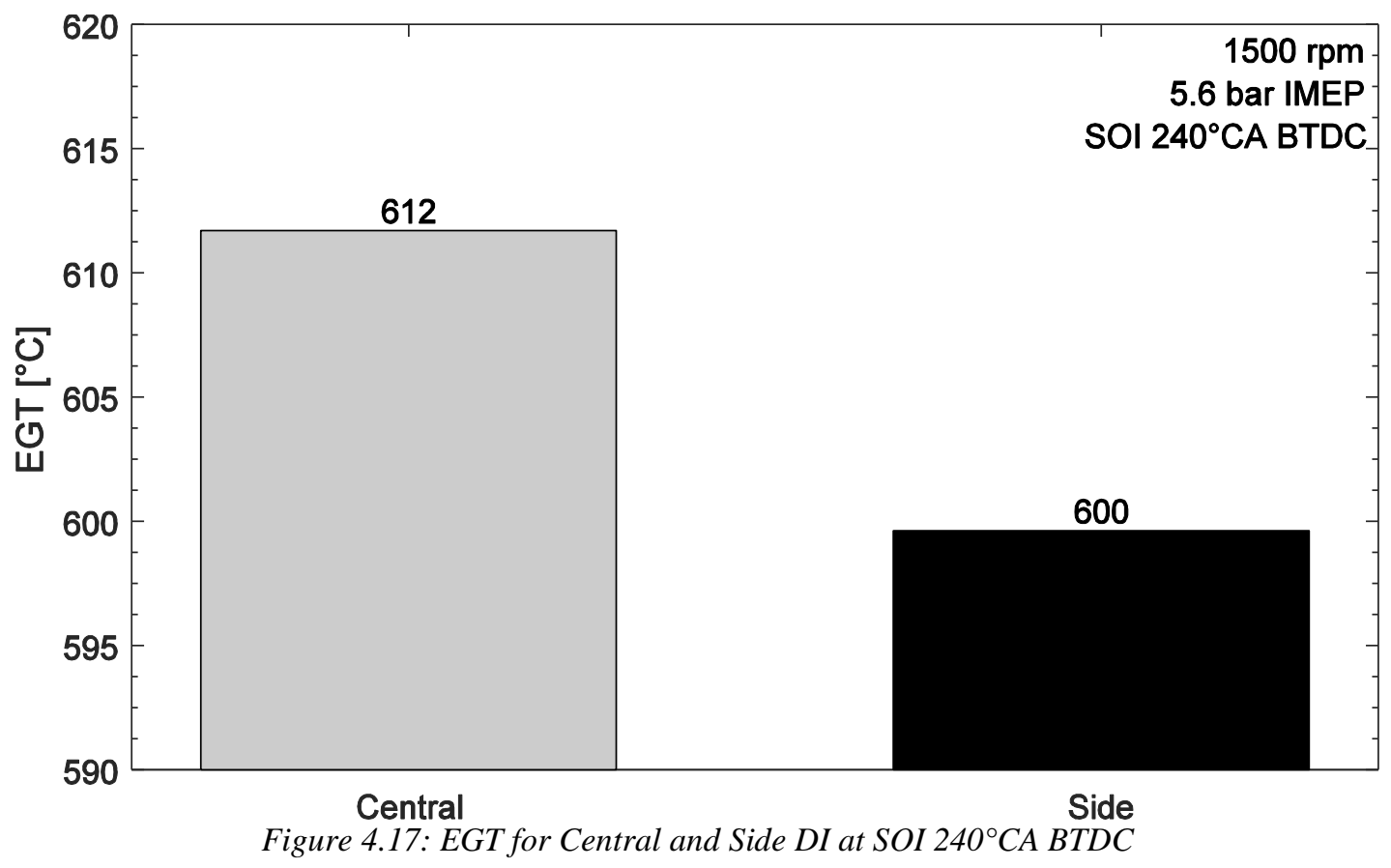


From the energy analysis in Figure 4.13, a $0.6 \%$ absolute reduction in combustion inefficiency from central to side DI was observed, supporting the higher exhaust enthalpy results for central DI. iSHC emissions, as shown in Figure 4.18, are higher for side DI by $10 \%$ compared to central DI. CFD results showed that side DI improved the charge motion and thus may push more fuel into the crevice volume.

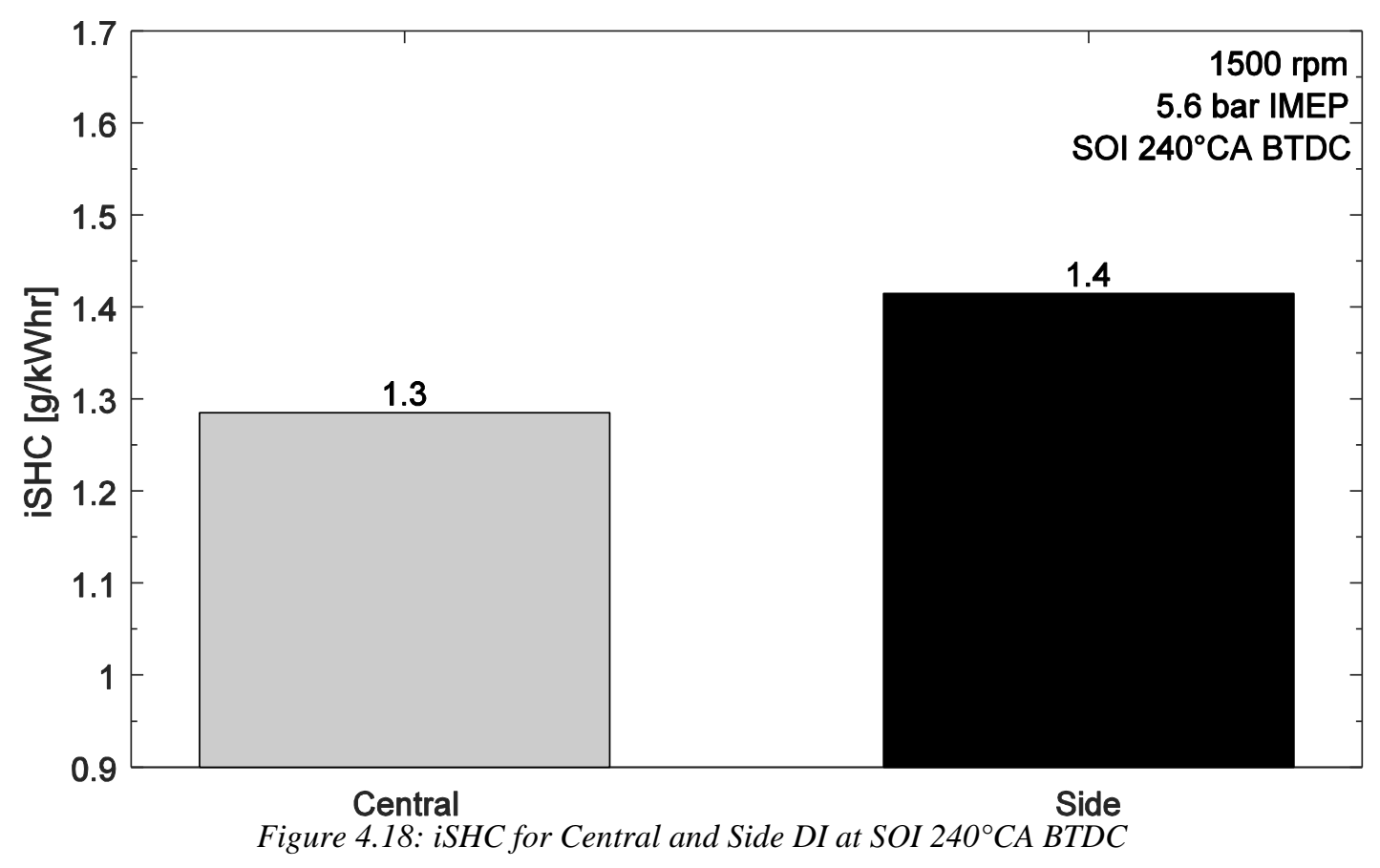


Figure 4.19 shows iSCO emissions for central and side DI at SOI $240^{\circ} \mathrm{CA}$ BTDC. Side DI reduces iSCO emissions by $5.1 \mathrm{~g} / \mathrm{kWhr}$. The difference in lambda between central and side DI was less than $0.4 \%$, indicating the difference in iSCO was due to in-cylinder inhomogeneity and not a global air-fuel ratio difference. Therefore, the combination of increased iSHC emissions and reduced iSCO emissions resulted in an overall reduction in combustion inefficiency for side DI.

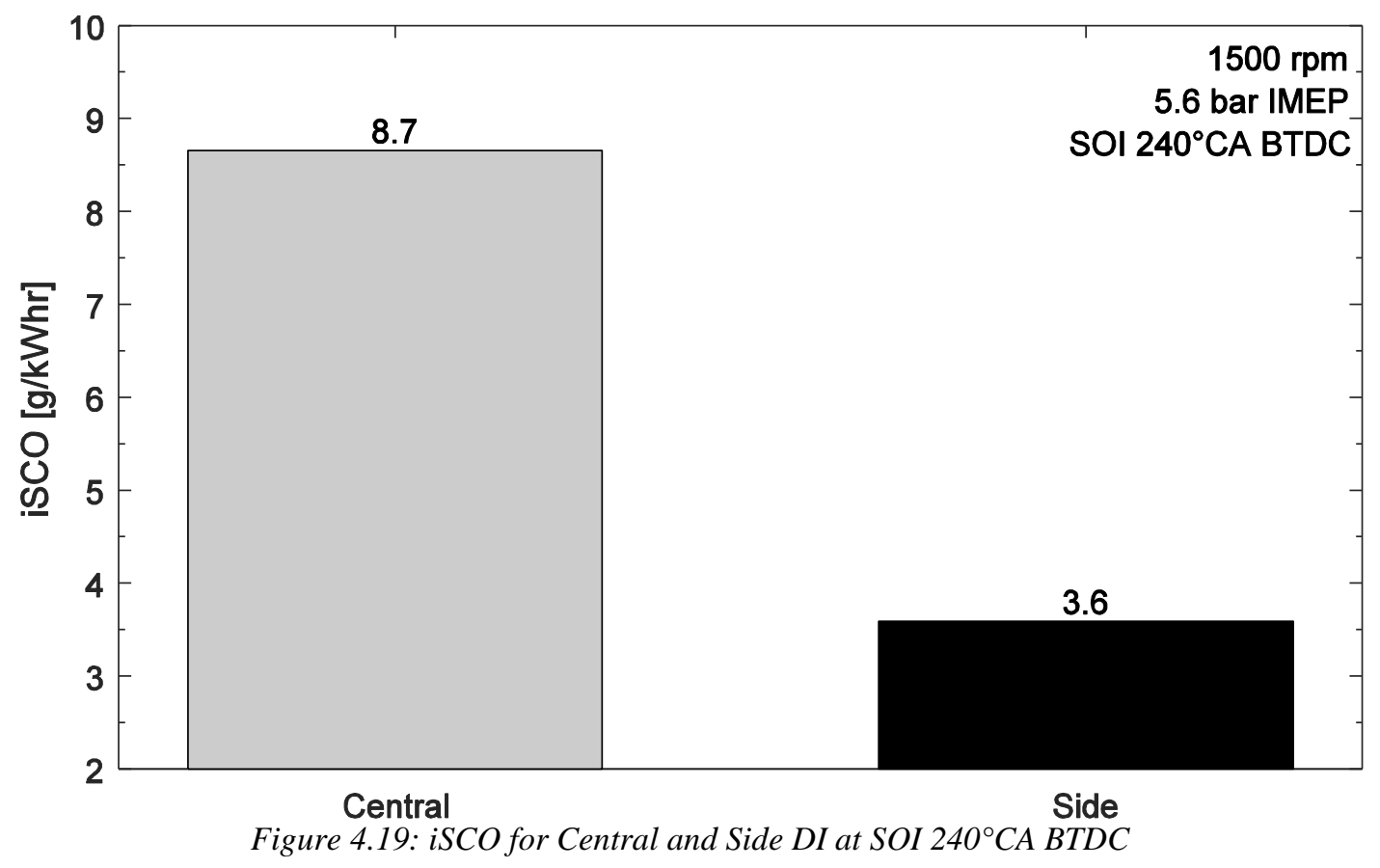


The global standard deviation of phi for central and side DI at SOI $240^{\circ} \mathrm{CA}$ BTDC is shown in Figure 4.20. Consistent with previous findings, side DI reduced the overall standard deviation of phi by 1.5 times. This supports the conclusion that injecting along the tumble motion led to better mixing within the cylinder.

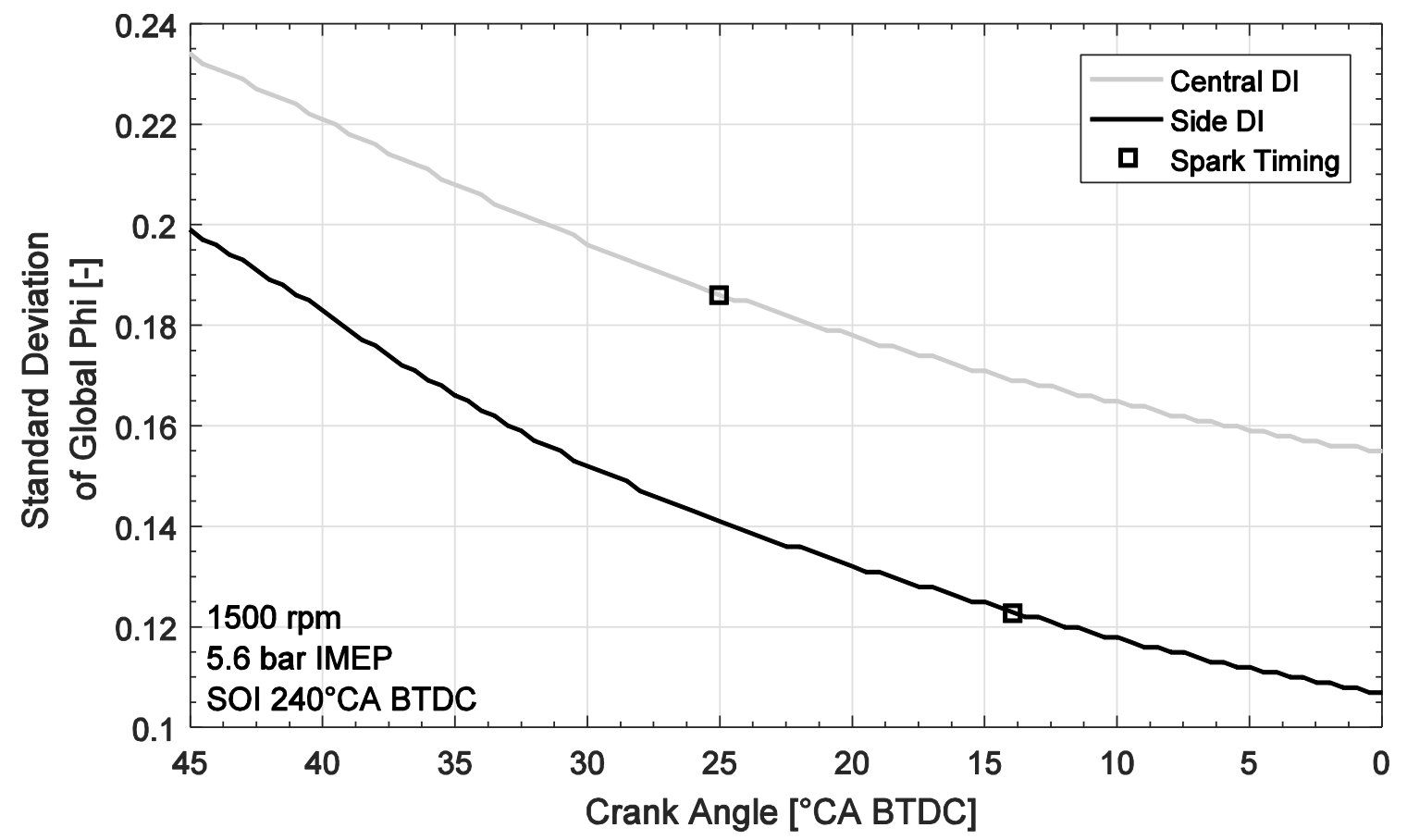

Figure 4.20: Global Standard Deviation of Phi for Central and Side DI at SOI $240^{\circ}$ CA BTDC 
As previously discussed, $\mathrm{NO}_{\mathrm{x}}$ emissions are dependent on in-cylinder temperatures.

Shown in Figure 4.21, side DI resulted in 10.3\% higher iSNOX emissions than central DI, consistent with lower exhaust enthalpy and lower combustion inefficiency.

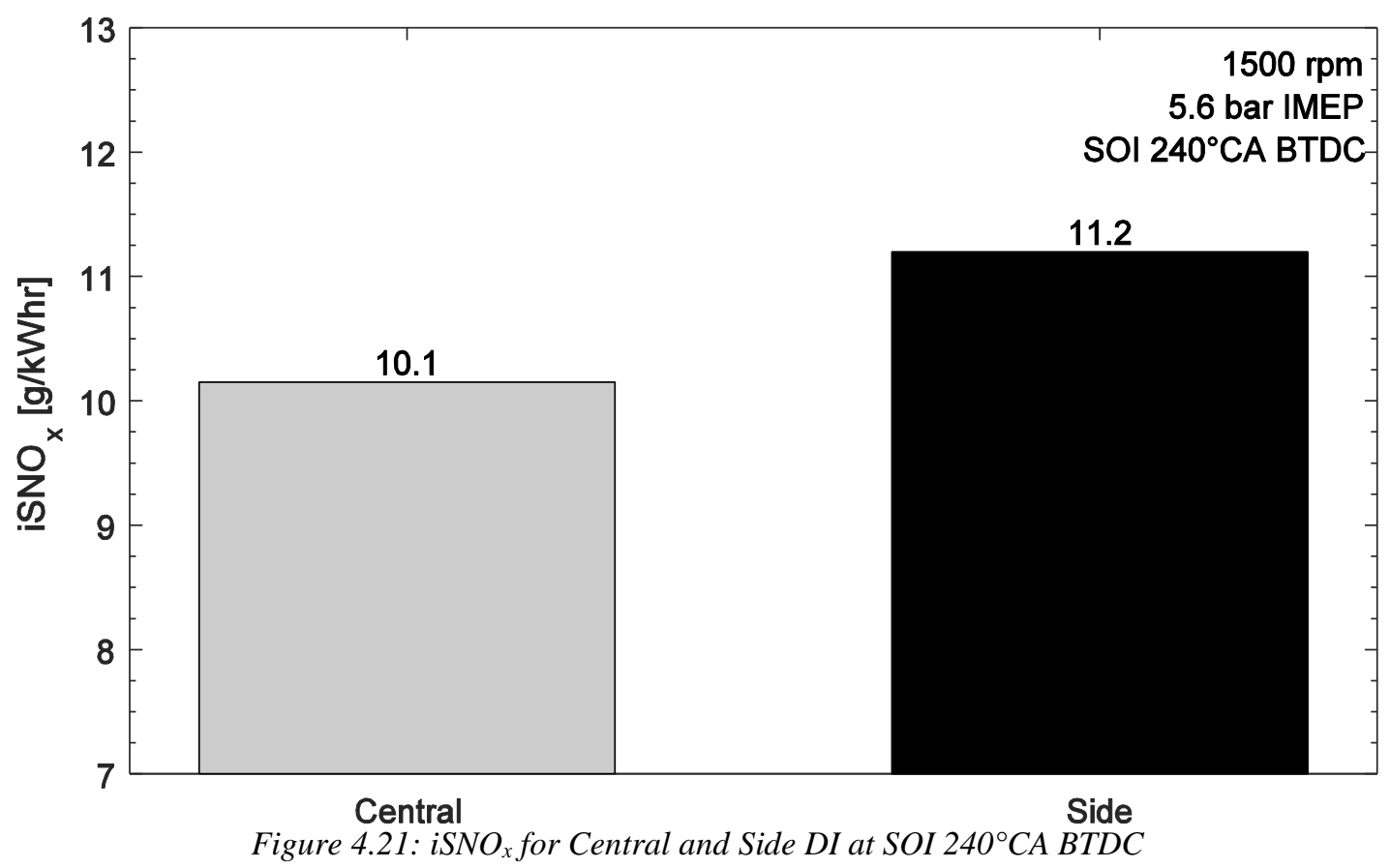

Figure 4.13 also shows that side DI results in $0.5 \%$ more fuel energy rejected to the coolant loop for SOI $240^{\circ} \mathrm{CA}$ BTDC. The higher amount of heat rejected to the coolant loop for side DI indicates higher in-cylinder temperatures, substantiated by the increased iSNO ${ }_{x}$ emissions shown in Figure 4.21. Additionally, the increased in-cylinder motion from side DI resulted in higher convective heat transfer.

Literature has shown that an increase in tumble motion can lead to an increase wall heat transfer and it is conceivable that due to side DI being injected along the tumble motion, wall heat transfer is increased relative to central DI [6]. This could be one possible increase for the miscellaneous heat losses for side DI. 


\subsubsection{SOI $120^{\circ} \mathrm{CA}$ BTDC Analysis}

Figure 4.22 shows the energy balance applied to central and side DI at SOI $120^{\circ} \mathrm{CA}$ BTDC, corresponding to a fully closed intake valve injection event. Consistent with the SOI 300 and $240^{\circ} \mathrm{CA}$ BTDC, side DI results in a $0.5 \%$ absolute greater net efficiency.

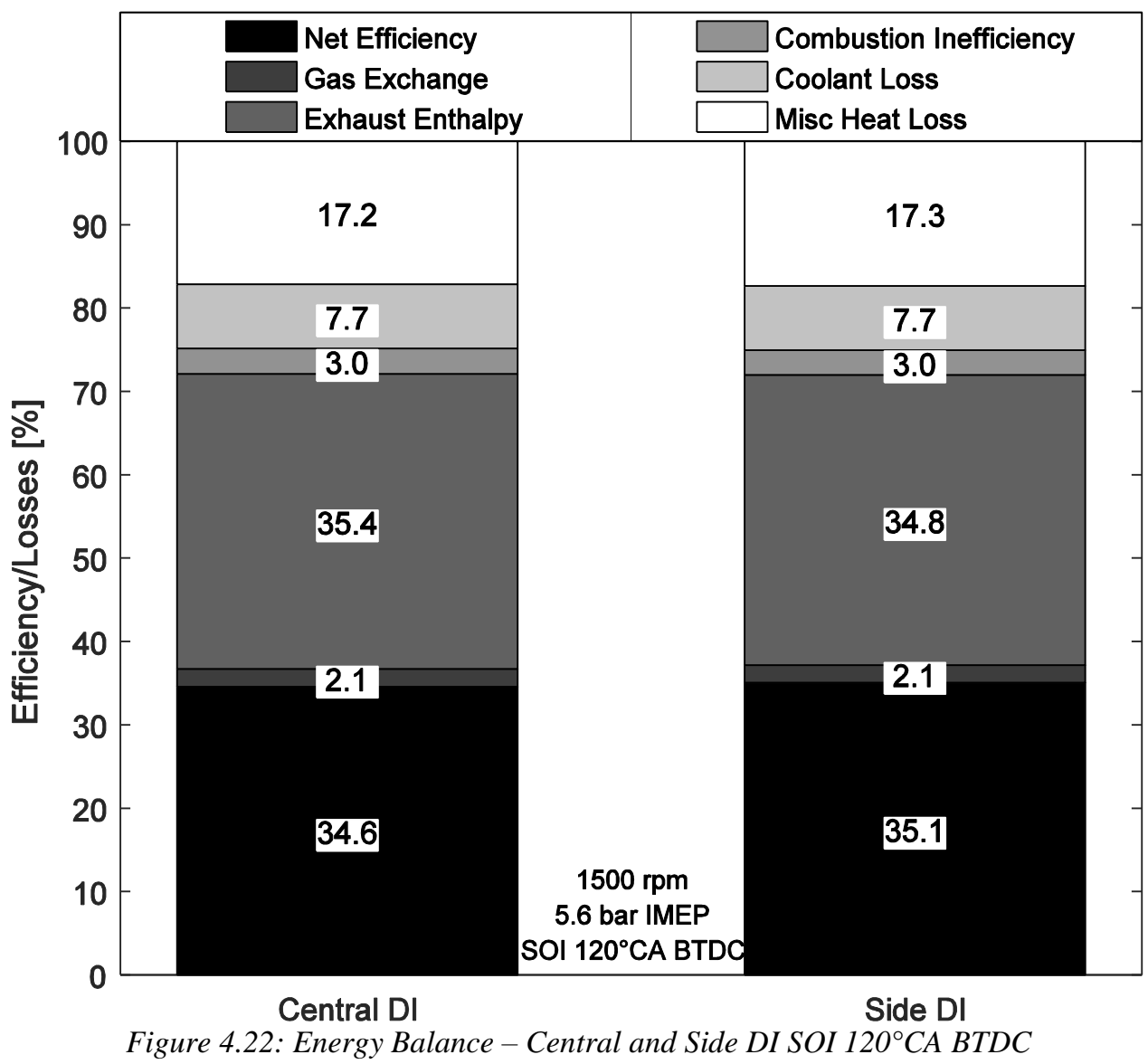


In Sections 4.1.1 and 4.1.2 the greater net efficiency of side DI correlated with a shorter overall CD. Therefore, the CD between central and side DI at SOI $120^{\circ} \mathrm{CA}$ BTDC is shown in Figure 4.23. For this condition, side DI results in a $0.6^{\circ} \mathrm{CA}$ shorter CD. Injecting late into the cycle can help to preserve charge motion of the NG DI injection event, while at the same time increase non-uniformity in the cylinder. Despite the $0.5 \%$ absolute difference in net efficiency, the difference CD is smaller than previous sections. Therefore, further investigation is required to account for the net efficiency difference.

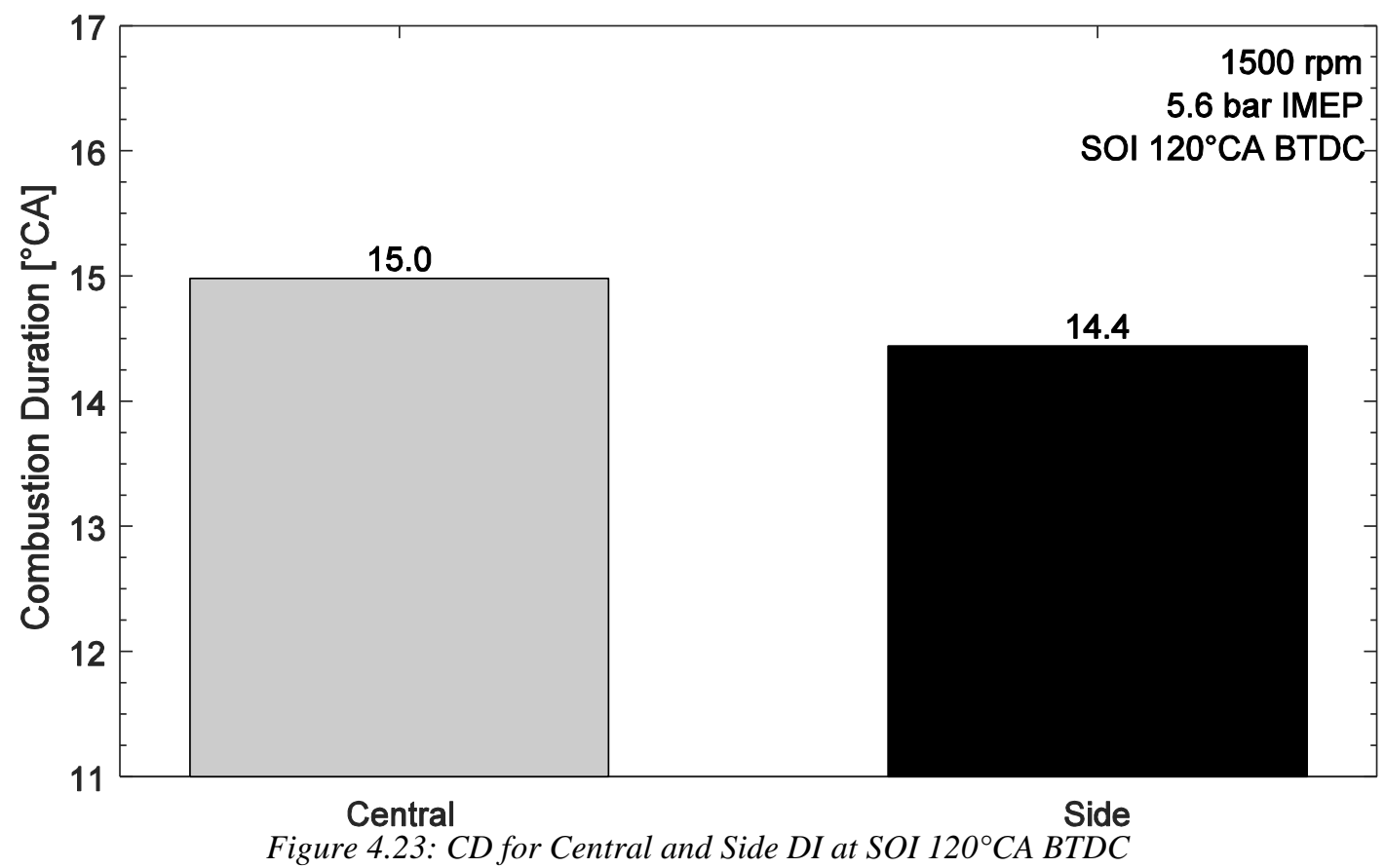


The results of 3D CFD, Figure 4.24, are used to show in-cylinder tumble motion for central and side NG DI at SOI $120^{\circ} \mathrm{CA}$ BTDC. Consistent with previous results, side DI results in an increase in the tumble motion, while central DI reverses the tumble motion. The reverse tumble motion can be one source of the net efficiency loss for central DI, as it would be expected to increase mixture non-uniformity.

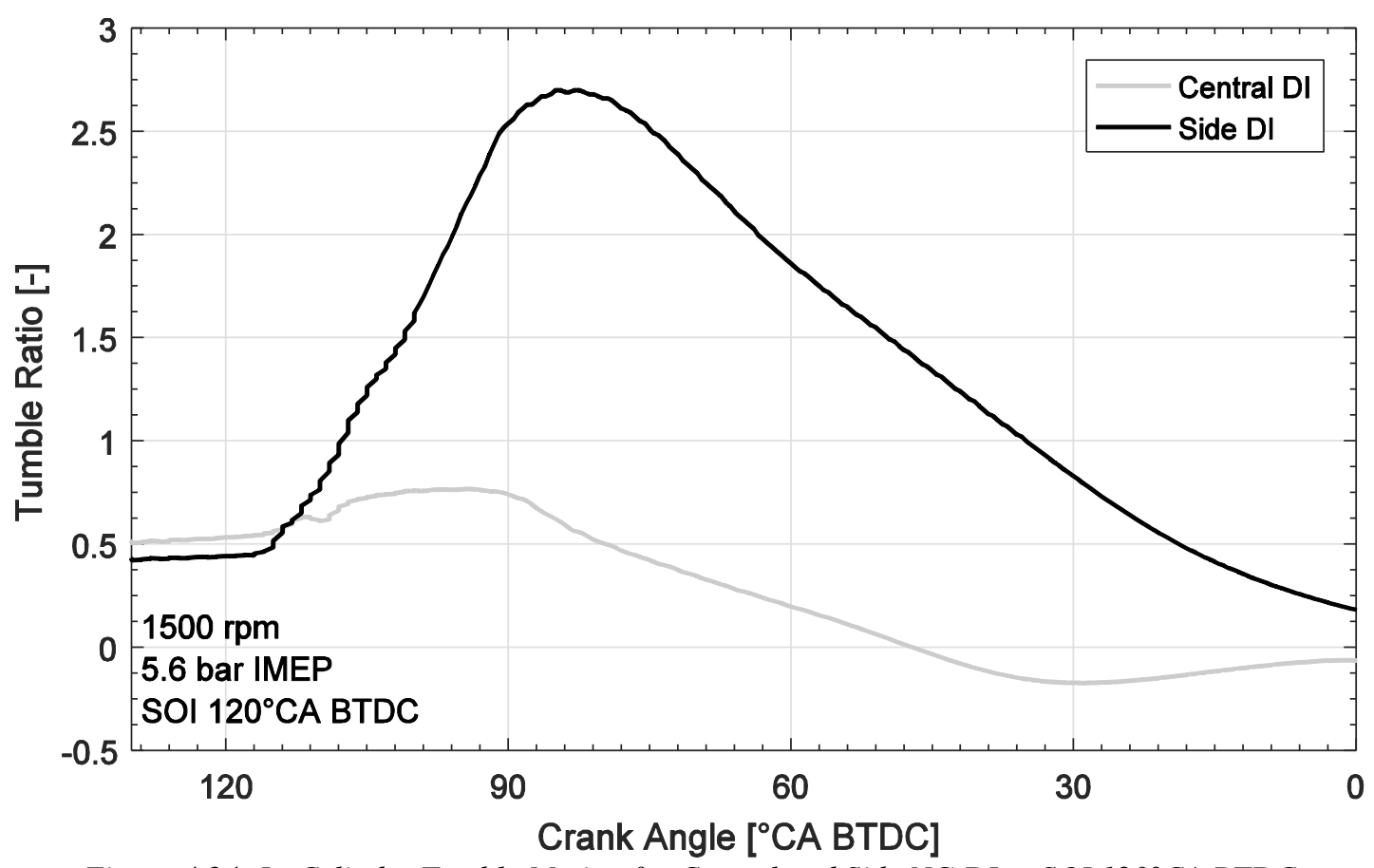

Figure 4.24: In-Cylinder Tumble Motion for Central and Side NG DI at SOI $120^{\circ}$ CA BTDC 
Figure 4.25 shows the global TKE for central and side DI at SOI $120^{\circ} \mathrm{CA}$ BTDC, with black squares indicating spark timing. For this condition, side DI has a $0.6^{\circ} \mathrm{CA}$ shorter $\mathrm{CD}$, yet CFD predicts central DI to have a higher TKE by $5 \mathrm{~m} 2 / \mathrm{s} 2$. While this trend does not follow SOI 300 and $240^{\circ} \mathrm{CA}$ BTDC, this condition has shown to be very similar and the overall magnitude of the differences is small. For comparison purposes, there is a $4.3^{\circ} \mathrm{CA}$ and $11 \mathrm{~m} 2 / \mathrm{s} 2$ difference in $\mathrm{CD}$ and TKE between central and side DI, respectively, at $\mathrm{SOI} 240^{\circ} \mathrm{CA}$ BTDC.

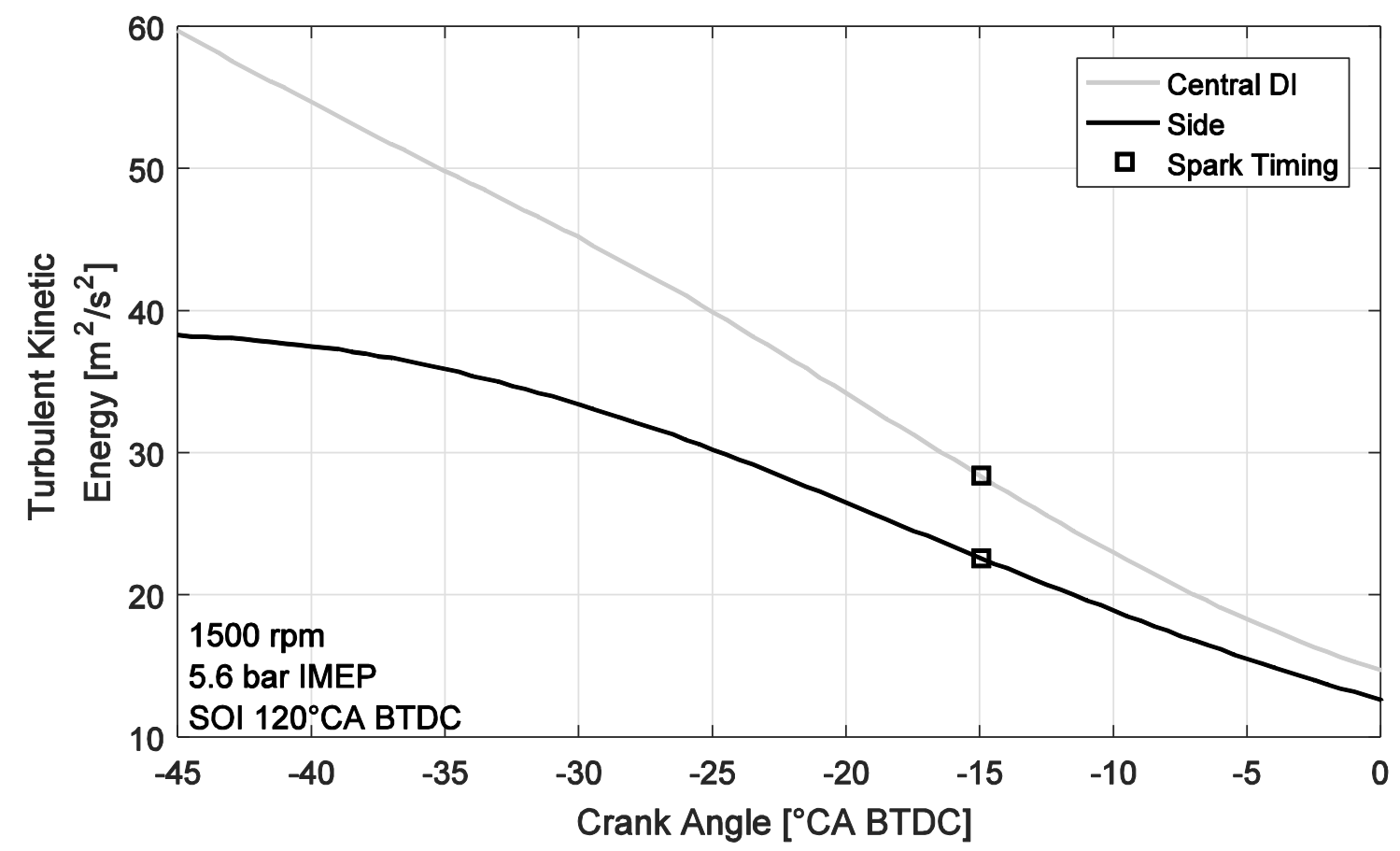

Figure 4.25: Global Turbulent Kinetic Energy for Central and Side DI at SOI $120^{\circ}$ CA BTDC 
Interestingly enough, gas exchange, combustion inefficiency, and heat transfer losses were the same between central and side DI at this SOI. Gas exchange losses are the same due to the fact that the fuel is injected after the intake valves close, allowing the engine to aspirate effectively the same amount of air for this condition; this has been shown in Figure 4.2 and Figure 4.3. The difference between central and side DI is in the remaining exhaust enthalpy. The lower exhaust enthalpy of side DI is conditionally dependent. While the EGT was similar between central and side DI $\left(594\right.$ and $\left.593^{\circ} \mathrm{C}\right)$, there was a lower mass flowrate of air through the engine for side DI, reducing exhaust enthalpy losses. This again provides indication that injecting along the tumble motion can help improve the combustion event, as shown by a decrease in remaining exhaust enthalpy. 
Seen in Figure 4.22, the combustion inefficiency between central and side DI are the same. However, the makeup of the combustion inefficiency is considerably different. Shown in Figure 4.26 is the iSHC emissions for central and side DI at SOI $120^{\circ} \mathrm{CA}$ BTDC. For this condition, there is the biggest difference in iSHC emissions; side DI results in $30 \%$ greater iSHC emissions. Given the close proximity of the piston and the amplification of the tumble motion, this further indicates that the side DI location pushes more unburned fuel to the crevice volume.

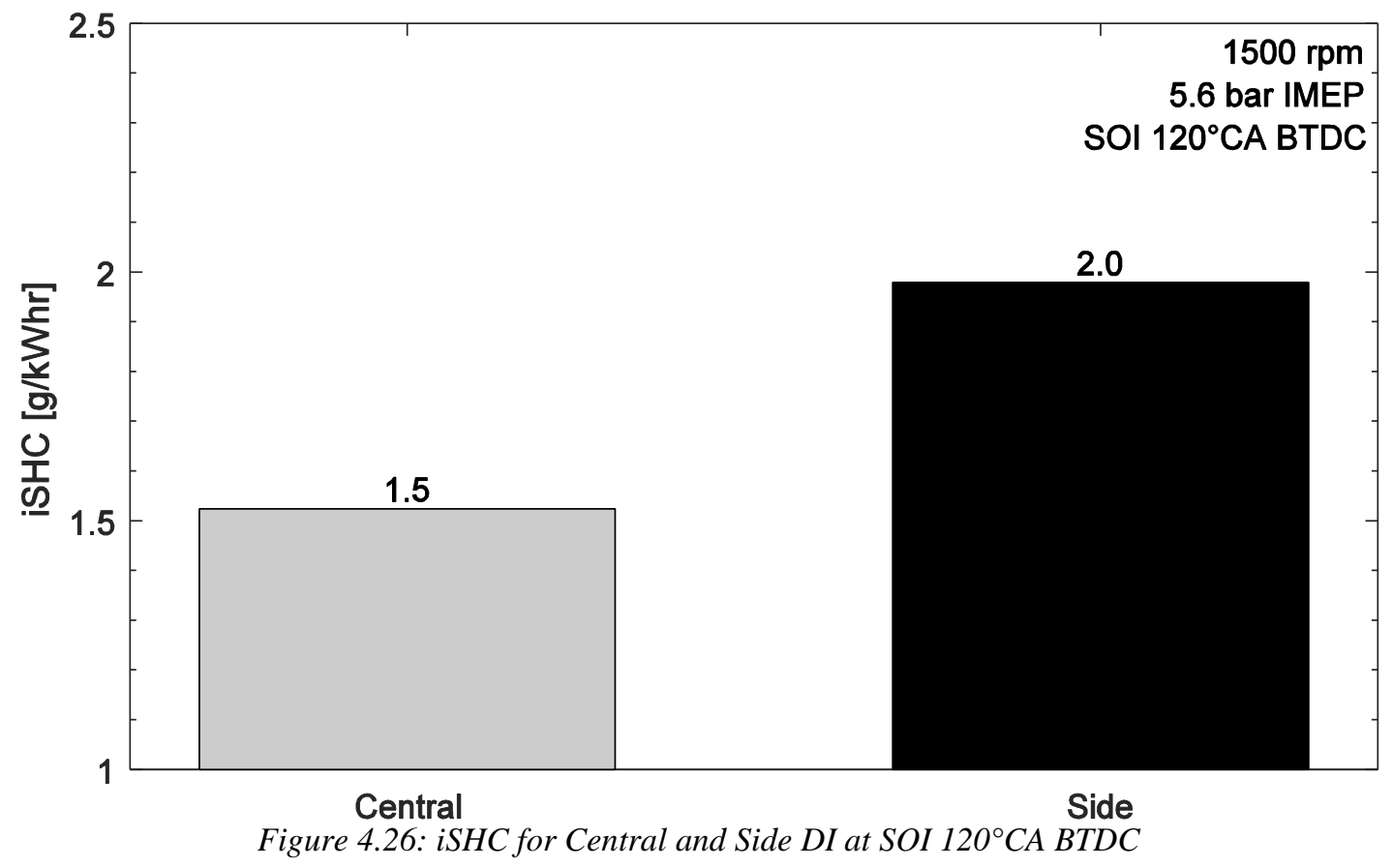


Figure 4.27 shows the iSCO emissions for central and side DI at SOI $120^{\circ} \mathrm{CA}$ BTDC. For this condition, central DI results in higher iSCO emissions than side DI. This increase in incomplete combustion could again be due to mixing, such that the reduced mixing of central DI leads to less complete combustion. At the same time, while the shorter timeframe between the end of injection (EOI) and spark timing can preserve the charge motion from the gaseous injection event, it can also increase levels of stratification due to less time for mixing.

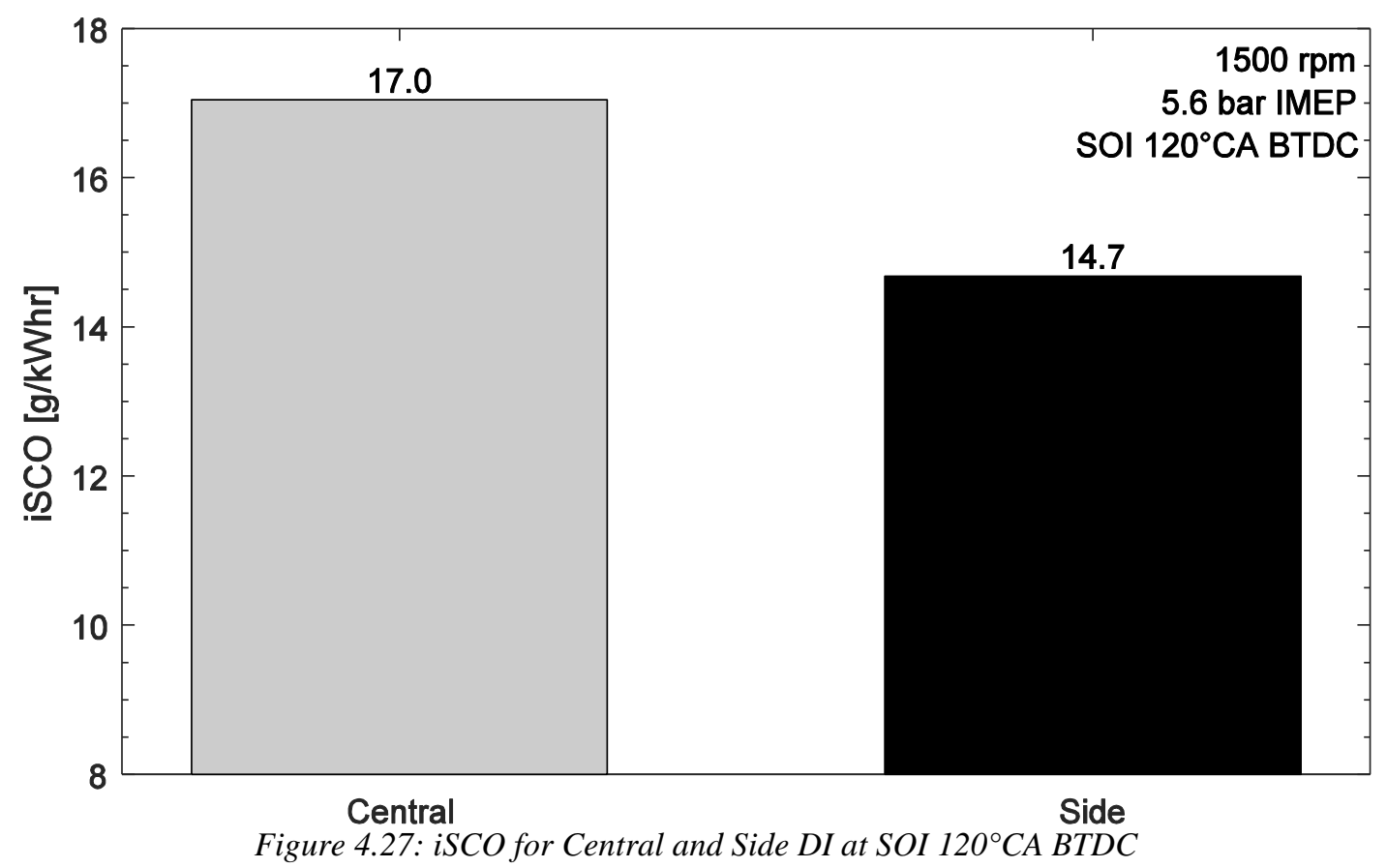




\subsubsection{Summary of Injection Location and SOI Impact on ITE $E_{N E T}$ at O\% EGR}

For the three SOI conditions evaluated, side DI resulted in a consistent increase in net efficiency compared to central DI. Improved mixture homogeneity leading to faster combustion was the primary reason for the increase in efficiency; lower iSCO emissions indicate improved in-cylinder mixing. For most conditions, side DI resulted in lower exhaust enthalpy and combustion inefficiency than central DI, showing that the path of the gaseous injection event is crucial in providing more complete combustion. At the same time, there was an increase in coolant and miscellaneous losses for side DI at SOI $240^{\circ} \mathrm{CA}$ BTDC. This indicates that there were competing effects within the cylinder. Literature has shown that injecting along the path of the tumble motion can improve mixing, at the risk of an increase in wall heat transfer due to higher temperature and increased charge motion.

As introduced in the beginning of Section 4.1, net efficiency differences at SOI $300^{\circ} \mathrm{CA}$ BTDC were statistically significant, insignificant at SOI $240^{\circ} \mathrm{CA}$ BTDC and nearly significant at SOI $120^{\circ} \mathrm{CA}$ BTDC; these differences are also shown in Figure 4.28.

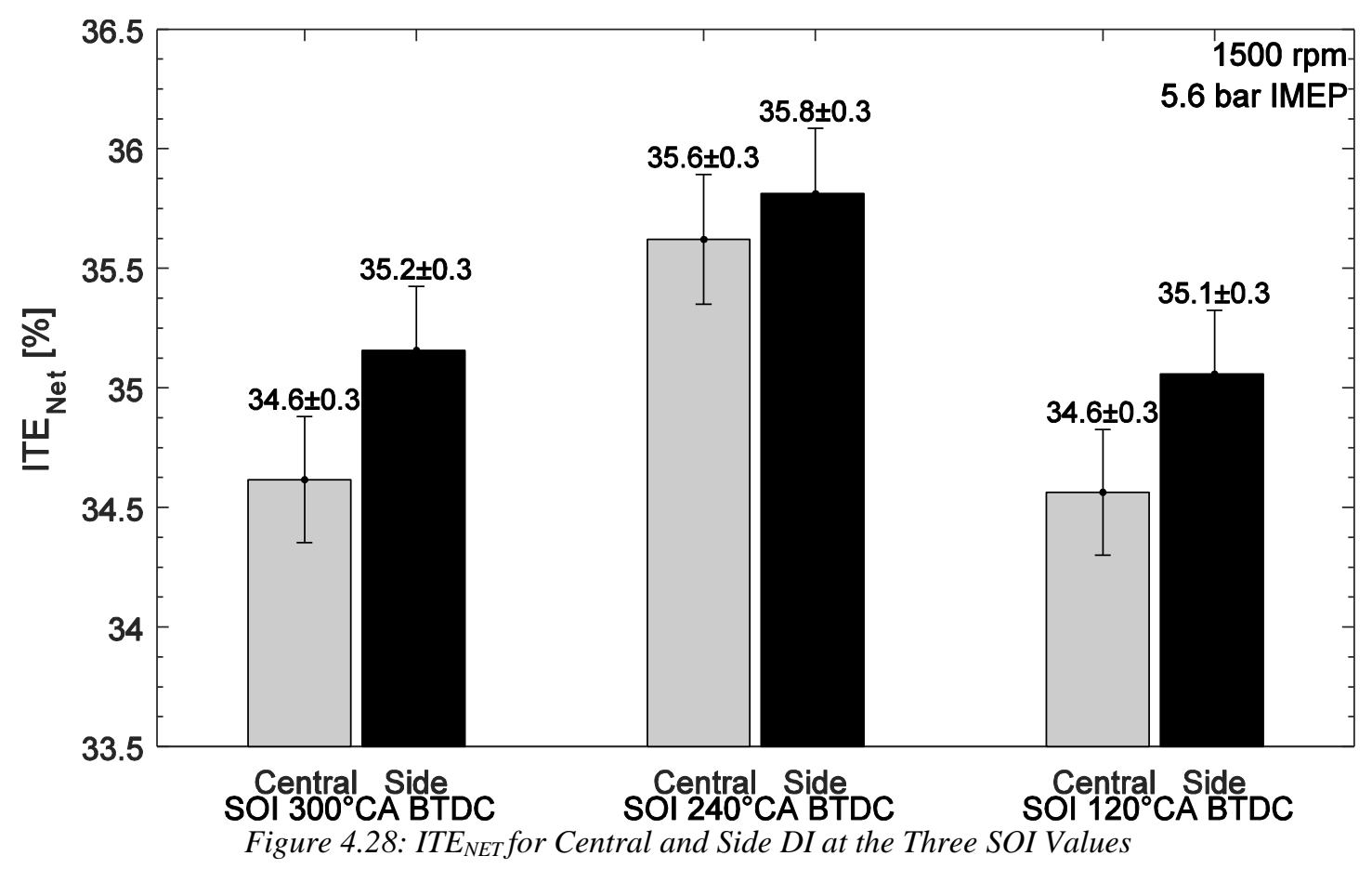

Despite being a poor mixing condition for both injection locations, it is possible that the charge motion of side DI led to enough of an improvement in mixing (seen as a reduction 
in iSCO) at $\mathrm{SOI} 300^{\circ} \mathrm{CA} \mathrm{BTDC}$ to create statistical significance. SOI $240^{\circ} \mathrm{CA} \mathrm{BTDC}$ has shown to be an optimal injection timing for both locations. While side DI showed a reduction in $\mathrm{CD}$, enthalpy, and incomplete combustion losses, the increased wall heat losses as shown by increase losses to the coolant loop, resulted in efficiency similar to central DI. At SOI $120^{\circ} \mathrm{CA}$ BTDC, the losses associated with combustion were similar between central and side DI. However, the reduced iSCO and lower exhaust enthalpy ultimately led to a nearly significant increase in net efficiency. 


\subsection{Injection Location and SOI Impact on ITE $_{\text {NET with }}$ EGR $^{2}$}

\subsubsection{EGR Dilution Sweeps}

The US DRIVE Advanced Combustion and Emission Control (ACEC) technical team has recently said, "dilute combustion in advanced gasoline spark ignition engines offers the greatest potential for decreasing petroleum consumption, since gasoline is the most widely produced and used fuel in the US - a trend expected to continue for the foreseeable future" [52]. Dilute combustion is one of the most researched means of increasing an engines efficiency, effectively decreasing petroleum dependency. EGR dilute operation is generally limited by deteriorating combustion stability with increasing inert gas levels. The combustion stability decreases due to reduced mixture flame speeds resulting in significantly increased combustion initiation periods and burn durations [29]. While the efficiency improvement and emissions reduction potential of EGR dilute operation of spark-ignition gasoline engines is well understood and documented, NG DI in a light duty vehicle application is still relatively new and therefore it is imperative to understand how EGR will affect the combustion process in a NG DI application.

EGR sweeps were performed for central and side DI at the three SOI values: 300, 240 and $120^{\circ} \mathrm{CA}$ BTDC. For each condition, the EGR rate was increased until the engine exceeded the combustion stability limit of $3 \% \mathrm{COV}$ IMEP.

2 Parts of the material contained in this chapter was previously published as a journal paper in the Society of Automotive Engineers. Reprinted with Permission from SAE International. 
Under EGR dilute conditions, the shortest possible FDA is desired, as a faster flame deflagration has shown to extend dilution tolerance [53]. The shorter FDA makes the combustion event less prone to extinguish due to any cycle-to-cycle variations in the flow field [7]. Shown in Table 4.1 is the FDA for central and side DI at the three SOI values.

Table 4.1: FDA for Central and Side DI

\begin{tabular}{|l|l|l|l|}
\hline FDA $\left[{ }^{\circ} \mathrm{CA}\right]$ & SOI $300^{\circ} \mathrm{CA}$ & SOI $240^{\circ} \mathrm{CA}$ & SOI $120^{\circ} \mathrm{CA}$ \\
\hline Central & 29.4 & 23.1 & 15.0 \\
\hline Side & 29.3 & 15.2 & 14.9 \\
\hline
\end{tabular}

It is expected that dilution tolerance will trend with FDA, such that SOI $300^{\circ} \mathrm{CA}$ BTDC has the lowest dilution tolerance and SOI $120^{\circ} \mathrm{CA}$ BTDC has the greatest dilution tolerance for central and side DI. Given the $7.9^{\circ} \mathrm{CA}$ difference in FDA, side DI should show a greater dilution tolerance than central DI at SOI $240^{\circ} \mathrm{CA}$ BTDC. At the same time, side DI at SOI $240^{\circ} \mathrm{CA}$ BTDC should yield a similar dilution tolerance to central and side DI at SOI $120^{\circ} \mathrm{CA}$ BTDC given similar FDA.

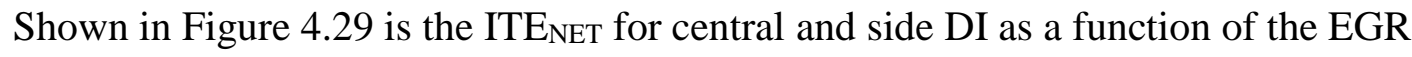

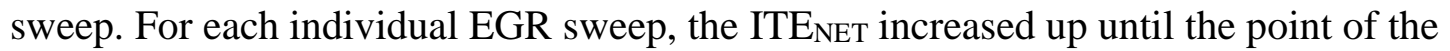
combustion stability limit; from there it decreased rapidly due to deteriorating combustion stability. In general, side DI resulted in the greatest ITE $_{\mathrm{NET}}$ improvement.
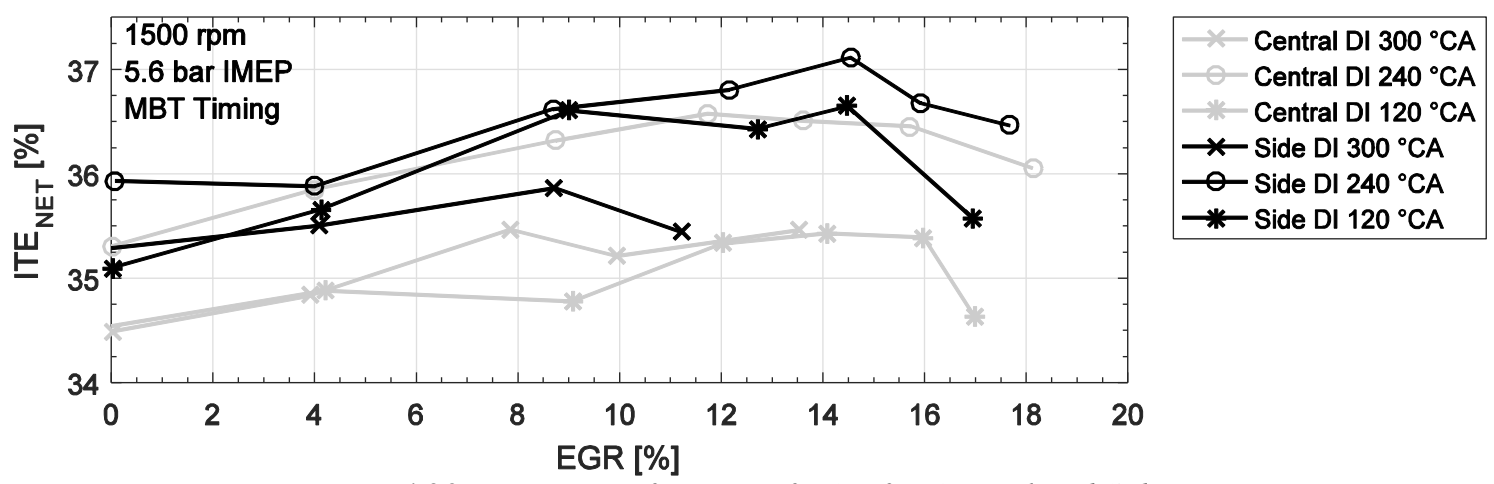

Figure 4.29: ITE $E_{N E T}$ as a function of EGR for Central and Side DI 


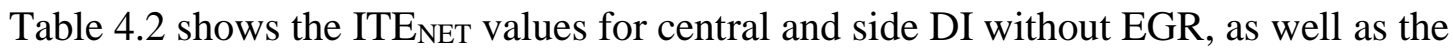
maximum absolute increase in ITE $E_{\text {NET }}$ due to EGR dilution. The effects of the induced tumble motion from central and side DI can been seen in Table 4.2. For central DI, SOI 300 and $120^{\circ} \mathrm{CA}$ start with the same ITE $\mathrm{NET}_{\mathrm{N}}$ and subsequently similar maximum $\mathrm{ITE}_{\mathrm{NET}}$. The main difference between these two SOI values is the mixture flame speeds under zero EGR conditions; SOI $120^{\circ} \mathrm{CA}$ BTDC results in a shorter FDA and CD, by 15 and $10^{\circ} \mathrm{CA}$, respectively. The shorter FDA should yield a greater dilution tolerance for SOI $120^{\circ} \mathrm{CA}$ BTDC based off literature.

Table 4.2: ITE $E_{N E T}$ with Zero EGR and Maximum Increase due to EGR

\begin{tabular}{|l|l|l|l|}
\hline ITE $_{\text {NET }} /$ Abs Incr [\%] & SOI $300^{\circ} \mathrm{CA}$ & SOI $240^{\circ} \mathrm{CA}$ & SOI $120^{\circ} \mathrm{CA}$ \\
\hline Central & $34.5 / 1.0$ & $35.3 / 1.3$ & $34.5 / 0.9$ \\
\hline Side & $35.3 / 0.3$ & $35.9 / 1.2$ & $35.1 / 1.6$ \\
\hline
\end{tabular}

At the same time, central and side DI at SOI 300 and $120^{\circ} \mathrm{CA}$ start with similar ITE NET values, respectively. Yet, there is a $1.1 \%$ difference at the maximum ITE $\mathrm{NET}_{\mathrm{N}}$ levels for these two SOI values for side DI. This further refutes the fact that injecting along the tumble motion can increase the rate of development and propagation for the combustion process, effectively helping to increase the efficiency [54]. When considering SOI

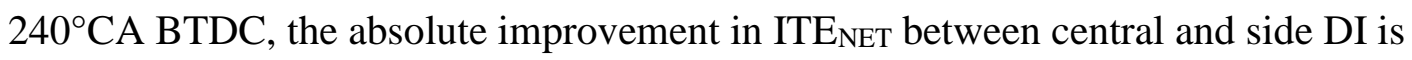
similar, indicating this is an optimal timeframe for injecting NG for this given test setup. However, the maximum ITE $_{\mathrm{NET}}$ due to EGR dilution is greater for side DI, again further supporting the argument that injecting along the tumble motion is beneficial for the combustion process. 
Figure 4.30 shows the $\mathrm{COV}_{\text {IMEP }}$ for an EGR sweep for central and side DI at the three SOI values. Consistent with ITE $_{\mathrm{NET}}$, each injection location and SOI has a very different response to EGR dilution. For central DI, the length of the FDA follows with the dilution tolerance such that a shorter FDA leads to increased dilution tolerance.

SOI $300^{\circ} \mathrm{CA} \mathrm{BTDC}$, corresponding to the condition of the longest FDA, has the lowest EGR dilution tolerance of 6.5 and 5.4\% EGR for central and side DI, respectively. This poor dilution tolerance can be attributed to a reverse tumble motion creating unfavorable conditions in the near spark region at the time of spark. Delaying the SOI to $240^{\circ} \mathrm{CA}$ BTDC helped to extend the dilution tolerance to 13.9 and $15.9 \%$ for central and side DI, respectively. This extension of the EGR dilution tolerance is to be expected, given the reduction of the FDA when delaying the SOI from 300 to $240^{\circ} \mathrm{CA}$ BTDC. At the same time, the $2 \%$ difference in EGR dilution tolerance for central and side DI agreed with the $9^{\circ} \mathrm{CA}$ difference in FDA. Delaying the SOI to $120^{\circ} \mathrm{CA}$ BTDC led to a 14.7 and 14.6\% EGR tolerance for central and side DI respectively. For the case of side DI, there is a $1.3 \%$ difference in EGR dilution tolerance between SOI 240 and $120^{\circ} \mathrm{CA}$ BTDC, despite there only being less than a $1^{\circ} \mathrm{CA}$ difference in FDA. While this does not fully agree with literature, this difference in EGR tolerance can be due to the difference in tumble motion, as previously shown by 3D CFD in Figure 4.15 of Section 4.1.2.

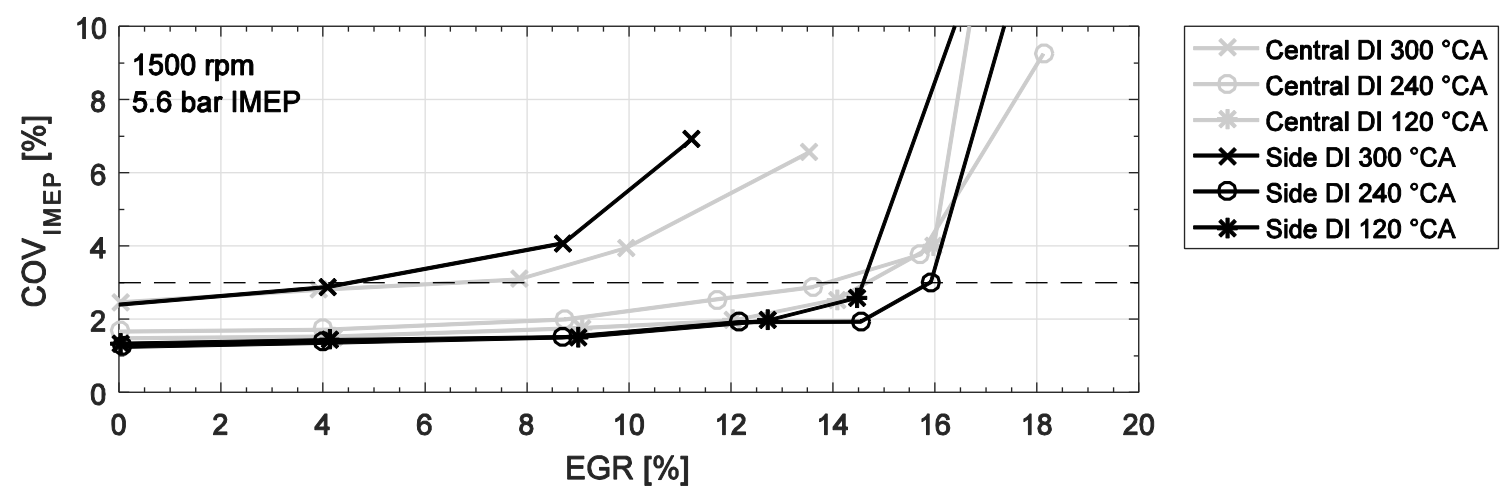

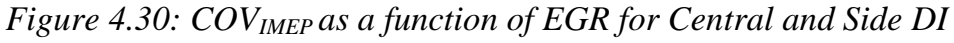


Because it has been shown in Section 4.1 that there are distinct differences between operation with central and side DI, an energy analysis was performed for the EGR dilute conditions. In order to further analyze these EGR dilute conditions, an EGR rate was chosen for central and side DI at each SOI. Table 4.3 shows the EGR rates for each condition to be used in future energy analysis. It was decided to compare central and side DI at similar EGR rates; a comparison could have made at the dilution tolerance limit, however, given the difference in dilution tolerance for some conditions, this would not have been a fair comparison.

Table 4.3: EGR Rates for Energy Analysis

\begin{tabular}{|l|l|l|l|}
\hline EGR $[\%]$ & SOI $300^{\circ} \mathrm{CA}$ & SOI $240^{\circ} \mathrm{CA}$ & SOI $120^{\circ} \mathrm{CA}$ \\
\hline Central & 3.9 & 13.6 & 14.1 \\
\hline Side & 4.1 & 14.6 & 14.5 \\
\hline
\end{tabular}




\subsubsection{SOI $300^{\circ} \mathrm{CA}$ BTDC Analysis}

Figure 4.31 shows an energy balance applied for central and side DI at SOI $300^{\circ} \mathrm{CA}$ BTDC with 4\% EGR. Consistent with results in Figure 4.4, side DI resulted in a greater net efficiency than central DI by $0.7 \%$ absolute. As shown in Section 4.1.1, the CD can be investigated in order to help explain the net efficiency difference.

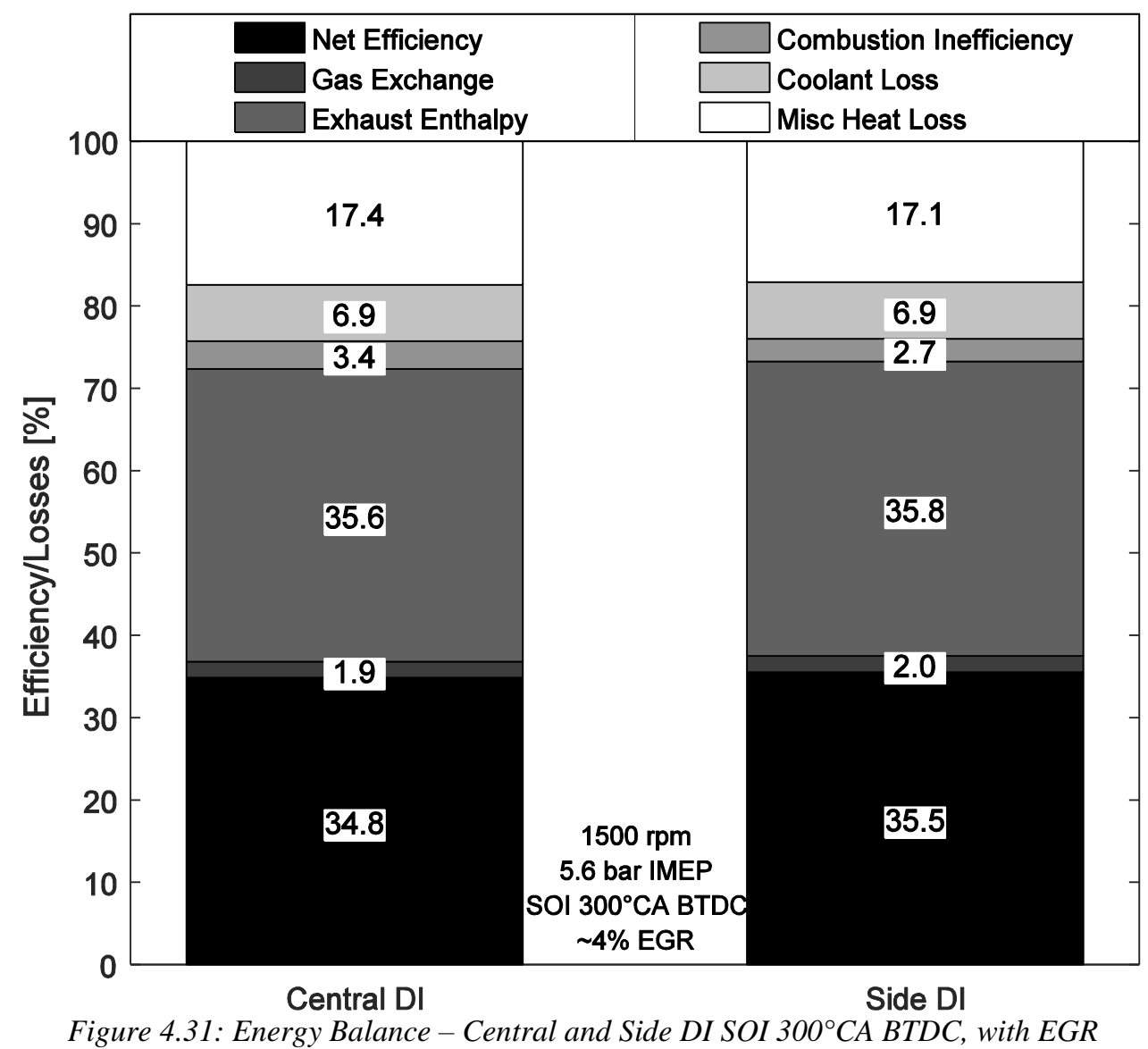


Shown in Figure 4.32 is the CD for central and side DI at SOI $300^{\circ} \mathrm{CA}$ BTDC. There was a $2.2^{\circ} \mathrm{CA}$ increase in $\mathrm{CD}$ at the $4 \%$ EGR rate for central and side DI. However, when comparing the absolute levels, there was a $2.6^{\circ} \mathrm{CA}$ difference in the $\mathrm{CD}$ between central and side DI. As previously discussed, a spark ignited engine follows the constant volume combustion cycle, stating that the combustion event needs to occur as fast as possible for the highest efficiency. Therefore, the shorter CD of side DI at $4 \%$ EGR helps to explain the net efficiency benefit. Although SOI $300^{\circ} \mathrm{CA}$ BTDC is characterized as a poor condition due to low ITE $_{\mathrm{NET}}$ and mixture flame speeds, the effects of injecting along the tumble motion can be seen by the difference in CD.

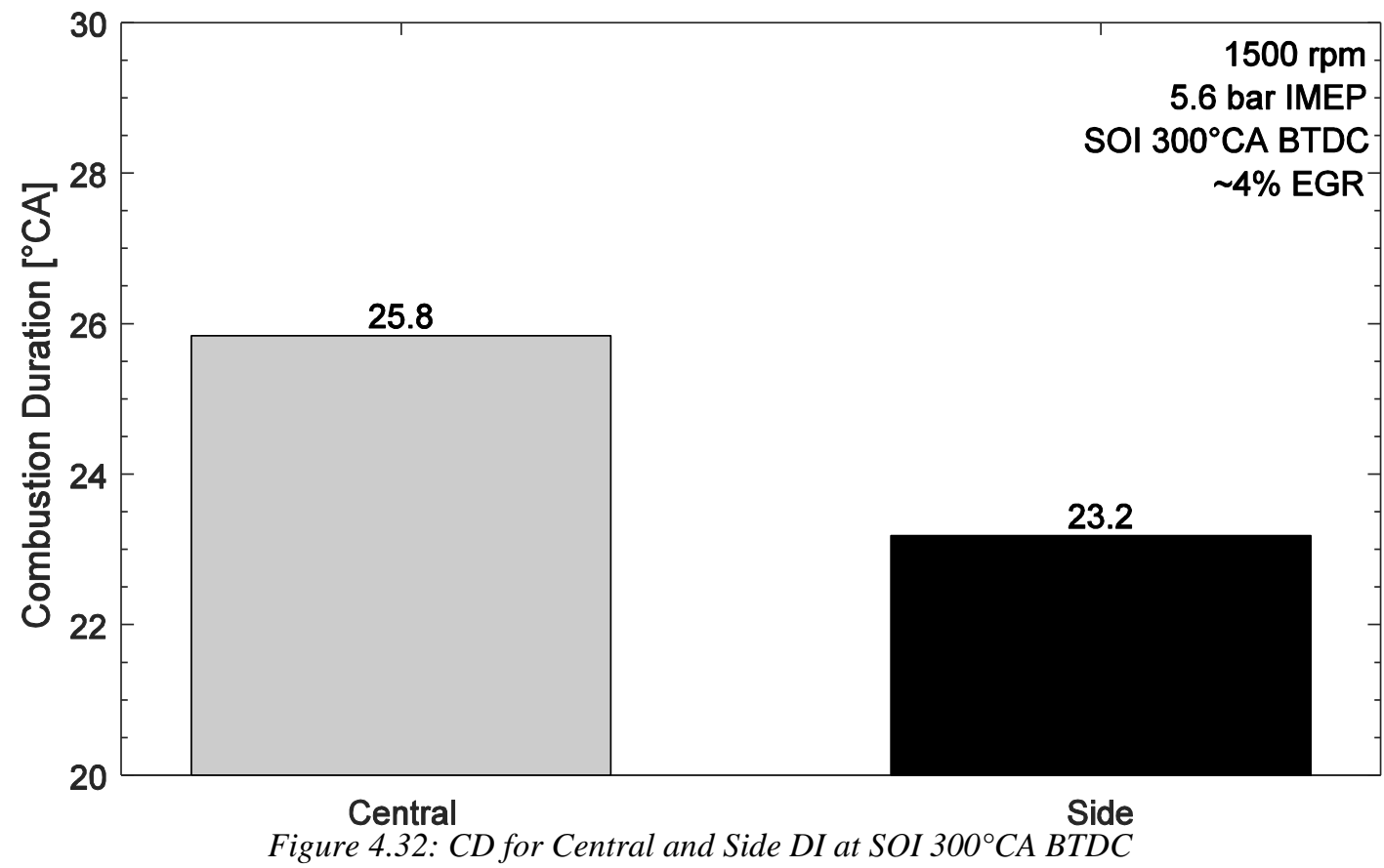

Losses due to gas exchange work and exhaust enthalpy are the same for this condition. The same amount of throttling was required for central and side DI at the $\sim 4 \%$ EGR condition. At the same time, a similar loss to exhaust enthalpy indicates similar exhaust mass flow rate and EGT. For reference, the EGT for central and side DI was $601{ }^{\circ} \mathrm{C}$. 
As introduced in the beginning of Section 4.2.2 in Figure 4.31, with 4\% EGR, side DI results in an improved combustion inefficiency by $0.7 \%$ relative to central DI. To further understand the change in combustion inefficiency, iSHC emissions for central and side DI are shown in Figure 4.33. Under this condition, the addition of $\sim 4 \%$ EGR led to a 14 and 7\% increase in iSHC emission for central and side DI, respectively. While it has been previously shown in Figure 4.9 that side DI results in $8 \%$ higher iSHC emissions under zero EGR conditions, at similar EGR rates side DI results in $15 \%$ lower iSHC emissions. It is conceivable that the added charge motion from side DI is beneficial with improving mixture homogeneity under dilute mixtures at this condition.

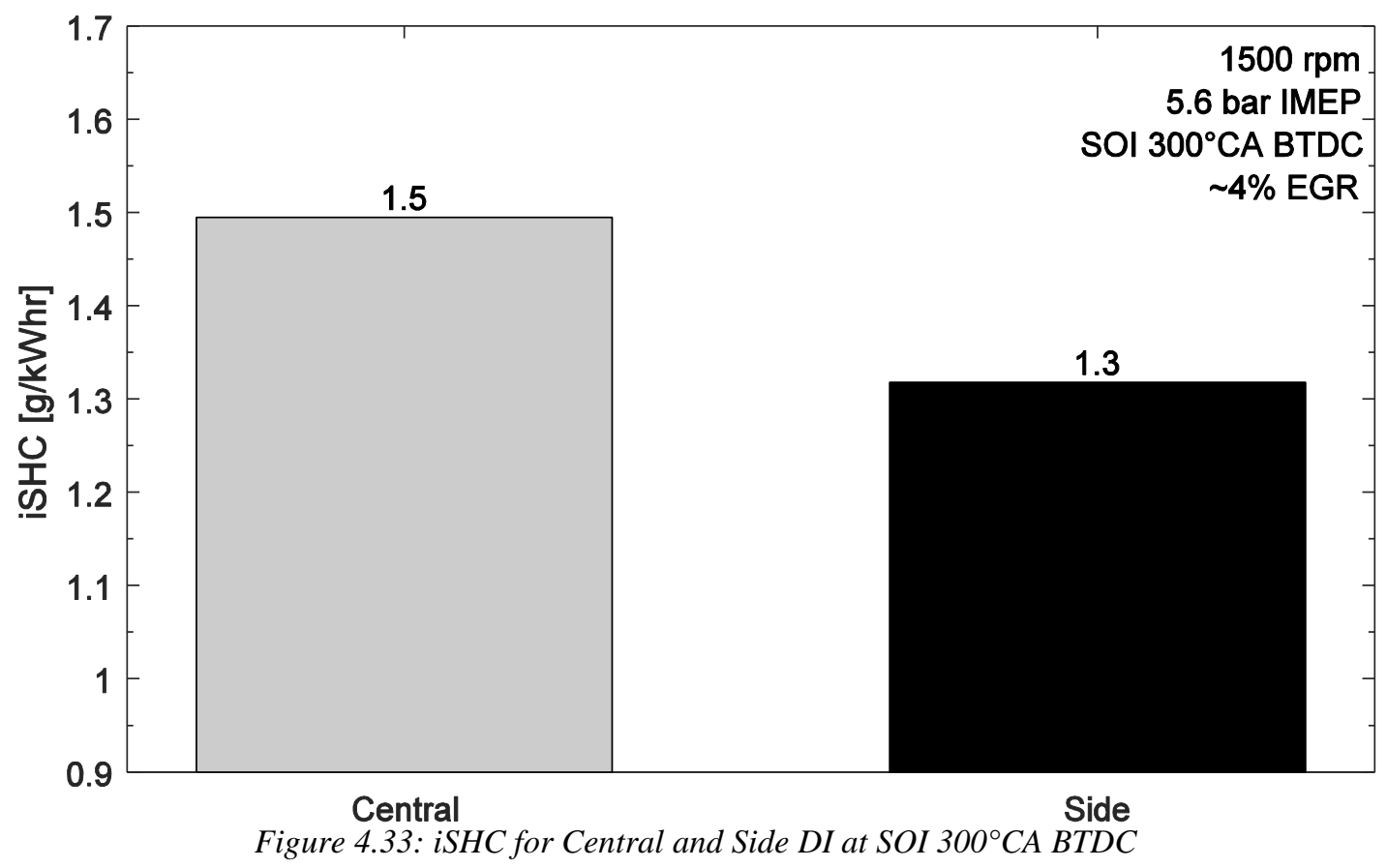


When considering iSCO emissions, there was a difference between central and side DI for SOI $300^{\circ} \mathrm{CA} \mathrm{BTDC}$ at $\sim 4 \%$ EGR. While it would have been anticipated that $\sim 4 \%$ EGR would have led to an increase in iSCO emissions, the combustion inefficiency remained constant over this condition and net efficiency increased, partially due to the fact that there was less fuel bound carbon being introduced to the engine. In addition, as EGR was introduced to the engine, in-cylinder pressure increased due to a higher trapped mass and temperatures decreased due to increasing diluent content. Literature has shown that when considering the equilibrium equation, $\mathrm{CO} 2=\mathrm{CO}+1 / 2 \mathrm{O} 2$, the rate of $\mathrm{CO}$ formation decreases with increasing pressure and decreasing temperature [43]. For this condition, the $33 \%$ difference in iSCO emissions between central and side DI also helped to accounts for the $0.5 \%$ difference in combustion efficiency at $\sim 4 \%$ EGR.

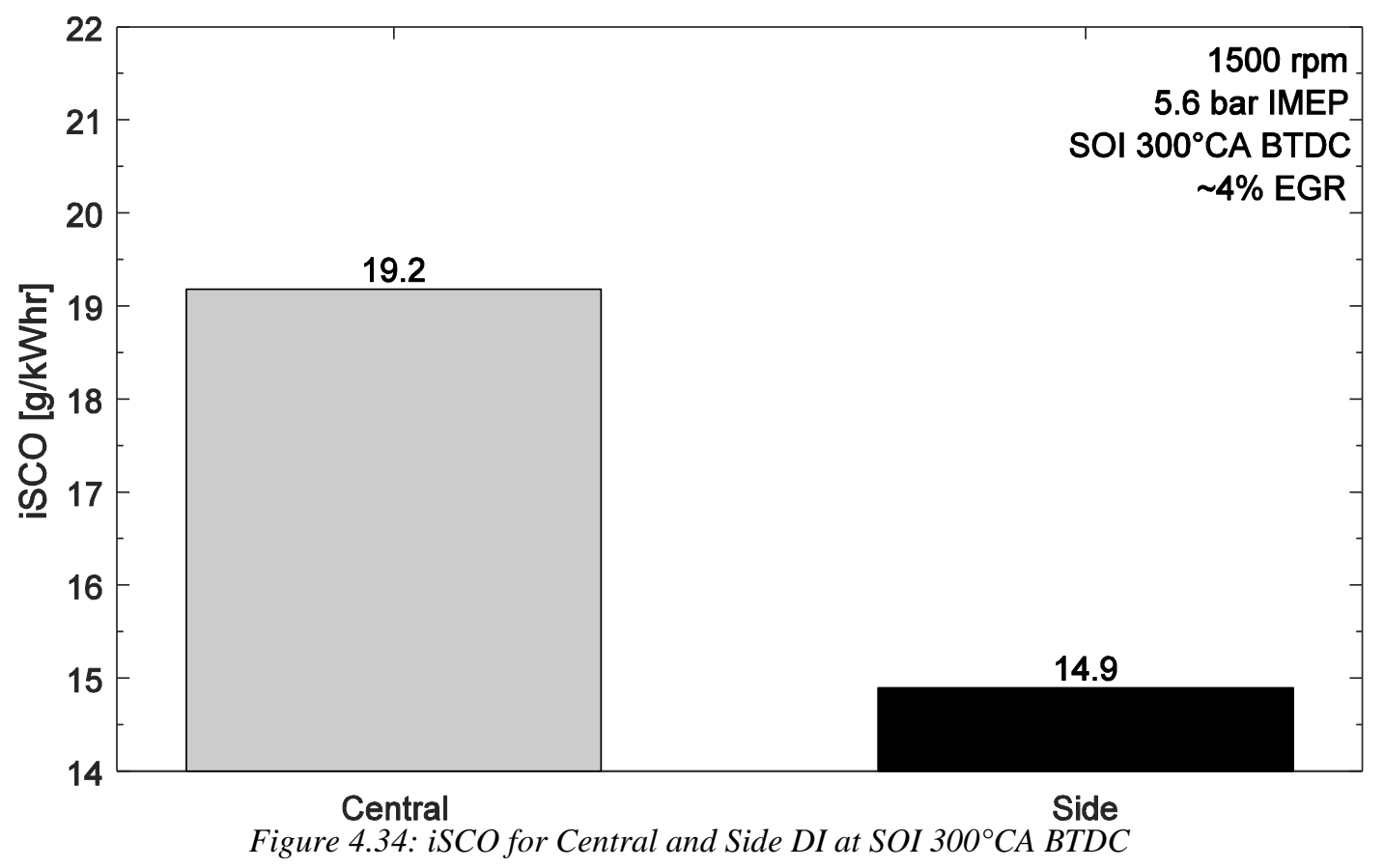

Losses due to heat being rejected to the coolant loop were the same for this condition, indicating similar in-cylinder temperatures. At the same time, miscellaneous heat losses are greater for central DI, by $0.3 \%$ absolute. It is again conceivable that at SOI $300^{\circ} \mathrm{CA} \mathrm{BTDC}$ injecting directly at the piston leads to a higher amount of wall heat transfer for central DI, increasing overall heat losses [51]. 


\subsubsection{SOI $240^{\circ} \mathrm{CA}$ BTDC Analysis}

Figure 4.35 shows the energy balance performed for central and side DI at SOI $240^{\circ} \mathrm{CA}$ BTDC with $\sim 14 \%$ EGR. Consistent with Figure 4.13 , side DI resulted in a greater net efficiency than central DI by $0.6 \%$.

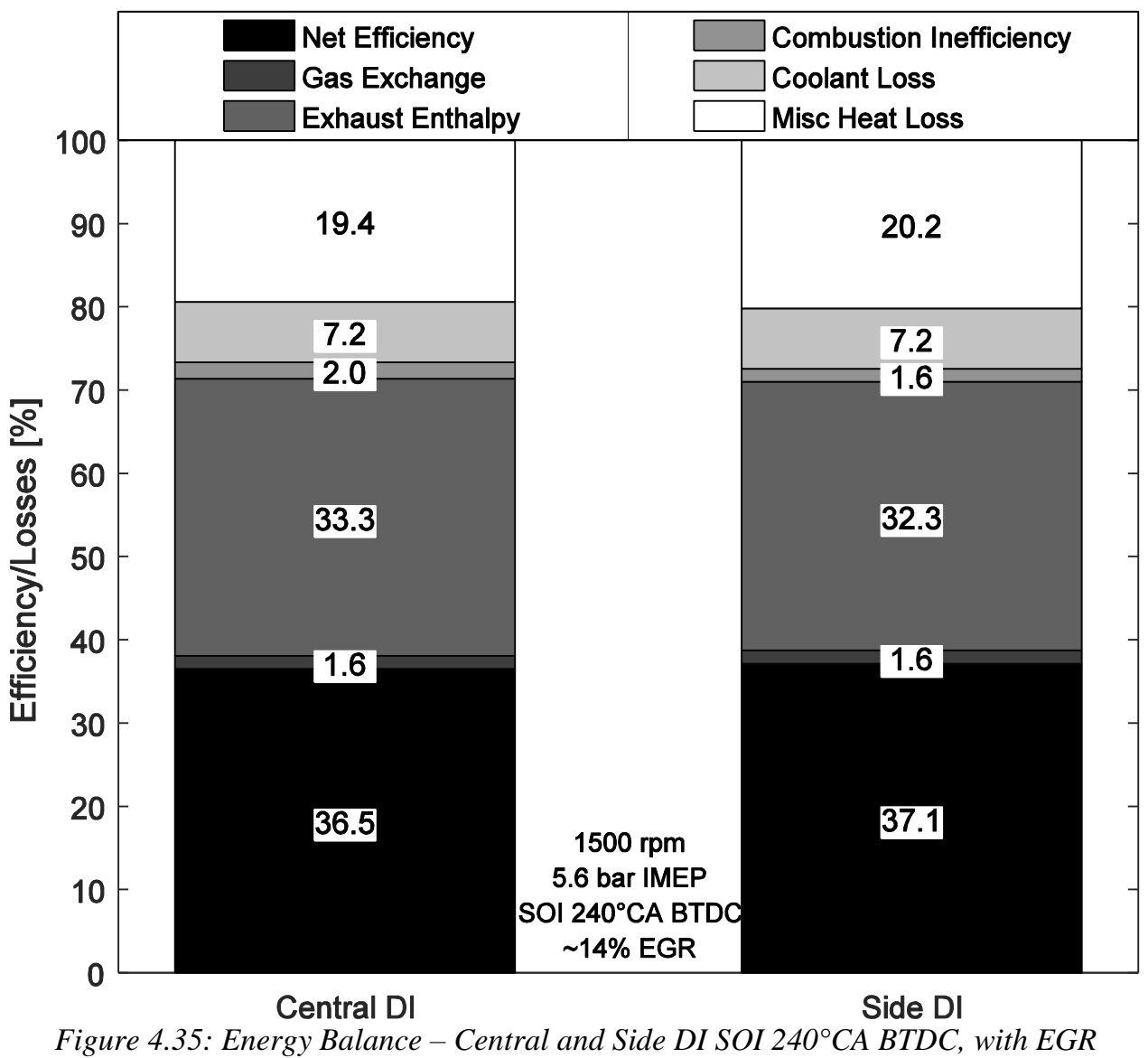


While efficiency levels can increase with increasing EGR content due to lowered heat transfer losses and improved specific heat ratios, mixture flame speeds also decrease. As shown in Figure 4.36, there was an increase in the CD for both central and side DI with the addition of $\sim 14 \%$ EGR. The CD increased to 30 and $23.7^{\circ} \mathrm{CA}$ for central and side DI, respectively. The shorter $\mathrm{CD}$ for side DI at similar a similar EGR rate is again due to the complimentary path of the injection event to the charge motion. The overall shorter CD at $\sim 14 \%$ EGR for side DI helped lead to a greater net efficiency.

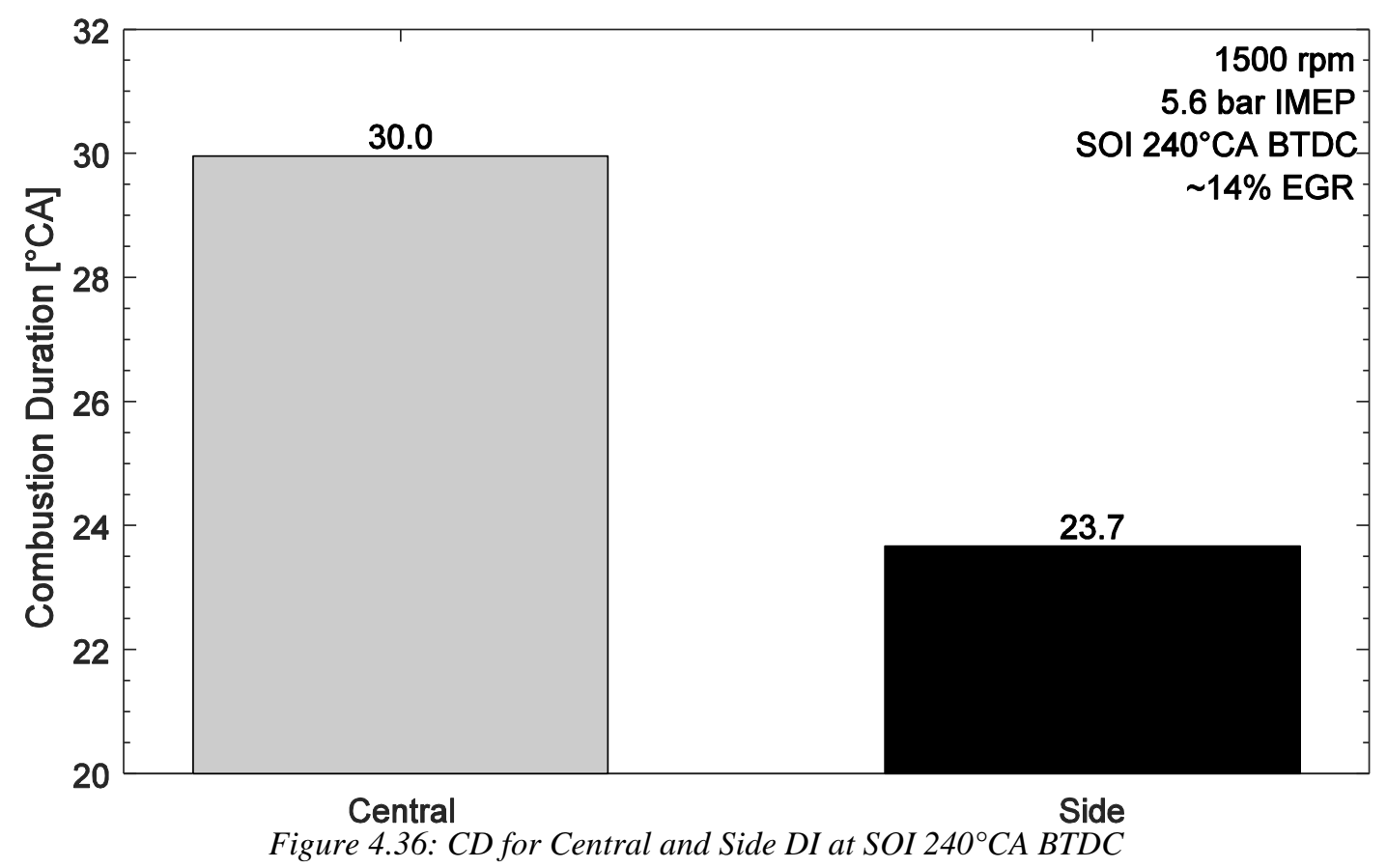

Losses due to gas exchange were the same for this condition because the same amount of throttling was required to maintain 5.6 bar IMEP. There was a $1 \%$ reduction in exhaust enthalpy for side DI which can be explained by looking at the EGT. The EGT for central and side DI at $\sim 14 \%$ EGR was 596 and $537^{\circ} \mathrm{C}$, respectively. The $59^{\circ} \mathrm{C}$ reduction in EGT is a strong driver for the lower exhaust enthalpy. 
The energy analysis in Figure 4.35 showed that side DI resulted in $0.4 \%$ lower combustion inefficiency than central DI. Shown in Figure 4.37 are the iSHC emission for central and side DI with 14\% EGR. As can be seen, the increase in iSHC emission for central and side DI are in fact similar for this condition. The similar increase in iSHC emissions for central and side DI provides indication that injection at SOI $240^{\circ} \mathrm{CA}$ BTDC is optimal for this test configuration. However, given the fact there is less than a $6 \%$ difference in iSHC emissions between central and side DI, the increase in iSHC emission cannot fully account for the difference in combustion inefficiency.

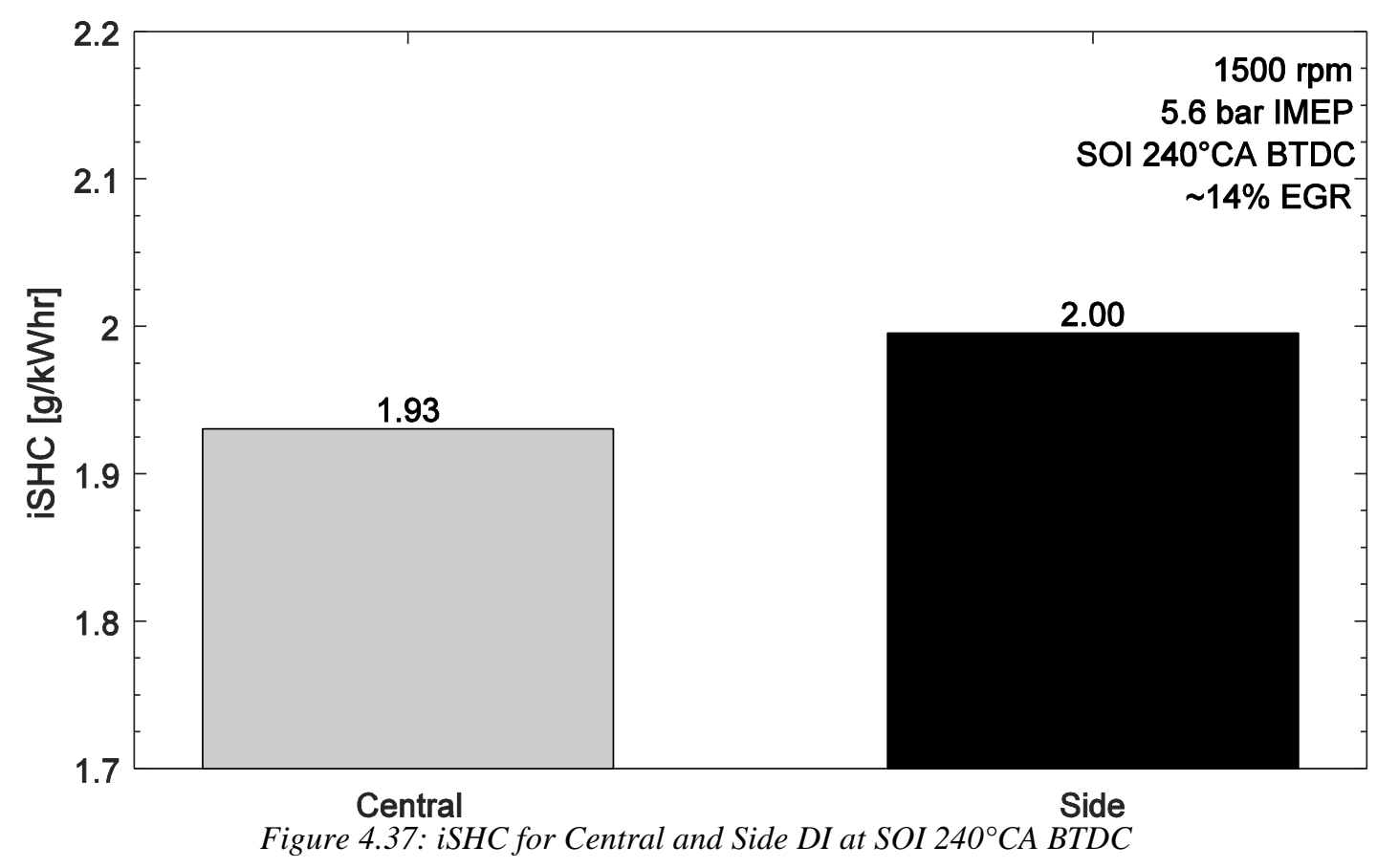


When considering the iSCO emissions, there is a greater difference at $\sim 14 \%$ EGR for central and side DI, as shown in Figure 4.38. With the introduction of 14\% EGR, iSCO emissions for central DI were reduced by 64\%. As mentioned in Section 4.2.2, the reaction mechanism for $\mathrm{CO}$ production decreases with increasing pressure and decreasing temperature. When comparing the two injection locations, side DI resulted in a 54\% reduction in iSCO emissions for the $\sim 14 \%$ EGR condition. This reduction provides further indication of the better mixing of side DI, even in the presence of added diluent. The lower combustion inefficiency of side DI appears to be a greater function of iSCO emissions, showing that combustion inefficiency at this condition are primarily driven by mixing.

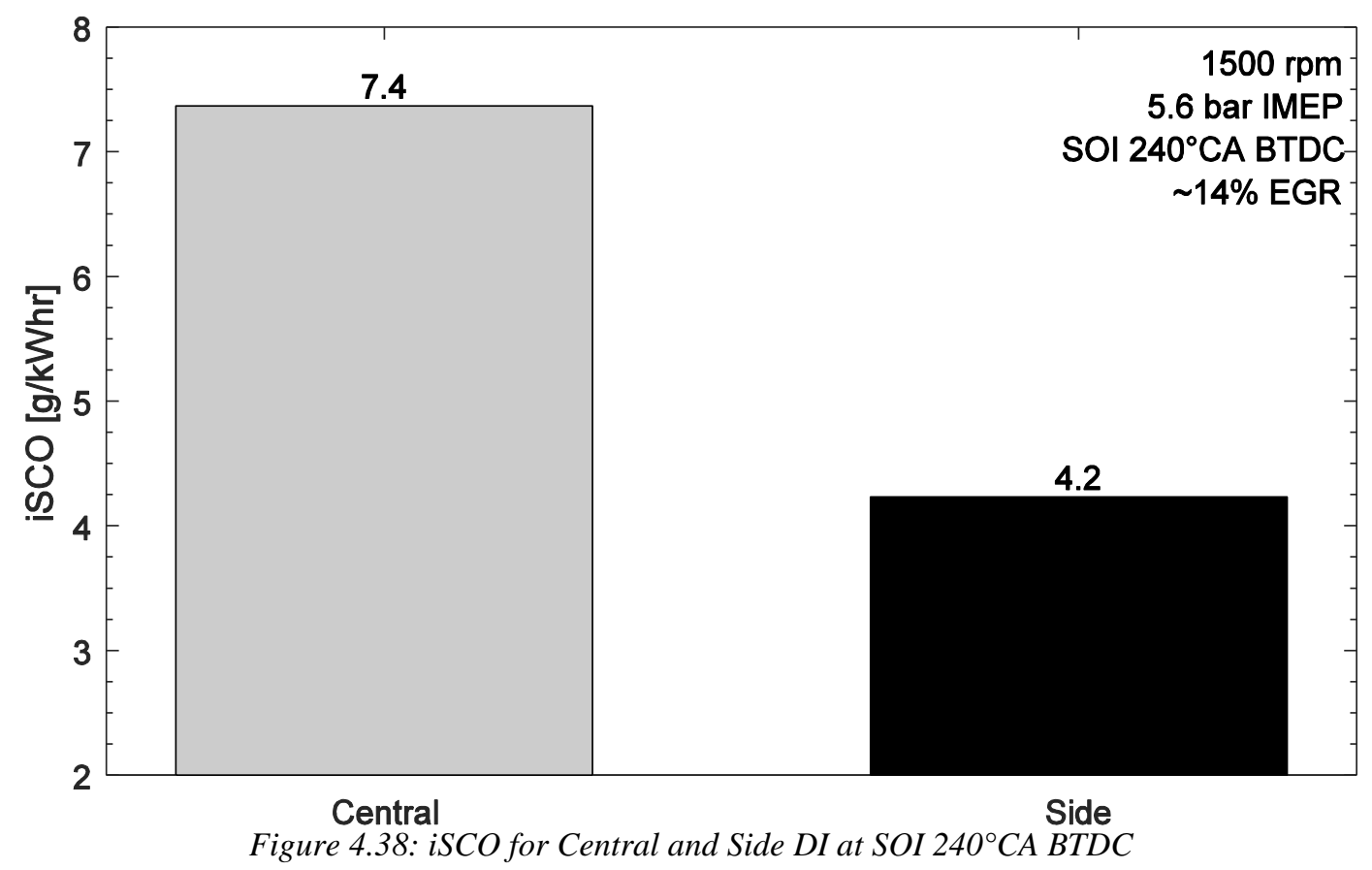

Figure 4.35 shows that there was a similar amount of heat rejected to the coolant loop and an increase in miscellaneous heat losses for side DI. It was introduced in Section 4.1.4 that there are competing effects for side DI, such that the improved tumble motion increased the rate of turbulent flame propagation, subsequently leading to an increase in heat transfer losses. Therefore, the increase in miscellaneous heat losses for side DI could be due to an increase in wall heat transfer. 


\subsubsection{SOI $120^{\circ} \mathrm{CA}$ BTDC Analysis}

An energy balance for central and side DI with $\sim 14 \%$ EGR at SOI $120^{\circ} \mathrm{CA}$ BTDC is shown in Figure 4.39. Once again, side DI resulted in a greater net efficiency than central DI, by $1.2 \%$ absolute.

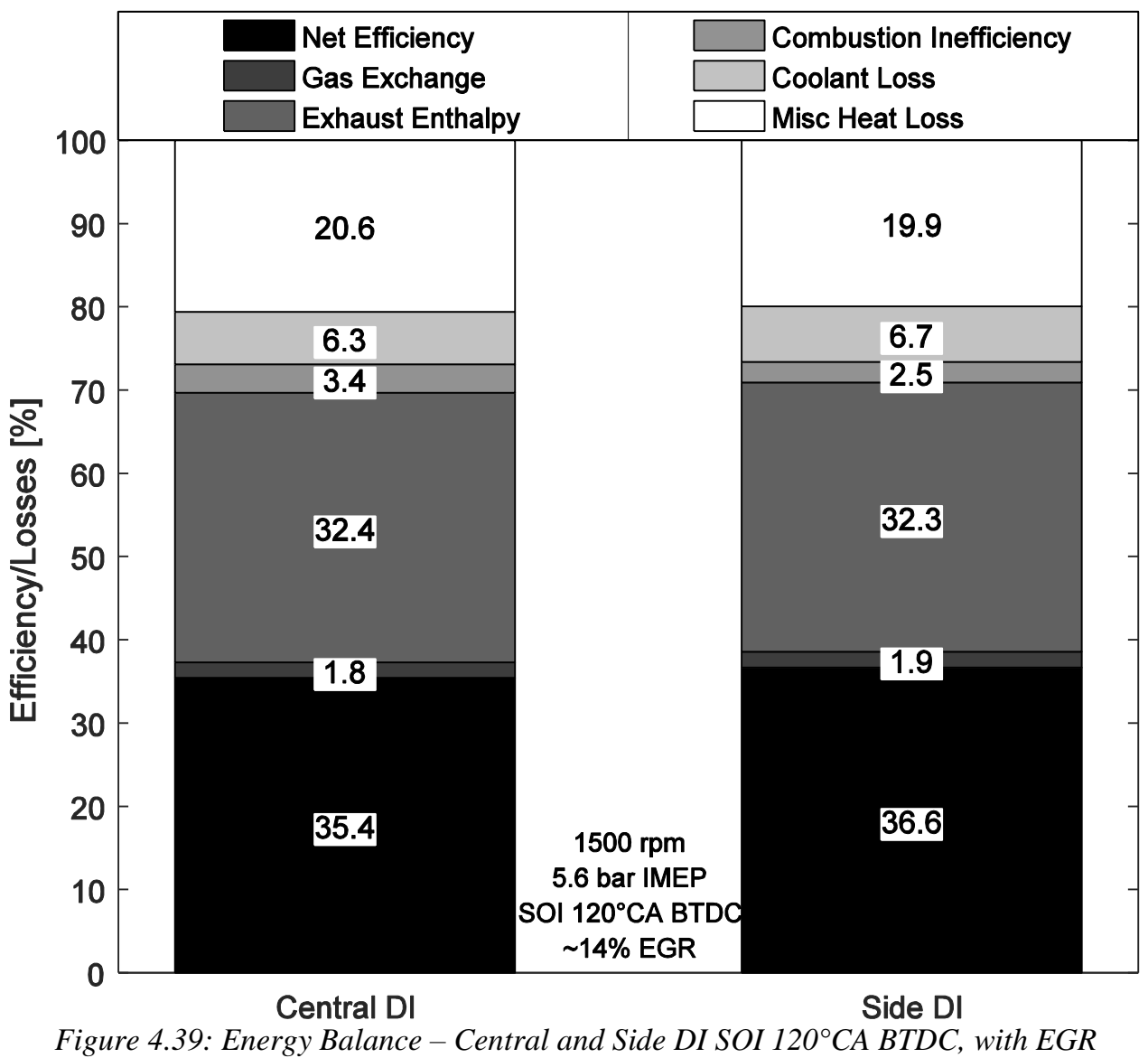


Figure 4.40 shows the CD for central and side DI with the addition of $\sim 14 \%$ EGR.

Consistent with zero EGR conditions, there is less than a $1^{\circ} \mathrm{CA}$ difference between central and side DI at $\sim 14 \%$ EGR. While the difference in CD is small at $\sim 14 \%$ EGR, the difference is likely caused by the complimentary charge motion of side DI. The small change in $\mathrm{CD}$ for this condition helps to improve the net efficiency of side DI relative to central.

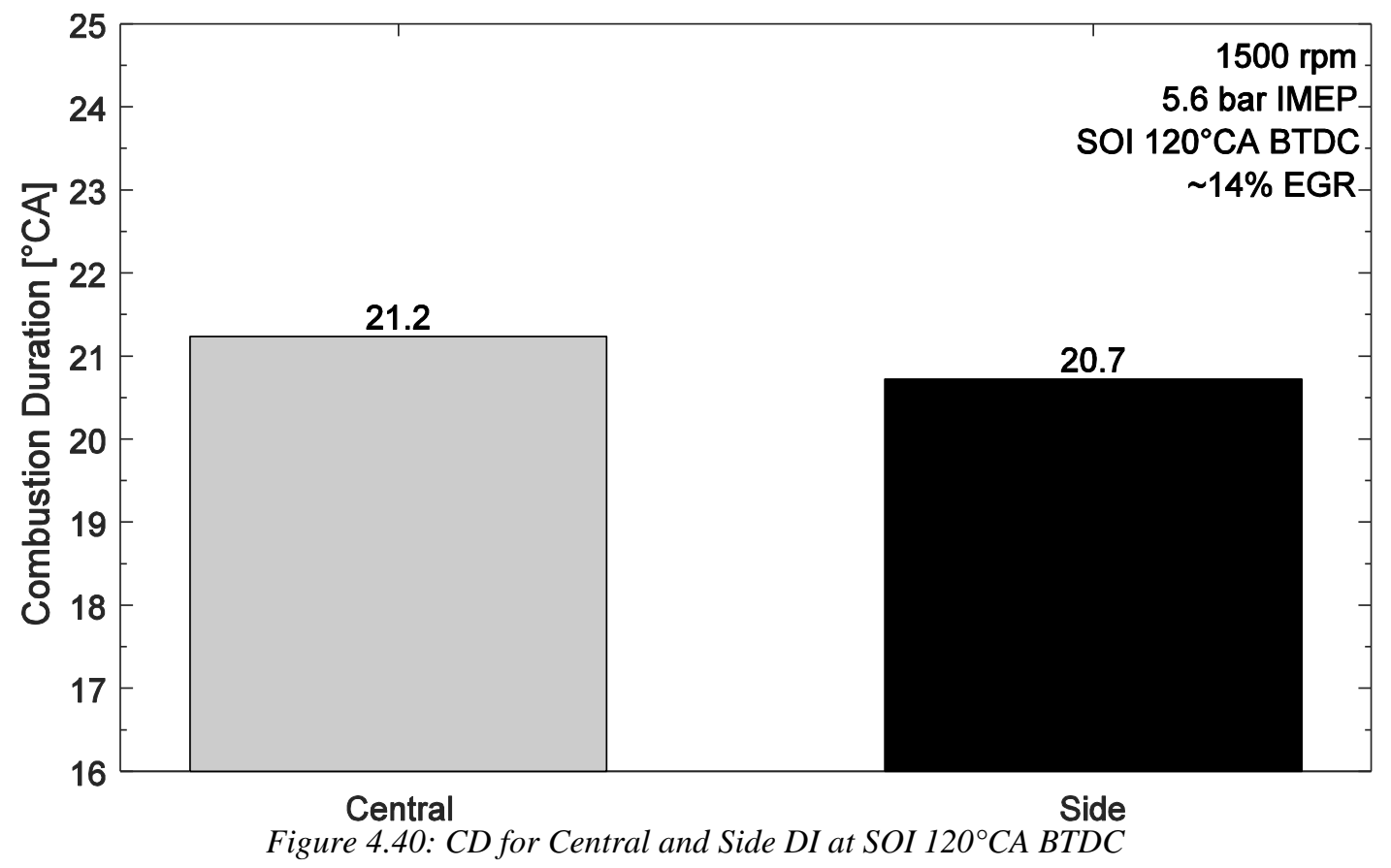

Pumping losses were similar between central and side DI at $\sim 14 \%$ EGR, again due to the fact that the same amount of throttling was required to maintain engine load. The $0.1 \%$ greater exhaust enthalpy for central DI can be explained using the EGT. The EGT for central and side DI was 606 and $595^{\circ} \mathrm{C}$, respectively. 
There is a $0.9 \%$ absolute difference in combustion inefficiency between central and side DI at this condition. To further understand this loss, the iSHC emissions can be looked at. Under zero EGR conditions, side DI results in approximately $30 \%$ greater iSHC emissions. With the addition of $\sim 14 \%$ EGR, the difference in iSHC emissions between central and side DI reduces to 23\%, seen in Figure 4.41. While it has been shown for multiple conditions that side DI helps to promote better mixing within the cylinder, it still results in a greater amount of unburned fuel. It is conceivable that the higher tumble pushes more fuel into the crevice volume where it cannot be fully consumed.

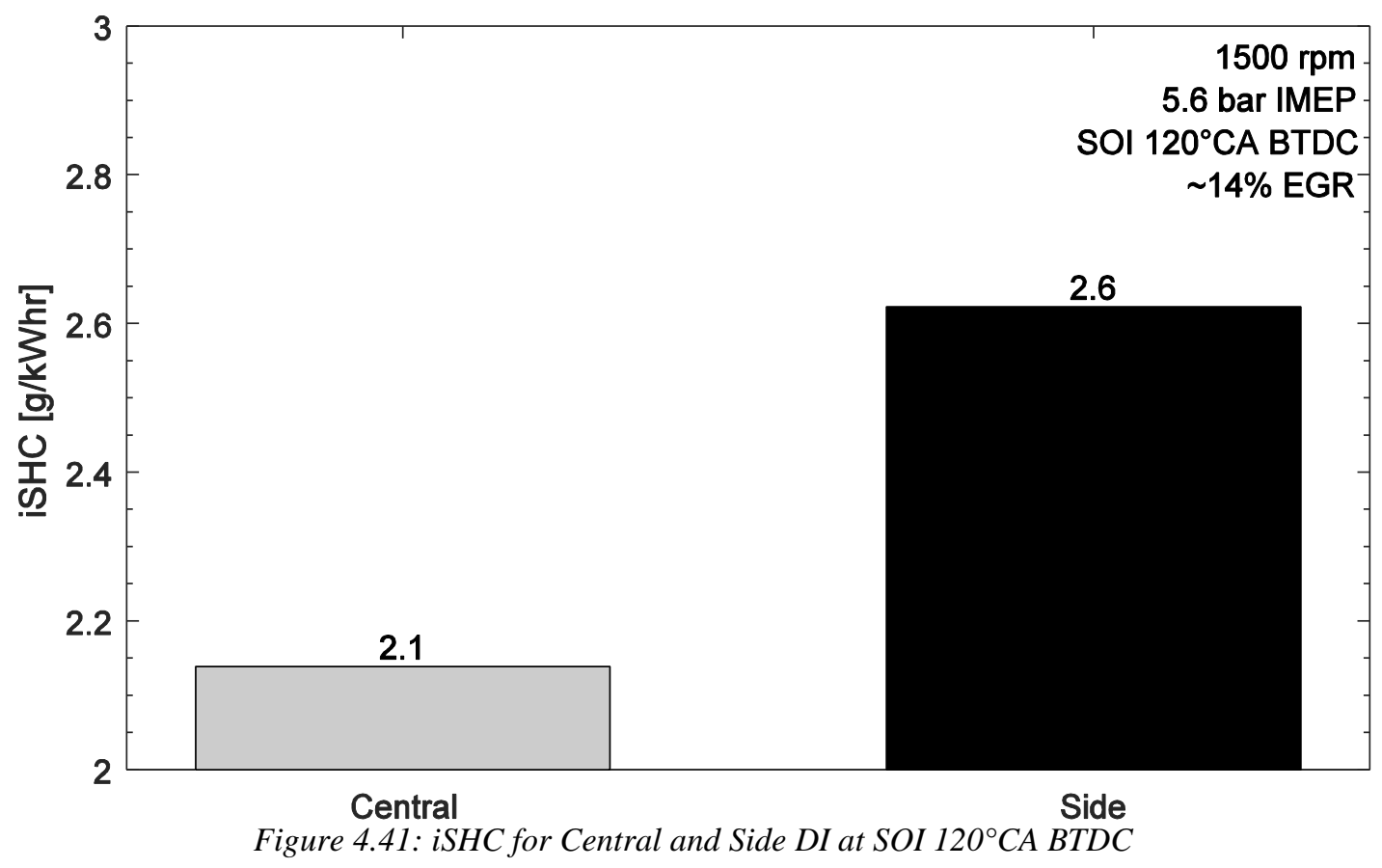


As introduced in Figure 4.27 in Section 4.1.3, side DI reduces iSCO emissions by up to $16 \%$ under zero EGR conditions. This reduction is magnified with the introduction of $\sim 14 \%$ EGR; side DI reduces iSCO emissions by a factor of two relative to central DI. The lower iSCO emission are arguably due to the better mixing associated with side DI. Despite an increase in iSHC emissions, the $0.6 \%$ reduction in combustion inefficiency for side DI is primarily driven by the large reduction in iSCO emissions.

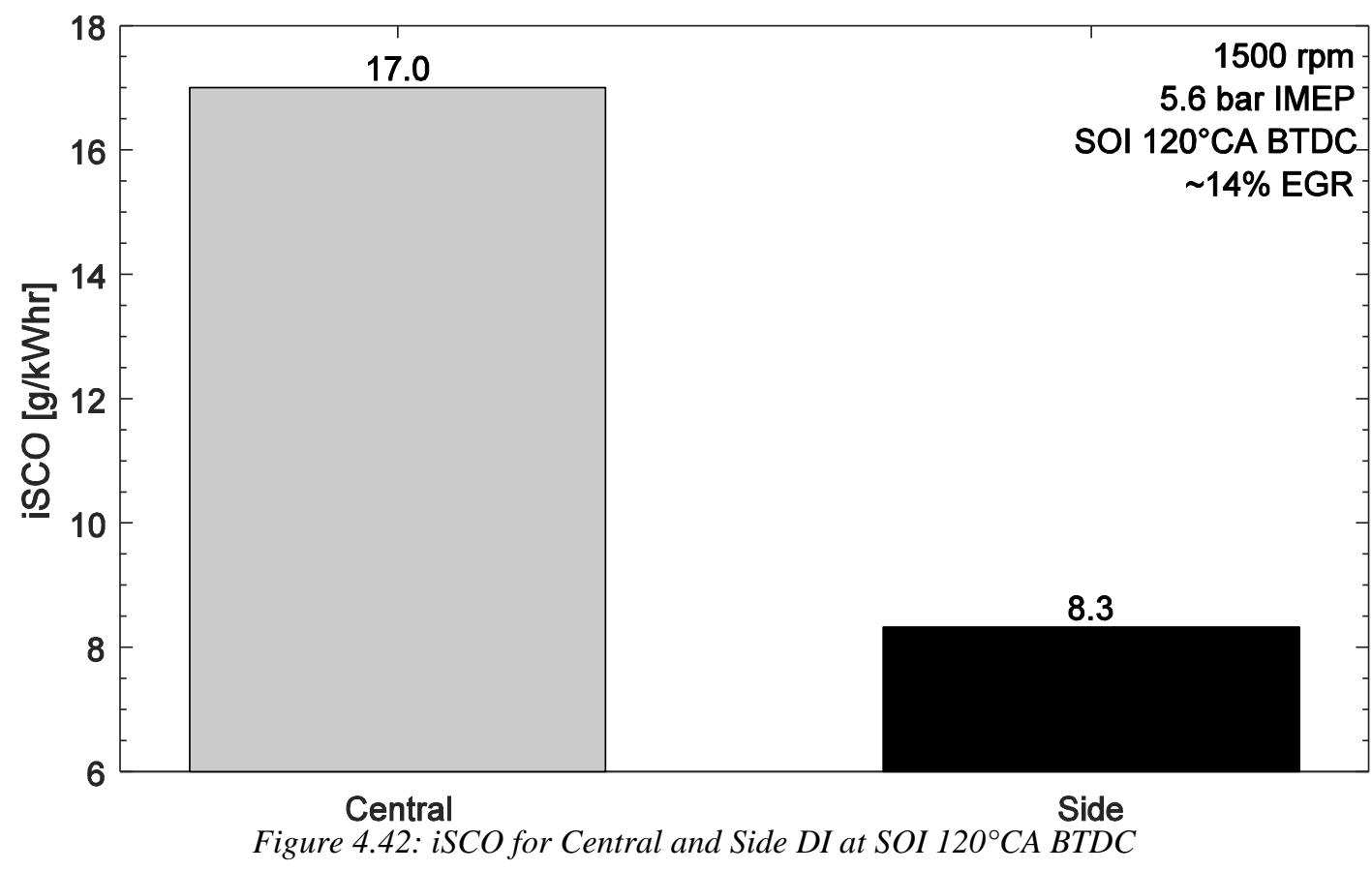

Figure 4.39 shows that heat rejected to the coolant loop was $0.4 \%$ higher for side DI at $\sim 14 \%$ EGR. This provides indication that there was a more wall heat transfer for side DI at this condition. This is further backed up by the shorter CD of side DI, while also the lower EGT.

There is also a $0.7 \%$ difference in miscellaneous heat losses. It has been stated that the EGT for central DI is $11^{\circ} \mathrm{C}$ higher than side DI for this condition. Therefore, radiative heat losses in the exhaust can be higher for central DI. 


\subsubsection{Summary for Injection Location and SOI Impact on ITE $E_{N E T}$ with EGR}

Consistent with previous findings in Section 4.1, side DI results in a greater net efficiency with the addition of EGR. The additive effect of the gaseous injection event from side DI was be clearly shown under EGR dilute conditions, especially for the case of SOI $240^{\circ} \mathrm{CA}$. Dilution tolerance limits correlated well with literature, such that a shorter FDA generally led to a greater dilution tolerance. Side DI at SOI $240^{\circ} \mathrm{CA}$ BTDC had the greatest dilution tolerance, likely due to the increase level of tumble motion from the gaseous injection event. For a given EGR rate, it was shown that losses for central DI were again driven by in-cylinder mixing, independent of SOI. Also, the energy balance approach helped to show that SOI $240^{\circ} \mathrm{CA}$ BTDC is an optimal injection timing, regardless of injection location.

Figure 4.43 shows the ITE $\mathrm{NET}_{\mathrm{N}}$ of central and side DI with EGR at the three SOI values.

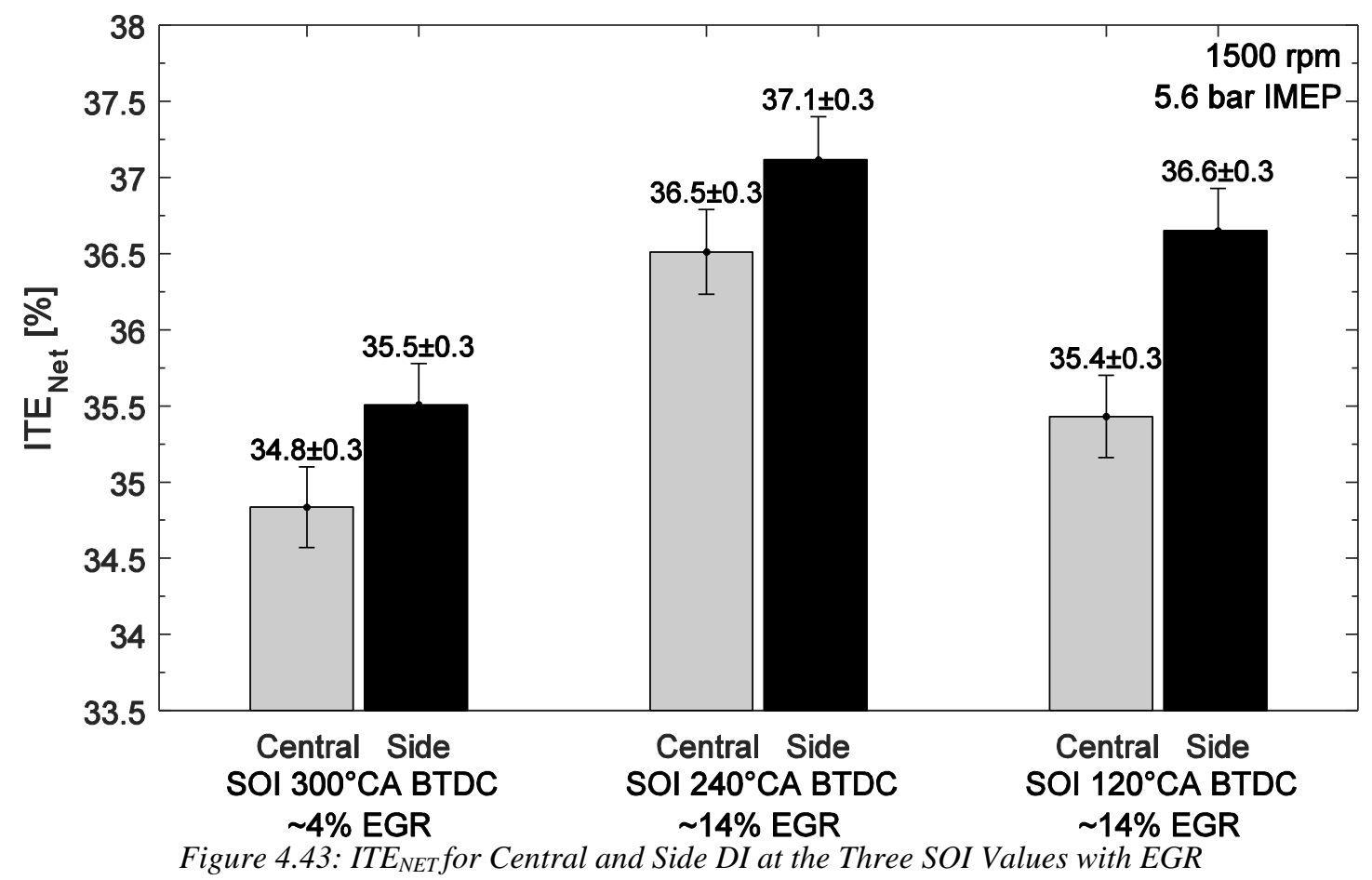

At the EGR rates chosen, side DI resulted in a statistically significant increase in ITE $E_{\text {NET }}$ over central DI. When considering the losses shown in each energy balance, combustion inefficiency resulted in the greatest reduction. On average, side DI provided a $23 \%$ relative reduction. Also, the difference in $\mathrm{ITE}_{\mathrm{NET}}$ at $\mathrm{SOI} 240^{\circ} \mathrm{CA} \mathrm{BTDC}$ became 
significant with the introduction of EGR, possibly due to the difference in $\mathrm{CD}$; under zero EGR the difference in $\mathrm{CD}$ was $4.3^{\circ} \mathrm{CA}$ while it increased to $6.3^{\circ} \mathrm{CA}$ with EGR. The increasing difference in $\mathrm{CD}$ for central and side provides indication of the improved mixing of side DI. The statistical significance at SOI $240^{\circ} \mathrm{CA}$ BTDC was further substantiated by the fact that the actual EGR rate for side DI is $1 \%$ absolute higher than central DI. 


\subsection{Varying Engine Load ${ }^{3}$}

Up until this point, all data analysis was performed for one load condition. In order to ensure the discussed trends remain the same for multiple operating conditions, data were collected at 3.2 and 8 bar IMEP for the three SOI values. Taking frictional losses into account, 3.2 bar IMEP is representative of the standard test condition of 2.62 bar brake mean effective pressure (BMEP) as used by Ford Motor Company. 8 bar IMEP was chosen as an intermediate load condition for this engine configuration, placing it between a part-load and a full load condition.

3 The data for central and side DI at 5.6 bar IMEP presented in Section 4.3 is the same test condition performed for central and side DI in Section 4.1. However, as indicated in Section 3.10, the data set collected for this section was collected nearly eight months after data collected in Section 4.1. Therefore, absolute magnitudes of variables may differ between the two sections. 


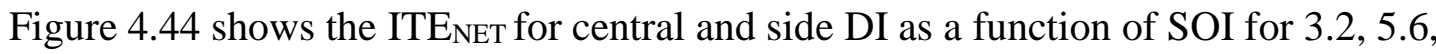
and 8 bar IMEP.

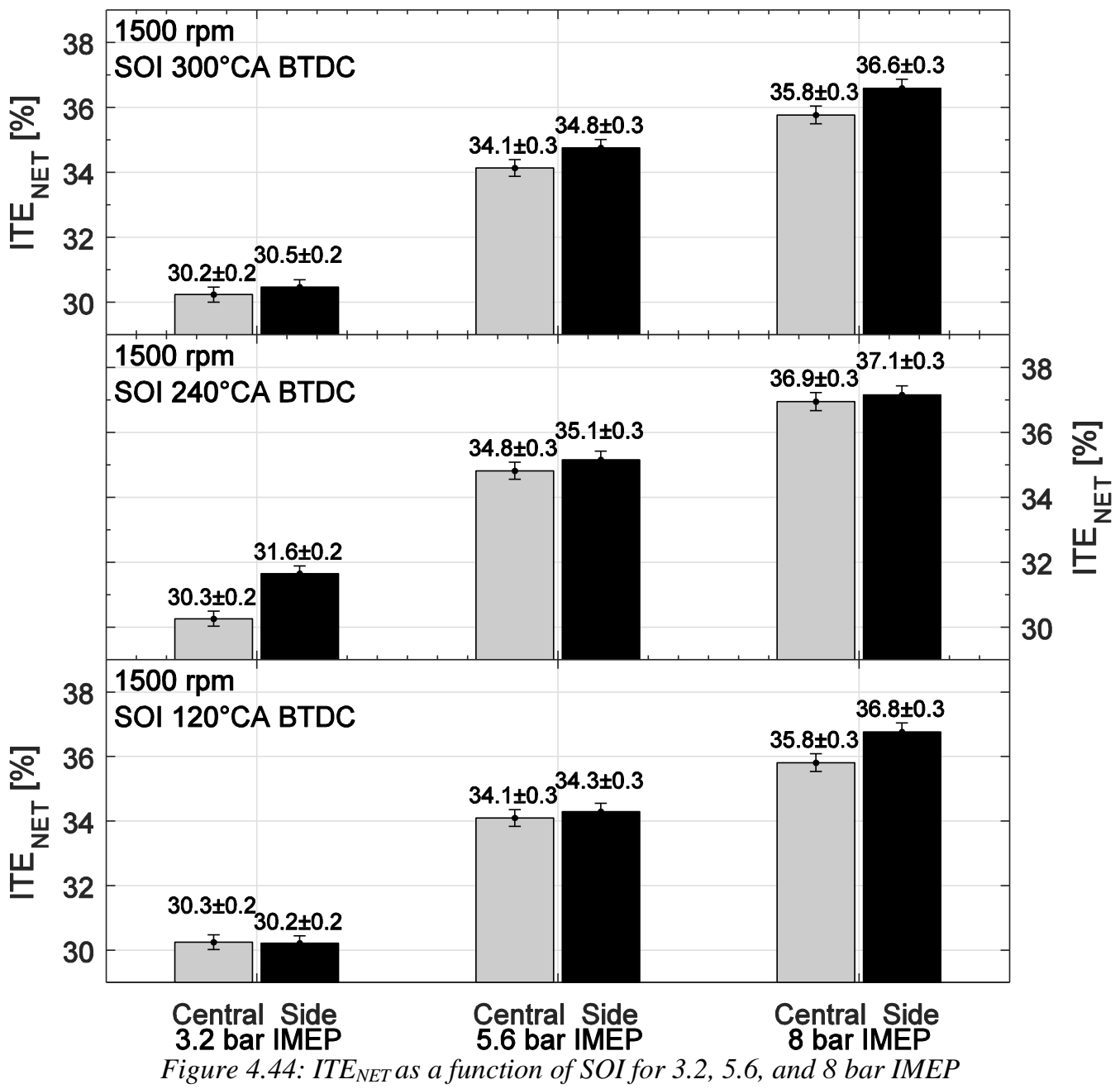

Consistent with previous findings, ITE $\mathrm{NET}_{\mathrm{N}}$ increased as the SOI was delayed to SOI $240^{\circ} \mathrm{CA} \mathrm{BTDC}$ and then decreased as the SOI is further delayed to $120^{\circ} \mathrm{CA}$ BTDC. The increase in ITE $_{\mathrm{NET}}$ is due to an increase in tumble motion creating favorable incylinder conditions, while the decrease in $\mathrm{ITE}_{\mathrm{NET}}$ towards SOI $120^{\circ} \mathrm{CA}$ BTDC is due to some levels of stratification occurring. For 3.2 bar IMEP, ITENET values for both central and side DI at SOI 300 and $120^{\circ} \mathrm{CA}$ BTDC show no statistical significance. When increasing the engine load to 8 bar, there is statistical significance between central and side DI. It is conceivable that the separation of the error bars at 8 bar IMEP is due to a different interaction between the gaseous injection event as the intake airflow increases 
with increasing load. That is, the neutral path of injection for central DI may damp out any increasing turbulence, and side DI may provide complimentary motion to the tumble. Consistent with Section 4.1 and 4.2, an energy balance was performed for data collected at the three SOI values at 3.2, 5.6, and 8 bar IMEP, to be discussed in subsequent sections. 


\subsubsection{SOI $300^{\circ} \mathrm{CA}$ BTDC Analysis}

An energy balance was performed in Figure 4.45 for central and side DI at SOI $300^{\circ} \mathrm{CA}$ BTDC as the engine load was swept from 3.2 to 8 bar IMEP.

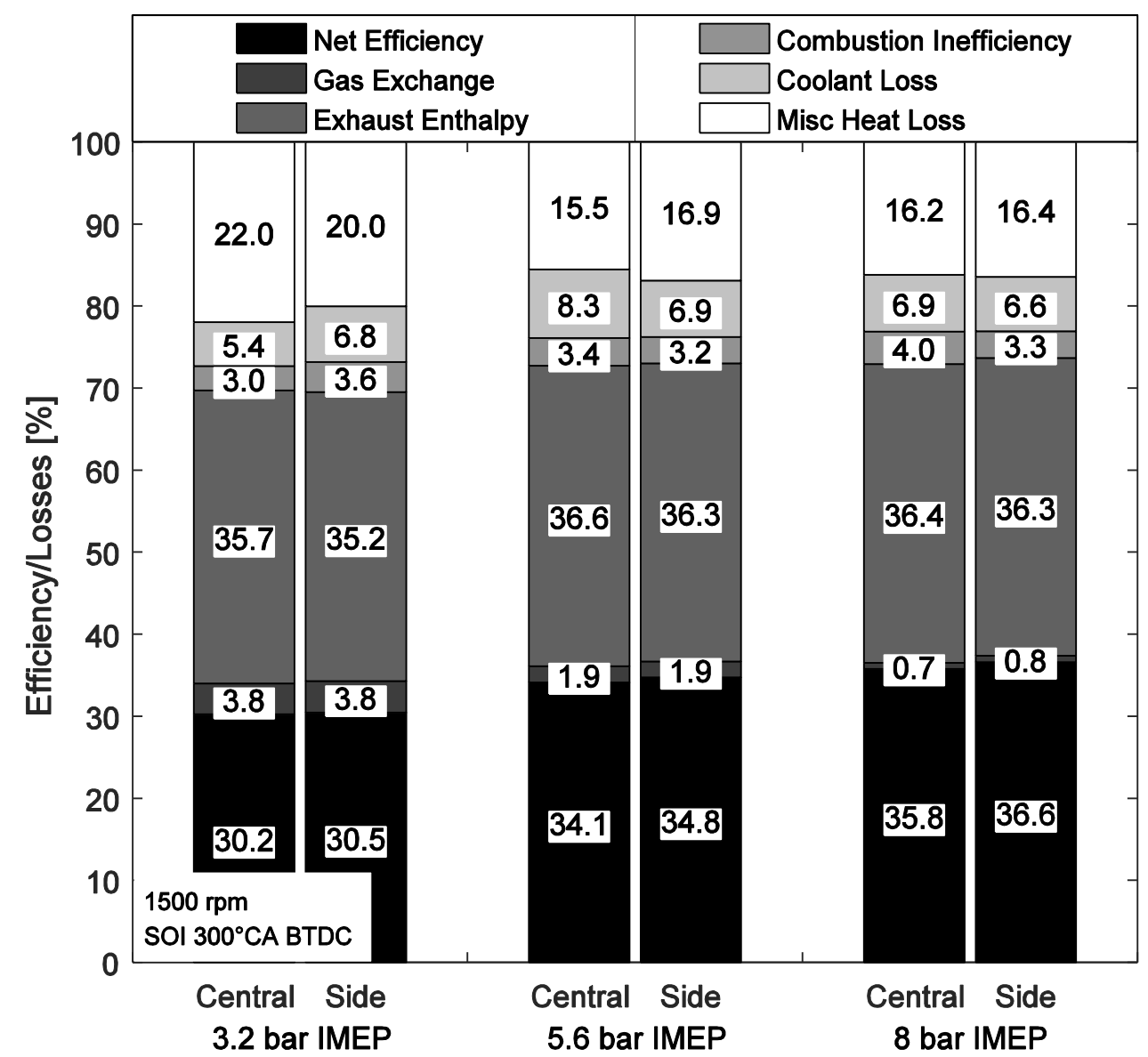

Figure 4.45: Energy Balance - Central and Side DI SOI 300 ${ }^{\circ} \mathrm{CA}$ BTDC, 3.2, 5.6 and 8 bar IMEP

For 3.2 bar IMEP, there is a $0.3 \%$ absolute net efficiency benefit to side DI. When increasing the load to 8 bar IMEP, the difference in net efficiency increased to $0.9 \%$ absolute. To further understand this net efficiency difference between central and side DI, the $\mathrm{CD}$ can be investigated as its duration relates back to the net efficiency. 
Figure 4.46 shows the $\mathrm{CD}$ for central and side DI at SOI $300^{\circ} \mathrm{CA}$ BTDC. For this condition, there was a negligible difference in the CD for 3.2 bar IMEP. However, increasing the engine load to 5.6 and 8 bar IMEP led to a 2.6 and $2.7^{\circ} \mathrm{CA}$ difference in the CD between central and side DI, respectively. As it has been shown, central DI injects directly into the tumble while side DI injects along the tumble. It is plausible that as the mass flowrate of air increases, flow velocities increase enough to overcome some the poor interaction from central DI and provide a reduction in the CD. At the same time, because side DI is reduced by a greater amount, this shows that the charge motion from side DI is complimentary to the tumble.

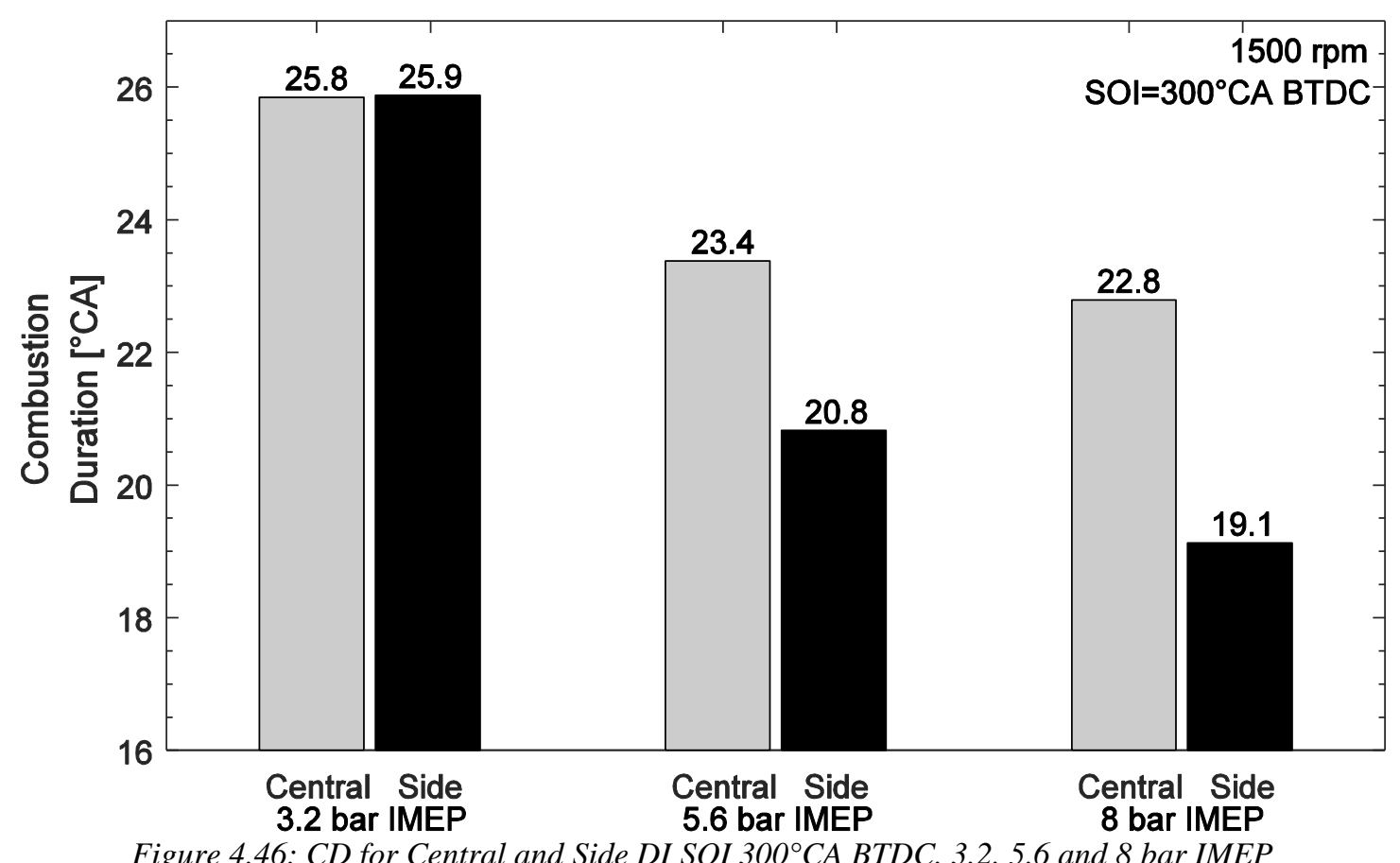


Gas exchange losses were similar between central and side DI at 3.2, 5.6, and 8 bar IMEP because the same amount of throttling was required for each respective condition between central and side DI. There is a lower amount of remaining exhaust enthalpy for side DI at 3.2 and 8 bar IMEP. As seen in Figure 4.47, side DI resulted in a lower EGT for 3.2 and 8 bar IMEP, lowering the exhaust enthalpy. Despite the lower EGT of side DI at 5.6 bar IMEP, a slightly higher mass flowrate across the engine may have increased the enthalpy.

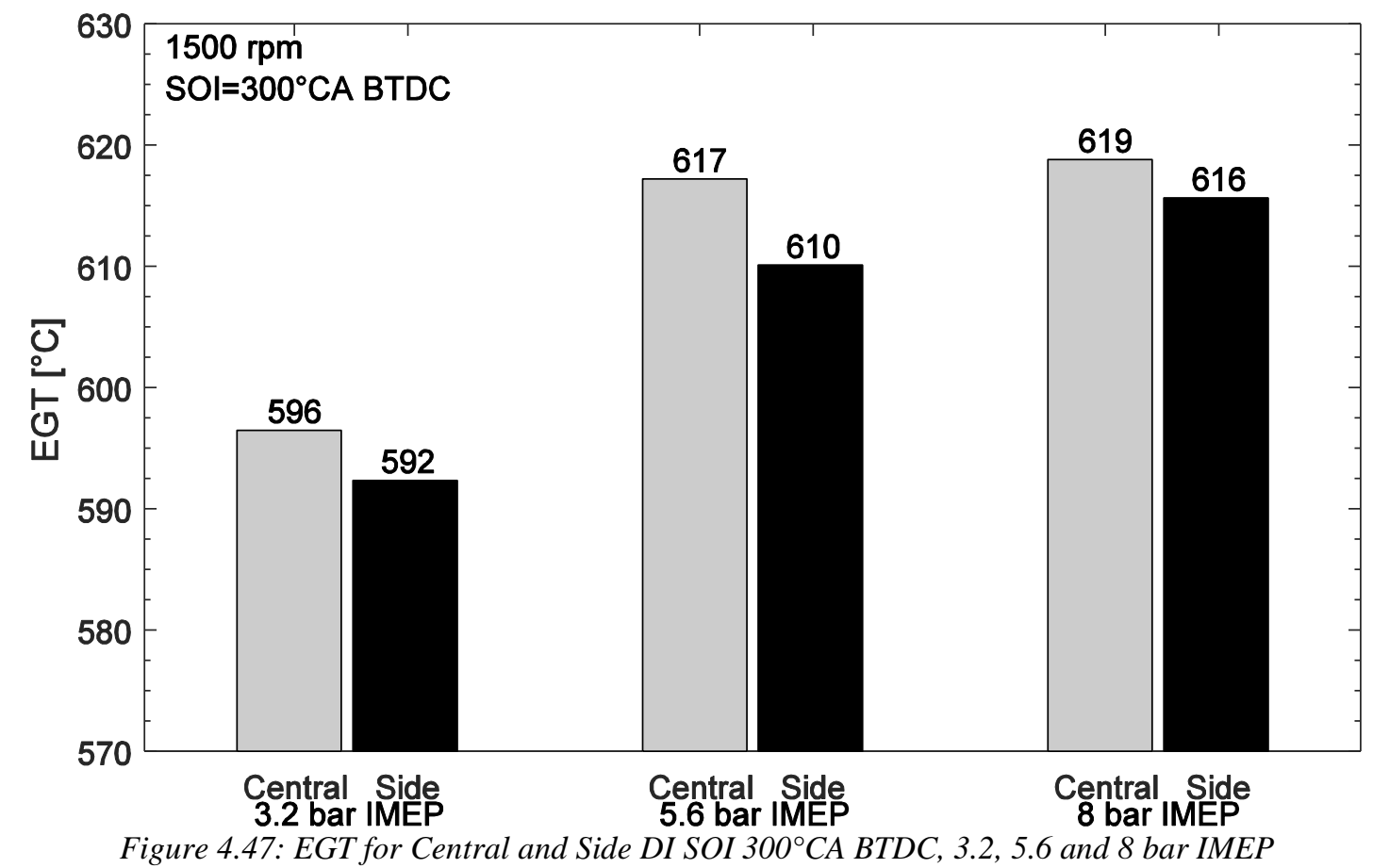

As seen in Figure 4.44, side DI provided a lower combustion inefficiency, except for 3.2 bar IMEP where the combustion inefficiency was higher than central DI by $0.6 \%$ absolute. In order to better understand this, an analysis of the combustion inefficiency is required. 
Figure 4.48 shows the iSHC emissions for central and side DI at SOI $300^{\circ} \mathrm{CA}$. For the 3.2 bar condition, there is a $17 \%$ difference in iSHC emissions for central and side DI. However, increasing the load to 5.6 bar IMEP decreased the difference to $8 \%$, which is consistent with findings in Figure 4.9. Finally, once the engine load was increased to 8 bar IMEP, the difference in iSHC emissions became less than $2 \%$. As the engine load was increased, the mass flow rate of delivered fuel and air also increased. It is conceivable that as the engine load was increased, in-cylinder turbulence levels increased improving mixture ignitability, allowing for a reduction in unburned fuel regardless of injection location. The elevated iSHC emissions for side DI at 3.2 and 5.6 bar IMEP is again possibly due to the higher charge motion pushing fuel towards the crevice volume.

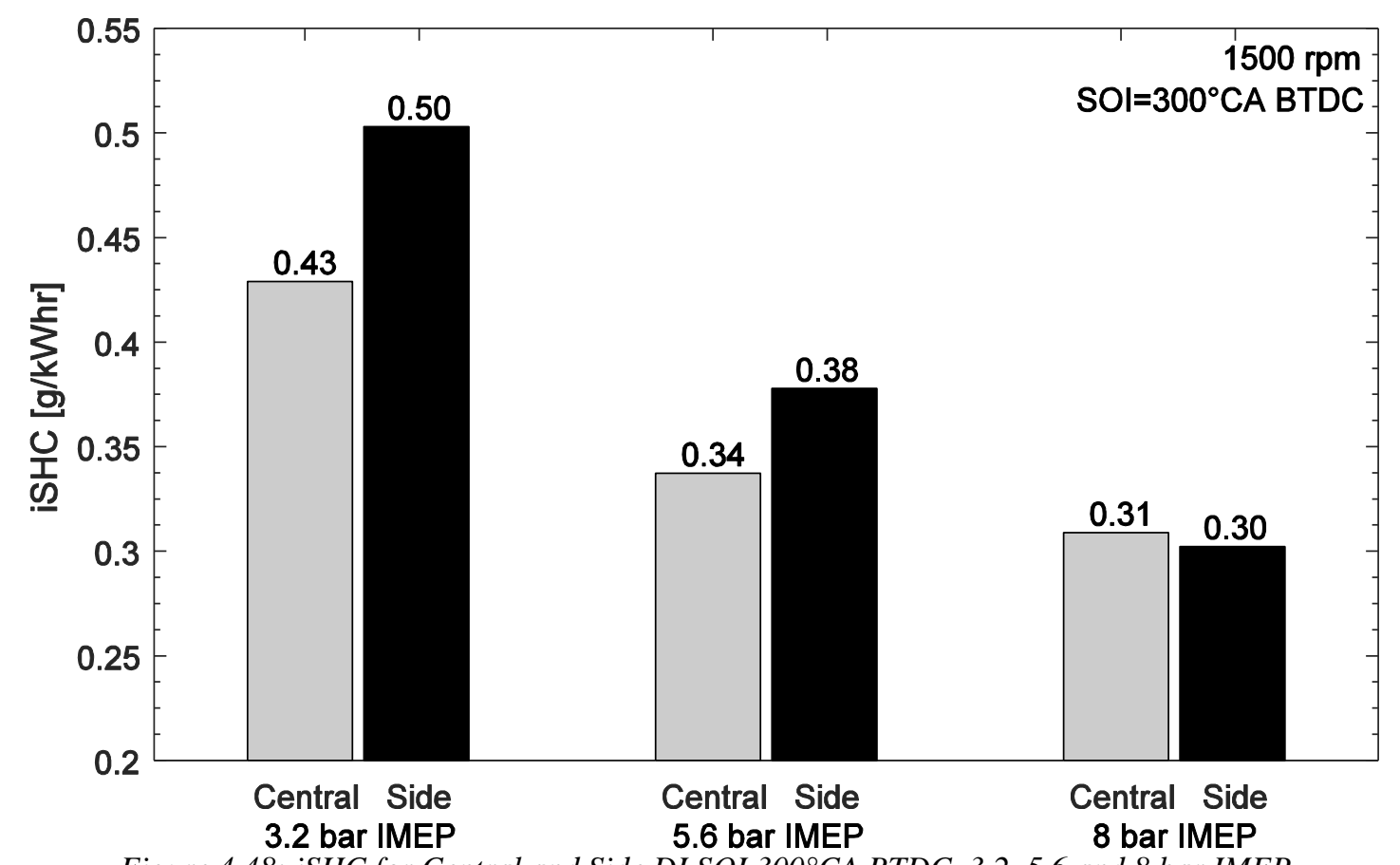

Figure 4.48: $i$ SHC for Central and Side DI SOI $300^{\circ} \mathrm{CA}$ BTDC, 3.2, 5.6 and 8 bar IMEP 
Figure 4.49 shows the iSCO emissions for central and side DI at SOI $300^{\circ} \mathrm{CA}$. While side DI generally shows an improvement over central DI, in Figure 4.49 side DI results in $23 \%$ higher iSCO emissions at 3.2 bar IMEP. It was shown in Figure 4.6 that central and side DI at SOI $300^{\circ} \mathrm{CA}$ BTDC reverse the tumble motion for 5.6 bar IMEP. It is possible that at 3.2 bar IMEP, the reverse tumble motion of side DI causes some disruption in the mixing, leading to more inhomogeneity. In addition, the emissions based lambda value deviates no more than $0.7 \%$ between central and side for a given load, providing further indication that any change in iSCO is due to in-cylinder mixing.

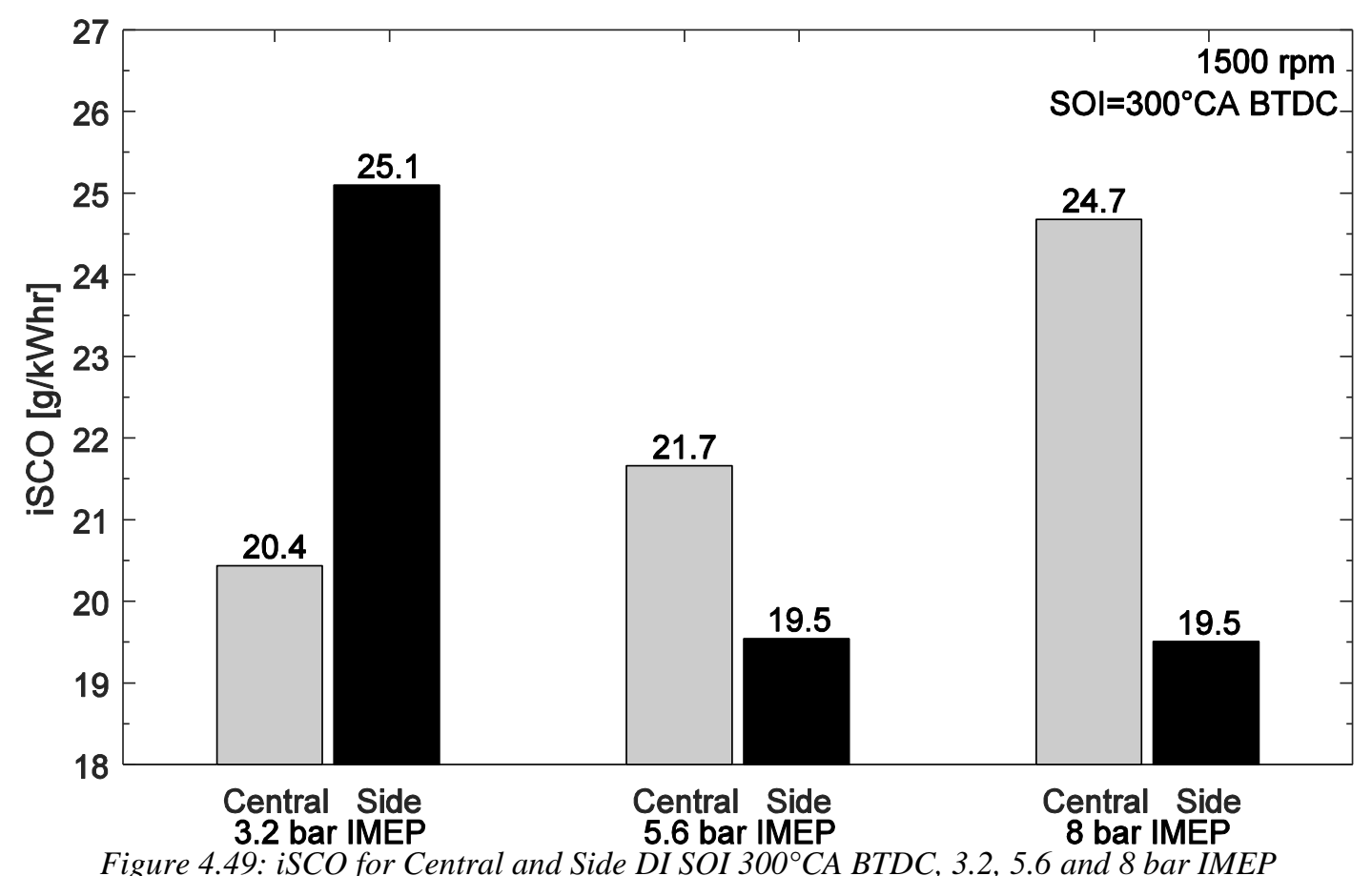


At 3.2 bar IMEP, side DI shows a higher amount of heat rejected to the coolant loop. It is plausible that under lower massflow conditions, the reverse tumble motion of side DI results in higher wall heat losses. However, as engine load is increased to 5.6 and 8 bar IMEP, central DI shows a higher loss to the coolant loop. It is again conceivable that due to the neutral path of the injection event, more heat is rejected to the piston. If there was a higher amount of heat rejected to the coolant loop for central DI, such as 5.6 bar and 8 IMEP, the miscellaneous heat transfer losses decreased. The miscellaneous heat loss term would decrease due to lower amount of fuel energy remaining to be lost to heat. At the same time, the miscellaneous heat term could also increase due to higher radiative heat losses in the exhaust, shown by the higher EGT of central DI in Figure 4.47 . 


\subsubsection{SOI $240^{\circ} \mathrm{CA}$ BTDC Analysis}

An energy balance was performed in Figure 4.50 for central and side DI at SOI $240^{\circ} \mathrm{CA}$ BTDC as the load was swept from 3.2, 5.6, and 8 bar IMEP.

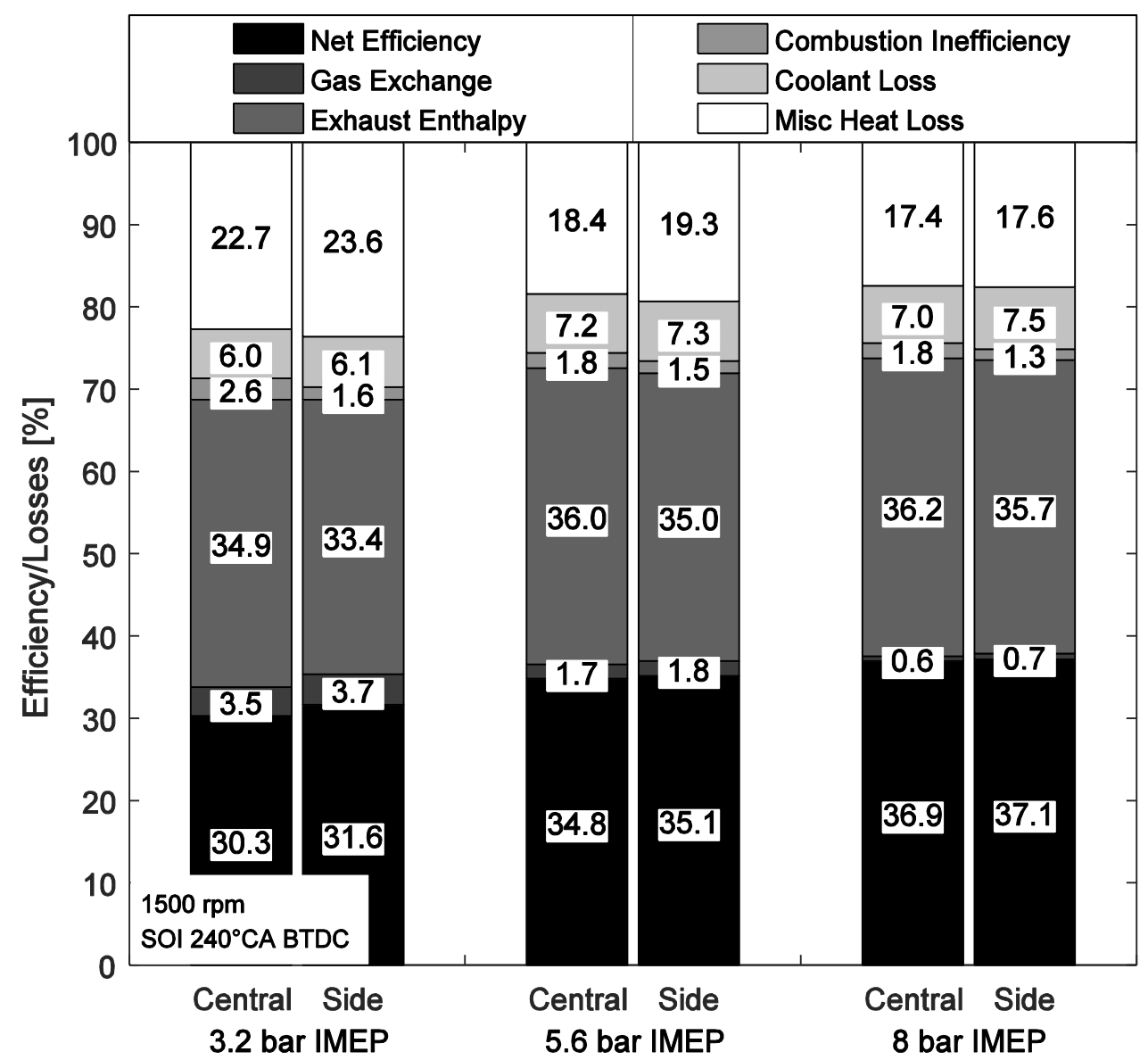

Figure 4.50: Energy Balance - Central and Side DI SOI $240^{\circ} \mathrm{CA}$ BTDC, 3.2, 5.6 and 8 bar IMEP

For 3.2 bar IMEP, there is a $1.3 \%$ absolute improvement in the net efficiency when transitioning from central to side DI. However, as the engine load was increased the difference in net efficiency between central and side DI reduced to 0.3 and $0.2 \%$ absolute at 5.6 and 8 bar IMEP, respectively. It is possible that as in-cylinder turbulence increases with increasing air mass flow rate, the effects of the gaseous injection event begin to become damped out, somewhat reducing the benefit of side DI at this SOI. 
As it has already been stated, for a constant volume combustion cycle, a shorter CD leads to a higher efficiency. The CD for central and side DI at SOI $240^{\circ} \mathrm{CA}$ is shown in Figure 4.51. As can be seen, central DI leads to a constant reduction in the CD, while side DI does not decrease much. As the engine load was increased, the difference in CD between central and side DI decreased. This reduction in the difference in CD trends directly with the decreasing difference in net efficiency with central and side DI. It is again plausible that as the mass flowrate of air increases with increasing engine load, flow velocities increase enough to overcome some the poor interaction from central DI and reduce the CD.

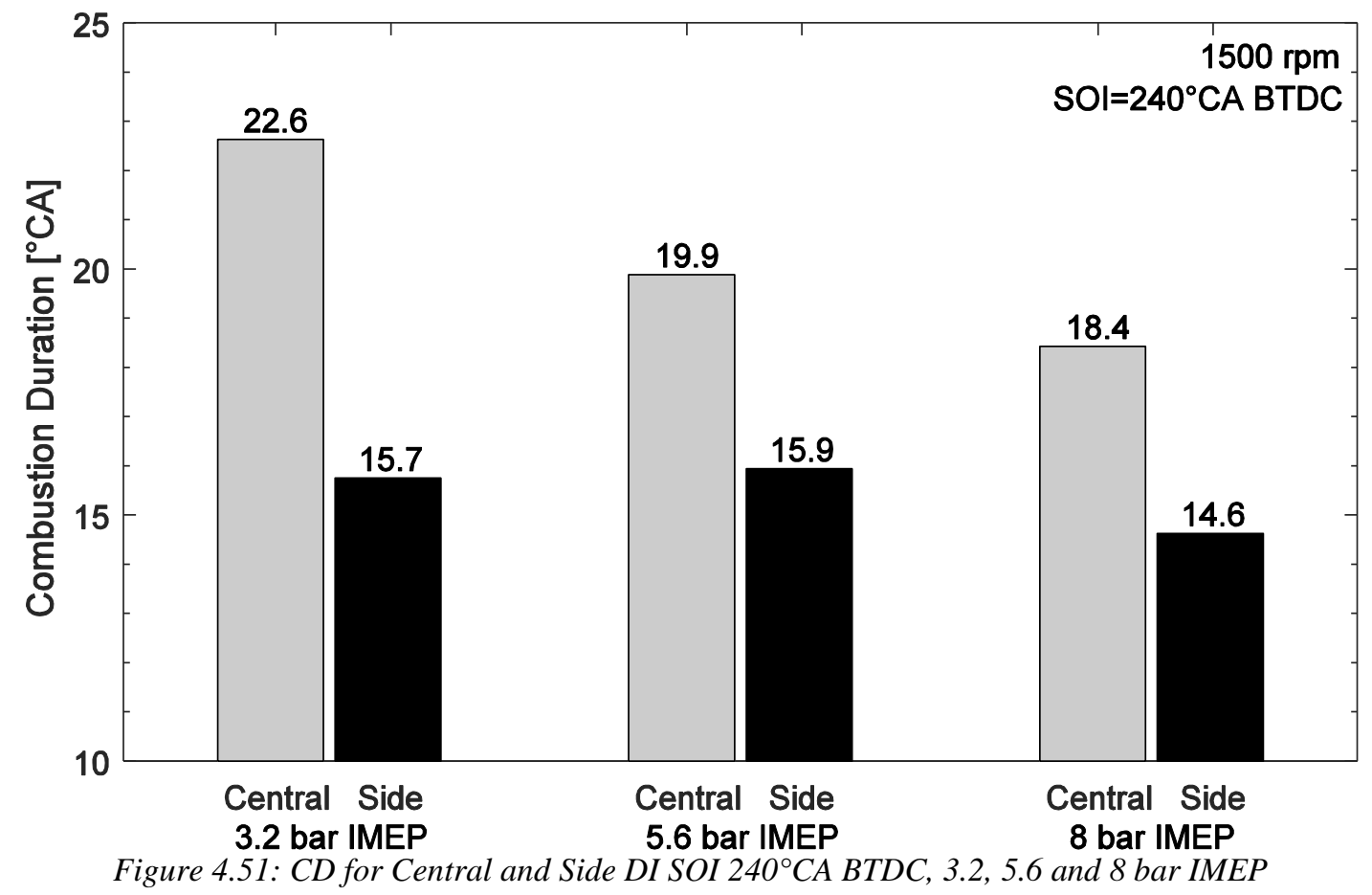


While gas exchange losses were slightly higher for side DI at 3.2 bar IMEP, it was not high enough to cause a drastic drop in the net efficiency. For 5.6 and 8 bar IMEP, gas exchange losses were effectively the same between central and side DI. For all load conditions, side DI results in lower exhaust enthalpy, explained by the lower EGT in Figure 4.52. In addition, as the engine load increased, the difference in exhaust enthalpy between central and side DI decreased, corresponding to a decreasing difference in EGT.

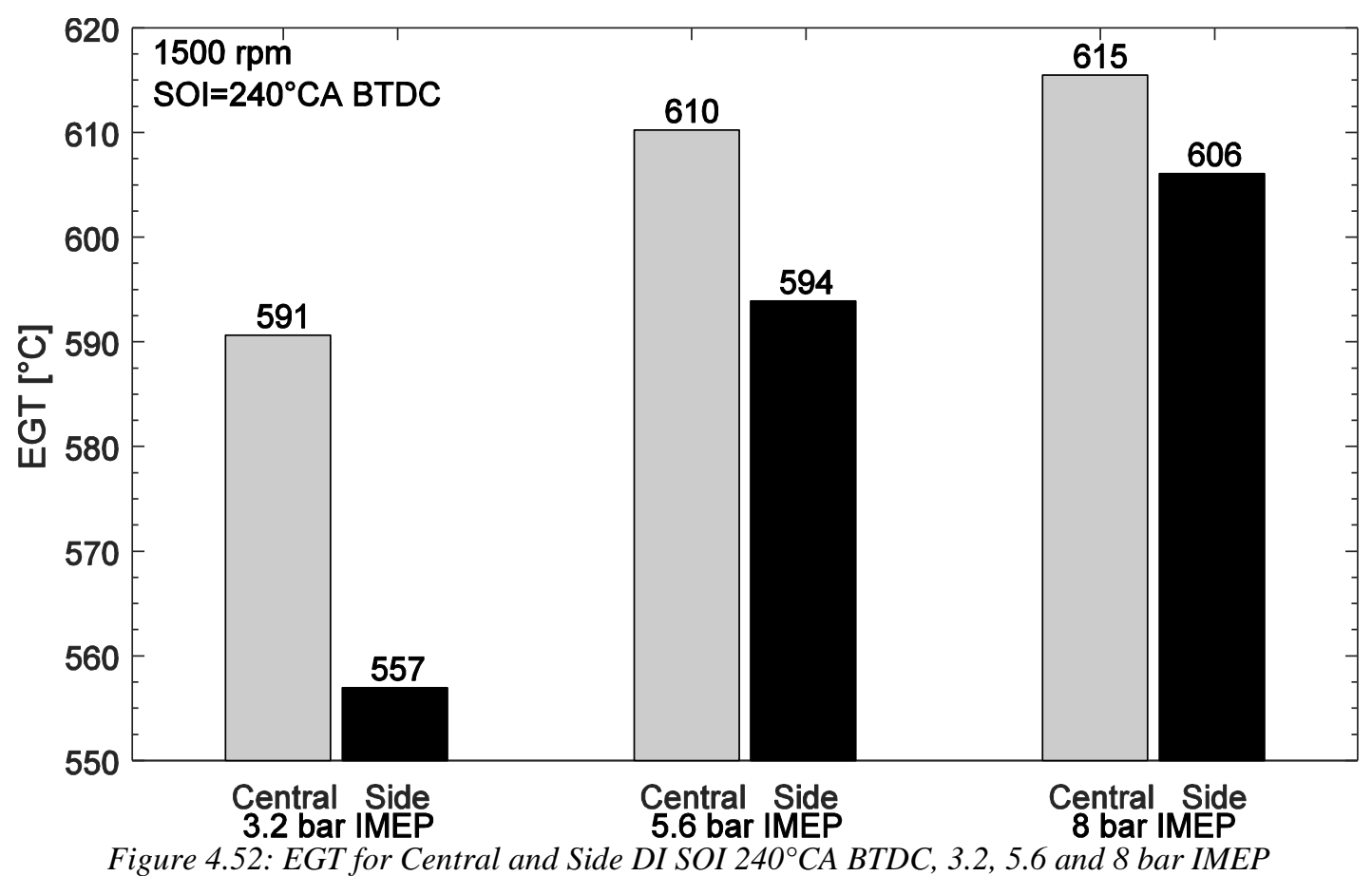


Side DI also results in lower combustion inefficiency for all load conditions; the two emission constituents that comprise this term can be investigated. Figure 4.53 shows the iSHC emissions for central and side DI at SOI $240^{\circ} \mathrm{CA}$ BTDC. There is an overall decreasing trend in iSHC emissions as the load is increased for central and side DI. As mentioned in Section 4.3.1, as the engine load increases, in-cylinder turbulence levels increase improving mixture ignitability, effectively reducing iSHC emissions. Also, there is still a consistent trend of side DI having higher iSHC emissions, especially for 3.2 bar IMEP. This again could be due to the greater tumble motion of side DI, pushing more unburned fuel into the crevice volume region.

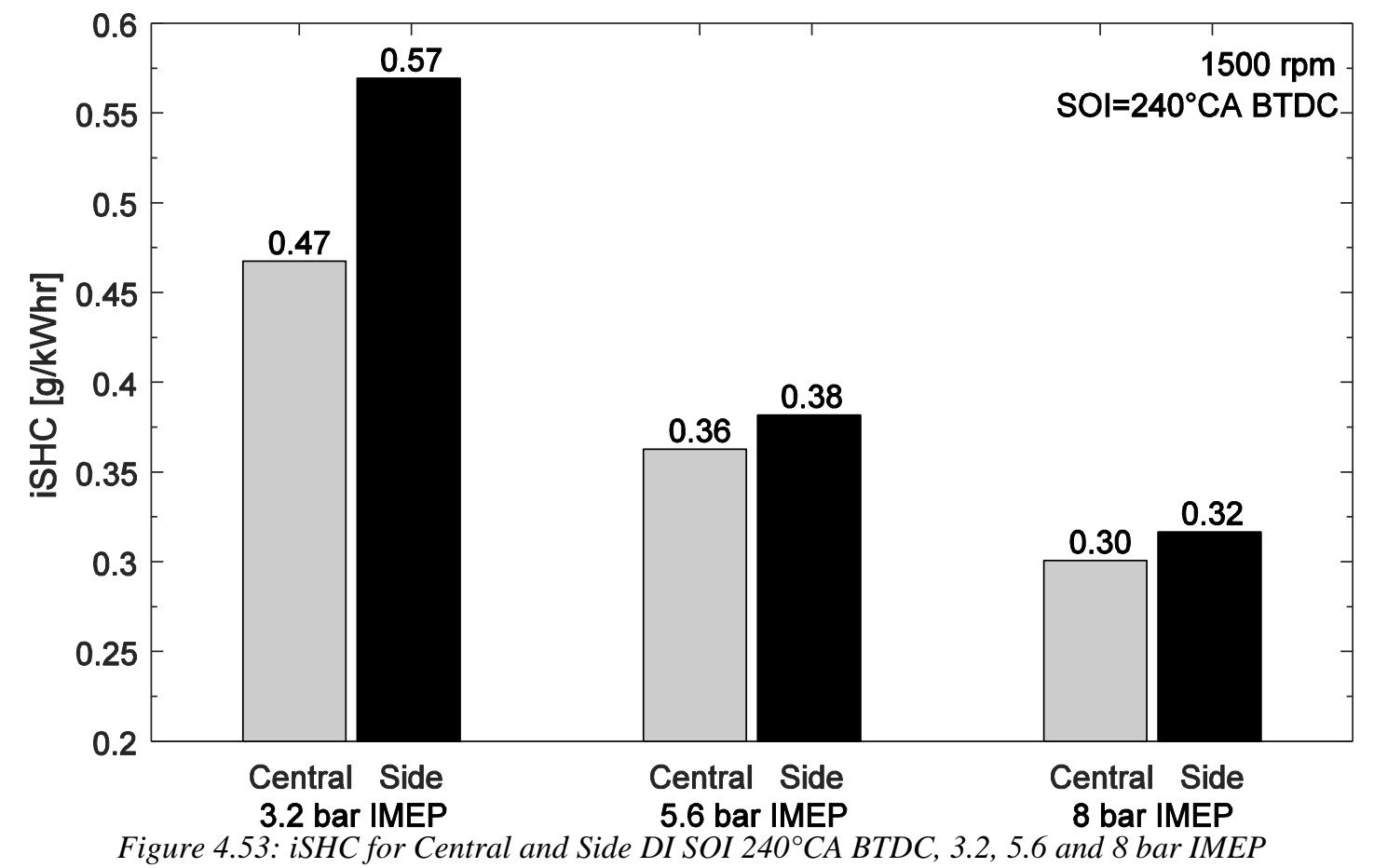


Figure 4.54 shows the iSCO emissions for central and side DI at SOI $240^{\circ} \mathrm{CA}$ BTDC. Consistent with Figure 4.53, iSCO emissions decreased with increasing engine load. While side DI does result in higher iSHC emissions likely due to the greater tumble motion pushing more fuel to the crevice volume, it also promotes better mixing within the cylinder. The more homogeneous mixture results in a reduction in iSCO emissions. This reduction in iSCO for side DI is greatest at 3.2 bar IMEP, decreasing iSCO emissions by 2.5 times, exemplifying the improved mixing with side DI. The difference between lambda for central and side DI for a given load is less than $0.8 \%$ for SOI $240^{\circ} \mathrm{CA}$ BTDC. Despite increased iSHC emissions, the constant reduction in iSCO emissions for side DI leads to lower combustion inefficiency for all load conditions presented.

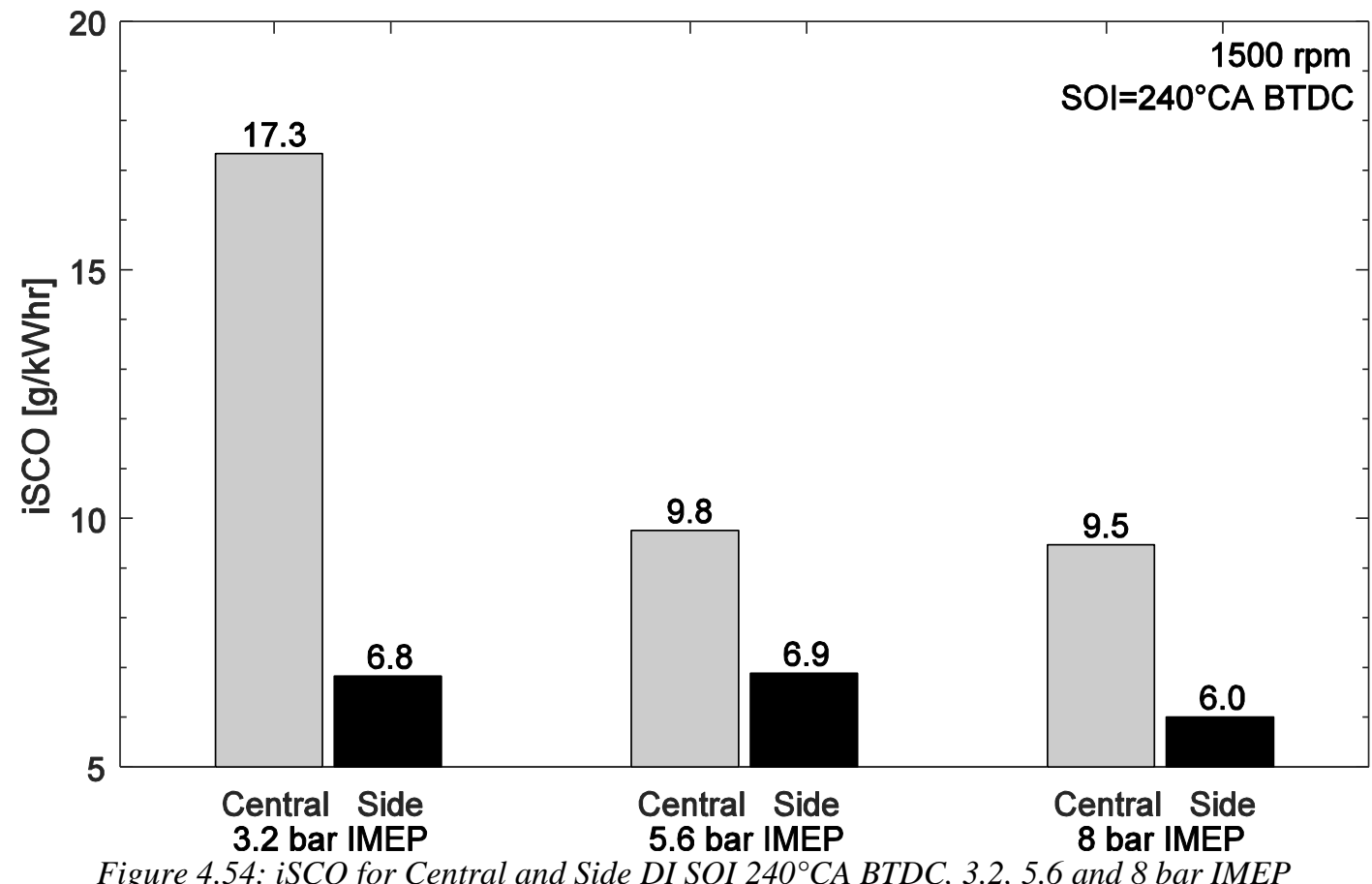

For all load conditions presented in Figure 4.50, side DI results in a greater amount of coolant heat transfer and miscellaneous heat losses at SOI $240^{\circ} \mathrm{CA}$ BTDC. It was introduced in Section 4.1.2 that an increase in charge motion can lead to an increase in heat transfer losses. As shown in Figure 4.51, side DI results in a shorter CD for all conditions relative to central DI. It is therefore conceivable that the shorter CD of side DI due to an increase in charge motion leads to an increase in coolant heat transfer and miscellaneous heat losses. 


\subsubsection{SOI $120^{\circ} \mathrm{CA}$ BTDC Analysis}

An energy balance was performed for central and side DI at SOI $120^{\circ} \mathrm{CA}$ BTDC as the load was swept from 3.2, 5.6, and 8 bar IMEP, shown in Figure 4.55.

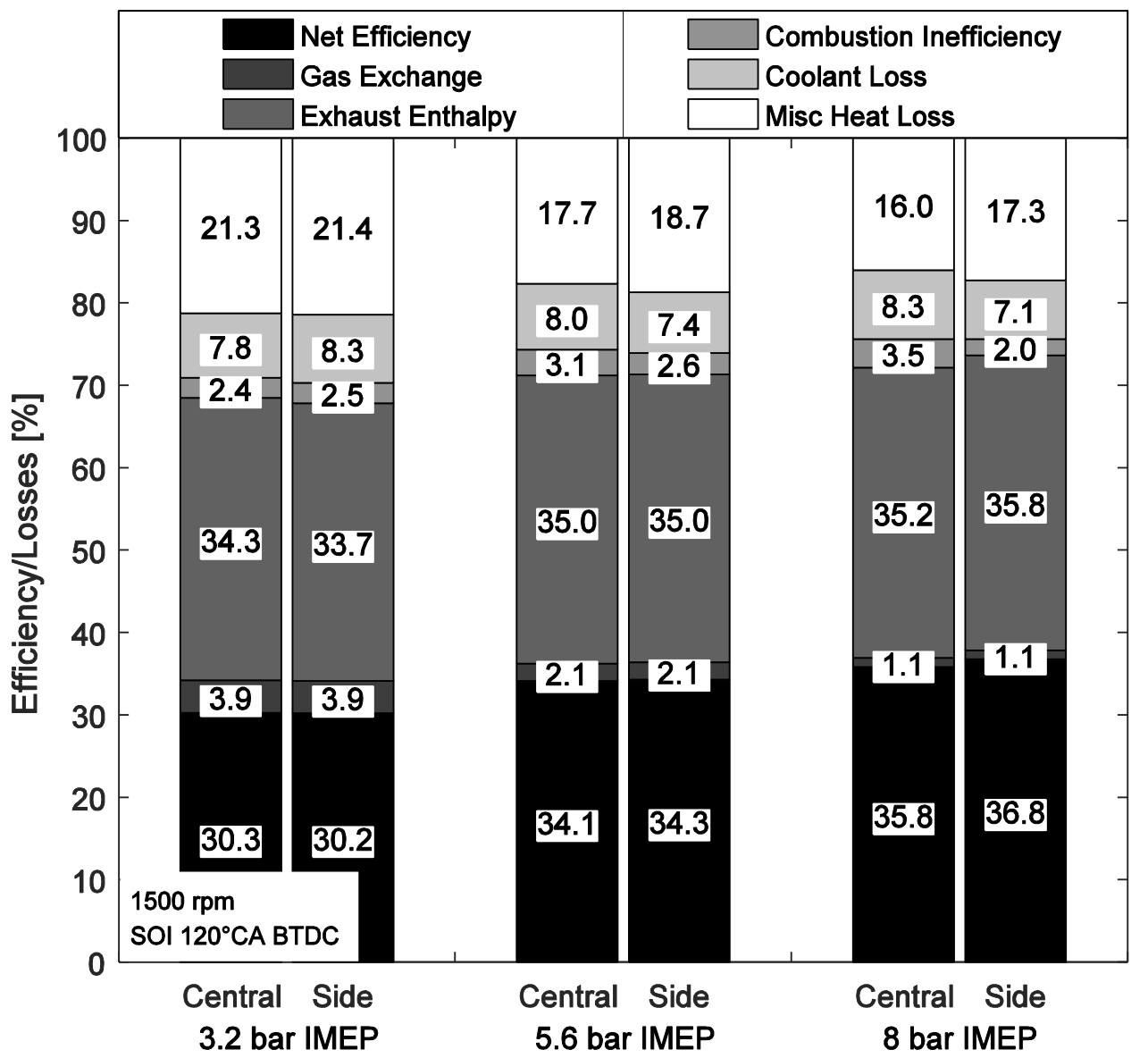

Figure 4.55: Energy Balance - Central and Side DI SOI $120^{\circ} \mathrm{CA}$ BTDC, 3.2, 5.6 and 8 bar IMEP

The difference in net efficiency between central and side DI begins to increase as engine load increases. The greatest different in net efficiency occurs at 8 bar IMEP, with side DI being $0.9 \%$ absolute higher. At SOI $120^{\circ} \mathrm{CA} \mathrm{BTDC}$, there is a decrease in available mixing time compared to SOI 300 and $240^{\circ} \mathrm{CA}$ BTDC. Despite the shorter mixing time, the improved mixing of side DI leads to a higher net efficiency. 
The CD for central and side DI at SOI $120^{\circ} \mathrm{CA}$ BTDC for all three load conditions is shown in Figure 4.56. In previous discussions, the CD was able to help explain the improvement in net efficiency; however, there is not a strong connection for these conditions. At 3.2 bar IMEP, side DI reduces the $\mathrm{CD}$ by $1.7^{\circ} \mathrm{CA}$ yet results in the same net efficiency as central DI. This indicates there are competing effects within the cylinder despite faster combustion event. At the same time, 5.6 bar IMEP yields the same CD with side DI having a $0.2 \%$ absolute benefit in net efficiency. The most striking trend is the $1.0 \%$ absolute improvement in net efficiency at 8 bar IMEP for side DI, yet central DI results in a $0.7^{\circ} \mathrm{CA}$ shorter $\mathrm{CD}$. Therefore, further analysis is required for these three conditions.

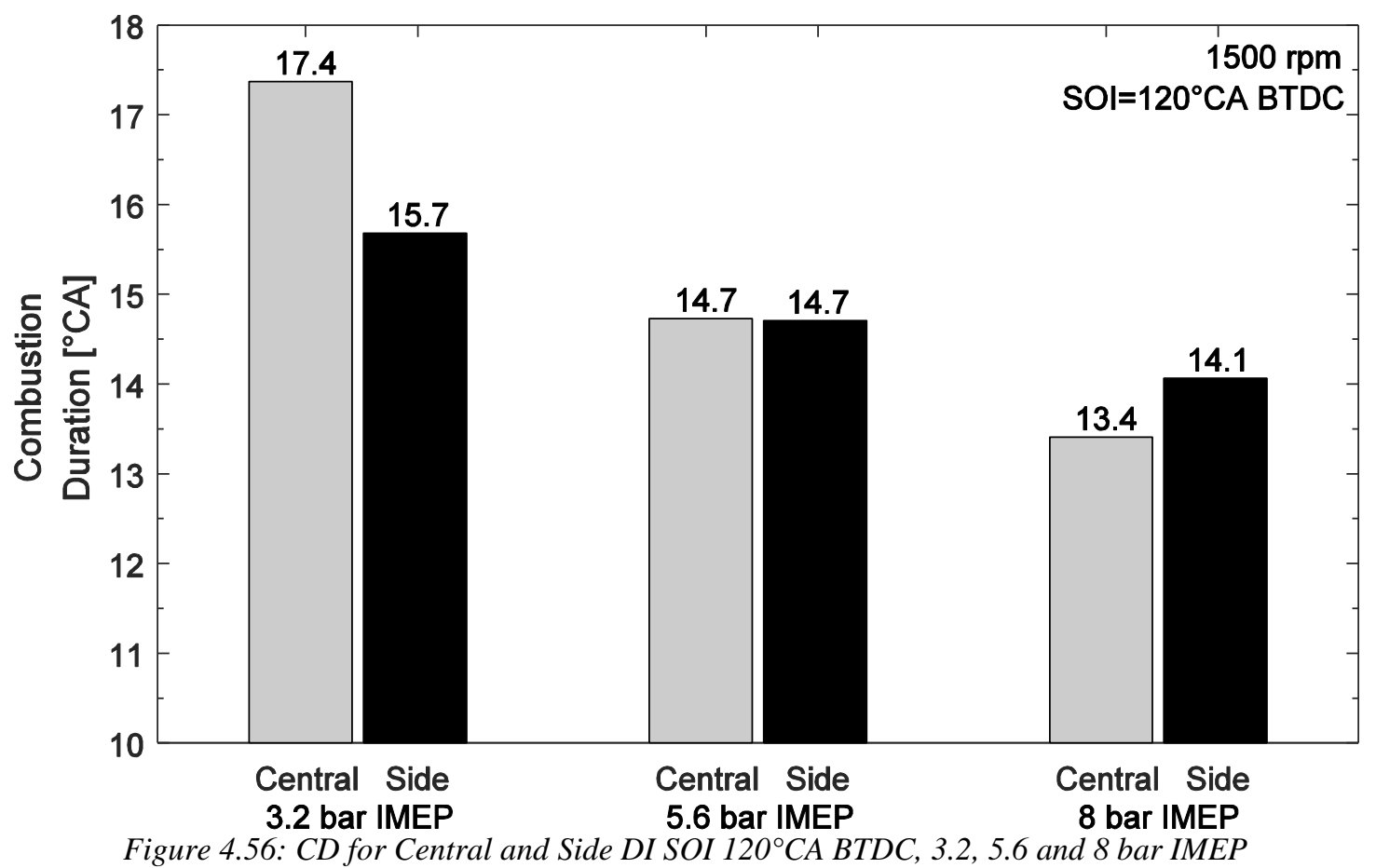


Because the shorter CD of central DI in Figure 4.56 was not anticipated, further investigation was required. Figure 4.57 shows the integrated heat release trace for central and side DI at 8 bar IMEP for SOI $120^{\circ} \mathrm{CA}$ BTDC. As can be seen, the heat release of central DI occurs sooner and at a slightly faster rate than side DI, explaining the shorter $\mathrm{CD}$. For reference, the ignition timing between the two test conditions were identical. For all conditions presented, MBT timing is held at $8 \pm 1^{\circ} \mathrm{CA}$ ATDC. The $50 \% \mathrm{MFB}$ location of central and side DI was 7.6 and $8.6^{\circ} \mathrm{CA}$ ATCD, respectively. It is conceivable that if the ignition timing of side DI at this condition was advanced by $1^{\circ} \mathrm{CA}$, the $\mathrm{CD}$ would be more similar.

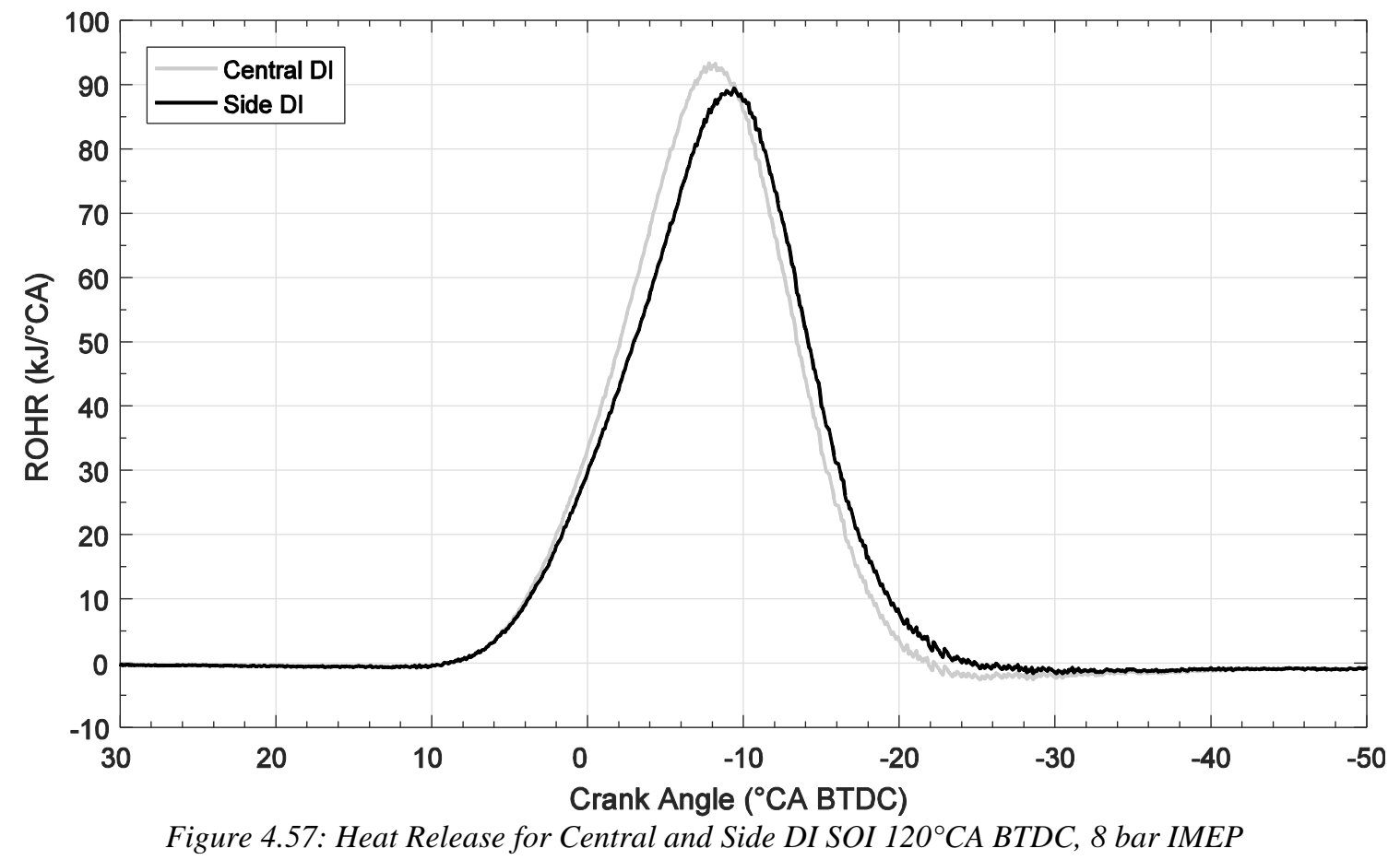

Gas exchange losses for these conditions are similar, due to the same amount of throttling required for central and side DI at each load condition. 
For the three load conditions presented, there is not a consistent trend in remaining exhaust enthalpy. 3.2 bar IMEP shows a decrease in exhaust enthalpy for side DI. Because Figure 4.58 shows that the EGT for side DI is $1^{\circ} \mathrm{C}$ greater than central DI, this indicates the lower exhaust enthalpy is due to a lower mass flow rate across the engine. 5.6 bar IMEP shows the same exhaust enthalpy between central and side DI. While Figure 4.58 shows $2.3^{\circ} \mathrm{C}$ difference in the EGT between central and side DI, central DI had a higher massflow across the engine. When operating at 8 bar IMEP, side DI results in $0.6 \%$ absolute higher remaining exhaust enthalpy. This is ultimately displayed by the $6.6^{\circ} \mathrm{C}$ difference in EGT.

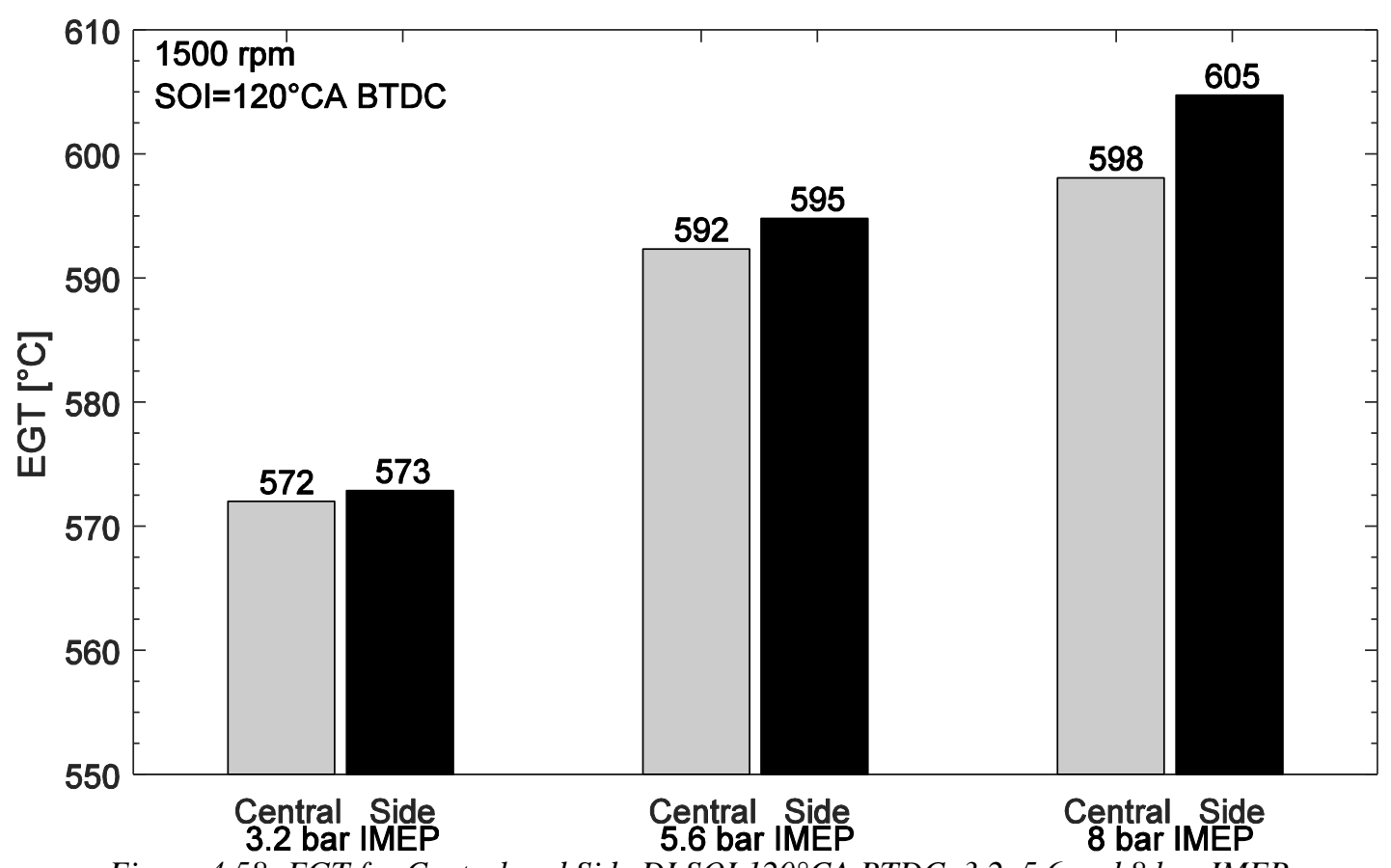

Figure 4.58: EGT for Central and Side DI SOI $120^{\circ} \mathrm{CA}$ BTDC, 3.2, 5.6 and 8 bar IMEP 
As the engine load was increased, there was a diverging trend in the combustion inefficiency. While there is a similar combustion inefficiency at 3.2 bar IMEP for central and side DI, this difference increases to up to $1.5 \%$ absolute at 8 bar IMEP. This divergence in combustion inefficiency can again be attributed to the favorable charge motion of side DI. To further understand this trend, iSHC and iSCO emissions can be investigated.

It has been shown in Sections 4.3.1 and 4.3.2 that iSHC emissions decrease with increasing engine load. The same trend can be found in Figure 4.59 for central and side DI at SOI $120^{\circ} \mathrm{CA}$ BTDC. For both 3.2 and 5.6 bar IMEP, side DI resulted in a greater amount of iSHC emissions, likely due to the added charge motion of side DI pushing more fuel to the crevice volume. However, this difference in iSHC emissions equalizes at 8 bar IMEP. It is possible that as the mass flow rate through the engine increases, the intrinsic turbulence of the engine overcomes any turbulence induced by the gaseous injection event.

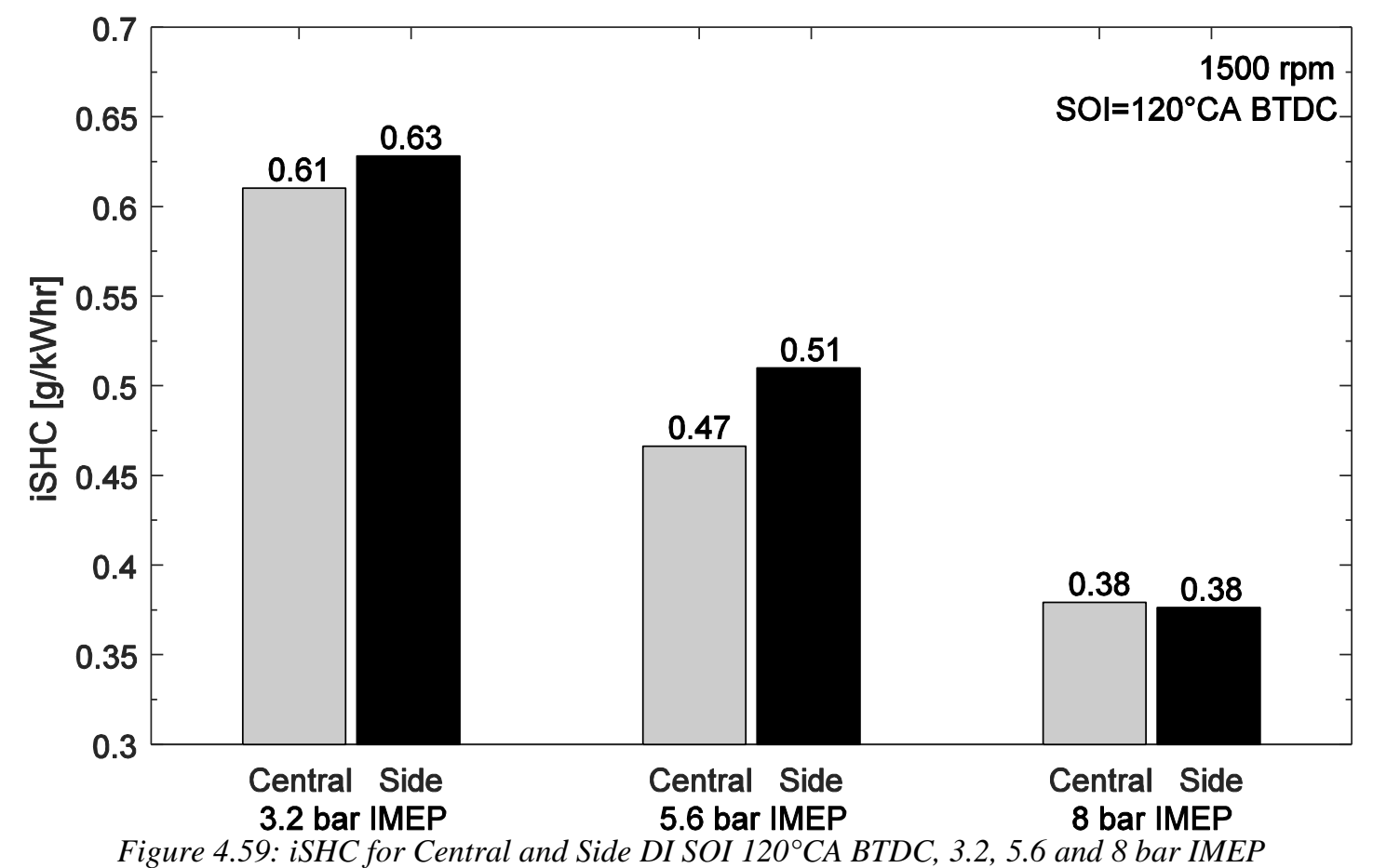


iSCO emissions for central and side DI are shown in Figure 4.60. There is a diverging trend in iSCO emissions between central and side DI as engine load increases, which can be explained from mixing. As the load increases for central, it is possible that the direct path of the injection disrupts the tumble motion, leading to increased non-uniformity. At the same time, it has been shown that side DI provides complimentary charge motion; as in-cylinder turbulence increases with increasing mass air flow, side DI can only benefit the mixing, hence the reduction in iSCO. For reference, the difference in the emissions based lambda value for all three conditions is less than $0.7 \%$. The energy balance in Figure 4.55 showed that there was a $1.0 \%$ absolute improvement in net efficiency for side DI at 8 bar IMEP. While the CD and iSHC emissions are the same between central and side, there is a factor of two difference in iSCO emissions. This large difference in iSCO emissions is one of the driving factors for the net efficiency difference at 8 bar IMEP.

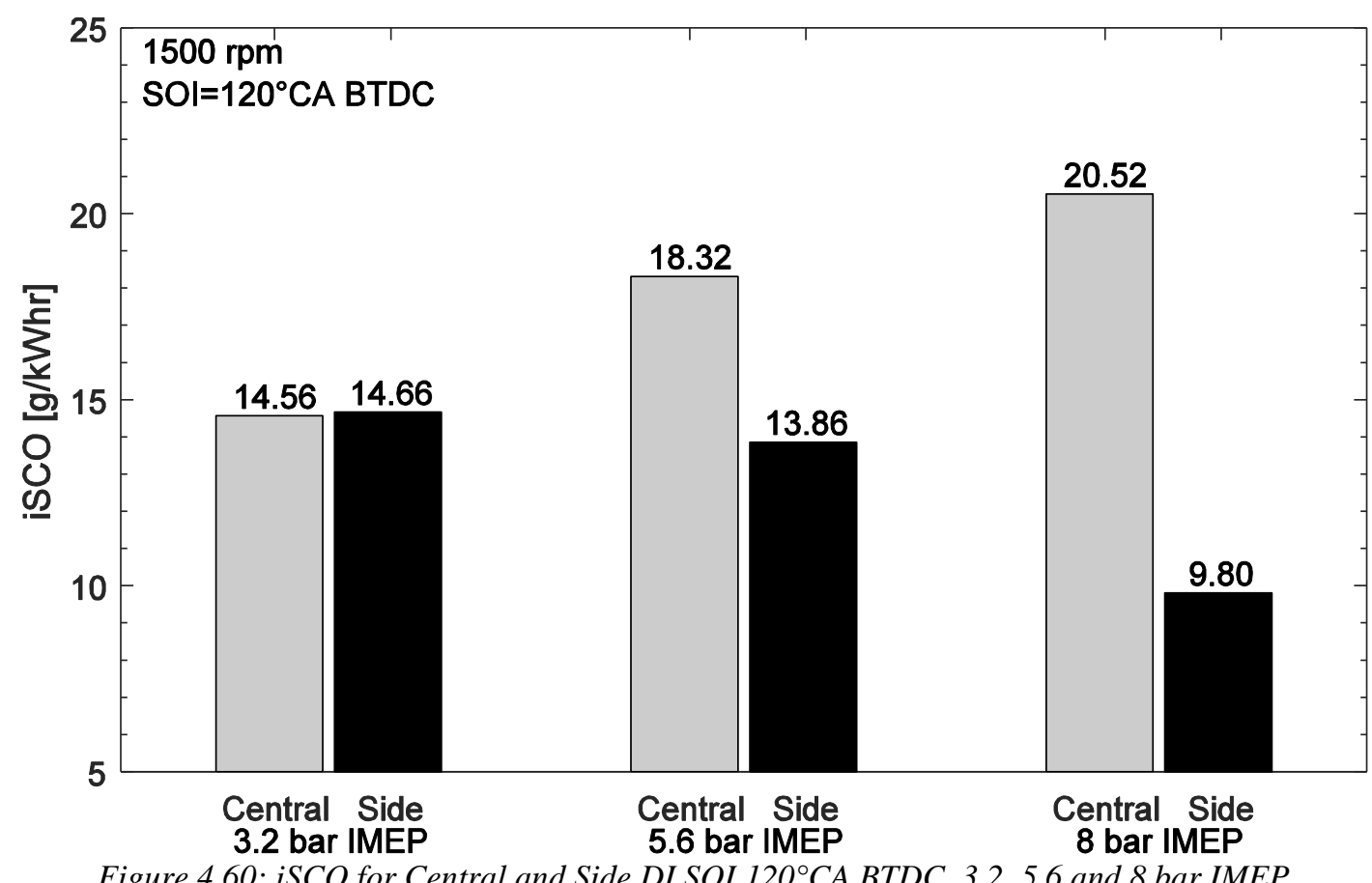

At the same time, the resulting heat losses tracked accordingly. If there was a lower loss due to exhaust enthalpy, such as the case for side DI at 3.2 bar IMEP, resulting heat losses were greater; the increase in heat losses could be due to wall heat transfer. In Figure 4.55 , central DI results in $0.8 \%$ absolute more heat rejected to the coolant loop. In previous sections, side DI resulted in increased heat rejection to the coolant loop, 
however, it was not enough to cause a large efficiency penalty. It is possible that combined with the greater amount of iSCO, the elevated heat transfer to the coolant loop caused an efficiency drop for central DI.

Side DI resulted in an increase in miscellaneous heat losses for all three load conditions. Figure 4.58 shows an increase in EGT for side DI at all load conditions. Therefore, the greater miscellaneous heat losses for side DI could be due to increased radiative heat transfer losses in the exhaust. 


\subsubsection{Summary for Varying Engine Load}

For central and side DI, as the engine load was swept from 3.2 to 8 bar IMEP and the SOI from 300 to $120^{\circ} \mathrm{CA} \mathrm{BTDC}$ for each load step, the effects of the gaseous injection event became clear. Regardless of injection location and engine load, it was shown that SOI $240^{\circ} \mathrm{CA} \mathrm{BTDC}$ is an optimal injection time for this test setup. However, as the engine load was increased for SOI 300 and $120^{\circ} \mathrm{CA}$ BTDC, the difference in net efficiency between central and side DI diverged. It is possible that with the increasing mass flowrate of air, central DI damped the increasing turbulence while side DI promoted it.

The constant reduction in $\mathrm{CD}$ for all conditions led to an increase in net efficiency. The $\mathrm{CD}$ for central and side DI at SOI $120^{\circ} \mathrm{CA}$ BTDC remained very similar. Interestingly enough, side DI had a 1\% absolute improvement in net efficiency relative to central DI at 8 bar IMEP and SOI $120^{\circ} \mathrm{CA}$ BTDC. While this central DI had a shorter CD for this condition, the large difference in net efficiency has shown to be a strong function of mixing. 


\subsection{PFI v. DI ${ }^{4}$}

NG DI has shown to be a promising alternative to NG PFI, with one of the large benefits at full load conditions. Because the fuel is injected directly into the cylinder, no air displacement occurs in the intake manifold and the full load power density is improved [27]. At the same time, delaying the start of injection can also improve the volumetric efficiency, increasing full load power density for a given MAP. As discussed in Section 2.1, production NG vehicles may have the EGR loop removed from the factory due to poor dilution tolerance associated with the combination of NG and NG PFI [17]. Because it has been shown both in literature [21] and experimentally that NG DI can increase in-cylinder charge motion, it is important to draw a comparison between NG PFI and DI.

An EGR sweep was therefore performed at $1500 \mathrm{rpm} 5.6$ bar IMEP for NG PFI and side DI. Consistent with Section 4.2, the EGR rate was increased for each condition until the $3 \% \mathrm{COV}_{\text {IMEP }}$ stability criteria was met. Because previous investigations have shown there to be minimal impact of SOI for NG PFI [27], only one SOI value was tested.

SOI $540^{\circ} \mathrm{CA}$ BTDC was chosen to provide ample mixing time. For comparison purposes, only side DI at SOI $240^{\circ} \mathrm{CA}$ BTDC was used. This combination of injection location and SOI has shown to result in the greatest net efficiency and lowest combustion inefficiency.

4 The data for side DI presented in Section 4.4 is the same test conditions performed for side DI in Section 4.2. However, as indicated in Section 3.10, the data set collected for this section was collected nearly one full calendar year after data collected in Section 4.2. Therefore, absolute magnitudes of variables for side DI may differ between the two sections. 


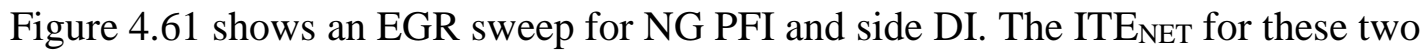
conditions begins to increase as the EGR rate was increased. NG PFI and side DI at SOI $240^{\circ} \mathrm{CA} \mathrm{BTDC}$ result in the same maximum net efficiency of $36.2 \%$, at $14.4 \%$ EGR. Interestingly enough, side DI sustains $2.6 \%$ more EGR and maintains the same ITE $_{\text {NET }}$ before an efficiency loss occurs.

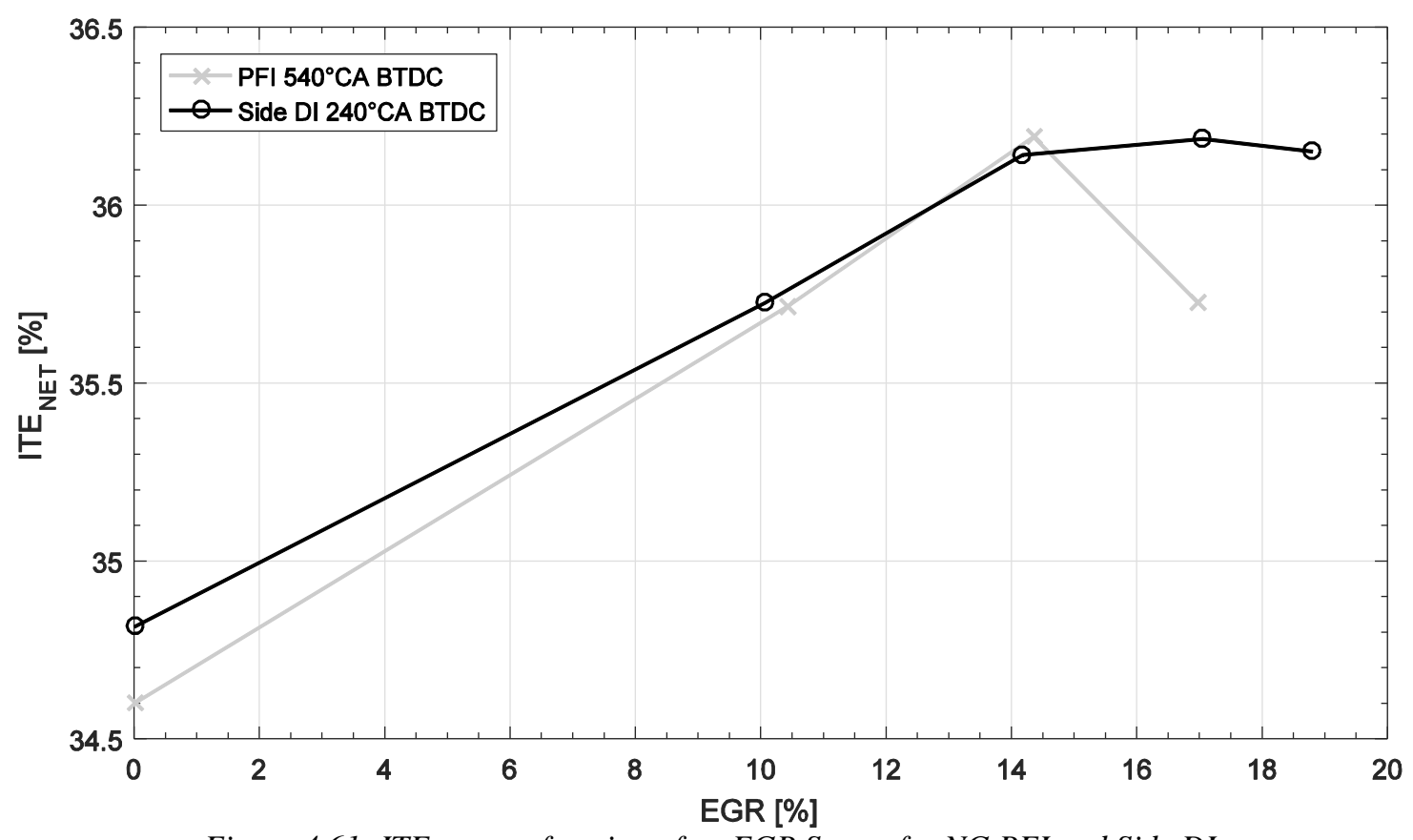

Figure 4.61: ITE $E_{N E T}$ as a function of an EGR Sweep for NG PFI and Side DI 
The $\mathrm{COV}_{\text {IMEP }}$ as a function of an EGR sweep for NG PFI and side DI is shown in Figure 4.62. NG PFI and side DI result in a dilution tolerance of $15.7 \%$ and $17.5 \%$, respectively. The $1.8 \%$ absolute extended dilution tolerance of side DI is likely due to the added charge motion from the gaseous injection event. Literature has shown that a faster developing flame kernel can lead to a higher dilution tolerance [7]. For reference, the FDA for NG PFI and side DI under zero EGR is 20.0 and $15.2^{\circ} \mathrm{CA}$, respectively.

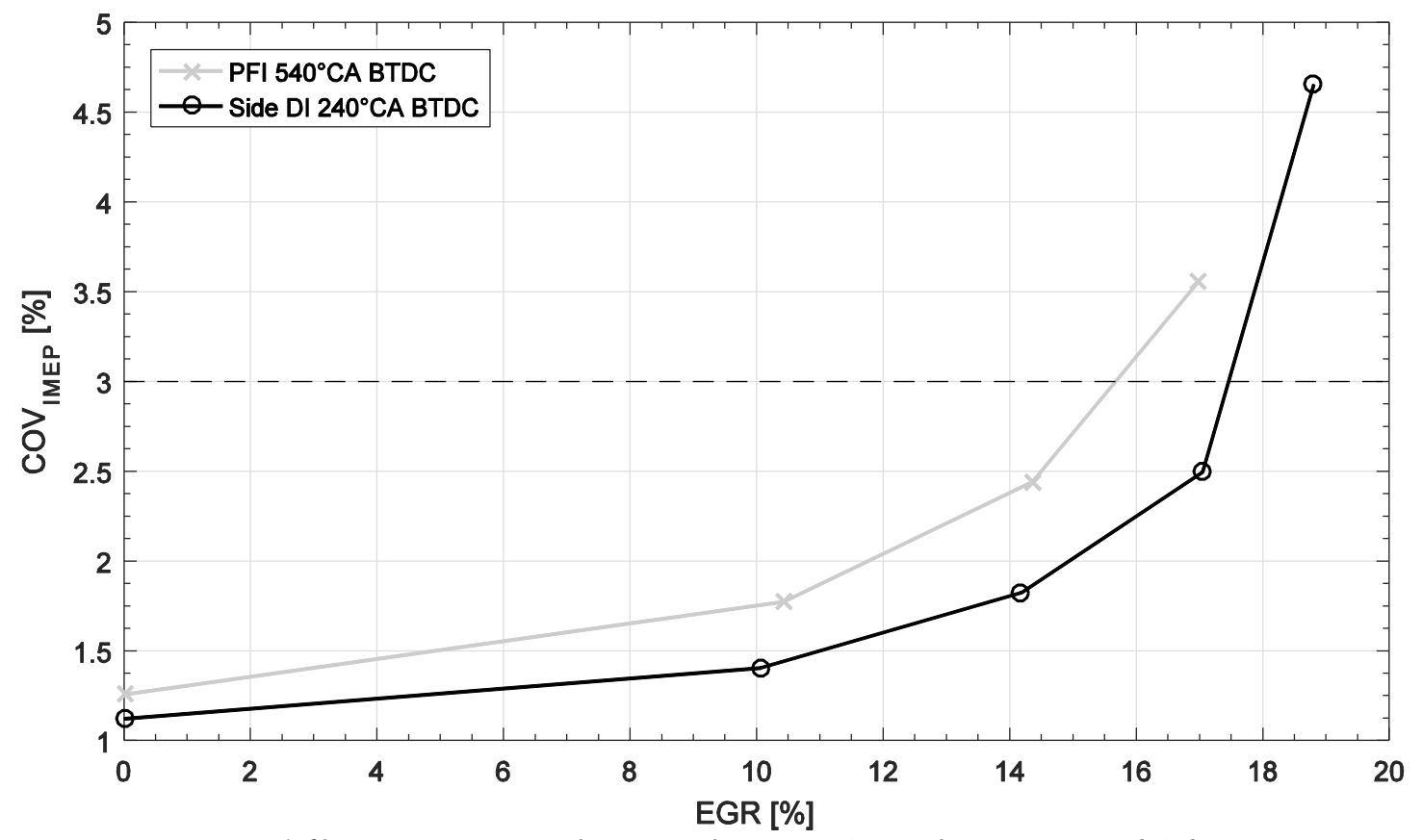

Figure 4.62: COVIMEP as a function of an EGR Sweep for NG PFI and Side DI

For previous energy balances performed, similar EGR rates were chosen when comparing two injection systems. However, it has already been shown one of the main benefits of NG DI is the added charge motion, which is reaffirmed by the $1.8 \%$ absolute extension in EGR rate. Therefore, $\sim 14.4 \%$ and $17.0 \%$ EGR were chosen for analysis for PFI and side DI, respectively. These EGR rates represent an appreciable increase in net efficiency, while also remaining below the stability limit. 


\subsubsection{Zero EGR}

Figure 4.63 shows the energy balance applied for NG PFI and side DI under zero EGR conditions. For this condition, there was a $0.2 \%$ absolute difference in the net efficiency between NG PFI and side DI. The resulting losses shown in Figure 4.63 can be investigated in order to understand the differences in net efficiency.

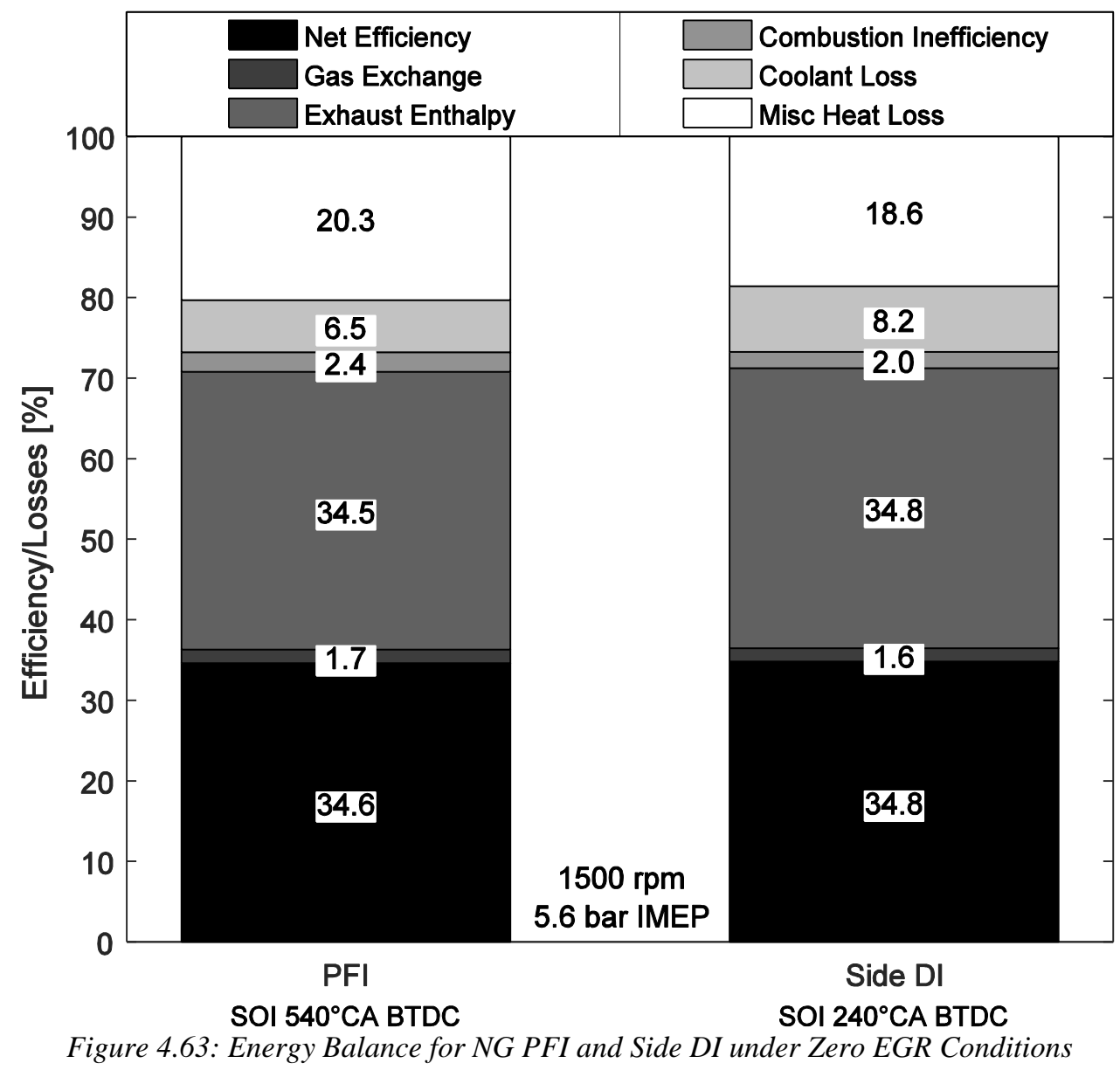


As the $\mathrm{CD}$ has been shown to have a strong connection to the net efficiency, the $\mathrm{CD}$ for these conditions are shown in Figure 4.64. Under zero EGR conditions, there was a $3.1^{\circ} \mathrm{CA}$ difference in the CD between NG PFI and side DI, providing indication for the higher efficiency of side DI. The faster CD of side DI can be attributed to the increased charge motion of the gaseous injection event, providing an increase to the tumble motion.

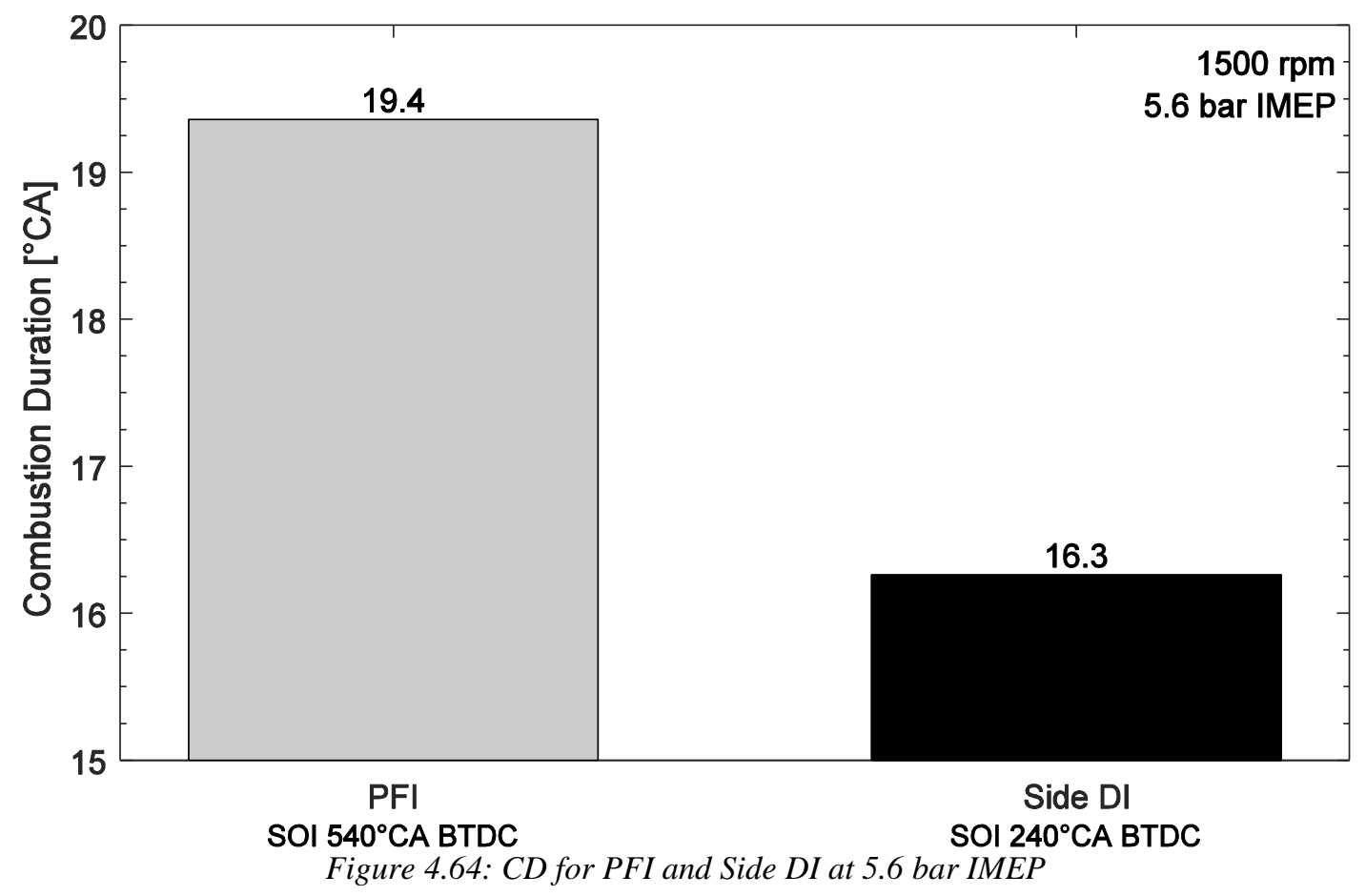


Gas exchange losses for NG PFI and side DI are similar at this condition, indicating a similar amount of throttling was required in order to maintain an engine load of 5.6 bar IMEP. At the same time, side DI resulted in a higher exhaust enthalpy by $0.3 \%$ absolute. The higher exhaust enthalpy was caused by the higher EGT of side DI, seen in Figure 4.65. It is possible that in-cylinder temperatures were higher for NG PFI compared to side DI, leading to a lower temperature in the exhaust. The $\mathrm{SNO}_{\mathrm{x}}$ emissions for this condition for NG PFI and side DI are 11.3 and $11.2 \mathrm{~g} / \mathrm{kWhr}$, respectively. The slightly elevated $\mathrm{iSNO}_{\mathrm{x}}$ emissions of NG PFI indicate higher in-cylinder temperatures, further backing up the lower EGT relative to side DI.

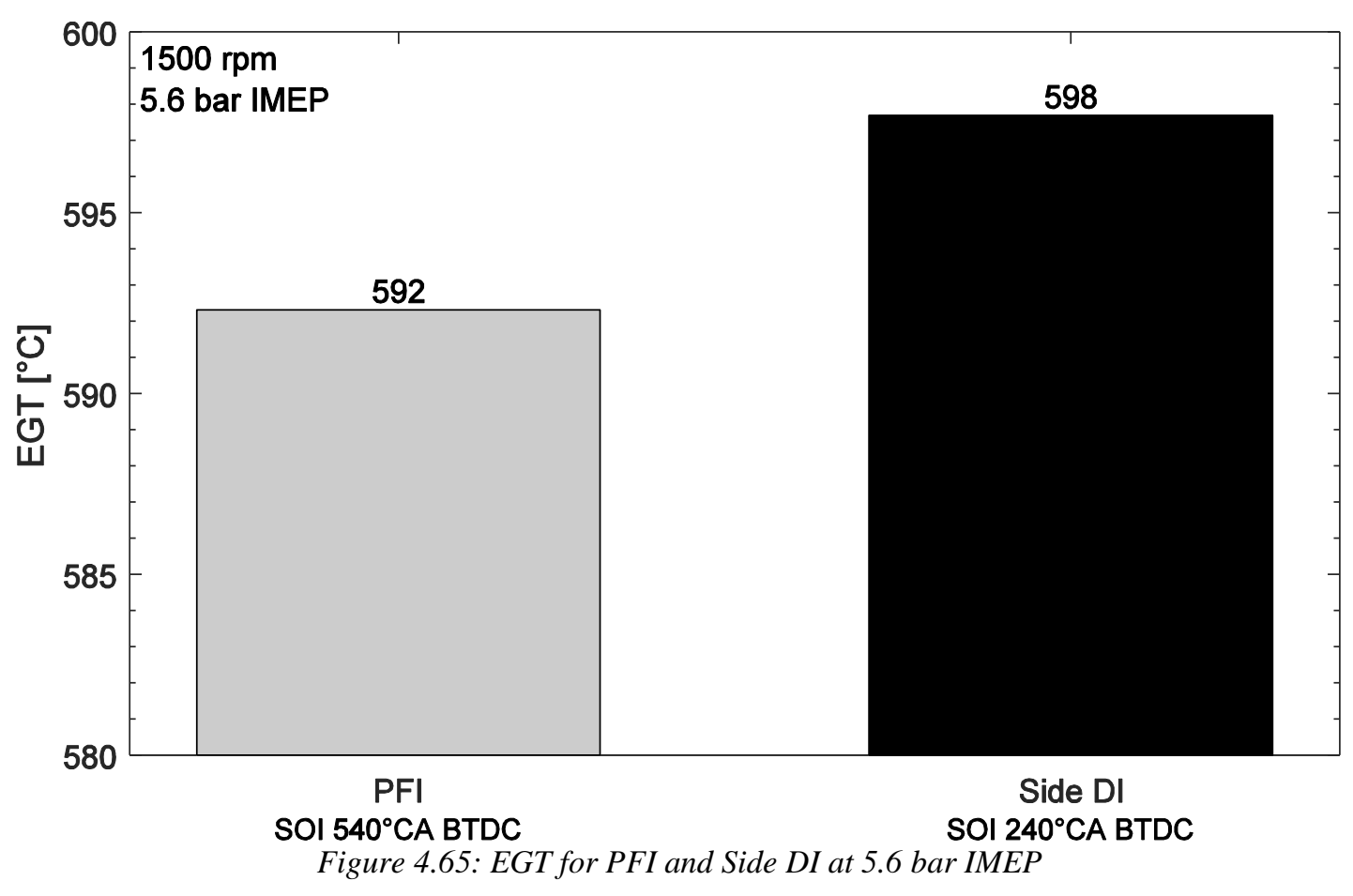


It would have been expected that the longer mixing time of NG PFI would have helped to improve the uniformity of the mixture, leading to a lower combustion inefficiency.

However, despite the shorter mixing time, side DI results in a lower combustion inefficiency than NG PFI. Therefore, the composition of the combustion inefficiency can be investigated. As shown in Figure 4.66, side DI reduced iSHC emissions by 13\%. It is possible that the added charge motion of side DI helped to increase mixture flame speeds, allowing more of the air-fuel mixture to be consumed.

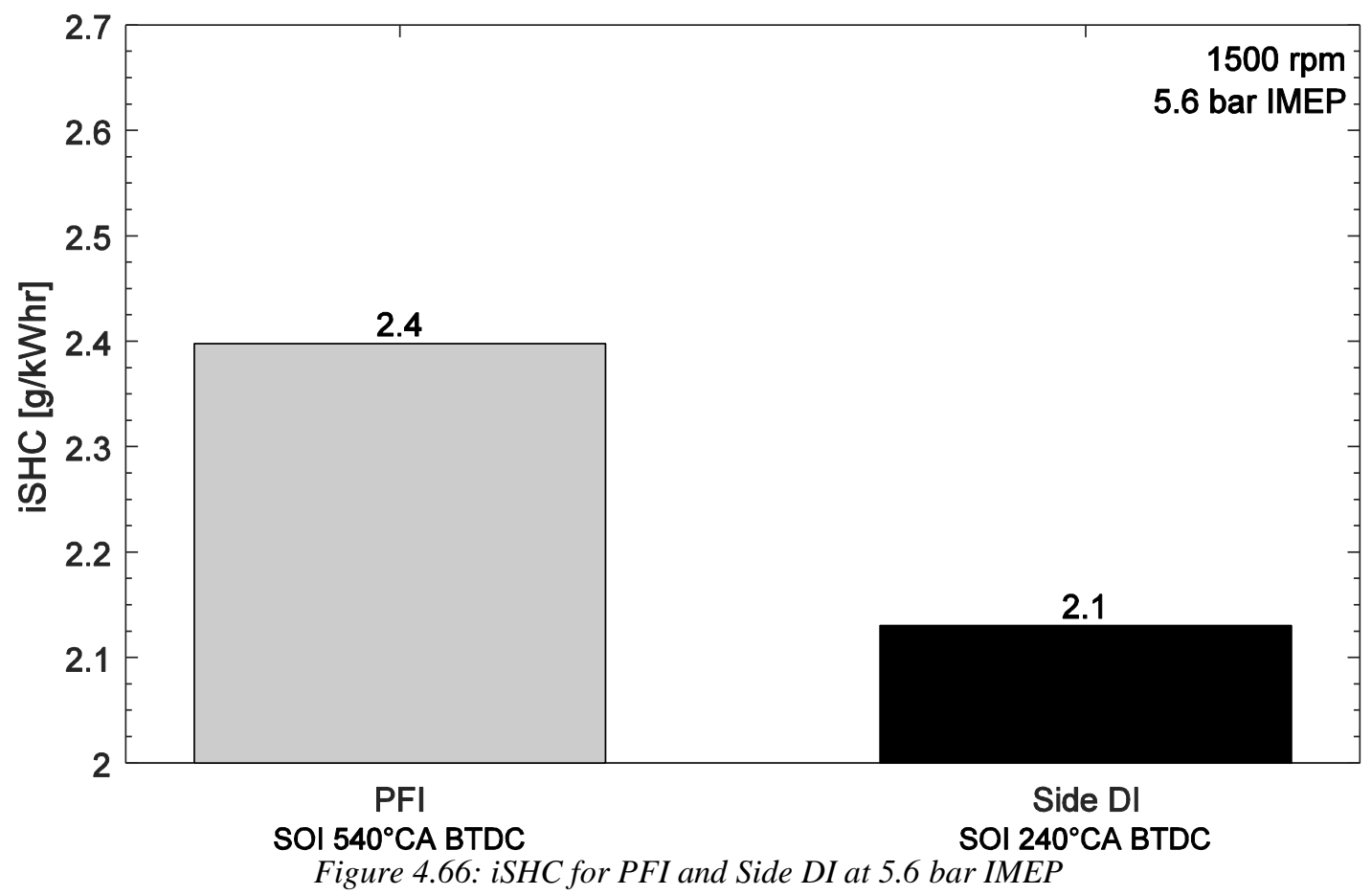


At the same time, the greater charge motion of side DI may have helped improve mixture homogeneity despite the shorter mixing time. Therefore, the iSCO emissions for NG PFI and side DI are shown in Figure 4.67. There is a $27 \%$ reduction in iSCO emissions for side DI at this condition. Because NG PFI is injected into the intake manifold before the intake valve opens, it does not introduce any additional charge motion; as the fuel and air enter the combustion chamber, any charge motion that occurs with NG PFI is due to the design of the intake manifold and intake runners, possibly leading to some level of mixture inhomogeneity. However, it has been shown that side DI improves mixture flame speeds as well as engine out emissions. It is therefore conceivable that the added charge motion of side DI increased mixture homogeneity resulting in a reduction in iSCO.

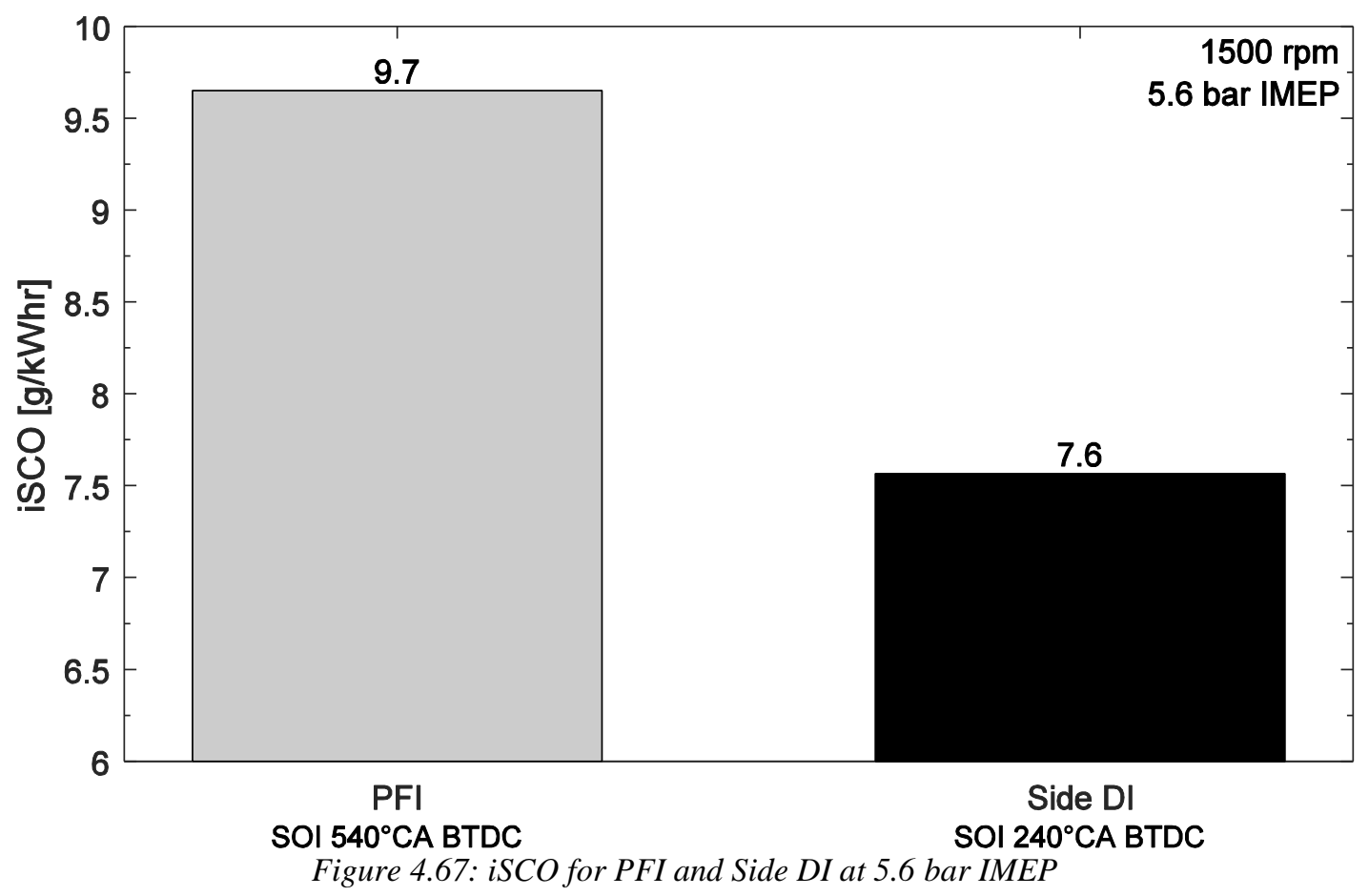

The greatest difference between NG PFI and side DI at this condition is the heat rejected to the coolant loop. Side DI results in a $1.7 \%$ absolute increase in heat rejected to the coolant loop. Literature has shown that an increase in charge motion can lead to an increase in turbulent flame propagation, at the risk of increasing heat losses. Because it has already been shown in Figure 4.64 that side DI results in a faster CD by $3.1{ }^{\circ} \mathrm{CA}$, it is conceivable that side DI increases wall heat losses. At the same time, because side DI 
results in greater heat losses to the coolant loop, it is possible that there is less remaining fuel energy to be lost to other miscellaneous sources.

\subsubsection{Elevated EGR Levels}

Consistent with Section 4.2, individual EGR rates were chosen for NG PFI and side DI in order to perform the energy balance. Shown in Figure 4.68, at the EGR rates selected NG PFI and side DI result in the same efficiency. At the same time, there is a 1.6 and $1.4 \%$ absolute improvement in net efficiency for NG PFI and side DI relative to 0\% EGR, respectively. Further investigations need to be performed in order to understand the difference in net efficiency as well as the losses associated with these conditions.

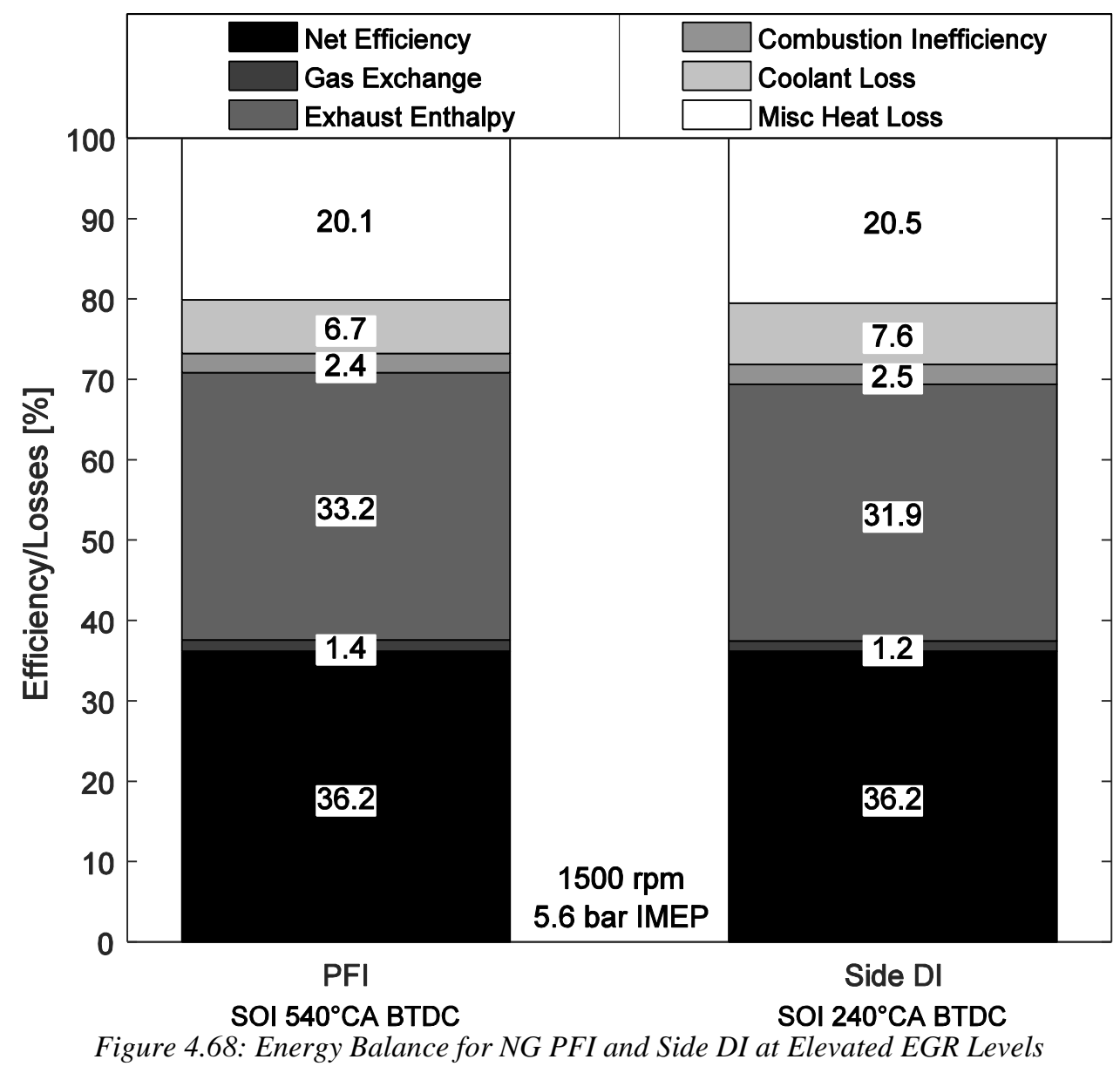


The CD for NG PFI and side DI at the elevated EGR condition is shown in Figure 4.69. Increasing the dilution level results in a 7.7 and $8.1^{\circ} \mathrm{CA}$ increase in the combustion duration for NG PFI and side DI relative to $0 \%$ EGR, respectively. Given the shorter FDA of side DI under zero EGR conditions, this helps to explain the greater EGR dilution tolerance [53]. However, the shorter CD at 17\% EGR for side DI does not explain the resulting similar net efficiency of side DI, therefore further investigation is required.

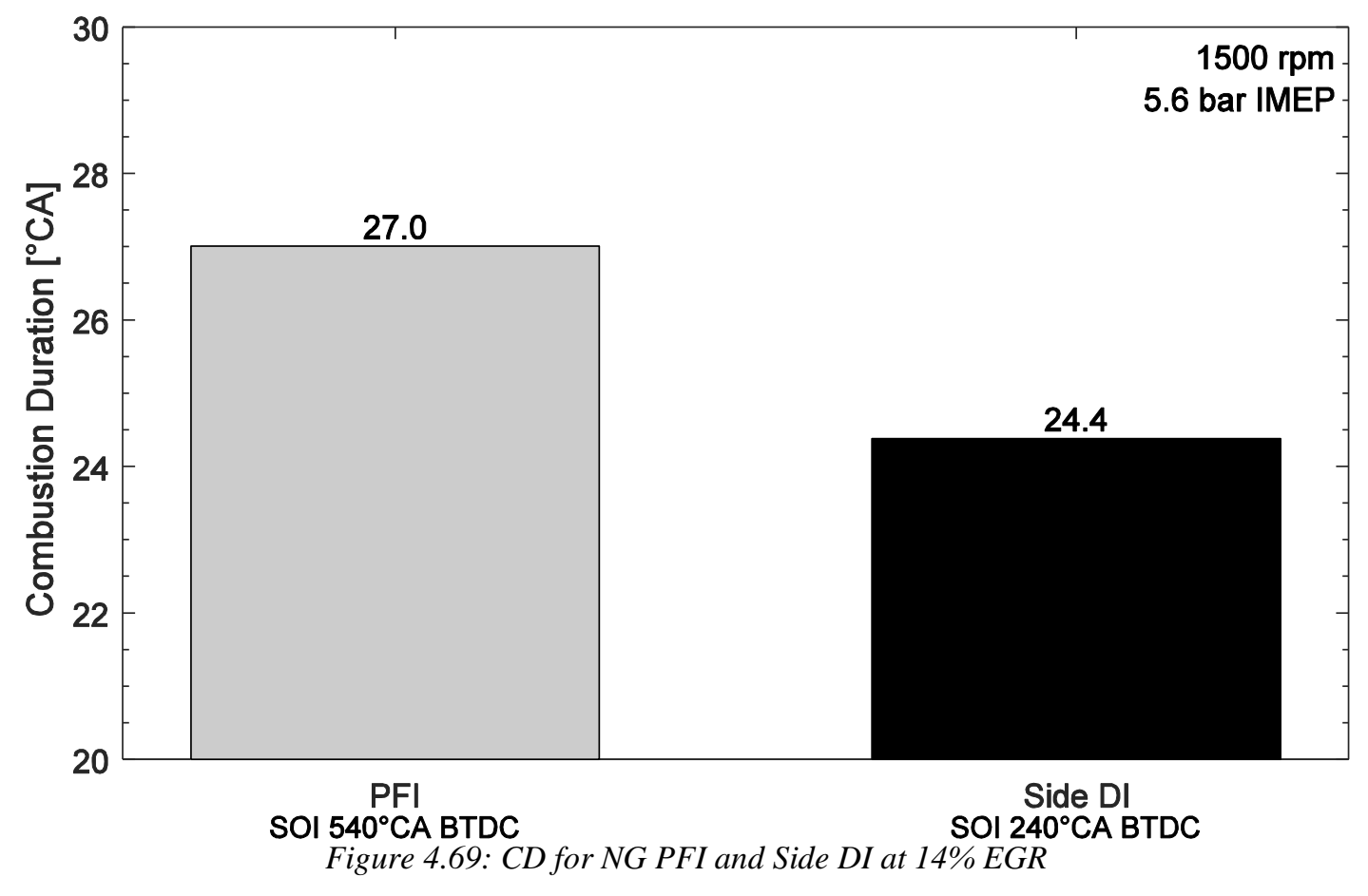


Relative to NG PFI, gas exchange losses were reduced by $0.2 \%$ absolute for side DI because a lower amount of throttling was required for this condition. Under these EGR conditions, there was a $1.3 \%$ absolute reduction in exhaust enthalpy for side DI. This reduction in exhaust enthalpy is strongly driven by a reduction in EGT for side DI, shown in Figure 4.70.

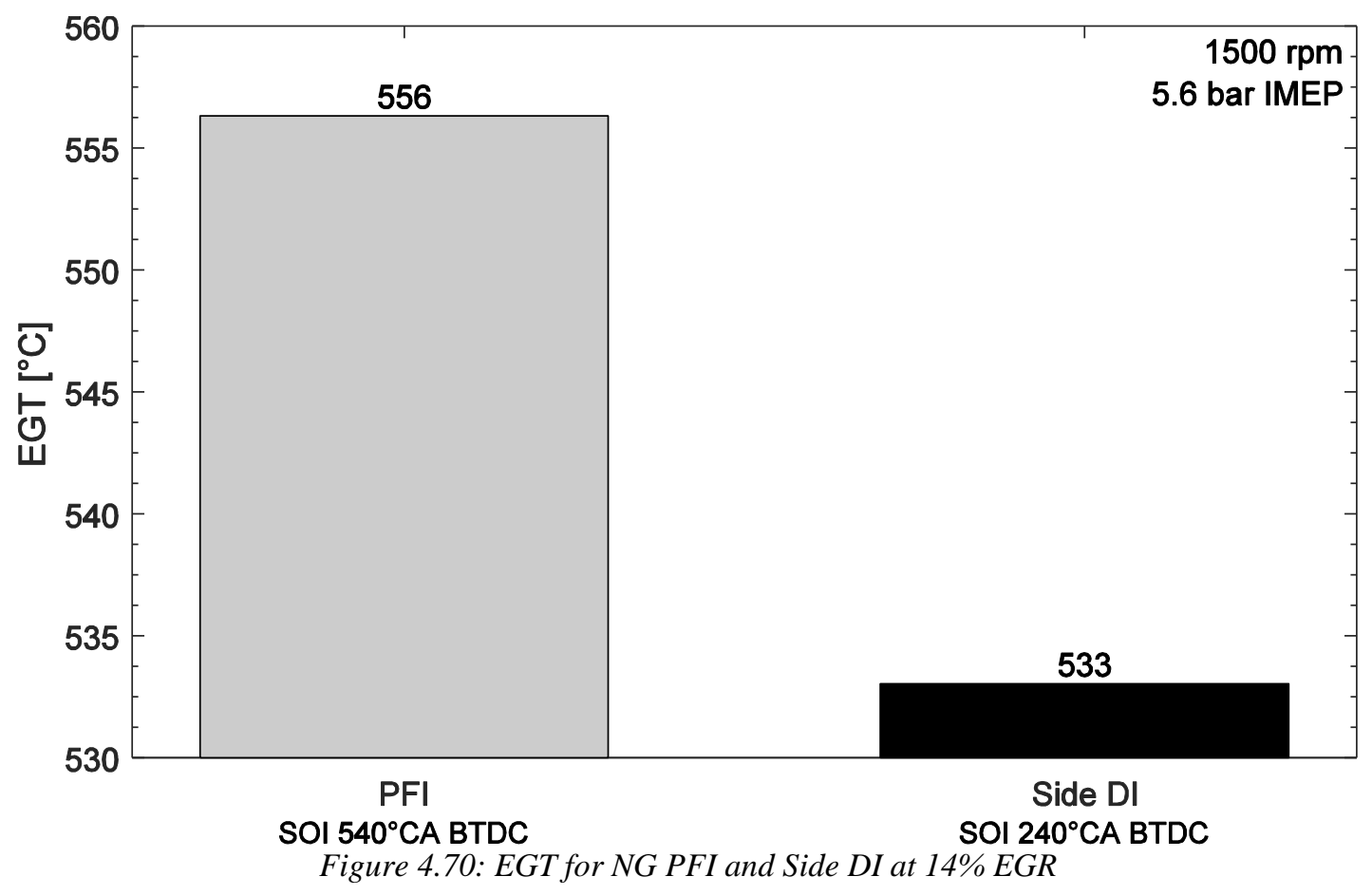


Consequently, side DI results in a $0.1 \%$ absolute increase in the combustion inefficiency at the increased EGR rate, relative to NG PFI. In order to understand this difference, iSHC and iSCO can be investigated. Shown in Figure 4.71, there is only a $1.1 \%$ difference in iSHC emissions for this condition. It is again possible that the greater charge motion of side DI pushed more fuel into the crevice volume.

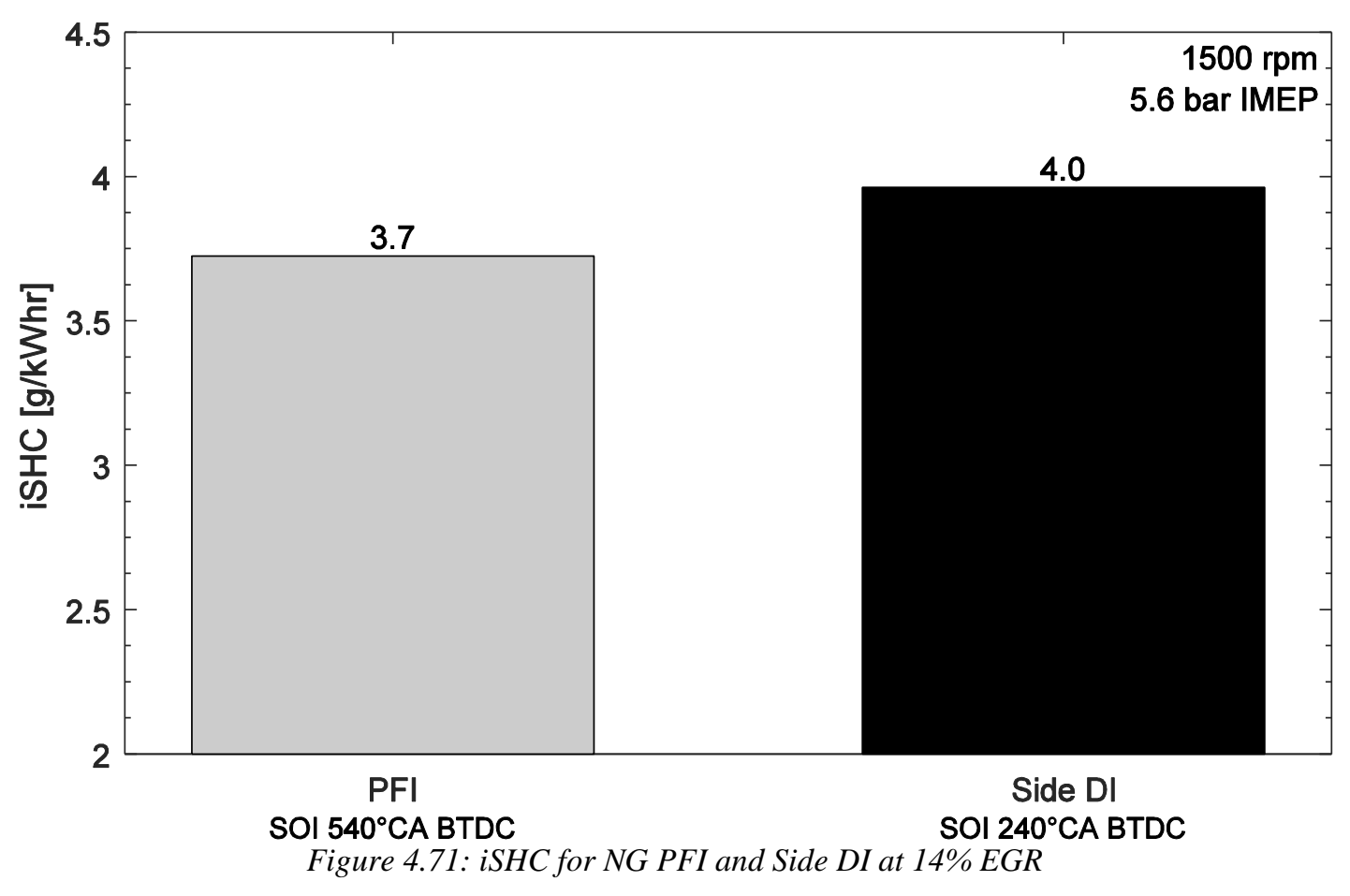


Because there is minimal difference in iSHC emissions between NG PFI and side DI, iSCO is the remaining factor that can influence the $0.1 \%$ absolute difference in combustion inefficiency. Shown in Figure 4.72, side DI reduces iSCO emissions by $9 \%$. Under elevated EGR conditions, the added charge motion of the gaseous injection event helped to promote better mixing, reducing iSCO.

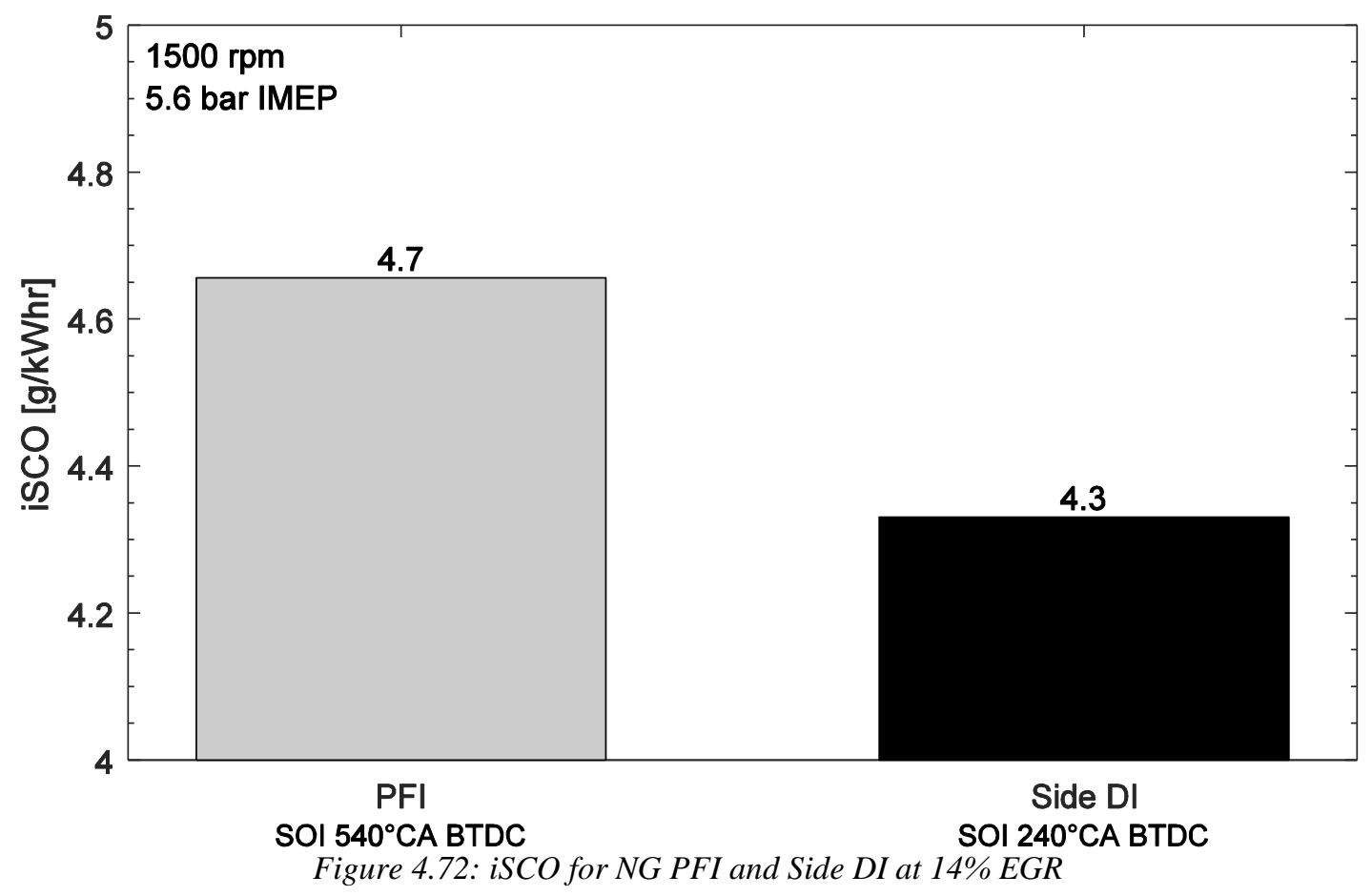

It is worth mentioning, the iSCO value for PFI in Figure 4.72 is an interpolated value.

The original measurements are shown in Figure 4.73 where iSCO emissions for NG PFI and DI are shown as a function of an EGR sweep. In Section 4.4.1 it was shown that NG DI reduces iSCO emissions relative to NG PFI due to the added charge motion. Because it was not anticipated that NG PFI would reduce iSCO emissions by a factor of two relative to side DI for only one EGR condition, further investigation is required. 


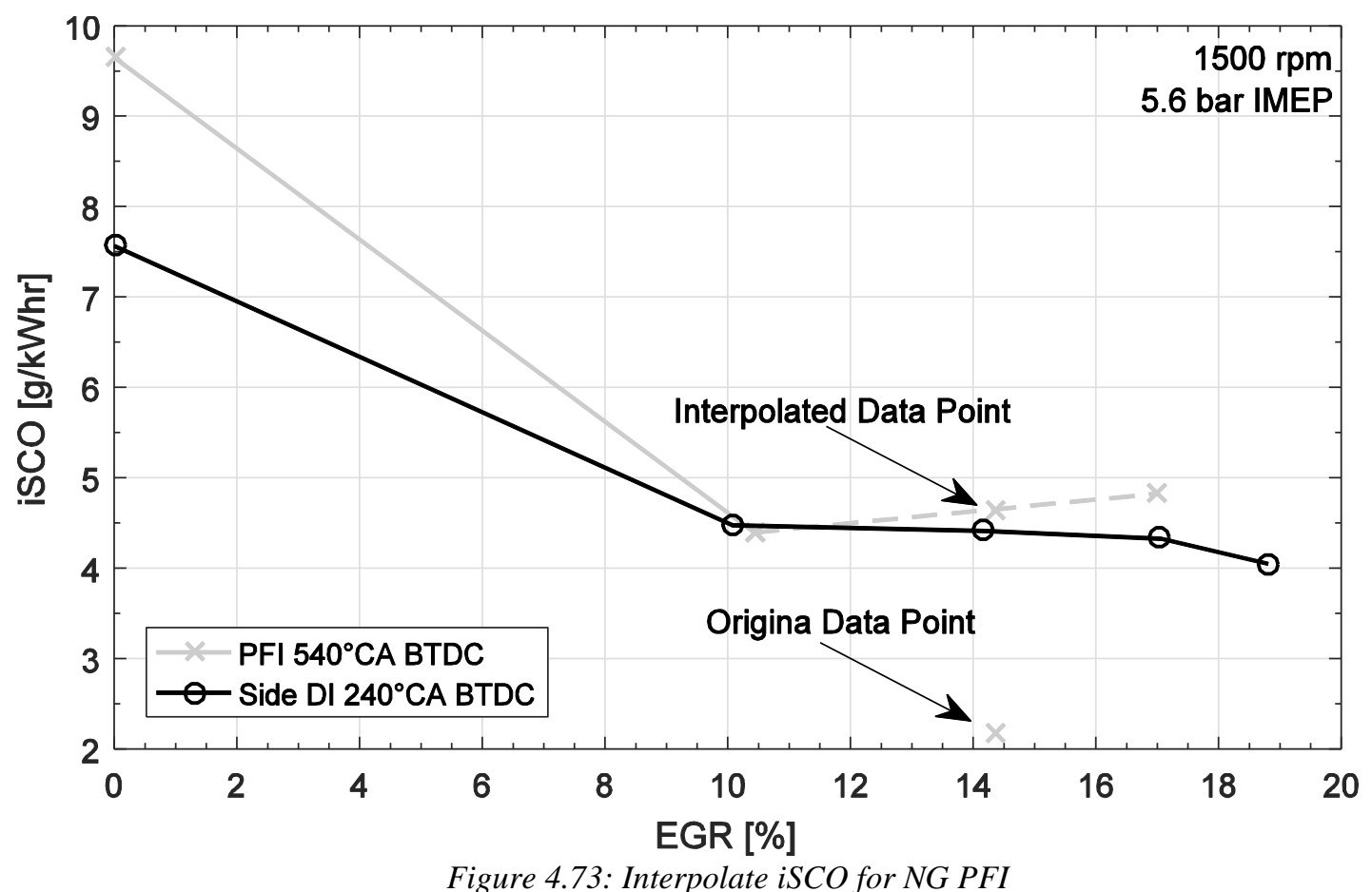

It has already been stated that $\mathrm{CO}$ emissions directly correlate with the actual air-fuel ratio. Therefore, the lambda value for NG PFI and side DI was calculated for the two EGR conditions three different ways. The first utilized the Brettschneider method using exhaust emissions, the second was the output of the $\mathrm{O}_{2}$ sensor on the Motec M800 and the last utilized measured air and fuel flow rates from the test cell. For all three methods, the difference in lambda between NG PFI and side DI is less than $0.7 \%$, indicating the difference in iSCO emissions is not due to a global shift in engine operation.

In addition, the raw engine data was analyzed and the IMEP, fuel flow, and $\mathrm{CO}_{2}$ for $\mathrm{NG}$ PFI and DI are very similar. Therefore, everything indicates that the drop in iSCO emissions for NG PFI at 14\% EGR was due to a measurement error. In addition, a similar test was performed the day before data was collected for Section 4.4. This test too shows similar unexpected variations in iSCO. This further corroborates that there was an isolated measurement error in the NDIR analyzer, affecting only iSCO calculations. While it does affect the combustion inefficiency, the change from 4.6 to $2.2 \mathrm{~g} / \mathrm{kWhr}$ is insignificant relative to the magnitude of iSHC when considering energy in the exhaust. 
With $17.0 \%$ EGR, side DI still results in an elevated heat transfer to the coolant loop. The increase in heat rejected to the coolant loop is a result of the increased charge motion and mixture flame speeds for side DI. At the same time, side DI results in a $0.4 \%$ absolute increase in miscellaneous heat losses, which could be due to more heat being transferred to the piston, and subsequently the oil reservoir. At the same time, the higher amount of heat transfer for side DI is further substantiated by the $23^{\circ} \mathrm{C}$ reduction in EGT, indicating more heat transfer may have occurred within the cylinder. 


\subsubsection{Summary for PFI v. DI}

As shown in Sections 4.4.1 and 4.4.2, NG PFI and side DI show similarities under conditions with and without EGR. For the conditions discussed, both systems result in near identical net efficiency values. The faster mixture flame speeds of side DI allow for a higher dilution tolerance, providing a further reduction in engine out emissions for the same net efficiency. Given the same fuel was injected, the faster mixture flame speeds of side DI were due to the increased charged motion caused by the gaseous injection event. While side DI results in improved mixture flame speeds, there were also competing effects within the cylinder. An energy balance shows that side DI resulted in higher transfer losses to the coolant loop, indicating increased wall heat transfer with side DI as a result of the increased charge motion.

While NG DI provided similar results relative to NG PFI, this only identifies one small area of the engine map. When considering the entire engine operation, NG DI provides considerable benefits to NG PFI. 


\subsection{Extension of Experimental Data}

Throughout the course of this document, a select number of experimental control parameters were changed and their resulting effect on the net efficiency was documented. Because it has already been established how intermediate variables, such as $\mathrm{COV}_{\text {IMEP }}$ and $\mathrm{CD}$, are affected by changes in the control parameters, it is valuable to extend this data set to understand how other parameters would affect the net efficiency.

One benefit of NG DI over NG PFI is the potential to increase the CR of the engine, providing an improvement in the maximum theoretical efficiency [6]. Literature has shown that current production NG vehicles do not necessarily utilize the full potential of NG due to some intrinsic limitations of the fuel injection system. In the study performed by Anderson [17], it was noted that despite the increased CR of the dedicated NGV, it resulted in a lower drive cycle fuel economy relative to the gasoline vehicle due to increased CD associated with the lower flame speeds of NG as well as limited use of EGR at part-load conditions limiting efficiency improvements. As shown throughout Section 4.4, NG DI can reduce mixture flame speeds relative to NG PFI. This reduction in mixture flame speeds has been shown to increase the EGR dilution tolerance of the engine, which improves the net efficiency. Therefore, an increase in CR for an engine operating with NG DI will provide a greater increase in net efficiency as compared to NG PFI. Note that an increase in CR will decrease the surface area to volume ratio of the cylinder, increasing in-cylinder heat transfer leading to a loss in the net efficiency. In addition, the increased CR combined with NG DI can lead to increased charge motion in the cylinder. While this can increase mixture flame speeds, this again could increase heat transfer leading to an efficiency loss at some critical CR [41].

In some applications, automotive manufactures will use tumble flaps in the intake manifold to close off part of the intake runners, improving charge motion within the cylinder. These flaps will open under high load applications to not inhibit the engines ability to aspirate air and cause a power density loss. For the engine used in this study, port-blocking plates, also known as tumble plates, can be used in order to improve charge motion within the cylinder. Combining the tumble plates with PFI fueling, for either NG or gasoline, has been shown to increase net efficiency due to decreased CD and extended 
dilution tolerance [55]. It is believed that for a NG DI application, the tumble plates would not lead to an efficiency improvement. In Section 4.1.2, the energy balance showed that under zero EGR conditions at SOI $240^{\circ} \mathrm{CA}$ BTDC, the limiting factor for an efficiency improvement for side DI was wall heat transfer losses. This is despite the fact that side DI resulted in a shorter combustion duration and lower combustion inefficiency. At the same time, the tumble plates could increase the charge motion for central DI at this condition such that there is an increase in charge motion. Therefore, it is believed that for this condition for central and side DI, tumble plates would not lead to a net efficiency improvement due to increases in wall heat transfer.

Spray targeting in the combustion chamber could be used as a means to improve incylinder mixing and resulting net efficiency. Spray targeting is a common technique used for high pressure fuel injection systems. It is common for GDI engines to use spray targeting to reduce the amount of liquid impingement while at the same time complimenting the tumble. The NG DI injectors used for this study utilized an outward opening cone angle. Depending on the location, it has been shown the injection event either complimented the tumble motion (side) or damped the tumble (central). There were clear benefits of the momentum of the fuel improving mixing. It has already been established in Section 4.1 and 4.2 that side DI injecting along the tumble motion increases the in-cylinder charge motion from the spray momentum, improving mixture flame speeds and resulting in an improvement in the net efficiency. Central DI did not yield such benefit because the spray momentum damped out the tumble motion. Therefore, utilizing an inward opening injector with a specified spray pattern in the central location would allow for an improvement in the combustion event and match the performance of side DI in terms of CD, net efficiency, combustion stability, etc. Optimization would be needed in order determine the correct injection angle to compliment the tumble motion. Angling the jets along the tumble motion would conceivably act like the side injection location, complementing the tumble. However, angling the jets in order to improve tumble would also lend to an increase in wall heat transfer. Literature has shown that there is an optimal level of charge motion in the cylinder before wall heat transfer ultimately limits efficiency improvements [6,41]. 
Under most circumstances, spark ignited engines operate with tumble motion while compression ignited engines use swirl motion. In some instances, diesel engines will be converted over to spark ignition, but the bulk flow motion still utilizes the swirl motion. The side injection location resulted in the greatest benefit due to an amplification of the tumble motion. While the central location did not amplify the tumble motion, it is believed an increase in the swirl motion would provide the most benefit at improving the net efficiency. Literature has shown that for a central injection location, increasing the swirl motion provided some net efficiency benefit and stability under dilute conditions [56]. Increasing the swirl motion will increase the charge motion within the cylinder, assisting in early flame kernel development [6]. At the same time, the swirl motion can create rich pockets in the near spark plug region which can be beneficial due to the harder mixture ignitibility of NG [57]. As shown in Section 4.4, the increased charge motion from side DI at SOI $240^{\circ} \mathrm{CA}$ BTDC led to a decrease in the CD, relative to NG PFI. At the same time, there was a $4.3^{\circ} \mathrm{CA}$ difference in $\mathrm{CD}$ between central and side $\mathrm{DI}$ at SOI $240^{\circ} \mathrm{CA}$ BTDC, as shown in Figure 4.14. For both conditions, side DI increased the bulk charge motion, reducing the $\mathrm{CD}$. Therefore, an increase in the swirl motion could assist in increasing mixture flame speeds for central DI, leading to an efficiency improvement. It is worth mentioning, the increase in swirl motion will benefit central DI the most; a side DI injection event disrupts any increase in swirl, much like central DI damps the tumble motion. 


\section{Conclusions and Recommendations}

\subsection{Conclusions}

The following goals were outlined in Section 2.4:

- Measure and quantify the effects of NG DI injection location on the combustion process and resulting thermal efficiency

- Characterize the influence of injection timing on the thermal efficiency for NG DI

- Quantify the effects of NG DI on part-load dilution tolerance

Through the analysis performed in Section 4.1, it was shown that under zero EGR conditions the side mounted injection location to be optimal. Side mounted NG DI allowed for an improvement in the tumble motion, which led to a shorter combustion process increasing the thermal efficiency of the engine.

Regardless of injection location, an injection event occurring midway through the intake stroke resulted in the greatest thermal efficiency. This timing allowed for an optimal tradeoff between mixing time, as well as preservation of the charge motion of the gaseous injection event. Injecting earlier than this led to a thermal efficiency penalty due to poor interaction with the intake flow, while injecting after this suffered from a decrease in mixing time leading to incomplete combustion products. The effects of side injection are compounded at the early and late injection timings, where the side location still provides a benefit to the net efficiency.

The dilution tolerance of the engine trended well with literature sources [7, 29], such that a shorter flame development period led to a higher dilution tolerance. The greatest dilution tolerance difference occurred at the optimal injection timing, where there is a large difference in the flame development period between the two injection locations. Finally, the analysis performed at a part-load condition showed that side injection provided a greater improvement in dilution tolerance relative to PFI, resulting in decreased engine out emissions. However, there is a tradeoff when operating with side mounted DI. The increased mixture flame speeds associated with improved tumble motion resulted to an increase in wall heat losses relative to PFI. 
The data analyzed in this document will provide vital information to researchers, automotive manufacturers, and even injector manufacturers. Traditionally, injecting NG using PFI resulted in a part-load efficiency loss due to poor dilution tolerance, as well as full-load power density losses. NG DI has shown to be a promising replacement due to improvements in mixture flame speeds and dilution tolerance, ultimately improving the thermal efficiency of the engine as well as reducing power density losses [14].

\subsection{Recommendations for Future Work}

- For all data collected, the fuel was injected in one continuous injection event. One possible method of further increasing the $\mathrm{ITE}_{\mathrm{NET}}$ or dilution tolerance is to perform multiple injection events. Literature showed that an early pulse helped to improve mixture homogeneity, and a late pulse helped to improve TKE in the near spark region [15].

- The central DI injector sits directly at the top of the pent roof combustion chamber. Literature [28], as well as ANL 3D CFD shows that some of the gaseous injection event may attach to the combustion chamber roof during an injection event. The tumble motion would not capture the gas that attaches to the combustion chamber roof. The wall attachment would also have an effect on mixture homogeneity, negatively affecting the thermal efficiency. Adjusting the penetration of the central DI injector into the combustion chamber could help to reduce any wall attachment that occurs, potentially improving the thermal efficiency.

- The testing performed in this study was with an outward opening NG injector, which only allows the jet to be injected in one direction. There were clear benefits of the momentum of the fuel improving mixing. As introduced in Section 4.5, it would beneficial to understand the influences of an inward opening injector, where the number of holes and their relative angle in the nozzle can be varied. An optimization of the number of holes and their relative angle could have a strong impact on the mixture formation process, such that the injection event can complement the tumble motion regardless of injection location. 


\section{Appendix}

\subsection{SAE Permissions Letter}

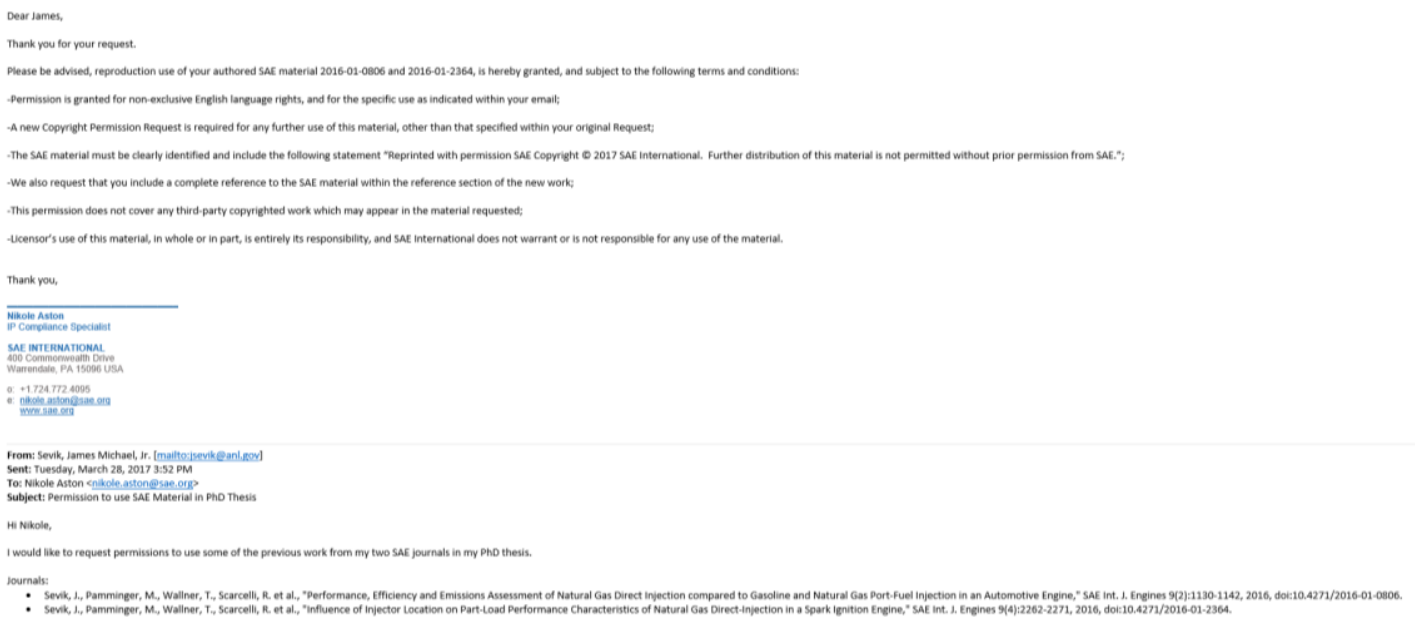

(6)

\section{References}

1 "U.S. Energy Information Administration - EIA - Independent Statistics and Analysis." Short-Term Energy Outlook - U.S. Energy Information Administration (EIA). N.p., n.d. Web. 07 Mar. 2017.

2 "Fuel Prices." Alternative Fuels Data Center.. N.p., n.d. Web. 22 Apr. 2016.

3 Security, U.s. Department Of Homeland. 2015 Energy Sector-Specific Plan (n.d.): n. pag. Web. 22 Apr. 2016.

4 "U.S. Energy Information Administration - EIA - Independent Statistics and Analysis." EIA's Annual Energy Outlook Is a Projection, Not a Prediction - Today in Energy - U.S. Energy Information Administration (EIA). N.p., n.d. Web. 07 Mar. 2017.

5 "Regulations for Greenhouse Gas Emissions from Passenger Cars and Trucks." EPA. Environmental Protection Agency, 17 Nov. 2016. Web. 22 Jan. 2017.

6 Heywood, J.B., "Internal Combustion Engine Fundamentals," McGraw-Hill Book.

7 Szybist, J. and Splitter, D., "Effects of Fuel Composition on EGR Dilution Tolerance in Spark Ignited Engines," SAE Int. J. Engines 9(2):819-831, 2016, doi:10.4271/2016-01-0715.

8 "Fuel for Thought." : The First Natural Gas Vehicles. N.p., n.d. Web. 22 Apr. 2016.

9 Verhelst, S., and Wallner, T., 2009 "Hydrogen-fueled internal combustion engines," Progress in Energy and Combustion Science, vol. 35, pp. 490-527

10 "Methane." Welcome to the NIST WebBook. National Institute of Standards and Technology, n.d. Web. 09 Mar. 2017.

11 "2,2,4-Trimethylpentane." Welcome to the NIST WebBook. National Institute of Standards and Technology, n.d. Web. 09 Mar. 2017.

12 Weber, C., Kramer, U., Klein, R., "CNG-Specific Downsizing - Potentials and Challenges”, Internationales Wiener Motorensymposium 2015.

13 Bach, C., "CO2 Reduction and Cost Efficiency Potential of Natural Gas Hybrid Passenger Cars," SAE Int. J. Engines 4(2):2395-2404, 2011, doi:10.4271/2011-24-0110.

14 Sevik, J., Pamminger, M., Wallner, T., Scarcelli, R. et al., "Performance, Efficiency and Emissions Assessment of Natural Gas Direct Injection compared to Gasoline and Natural Gas Port-Fuel Injection in an Automotive Engine," SAE Int. J. Engines 9(2):2016, doi:10.4271/2016-01-0806. 
15 Seboldt, D., "Potential of multiple injection for lowering HC engine-out emissions from CNG-DI SI engines," 11TH CONFERENCE ON GAS-POWERED VEHICLES, POTSDAM 2016.

16 Pamminger, M., Wallner, T., Sevik, J., Scarcelli, R. et al., "Performance, Efficiency and Emissions Evaluation of Gasoline Port-Fuel Injection, Natural Gas Direct Injection and Blended Operation", ASME ICEF 2016, ICEF2016-9370.

17 Anderson, J., Miers, S., Wallner, T., Stutenberg, K. et al., "Performance and Efficiency Assessment of a Production CNG Vehicle Compared to Its Gasoline Counterpart," SAE Technical Paper 2014-01-2694, 2014, doi:10.4271/2014-01-2694.

18 Neame, G., Gardiner, D., Mallory, R., Rao, V. et al., "Improving the Fuel Economy of Stoichiometrically Fuelled S.I. Engines by Means of EGR and Enhanced Ignition - A Comparison of Gasoline, Methanol and Natural Gas," SAE Technical Paper 952376, 1995, doi:10.4271/952376.

19 Alger, T., Gingrich, J., and Mangold, B., "The Effect of Hydrogen Enrichment on EGR Tolerance in Spark Ignited Engines," SAE Technical Paper 2007-01-0475, 2007, doi:10.4271/2007-01-0475.

20 Delpech, V., Obiols, J., Soleri, D., Mispreuve, L. et al., "Towards an Innovative Combination of Natural Gas and Liquid Fuel Injection in Spark Ignition Engines," SAE Int. J. Fuels Lubr. 3(2):196-209, 2010, doi:10.4271/2010-01-1513.

21 SHIGA*, S., ARAKI, M., OBOKATA, T., HUANG, Z. et al., "Basic Aspect of Combustion of CNG Incylinder Direct-Injection with Spark-Ignition," SAE Technical Paper 2005-26-352, 2005, doi:10.4271/2005-26-352.

22 Iyer, C. and Yi, J., "3D CFD Upfront Optimization of the In-Cylinder Flow of the 3.5L V6 EcoBoost Engine," SAE Technical Paper 2009-01-1492, 2009, doi:10.4271/2009-01-1492.

23 Douailler, B., Ravet, F., Delpech, V., Soleri, D. et al., "Direct Injection of CNG on High Compression Ratio Spark Ignition Engine: Numerical and Experimental Investigation," SAE Technical Paper 2011-010923, 2011, doi:10.4271/2011-01-0923.

24 Tadesse, G. and Aziz, A., "Effect of Boost Pressure on Engine Performance and Exhaust Emissions in Direct-Injection Compressed Natural Gas (CNG-DI) Spark Ignition Engine.," SAE Technical Paper 200932-0135, 2009.

25 Zeng, Ke, Zuohua Huang, Bing Liu, Liangxin Liu, Deming Jiang, Yi Ren, and Jinhua Wang.

"Combustion Characteristics of a Direct-injection Natural Gas Engine under Various Fuel Injection Timings." Applied Thermal Engineering 26.8-9 (2006): 806-13. Web.

26 Kalam, M., Masjuki, H., Mahlia, T., Fuad, M. et al., "Experimental Test of a New Compressed Natural Gas Engine with Direct Injection," SAE Technical Paper 2009-01-1967, 2009, doi:10.4271/2009-01-1967. 27 Sevik, J., Pamminger, M., Wallner, T., Scarcelli, R. et al., "Performance, Efficiency and Emissions Assessment of Natural Gas Direct Injection compared to Gasoline and Natural Gas Port-Fuel Injection in an Automotive Engine," SAE Int. J. Engines 9(2):2016, doi:10.4271/2016-01-0806.

28 Sankesh, D. and Lappas, P., "Natural-Gas Direct-Injection for Spark-Ignition Engines - A Review on Late-Injection Studies," SAE Technical Paper 2017-26-0067, 2017, doi:10.4271/2017-26-0067.

29 Sevik J, Wallner T, Pamminger M, Scarcelli R, Singleton D, Sanders J. Extending Lean and Exhaust Gas Recirculation-Dilute Operating Limits of a Modern Gasoline Direct-Injection Engine Using a LowEnergy Transient Plasma Ignition System. ASME. J. Eng. Gas Turbines Power. 2016;138(11):112807112807-8. doi:10.1115/1.4033470.

30 Wallner, T., Sevik, J., Scarcelli, R., Kaul, B. et al., "Effects of Ignition and Injection Perturbation under Lean and Dilute GDI Engine Operation," SAE Technical Paper 2015-01-1871, 2015, doi:10.4271/2015-011871.

31 Kolodziej, C., Pamminger, M., Sevik, J., Wallner, T. et al., "Effects of Fuel Laminar Flame Speed Compared to Engine Tumble Ratio, Ignition Energy, and Injection Strategy on Lean and EGR Dilute Spark Ignition Combustion," SAE Int. J. Fuels Lubr. 10(1):82-94, 2017, doi:10.4271/2017-01-0671.

32 Husted, H., Karl, G., Schilling, S.,Weber, C., "Direct Injection of CNG for Driving Performance with Low CO2," 23rd Aachen Colloquium Automobile and Engine Technology 2014. 
33 Weber, C., Kramer, U., Klein, R., "CNG-Specific Downsizing - Potentials and Challenges", Internationales Wiener Motorensymposium 2015.

34 Van Alstine, D., Montgomery, D., Callahan, T., Florea, R., "ABILITY OF THE METHANE NUMBER INDEX OF A FUEL TO PREDICT RAPID COMBUSTION IN HEAVY DUTY DUAL FUEL ENGINES FOR NORTH AMERICAN LOCOMOTIVES", ASME ICEF 2015, ICEF2015-1119.

35 Kubesh, J., King, S., and Liss, W., "Effect of Gas Composition on Octane Number of Natural Gas Fuels," SAE Technical Paper 922359, 1992, doi:10.4271/922359.

36 Standard Test Method for Motor Octane Number of Spark-Ignition Engine Fuel, ASTM International D2700.

37 "Fuel Quality Calculator." Cummins Westport. N.p., n.d. Web. 23 Oct. 2015.

38 "AVL Indimodul 621." AVL Combustion Measurement Equipment - Modular Indicating Systems. N.p., n.d. Web. 2 Feb. 2017.

39 "Crank Angle Encoder of 365-Series." Crank Angle Encoder of 365-Series - Combustion Measurement. N.p., n.d. Web. 22 Mar. 2017.

40 Thermodynamics: an engineering approach. Yunus A.Çengel - Michael A.Boles - McGraw-Hill Higher Education - 2008

41 Ogink, R. and Babajimopoulos, A., "Investigating the Limits of Charge Motion and Combustion Duration in a High-Tumble Spark-Ignited Direct-Injection Engine," SAE Int. J. Engines 9(4):2016, doi:10.4271/2016-01-2245.

42 Silvis, W., "An Algorithm for Calculating the Air/Fuel Ratio from Exhaust Emissions," SAE Technical Paper 970514, 1997, doi:10.4271/970514.

43 "An introduction to combustion: concepts and applications," Stephen R.Turns - WCB/McGraw-Hill 2000

44 Kline, S. J., and F. A. McClintock: "Describing Uncertainties in Single-Sample Experiments", Mech.

Eng., p. 3, January 1953.

45 Holman, J. P.: "Experimental Methods for Engineers", McGraw-Hill, Eighth Edition, 2011.

46 Ps-00374, Rev. F., and June 2006. Micro Motion ® ELITE ® (n.d.): n. pag. Web.

47 Scarcelli, R., Wallner, T., Salazar, V., and Kaiser, S., "Modeling and Experiments on Mixture

Formation in a Hydrogen Direct-Injection Research Engine," SAE Int. J. Engines 2(2):530-541, 2010, doi:10.4271/2009-24-0083.

48 Scarcelli, R., Wallner, T., Matthias, N., Salazar, V. et al., "Mixture Formation in Direct Injection Hydrogen Engines: CFD and Optical Analysis of Single- and Multi-Hole Nozzles," SAE Int. J. Engines 4(2):2361-2375, 2011, doi:10.4271/2011-24-0096.

49 Bartolucci, L., Scarcelli, R., Wallner, T., Swantek, A. et al., "CFD and X-Ray Analysis of Gaseous Direct Injection from an Outward Opening Injector," SAE Technical Paper 2016-01-0850, 2016, doi:10.4271/2016-01-0850.

50 Wallner, T., R. Scarcelli, Sevik, J. et al., " EFFICIENCY-OPTIMIZED DUAL FUEL ENGINE WITH IN-CYLINDER GASOLINE/CNG BLENDING". 2016 DOE Merit Review, Washington, D.C.

51 Hohenberg, G., "Advanced Approaches for Heat Transfer Calculations," SAE Technical Paper 790825, 1979, doi:10.4271/790825.

52 US DRIVE Advanced Combustion and Emission Control (ACEC) Technical Roadmap for Light-Duty Powertrains

53 Szybist, J. and Splitter, D., "Effects of Fuel Composition on EGR Dilution Tolerance in Spark Ignited Engines," SAE Int. J. Engines 9(2):819-831, 2016, doi:10.4271/2016-01-0715.

54 Seboldt, D., Lejsek, D., Bargende, M., "Untersuchungen zum Einfluss von Einblasebeginn und Einblaserichtung auf die Gemischbildung und Verbrennung an einem $\lambda=1$ betriebenen Ottomotor mit CNG-Direkteinblasung," 2015 IAV Conference.

55 Sevik, J., Pamminger, M., Wallner, T., Scarcelli, R. et al., "Influence of charge motion and compression ratio on the performance of a combustion concept employing in-cylinder gasoline and natural gas blending", ICEF2017-3661, Peer review ready manuscript submitted to ASME ICEF 2017 conference. 
56 Wallner, T., R. Scarcelli, Matthias, N., "High Efficiency GDI Engine Research with Emphasis On Ignition Systems". 2013 DOE Merit Review, Washington, D.C.

57 Lippert, A., El Tahry, S., Huebler, M., Parrish, S. et al., "Development and Optimization of a SmallDisplacement Spark-Ignition Direct-Injection Engine - Stratified Operation," SAE Technical Paper 200401-0033, 2004, doi:10.4271/2004-01-0033. 